Portland State University

PDXScholar

Fall 11-12-2013

\title{
The Impacts of Change in Governance on Faculty and Staff at Higher Education Institutions: A Case Study of OHSU
}

Dana L. Director

Portland State University

Follow this and additional works at: https://pdxscholar.library.pdx.edu/open_access_etds

Part of the Business Administration, Management, and Operations Commons, Health and Medical Administration Commons, Medical Education Commons, and the Work, Economy and Organizations Commons

Let us know how access to this document benefits you.

\section{Recommended Citation}

Director, Dana L., "The Impacts of Change in Governance on Faculty and Staff at Higher Education Institutions: A Case Study of OHSU" (2013). Dissertations and Theses. Paper 1490.

https://doi.org/10.15760/etd.1489

This Dissertation is brought to you for free and open access. It has been accepted for inclusion in Dissertations and Theses by an authorized administrator of PDXScholar. Please contact us if we can make this document more accessible: pdxscholar@pdx.edu. 
The Impacts of Change in Governance on Faculty and Staff at Higher Education Institutions: A Case Study of OHSU

by

Dana L. Director

A dissertation submitted in partial fulfillment of the requirements for the degree of

Doctor of Philosophy

in

Public Affairs and Policy

Dissertation Committee:

Lindsay Desrochers, Chair

Jay Kenton

Masami Nishishiba

Nancy Koroloff

Portland State University 2013 
(C) 2013 Dana L. Director 


\begin{abstract}
In the early 1990’s, Oregon Health \& Science University leadership examined the political and economic landscape and determined it needed a new operational model to survive and thrive. In 1995 OHSU separated from the state higher education system and became a public corporation, with goals of increased efficiency, customer-focus, ability to attract world-class researchers and physicians, and salaries commensurate with an urban academic health center.

This research examines the internal impacts when universities undergo significant change, using OHSU's governance change as a case study. Central is the question: what effect(s) did OHSU's decision to become a unique public corporation have on specific employee groups? This study looks at two groups and their perceptions of the change: faculty, and union-represented staff.

The author interviewed the leadership team who led the transition, reviewed historical and organizational documents and archives, and examined quantitative data such as tuition, state funding, research, and salaries. Interviews were then conducted with longtime and former employees to obtain employee perceptions. Finally, the study compares employee perceptions about process, culture, and job satisfaction, to the goals established by the leadership.

The results of this study reveal that, while there were internal and external challenges, the transition to a public corporation was successful according to the perceptions of most employees when compared to the goals. After the transition, OHSU did become more efficient and more nimble for a time, able to recruit world-
\end{abstract}


class employees and pay competitive salaries. Staff felt empowered and some faculty felt it made OHSU a better institution. However, some faculty felt that OHSU's transition to the public corporation eventually led to increased bureaucracy, as well as to the loss of shared governance, tenure practices, and other cultural norms inherent to academic institutions.

By examining OHSU's transition and the impacts on employee groups, this study provides insight to other universities contemplating this type of change. While each institution is unique, understanding the impacts to these key stakeholders can help universities plan for and implement significant governance change. 


\section{ACKNOWLEDGEMENTS}

I owe my gratitude to many for helping me through this journey. I want to first acknowledge my fellow students in the Public Affairs and Policy program. My colleagues in this program—diverse in backgrounds, interests, and ideas-inspired and encouraged me. We shared laughter, tears, frustrations, challenges, and successes. In particular, I want to thank Molly Griffith, who has been a friend and advisor from day one. I also appreciate Tiffany Conklin, a masterful coder for this research project.

I have so many to thank at OHSU. I truly valued the help of Karen Peterson and Maija Anderson, OHSU's dedicated archivists. They take prodigious care of OHSU's historical collections and in addition to pulling many boxes of files for me during my research, they provided pointers on how and where to find useful information. I am so grateful to Drs. Peter Kohler and Lesley Hallick, and Jim Walker, Lois Davis, and Janet Billups. They were exceedingly generous with their time and memories. Their respect for each other and for OHSU was-and continues to beinspiring to me and I feel fortunate to have worked with them. Thanks also go to Diane Lovell of AFSCME for sharing her OHSU-related memories. I am always impressed by Diane's knowledge and honesty.

I am also fortunate to work with outstanding people at OHSU who have endured this program with me. I want to thank Dr. Dan Dorsa and my colleagues Dr. Rachel Dresbeck, Lisa Kendig, Jennifer Crosby-Meurisse, and Bobbi Luper for their patience and unwavering support. I especially want to thank Robert Oster-a 
colleague, friend, and a rock throughout—always willing to listen to me vent. I also appreciate Dr. Joe Robertson for his support of this project. I want to thank all of the current and former OHSU employees who were subjects in my project; their ability to remember and articulate the events of eighteen years ago was remarkable and key to this endeavor. I appreciate their time and interest in this project.

I am tremendously grateful to my dissertation committee. As chair, Dr. Lindsay Desrochers was an endless source of encouragement and guidance. She was always eager to share her knowledge and insights about higher education administration and organizational politics and I was lucky to be privy to her wealth of knowledge. Drs. Masami Nishishiba and Nancy Koroloff were generous with their time and expertise, challenging and encouraging me throughout the dissertation process. Finally, Dr. Jay Kenton was an exceptional advisor. He became my advisor early in this journey and was a teacher, counselor, and mentor. I valued his wisdom and his depth of knowledge about higher education administration in general and about the inner workings of Oregon's universities specifically. I will always remember and value the extra time he spent with me discussing the ins and outs of higher education in the U.S., and the people, places, and politics that make the Oregon university landscape unique, challenging, and exceptional.

Last but certainly not least, I am so grateful for the support of my family and friends. Many did not understand why I needed to take this journey, but they supported me nonetheless. My husband, Aaron, deserves and will get my undying gratitude. He has supported me tirelessly and in so many ways. From feeding me 
while I was studying, to boosting me up during the frustrating times, to helping me plod through data on this project, to reading, editing, and re-reading my dissertation. He has been there every step of the way-making me laugh and keeping me goingas my best friend, my partner, and my not-so-secret weapon. His support made this possible. 


\section{TABLE OF CONTENTS}

Abstract $\quad$ i

Acknowledgements $\quad$ iii

List of Tables $\quad$ xii

List of Figures $\quad$ xiii

Chapter 1: Introduction, Purpose of This Study, Research Questions _ 1

A. Introduction

B. Purpose of This Study 3

C. Research Questions 4

D. A Brief History of OHSU 5

Chapter 2: Literature Review $\quad 20$

A. Introduction $\quad 20$

B. Literature Review

i. The Role of the University 20

ii. Universities As Organizations: Change Inside and Out 22

iii. Universities and the "Love/Hate" Relationship With Change 26

iv. Desperately Seeking Independence $\quad 30$

v. University Employees and Job Satisfaction 37

vi. Faculty Satisfaction and Morale 38

vii. Staff Satisfaction and Morale $\quad 42$

viii. Union Populations $\quad 45$

ix. Organizational Theory and Universities $\quad 48$ 
Chapter 3: Research Methods

A. Introduction 55

B. Questions Addressed

C. Justification for the Case Study Approach 57

i. Case Study In Higher Education

D. Utilizing Multiple Sources in Data Collection 61

E. Data Collection 62

i. Overview 62

ii. Document Review 63

a. OHSU Archives 63

b. Oral Histories 64

c. General Counsel Files

d. Local and Regional News Reports and Articles

iii. Interviews 65

a. Introduction $\quad 65$

b. Study Participants $\quad 66$

1. Profile of Study Participants $\quad 66$

2. Sample Size $\quad 69$

c. Interview Participant Recruitment $\quad 70$

iv. Quantitative Data 75

F. Data Analysis and Management 75

i. Overview 76 
ii. Document Review

iii. Interviews

iv. Quantitative Data

G. Research Methods Summary.

Chapter 4: Results and Findings

A. Introduction

B. Research Findings

i. Document Review and Leadership Interviews

a. Interview Themes

b. Drivers of Change

c. Internal Goals for OHSU

ii. Current and Former Employee Interviews

2. Former Employees Employed Prior to 1995 Who Left the University Within Ten Years After The Transition

b. Findings

a. Staff, Faculty, Former Employees: Day-to-Day Process

a. Staff, Faculty, Former Employees: Job Clarity

2. Culture

a. Staff, Faculty, Former Employees: Culture Change

b. Staff, Former Employees: Freedom 
c. Staff, Faculty, Former Employees: Pressure

d. Staff, Faculty, Former Employees: Customer Focus

3. Job Satisfaction

a. Staff, Faculty, Former Employees: Value

b. Staff, Faculty, Former Employees: Expectations About Pay and Actual Pay

c. Staff, Faculty, Former Employees: Recognition

d. Staff, Faculty, Former Employees: Overall Satisfaction

4. Faculty Matters

a. Current, Former Faculty: Shared Governance

b. Current, Former Faculty: Academic Freedom

c. Current, Former Faculty: Expectations About Productivity

d. Current, Former Faculty: Promotion and Tenure

5. Overall Impact: Staff, Faculty, Former Employees

iii. Findings From Quantitative Analysis

a. About OHSU

b. Increased Productivity

c. Staff Satisfaction Factors: Staff Salary Data

d. Faculty Satisfaction Factors: Faculty Tenure \& Salary

C. Conclusion

A. Introduction

B. Comparison of Goals to Perceptions 
i. Goals and Perceptions About Efficiency and Process

a. Goals: Efficiency and Process

b. Perceptions: Efficiency and Process

180

c. Summary: Efficiency and Process

182

ii. Goals and Perceptions About Employee Satisfaction and the

Relationship With AFSCME

a. Goals: Employee Satisfaction and AFSCME

b. Perceptions: Employee Satisfaction and AFSCME

c. Summary Employee Satisfaction and AFSCME

iii. Goals and Perceptions About OHSU's Culture

a. Goals: Culture

b. Perceptions: Culture

c. Summary: Culture

iv. Goals and Perceptions About OHSU's Faculty.

a. Goals: Faculty

b. Perceptions: Faculty

c. Summary: Faculty.

v. Goals and Perceptions About OHSU As a Customer-Focused Business 203

a. Goals: Customer-Focused Business 203

b. Perceptions: Customer-Focused Business 204

c. Summary: Customer-Focused Business 205

vi. Goals and Perceptions About OHSU's Leadership 206

a. Goals: Leadership 206 
C. Discussion of Framework For Effective Governance Change In Universities 212

i. Opportunity, Action, Outcome 1: Acknowledge and Embrace What Exists Now (Culture, Structure, State)

ii. Opportunity, Action, Outcome 2: Leadership-Understanding and Utilizing The Power To Change.

iii. Timing and Environment-Considerations For The Change Framework 224

D. Broader Implications of This Research

E. Limitations of This Study 233

F. Future Research 238

G. Conclusion 240

References 242

Appendix A: OSSHE Proposed Governance Structure 252

Appendix B: OHSU 1995 Leadership Team Interview Guide 253

Appendix C: Interview Guide (for OHSU current employees) 255

Appendix D: Interview Guide (for OHSU former employees) 261

Appendix E: Invitation To Participate In Study 267

Appendix F: Informed Consent 269

Appendix G: Graphical Representations of Participant Responses 271 


\section{LIST OF TABLES}

TABLE

PAGE

1. Number and Type of Participants In This Study 67

2. Research Methods Overview 83

3. Process 119

4. Culture 129

5. Job Satisfaction 146

6. Faculty Overall Satisfaction Breakdown 147

7. Faculty Matters 155

8. Overall Impact of OHSU Becoming A Public Corporation 163 


\section{LIST OF FIGURES}

FIGURE

PAGE

1. Operating Budget 164

2. State Appropriations 165

3. OHSU Employees \& Students 166

4. OHSU Loans/Long-Term Debt

5. Tuition 168

6. Research Grants 169

7. Number of Hospital Patients 1995-2010 170

8. Classified Salary Comparison

9. Professor Salaries 174

10. Associate Professor Salaries 174

11. Assistant Professor Salaries 175

12. Instructor Salaries

13. Understanding The Structures In An Organization _ 226

14. Leadership Understanding The Needs In An Organization _ _ 228

15. One Framework For Effective Governance Change In Universities _ 230 


\section{Chapter 1: Introduction, Purpose of This Study, Research Questions}

\section{A. Introduction}

As human beings in society, we spend most of our lives within organizations-workplaces, schools, social associations, political affiliations, religious groups, sports clubs. Yet there are aspects of organizational life and culture that we struggle to understand, such as how organizational culture works, how it evolves, how it transforms when significant events occur that drive change, and how participants and employees are impacted when change happens. Within the organizational framework, higher-education institutions ("universities") are particularly intriguing to those who study organizations, and to internal and external stakeholders. Universities are the organizations in which we form our professional and personal identity, educate future leaders, make scientific discoveries, shape our ideas about civic responsibility, and form communities that we retain throughout our lives (Checkoway, 2001; Cole 2009; Thornton \& Jaeger, 2006). Universities are pivotal organizations in society, but they often demonstrate an ambivalent relationship to change (Kezar \& Eckel, 2002; Kezar, 2005; Tierney, 1988). Transformation can be simultaneously rapid and also painfully slow, with unclear results.

In Oregon and across the country, the winds of change are blowing as a number of flagship universities, including the University of Oregon, University of Wisconsin, University of California at San Francisco, and others have presented arguments to separate from their state systems and become independent 
universities (Edwards, Bates, Beyer, Devlin, Kruse, Barnhart, Beyer, Harker, Holvey, Hoyle, \& Nathanson, 2011; Lewin, 2011; Salins, 2011). The Oregon Health \& Science University (OHSU) successfully lobbied to do the same thing in 1995 when it became a public corporation and separated from the Oregon State System of Higher Education (OSSHE), the forerunner to the current Oregon University System (OHSU, 2007). In 1995, OHSU argued for this separation from the system to more efficiently administer the complexities of an academic health center, including professional medical, nursing, and dental schools along with two associated hospitals (Kringen, 2011; OHSU, 1994a \& b; Timms, et. al., 1995;). It is important for universities considering these transitions to understand the impacts of governance change on the organization, the culture, and the employees. Utilizing all the information available to fully comprehend organizational change at universities will help determine if this type of transformation is achievable, effective, and beneficial to stakeholders.

Given the importance of the role of universities in society, it is critical for us to understand these complex organizations better, and to understand whether this type of remarkable change provides an advantage to the parties impacted-whether it will help universities continue to shape future leaders, be accessible hubs of learning and exploration, and persist as thriving organizations with well-defined organizational cultures. 


\section{B. Purpose of This Study}

This research seeks to understand OHSU's history and culture as part of the state system, its separation from OSSHE in 1995, and most importantly, the impacts to the organization and its employees when it became an independent public corporation. This research will provide insight into the broader issue of organizational change in universities, as well as the pressing question of the benefits, challenges, and potential consequences (intended and unintended) for states across the country if their flagship universities are successful in their bids for change in governance and independence. The study will contribute to the knowledge in the theoretical and practical realms of organizational change. The theoretical contribution stems from viewing universities as organizations and applying organizational theory to the context of governance at a university such as OHSU. In doing so, it will also lead to a better understanding of OHSU's organizational culture, then and now. Combining the relevant theories with the lessons learned in this specific case study offers the opportunity to explore a framework for effective governance change in universities. This study examines the campus culture from the employee perspective and whether the work life and culture of OHSU changed. The practical contribution of this research is to inform other universities contemplating this type of change: on the impacts to employee attitudes and job satisfaction, and to the operational processes of the organization. It will also provide the first retrospective study of the employee perspective of an ambitious organizational and legislative plan imagined in 1990 and executed within five years. 


\section{Research Questions}

Central to this research is the question: What effect(s) did OHSU's decision to become a unique public corporation, separate from the Oregon State System of Higher Education, have on specific employee groups? Further, if the systems and processes in the organization changed because of the change in governance structure, how did this impact those employees? This study will examine two employee groups: the OHSU faculty, and the staff represented by the bargaining unit, American Federation of State, County, and Municipal Employees (AFSCME).

These two groups are important to study for several reasons. First, the governance change impacted perceptions about faculty tenure and promotion processes, shared governance practices, and expectations about faculty productivity. How those changes affected faculty job satisfaction and the culture of shared governance will be important to understanding universities as organizations in general, and in this case will illuminate the success of OHSU's governance change as measured by faculty satisfaction. Second, there is scant study to date of unionrepresented employees within universities. How the AFSCME-represented staff reacted to the changes at OHSU and how it affected their work life and job satisfaction will help us appreciate this important, yet little studied group. Finally, it will be useful to compare the reactions of these two divergent groups to this important event in OHSU's history. 
The questions that will be answered by this study:

- How do employees describe the impact of the new business model on their work and productivity levels?

- Did the campus culture and work life of OHSU change from the employee perspective?

- What was the effect on employee satisfaction?

○ Did compensation, benefits, or promotion practices change?

- For faculty, were there perceived changes in tenure opportunities, expectations about faculty productivity, and shared governance?

- Finally, the study will examine if OHSU became more bottom-line and/or customer driven and whether that impacted how these employee groups felt about working at OHSU. One of the motivating factors of OHSU's separation was to become more responsive to customers and to be more efficient and nimble in operations. The study will explore the intent to shift to more business- and customer-driven business practices and the impact this had on employees.

\section{A Brief History of OHSU}

OHSU's origins date back to the 1880 s, shortly after Oregon became a state. The University of Oregon formed its Department of Medicine in 1887. University of Oregon and Willamette University each began offering medical programs at approximately the same time, and then the two entities merged their programs in 1913. The Oregon College of Dentistry was founded in 1898, and in 1919 the University of Oregon began offering nursing courses. In the early part of the $1900 \mathrm{~s}$ 
many factors converged to bring all these entities together. What is now OHSU's 116-acre Marquam Hill campus got its start with a 20-acre tract of land that was donated by the Oregon Railroad and Navigation Company, and an 88-acre tract donated by the family of C.S. Jackson, former publisher of the Oregon Journal. Legend has it that in 1880 the Oregon Railroad and Navigation Company bought 360 acres of land "sight unseen" for a planned railroad depot and terminal. However, the land (now OHSU's campus) turned out to be at the top of Marquam Hill-rendering it impractical for a railroad depot, and thus after much persuasion from the railroad's chief medical officer, Dr. Kenneth A.J. McKenzie-also the dean of the medical school at the time-the railroad later donated some of the land to University of Oregon (OHSU, 2004).

In 1923, the Multnomah County Hospital opened on Marquam Hill and the medical school was contracted to run it, and in 1926, Doernbecher Children's Hospital opened as Oregon's first children's hospital. OHSU took over the operation of Doernbecher in 1928. In the 1930s and 1940s the Schools of Dentistry and Nursing became more closely aligned with the University of Oregon and by the late 1950s, University of Oregon was operating the University of Oregon Schools of Nursing and Dentistry, as well as having just built the Medical School Hospital. The Medical School Hospital and the Multnomah County Hospital merged in 1973, consolidating operations. Ultimately, in 1974, University of Oregon Health Sciences Center was formed under the direction of the Oregon State System of Higher Education. The schools of Dentistry, Medicine and Nursing were brought together 
under one umbrella to create this new center and it became Oregon's only academic health center and one of 125 in the nation.

In the next two decades, the academic health center continued on the path of significant growth and change. In 1981 it was renamed to Oregon Health Sciences University and that is when significant physical growth began: the Vollum Institute for Advanced Biomedical Research was built in 1987 following a large endowment donation from Howard Vollum, co-founder of Tektronix; the Oregon office of Rural Health joined OHSU in 1989, as did the Center for Ethics in Health Care. 1990 through 1992 saw the additions of the Dotter Interventional Institute, the Casey Eye Institute, and the Center for Research on Occupational and Environmental Toxicology (CROET), an institute that to this day receives base-funding from the Oregon Workers' Compensation Fund to study and improve the workplace environments of Oregonians. A new School of Nursing building opened in 1992 and a new clinical building, Physicians Pavilion, opened in 1993. Also in 1992, the Veteran's Affairs Medical Center bridge connecting OHSU and the VA Hospital opened, further integrating and connecting healthcare, education and research throughout Marquam Hill.

OHSU became a public corporation and separated from the Oregon State System of Higher Education in 1995. At this time, governance of OHSU shifted from the Board of Higher Education to a newly formed OHSU Board of Directors, whose members are nominated by the governor and approved by the Oregon Senate. Prior to OHSU's separation from OSSHE, OHSU's annual budget was $\$ 420$ million $(\$ 65$ 
million from research grants and contracts) and there were 6,651 employees (OHSU 1994c). At the time OHSU was Oregon's $7^{\text {th }}$ largest employer, made up of 1,646 faculty, 4,048 non-academic employees (including nurses, executives, and nonprofessional staff), and 957 house officers and student employees (OHSU, 1995d). There were 2,350 graduate and professional students in the Schools of Medicine, Nursing, and Dentistry and 120,000 patients served annually (OHSU, 1994a).

In 1998, OHSU merged with the Oregon Regional Primate Research Center (now the Oregon National Primate Research Center), located in Hillsboro. At the same time, the Neurological Sciences Institute joined OHSU. In 2001 the university completed the NSI and the Vaccine and Gene Therapy Institute building, located on a growing West Campus. Also in 2001, OHSU further expanded this campus when the Oregon Graduate Institute of Science \& Technology merged with OHSU, and Gov. John Kitzhaber signed legislation expanding OHSU's mission and changing the name to Oregon Health \& Science University.

More growth followed between 2001 and 2010 and continues to this day. In addition to acquiring the Pacific Oncology Group into the OHSU Knight Cancer Institute, in 2003 OHSU broke ground on the South Waterfront District to build the Center for Health and Healing and, in partnership with the City of Portland, the Portland Aerial tram connecting the South Waterfront to Marquam Hill (both opened in 2006). Simultaneously, building continued on Marquam Hill, with the Biomedical Research Building (opened in 2005) and the Peter O. Kohler Pavilion, a patient-care facility (opened in 2006). In 2004 the Schnitzer Investment 
Corporation donated 20 additional acres of property in South Waterfront to OHSU and in 2011 a partnership of OHSU and the Oregon University System broke ground on the OHSU/OUS Collaborative Life Sciences Building, scheduled to open in 2014 with education and research programs from Portland State University, Oregon State University and OHSU.

This continued growth in the last two decades, physically and otherwise, may demonstrate OHSU's increased agility since separating from OSSHE in 1995. In addition to growth, there have been struggles since the change in governance at OHSU, including challenges with credit ratings and debt, decisions to increase tuition rates, competition from other healthcare systems, struggles with unions, and fluctuations in patient satisfaction levels and public perceptions about quality of care. Some observers have noted that OHSU's challenges since becoming a public corporation make it less successful than originally proposed and imagined.

OHSU leadership at the time stated that once OHSU became a public corporation, having access to the debt markets permitted immediate upgrading of equipment and facilities (Redding, 2009), allowing OHSU to be competitive in the healthcare arena. However, with less state support for education and the pursuit of bonds and debt, OHSU has had to raise tuition rates over the years, making it difficult for Oregonians to afford education in the health professions and making OHSU's tuition rates some of the highest in the nation (Oregonian, 2013). This was discussed in an earlier study of OHSU by Michael Redding describing a situation in 2008 when OHSU restructured, implemented layoffs, and raised tuition up to $20 \%$, 
because "OHSU's losses are draining its cash reserves and potentially jeopardizing its credit rating" (Redding, 2009, p. 97). Further, as reported locally in 2009, 0HSU was at risk of having its credit rating downgraded “...and lenders forced it to put up cash collateral on $\$ 195$ million in loans it took out when it merged with its physicians group and had to refinance their clinical building on South Waterfront" (Sickenger, 2009). Pursuit of debt was thoughtful, though, and important for OHSU to be able to build research and healthcare facilities that allowed for recruitment of world-class researchers and physicians. It also gave OHSU the ability to be more nimble in building and recruiting (Redding, 2009). Initially the debt portfolio was correlated to the growth in research and clinical revenue (see graphs in chapter 4), however the correlation began to diverge (Oregonian 2013; Sickenger, 2009), causing tuition increases and other measures.

In addition to credit rating/debt struggles, and higher tuition rates, OHSU has had other struggles since 1995, including challenges with unions and patient satisfaction ratings. While currently rated among the best regional hospitals by consumer rating services, such as the Centers for Medicare and Medicaid Services and U.S. News \& World Report (CMS 2013; Rojas-Burke, 2012; U.S. News, 2013), in earlier ratings OHSU ranked lower-neither at the top nor the bottom, but somewhere in the middle (Lund-Muzikant, 2009). A topic that will be discussed in detail as part of this study is OHSU's relationship with the AFSCME bargaining unit. Leadership described OHSU's relationship with the union prior to 1995 as strong, and AFSCME did support the public corporation concept, but shortly after OHSU 
separated from OSSHE, AFSCME employees went on strike: “...[S]ome employees expected more out of the move to public corporate status. Last October's four-day strike by the local chapter of the American Federation of State, County and Municipal Employees—representing a wide range of OSHU employees, from clerical to laboratory personnel—centered on compensation, specifically market-level wages associated with public business" (Ritter, 1996).

Still, while OHSU has had its struggles in these areas, others believe that with the realities of public funding for higher education at all time lows in the last two decades, OHSU would be facing far greater problems were it not a public corporation (PSU, 2009). The brief history described above speaks to the steady growth trajectory of OHSU in its early development and to the opportunistic and entrepreneurial spirit and culture that existed from its early stages, despite challenges and setbacks in the early days of the public corporation.

In the mid-1990s, Dr. Peter Kohler, then president of OHSU, recognized that the higher education funding climate in Oregon was going to become more and more challenging with the passage of a state ballot measure limiting property taxes for Oregonians (Ballot Measure 5) and, among other things, causing cuts to higher education budgets. In addition, healthcare reforms at the time placed emphasis on a need for OHSU to be more responsive to the local healthcare markets in order to remain competitive. Redding illustrates the challenges associated with healthcare reforms for OHSU: 
"The emerging managed-care environment was changing the competitive playing field for OHSU. The state funding reductions and tuition increases accelerated OHSU's dependence on new market-based revenues and encouraged the university to emphasize revenue generation from private philanthropy, sponsored research, and patient-care services. The increased dependence on market-based revenues to fulfill its mission and the need to generate new institutional revenues was a primary factor in OHSU's move toward greater autonomy and flexibility." (Redding, 2009, p. 85)

These drivers of change were combined with the frustration Kohler was experiencing with the state's bureaucratic methods of doing business. He was stymied in trying to perform the business functions of running two modern hospitals, numerous clinics, and a health sciences university in an environment that required him to seek legislative approval for any proposed capital projects-thus putting OHSU at a disadvantage in the competitive healthcare field. An example of this was OHSU's attempt to add a maternity unit to the University Hospital building, a plan developed in 1986 (Oregonian, 1994). Kohler asked OSSHE for permission to build the addition in 1987. OHSU had the funds and did not require money from the state general fund, but OHSU was required to go through the state process. OSSHE did not forward the request to the legislature in 1987, or in 1989, and ultimately in 1993 the Legislative Emergency Board gave OHSU the approvals to proceed. However, due to the elapsed time since original bids were obtained, the contractors and bidding process were challenged and the state Attorney General required OHSU 
to start the process over. Eventually the project proceeded and late in 1994 OHSU had a new maternity unit, but Kohler was frustrated at the nine years it took to complete the project: "During that time, OHSU had to send some of its own patients to other local hospitals. If it hadn't been subject to cumbersome state rules, Kohler contends, the addition could have been ready much earlier. And it would have made OHSU a stronger competitor in maternity care" (Oregonian, 1994). Kohler went on to assert that the delays cost OHSU millions of dollars per year (Oregonian, 1994). Kohler, with the backing of a group of community and business supporters on the OHSU Foundation Board, began to pursue the notion of becoming an independent entity—outside the state system. He and his executive staff including the chief financial officer, provost, director of government relations, and general counsel, began to explore the options. From 1990 to 1994 the group, along with a task force that included members of the legislature, other Oregon universities, local business leaders, and a representative from the governor's office, examined scenarios and options that included (Alexander, Davis, \& Kohler, 1997):

- Complete privatization. This option was discarded because it was inconsistent with the OHSU's public mission and would likely result in loss of public funding

- Partnering with the Oregon Health Division (State Department of Public Health). While this had some benefits, it would not alleviate the bureaucratic burden OHSU was struggling with and would force two agencies with two very different missions to join together 
- Partnering with another healthcare system (e.g., Kaiser). This was considered but then rejected, primarily for the same reasons as complete privatization

- Doing nothing. While this was considered the "comfortable" option, this scenario provided no new ways to address the problems OHSU was confronting

- Alternative structure. Ultimately this was the option pursued-to structure OHSU as a quasi-public corporation, "...freed of some of the restrictions of the bureaucracy tied to the state system of higher education, yet still being accountable to the state for public service and education" (Alexander, Davis, \& Kohler, 1997, p. 262).

As the OHSU leadership refined the concept, they began taking this notion of independence to members of the OSSHE board, the governor, and legislators-to socialize the idea and to secure backing. It was neither a quick nor completely smooth process, but eventually both outgoing governor Barbara Roberts, and the incoming governor, John Kitzhaber, himself a physician and graduate of OHSU in 1973, backed it, as did a number of legislators. OSSHE was a much harder sell and numerous contentious discussions and meetings ensued (J. Billups, interview, December 8, 2011). Eventually, in early 1994, Governor Roberts, in her budget message to all state agencies, instructed OSSHE to develop its next budget without OHSU included (Roberts, 1994). This was the signal that OHSU had successfully made its case to separate. The OHSU Public Corporation Advisory Committee, created by Kohler and made up of the supporters from the OHSU Foundation Board and community members, wrote an advisory report detailing the benefits of the 
separation and outlining what they saw as the dire consequences if OHSU were to remain part of the state system (Buckman, Gilbaugh, Gray, Goldschmidt, Meyer, Stewart, Thorne, \& Whiteley, 1995). They submitted this report and provided inperson testimony in support of Senate Bill 2 (SB 2), which was sponsored by state senator Gene Timms, from Oregon's District 30, a rural district. The bill passed and was signed by Governor Kitzhaber, to be effective July 1, 1995.

OHSU's leadership established a transition team to spearhead the many facets of organizational and structural change needed-and there were many internal and external factors to consider. Externally, OHSU still needed to maintain relationships with the other Oregon universities, with the legislature, and with state bureaucracy. There were hurdles to overcome with regards to a range of topics, from ensuring a smooth transition for students and the academic programs to ensuring alignment with the other universities, to financial issues including bond issue delays and ownership of the property on which the OHSU campus stood. Internally the primary foci were employees, policies, and processes. In 1995, just prior the implementation of SB 2, Kohler stated to OHSU employees: “...we are entering one of the most exciting, challenging, and significant times in the history of the university. The tools we will need to be more efficient and productive will take time to develop and implement. It is important to remember that on July 1, 1995, you will not see a sudden change in business operations" (Kohler, 1995).

OHSU's leadership attested to employees that one of the primary goals of restructuring to become a public corporation was operating efficiency. They 
stressed that the legislation "would not disturb matters such as collective bargaining contracts or representation, seniority, or tenure rights" (OHSU, 1994b). SB 2 provided that all employees would continue their employment at OHSU, that the Public Employees Retirement System (PERS) would be retained—and that alternative retirement plans would also be designed. Further, OHSU leadership indicated that OHSU's independence would allow the flexibility to offer new and more robust employee benefits plans (health, dental, etc.), and that OHSU would have the ability to pay more competitive market-based salaries more suitable to an urban academic health center than to a state agency (OHSU, 1994b). Among the stated motivations, Kohler and the leadership promised to (Kohler, 1996):

- Improve services to employees through combined and coordinated human resources, recruiting, training, affirmative action, and payroll functions;

- Continue a commitment of labor-management cooperation;

- Begin moving total compensation packages to market levels and reward performance and merit rather than just seniority; and

- Provide more flexibility in employee health and retirement benefits.

In 1995, Kohler said: “We don't want to change the business we do-but we want to change the way we do business" (Rubenstein, 1995). Kohler had successfully argued the case for OHSU to become an independent public corporation to the governor of Oregon and the Legislature. He and the OHSU leadership team had also successfully lobbied internal stakeholders that work life and benefits at OHSU would improve, while still maintaining OHSU's entrepreneurial and 
innovative culture. Redding points out that this is the point where OHSU began to struggle with the balance between the new market-focused business model needed to sustain innovation and increased patient-services in a competitive healthcare marketplace, and the commitment to its historic public mission (Redding, 2009).

This study explores what changes did occur and how they impacted operations and employees. Once OHSU became a public corporation, the new flexibility required better internal systems and processes, as discussed in another study of OHSU by Barbara Archer in 2002: "A number of changes in organizational structure were required. These changes included developing and implementing operations systems that the organization lacked as a sub-unit of a state agency" (Archer, 2002, p. 202). Archer also points out that prior to the separation, OHSU had a bureaucratic model:

“Organizational and leadership culture also had to change. Prior to OHSU's conversion to a public corporation, the bureaucratic model dominated the organization's activities and its culture. Marketplace forces did not drive the organization's operations or decision-making. After the conversion to a public corporation, the process-oriented culture and pace had to give way to a market-oriented, outcomes-oriented culture with a much faster action and decision-making pace." (Archer, 2002, p. 202).

The internal response by employees to OHSU's new business model and governance structure is the focus of this study. Interviews with employees in the two targeted groups were conducted, as well as review of internal documents, 
memos, and newsletters, examination of objective/quantitative data before and after the separation, and review of external data and news reports are all a part of the research.

Chapter two describes the literature and theoretical frameworks that are relevant to how organizational change impacts employees, specifically at universities. It also explores literature about other universities who have achieved or are seeking independence and the impacts of those efforts. In addition, it examines drivers of faculty and staff satisfaction, particularly the literature available on this topic that is focused on employee satisfaction at universities. Chapter three discusses the research model for this study and the methods of data collection and analysis deployed to more fully appreciate this time in OHSU's history. This chapter also presents the profiles of the study participants.

Chapter four explores the findings of the three types of data collected. First, the numerous documents reviewed from the OHSU archives, including oral histories, internal memos and newsletters, communications between OHSU and relevant partners, and recent direct interviews with the 1995 leadership team. This review of the pertinent documents and preparatory interviews lays a foundation for the study of OHSU's governance change through the eyes of specific employee groups. Then chapter four discusses the findings of the primary research: the interviews with current and former OHSU employees in the two employee groups (OHSU faculty, and AFSCME-represented staff). The interviews sought to discuss the impacts of the governance change with employees who experienced it before, during, and after the 
1995 transition. Chapter four also presents findings of the information collected in the interviews. The third data component, quantitative data, is also reviewed in chapter four to provide a quantitative context for the qualitative case study.

Finally, chapter five examines the findings of the research and compares the goals of OHSU's transition to a public corporation with the perceptions of the select employee groups in the context of the research questions. In this chapter, the relevant organizational theories are discussed in the context of this particular case study and a framework is considered that melds elements of those existing theories with elements gathered and lessons learned from this case study into a proposed framework for effective governance change in universities. This dissertation concludes with a brief discussion of the implications of this research, some of the limitations of this study, and recommended future research that may complement this study and further the knowledge in understanding universities as organizations. 


\section{Chapter 2: Literature Review}

\section{A. Introduction}

Abraham Flexner said: "A university, like all other human institutions-like the church, like governments, like philanthropic organizations-is not outside, but inside the general social fabric of a given era...It is...an expression of an age, as well as an influence operating upon both present and future" (in Cole, 2009, p. 11). Because universities are such a critical part of the fabric of our society, they are worth understanding as organizations.

This review first examines literature focused on the role of universities in society and understanding them as organizations, followed by a brief review of literature pertaining to universities going through organizational change and explores work related to other universities seeking independence and the implications of those efforts. It then reviews the literature found on different types of employees in universities and the factors that contribute to job satisfaction. Since this dissertation focuses on OHSU's governance and structural change in 1995 and the impact to employees of the organization, it will be helpful to understand what factors drive employee satisfaction at universities. This literature review also discusses how organizational theory frameworks apply to universities.

\section{B. Literature Review}

i. The Role of the University

Universities have been slowly evolving for centuries (DeMillo, 2011) and the role universities play in society also changes: "The evolving idea of the university 
mirrors shifting values and trends in American society, including our attitudes toward science and engineering, industrialization, social reform, social mobility and opportunity, healthcare, and national security" (Cole, 2009, p. 12). The university in our society reflects our beliefs about the importance of new knowledge and discovery in how we progress, socially and economically (Cole, 2009).

Over the years, Americans have walked a tightrope trying to balance the sometimes-competing desire to maintain universities in the European tradition, as insulated temples for the elite to acquire higher knowledge, with the growing desire that higher education is and should be a public good that exists to serve the shifting, practical needs of larger portions of society (Cole, 2009; Hacker \& Dreifus, 2010; Kamenetz, 2010). These internal struggles for balance of identity have been coupled with an ever-changing climate outside of the university. Economic realities in the U.S. have driven policy on how to fund higher education and, to a great extent, universities have lost out to other societal needs, such as K-12 education, health and human services, corrections, and public safety (Hovey, 1999; Jones, 2003). This is also highlighted by Desrochers (2011) in a study of how the University of California system built the new Merced campus, which opened in 2005. As discussed in the article, the UC system had not built a new campus in three decades, but had built twenty new prisons in less time (Desrochers, 2011). Similarly, Portland State University, in a 2009 white paper regarding potential governance change pointed out that in Oregon, the state subsidy for public higher education has declined by $40 \%$ over the past two decades and "there is little reason to assume the state will be 
able to backfill this gap with state general funds in the foreseeable future" (PSU, 2009, p. 8). These financial choices, brought on by societal pressures and priorities, have left many states unable to form cohesive and comprehensive policy around how to prioritize funding for higher education, and with no systematic relationship between appropriations for higher education versus other public goods and services (Hossler, 1997). While funding policies around higher education may be debated for years to come, and actual funding for higher education will continue to be inconsistent and historically low, the importance of the university as an organization in our society remains steady.

\section{ii. Universities As Organizations: Change Inside and Out}

Universities as organizations are unique. Culture and power are often distributed at universities—among different schools, departments, and units. This makes them all the more challenging and intriguing to understand as organizations. Most of the applicable literature finds universities to be dispersed-in culture, structure, and balance of power. Baldridge (1971) discussed the organizational aspects of universities in terms of whether they fall into a bureaucratic paradigm, a collegial paradigm, or a political paradigm (Baldridge, 1971)—discovering that they often have aspects of all three. His research focused on the political paradigm, particularly at New York University. He discussed the bureaucratic paradigm in terms of Weber (1922), but dismissed this structure as too rigid and centralized to apply to universities. The collegial paradigm is concerned with how universities are 
viewed as "communities of scholars" and how power versus authority and structure versus process are balanced.

This pursuit of balance is relevant in terms of OHSU and other universities, particularly academic health centers: there exists a mix of paradigms between the hospital, which is by nature hierarchical; and the university, which is normatively collegial and distributed-with political frameworks existing in both. In the study of OHSU's employees and their reactions to change, an important question to understand, given the distributed nature of universities, is whether satisfaction varies depending on the employee's place within the organization (department and position type), and whether it varies by other factors such as longevity or age group. The crux of the collegial paradigm is whether it is descriptive or normative-many feel it is normative and is expressed in terms of how universities should be rather than how they are (Baldridge, 1971).

Baldridge examined significant change at NYU—in governance, in administrative models, and in student and faculty composition—and found that change in this type of organization is difficult (Baldridge, 1971). He discussed the difficulty and complexity of moving away from the organizational status quo and discovered how change is often not uniform across a university. Due to the complexity of the organization, Baldridge noted that change can never really be uniformly adapted—a conclusion about the distributed nature of structure and power in universities that many have reached, and one that applies to OHSU. Mintzberg (1983), an organizational theorist, supports this notion and asserts that 
the more complex the environment, the more decentralized the structure will be (Mintzberg, 1983).

As mentioned earlier, Baldridge also looked at power versus authority and how this manifests itself at universities-sometimes formally structured and acknowledged, and at other times informally applied depending on the situationwith regards to expertise, emotion, mass appeal, and momentum. University power, governance structure, and allegiance have feudal origins and some of that environment is residual today (Baldridge, 1971; Cole, 2009; Krause, 1996). This is supported in Biglan's studies of universities based on departmental norms and scientific or academic foci and how social structure and hierarchy are often determined by those foci (Biglan, 1973a \& b). Kenton discusses this as well, highlighting Biglan's theory that faculty in hard sciences in particular (such as the basic sciences at OHSU) tend to share the same approach and style and to identify with each other and even other professionals outside the institution, rather than the institution itself (Kenton, 2000).

Two additional Baldridge notes are important to consider in the context of universities as organizations. First is the notion of social structures of universities, and their "pluralistic" nature as a confederation of diverse units that are loosely coupled, with varying loyalties (Baldridge, 1971). This is a factor to keep in mind when exploring campus culture-and as mentioned earlier, may be a key variable as it relates to employees' perceptions of job satisfaction. Second is the decision making process (or internal legislative process) and how it creates a three-legged 
stool of the aspects of decision making, including "who decides", "what is decided", and "how decisions are made" (Baldridge, 1971, p. 193-194). There is a great deal in Baldridge's work with NYU that applies to other universities (even though Baldridge is careful to caution that any case study of a single university may not be generalizable, a factor that will be discussed in chapter three of this dissertation)such as embedded and diverse cultural norms and allegiances, distributed power versus who has formal authority and what happens when those clash, and how and what role administrators, faculty and students play in the culture and power structure of a university. Krause (1996) also touched on these themes with regards to the community of scholars-and how the "guild" of scholars exercises power and control over the university domain by strength gathered in their membership and association (Krause, 1996). Clark (1972) also examined the meaning of "saga" in university culture, asserting that "saga" is more than a chronicle or story, but is the forum in which universities store their history, lore, culture, and symbols. He concludes that an organizational saga is a powerful means of unity (Clark, 1972) and that it cuts across internal divisions and organizational boundaries. This is useful to understanding university cultural norms, but conflicts with work by Baldridge (1971) and Biglan (1973a \& b) asserting that unity is more likely at departmental and unit levels than at the university level.

This theme of scattered unity and decentralized decision making, and even loyalty, emerges frequently when reviewing the literature on universities: "The irony of this pattern of decentralization was that the quality of local leadership was 
improved, but the level of local isolation was increased. It became difficult for knowledge to move across the internal borders of the university's schools and departments" (Cole, 2009, p. 489).

Bolden, Petrov, and Gosling (2008) examined the concept of distributed governance models in U.K. universities and, through their study, developed a model for university leadership at individual, group, and organizational levels. Their research demonstrated the multifaceted nature of universities and determined that rather than adopting a purely distributed structure, most universities are well served with a hybrid model—with leadership and organizational identification acknowledged at multiple levels of the organization.

University structure, as defined by Baldridge, Biglan, and others, is important with regards to this study of OHSU and to the study of other universities, because it helps put a framework around university culture, how it evolves, and how these organizations function, before, during, and after change. As many of these authors and researchers identify, reactions to change within a university may vary based on the very distributed nature of these organizations. This study of OHSU explores that concept through interviews with employees from a variety of areas around the institution.

iii. Universities and the "Love/Hate" Relationship With Change

Adrianna Kezar and her colleagues (Kezar \& Eckel, 2002; Kezar, 2005; Kezar, 2006) have examined culture and change in universities in several different ways. Kezar and Eckel (2002) conducted ethnographic and case study research to 
determine relationships between institutional culture and change and whether (or to what degree) ignoring culture can thwart change. They found, among other insights, that culture is intertwined with change and ignoring the culture will be a significant barrier to affecting change.

Organizational culture, as described by Kezar (2005) and others, is often described as the collective behavior of people that are part of the organization. This is something Kohler and the leadership team recognized but may not have fully addressed in OHSU's move to become an independent public corporation in 1995a factor that is explored in this study. In addition, Kezar (2005) examined the consequences of radical change in university administration. She found that radical change can have considerable negative consequences and that gradual change coupled with innovation is more promising to enhance administration of universities.

Understanding universities and their ability to change and adapt includes looking at their ability to plan and strategize. Hearn, Clugston, and Heydinger (1993) looked at environmental scanning and strategic planning in universities. They studied the University of Minnesota, first to learn about the university's overarching strategic planning efforts, and then later to determine if strategic planning was still being practiced after a period of time. They asserted that strategic planning (defined as integrated decision-making and planning processes-having relevance to current and emerging issues-done holistically, iteratively, continuously, and heuristically, and balancing qualitative and quantitative data) is 
poorly understood at universities (Hearn, Clugston, \& Heydinger, 1993). When they returned to determine whether strategic planning had continued, they found that it had significantly decentralized-it was being adopted at the unit level, but not centrally, for three reasons: first, the slowness of large universities to respond at a central level; second, the connection of individual academic departments to emerging external issues; and finally, the difficulties in institutionalizing strategic organizational innovations (Hearn, Clugston, \& Heydinger, 1993). This theme of the distributed nature of universities is consistent with the findings of authors previously discussed (e.g., Baldridge, 1971; Biglan 1973a \& b; Carpenter, 2009).

Hearn, Clugston, and Heydinger (1993) also discussed why there are tensions between units and central administration and the propensity to avoid systematic planning. Strategic planning decentralizes because the size and complexity of universities makes success unlikely at the central level. Another reason it tends to fail at a central level is the absence of a high-level champion. Other reasons include that it is difficult to institutionalize theoretically-based scanning unless rooted at the academic unit level (similar to Biglan's findings, 1973a \& b); there is sometimes a policy vacuum in place; resources are not available to dedicate staff time to strategic planning; and sometimes there is a lack of clarity of the mission (Hearn, Clugston, \& Heydinger, 1993). Given that these planning efforts were not successful over the long term at UM, the authors proposed factors for success, including a need for integrated decision-making; an orientation toward output (also found in Tierney, 1998); openness to dynamic and unexpected changes; 
and that the proposed changes need to be a priority of top administrators (Hearn, Clugston, \& Heydinger, 1993). These are important factors with regards to this study of OHSU's change in governance structure in 1995, particularly the thorough environmental scanning by Kohler and his leadership team that went into preparing for the new independent organization.

Also relevant to this study is Tierney's (1988) research, which attempted to provide a working framework of organizational culture in higher education-for the purpose of helping universities overcome problems emblematic at higher education institutions and to minimize conflict. Tierney (1988) pointed out that universities are influenced by external (e.g., economic, political, demographic) factors as well as strong internal forces (e.g., values, entrenched processes, goals). Similar to Kezar (2002), he found that understanding organizational culture helps administrators spot and resolve conflicts and operate more effectively and efficiently. One of Tierney's key points was that university culture involves management of meaning (ensuring those within it know what is important to the university life and environment) and management of social integration (rallying support for what is important culturally) (Tierney, 1988). Another important point is about leadership: presidential clarity about institutional mission is critical (Tierney, 1988).

A later work of Tierney's (1998) discussed the need for universities to be more responsive. He argued that universities need to listen to those who are being served - to the extent of using "customer" language when thinking of students, but he acknowledged that this concept is a barrier: "Many in higher education are 
offended by the term or simply find it inappropriate" (Tierney, 1998, p. 19). This is relevant to universities in the modern era and to OHSU in particular, as a customerdriven model (patients and students) was a key component of OHSU's quest to become independent. Tierney's (1998) point was that in the 21st century, universities need to be more responsive to internal stakeholders (students seeking degrees, faculty and the ramifications of tenure, and staff) as well as external stakeholders (potential students, legislators, donors, private partners), and universities need to reconcile that operating in a somewhat commercial frame does not mean abandoning academe (Tierney, 1998, p. 164). Tierney's conclusion is that universities need to justify their roles and existence via outcomes rather than solely based on inputs, as they have in the past (Tierney, 1998). "When faced with competition, some institutions reinvented themselves, but most of them clung to the belief that change, if it came at all, would be gradual. They seemed to be helpless bystanders as their value was quickly eroded by newer-often more agileinstitutions" (DeMillo, 2011, p. 243). DeMillo and Tierney are demonstrating that universities need to do what Kohler asserted OHSU needed to do to survive: adapt and focus on customers. iv. Desperately Seeking Independence

While not common, it is also not novel for universities to seek independence from their higher education system or from status as a state agency. Some of the reasons include those already discussed, including greater autonomy to make decisions without micromanagement from bureaucratic entities and dwindling 
funding from State and Federal sources that drive universities to seek other funding models: "The public universities say that with less money from state coffers, they cannot afford the complicated web of state regulations governing areas like procurement and building, and that they need more flexibility to compete with private institutions" (Lewin, 2011). In 2010 the University of Oregon proposed such a transition to separate from the state higher education system (OUS), and subsequently won approval from the Oregon Legislature in 2013 to create its own board of directors. The OUS itself (the coordinating body over all of the Oregon public universities) proposed—and was successful—separating from state agency status in 2011. Similarly, a Louisiana business-backed group has successfully separated Louisiana State University from the state system.

Additional stories emerge from Wisconsin and other states, including the University of California at San Francisco. UCSF is quite similar in structure to OHSU, with strong research and medical programs and no undergraduate students. UCSF's chancellor, Susan Desmond-Hellman, proposed a "novel governance" structure that would allow UCSF to break some of the ties to the UC system that create a financial burden, and create its own governing board more suited to an academic health center than the University of California Board of Regents (Asimov, 2012; Leuty, 2012a \& b). Among other things, Desmond-Hellman hoped to become less reliant on the vagaries of state funding. Reiterating the challenge discussed earlier, and illustrated by Desrochers in describing funding for the UC Merced campus: "UC leaders were required to make the annual trek to the State Capital, Sacramento, like 
any other public agency—for the lifeblood of any public university, state funds" (Desrochers, 2011, p. 4). An historical example of university restructuring is Rutgers University, which became a public corporation similar to OHSU, as well as a Land Grant University.

In 2007, the Medical College of Georgia, formerly part of the University of Georgia system, also undertook a structural change, with the separation of their hospitals and clinics to a private entity, MCG Health, Inc., while the Medical College eventually became part of Georgia Regents University (Rausch, 2007). OSSHE actually offered this model as an alternative to what OHSU was proposing. In November 1994 Joseph Cox, then chancellor of OSSHE, proposed an alternative that separated OHSU's hospitals and clinics, but kept the university as part of OSSHE (see Appendix A for OSSHE's proposed model). Cox argued that he understood the issues OHSU was facing, but believed "that the academic programs must remain part of the Oregon University System if we are to meet our responsibilities to the people of Oregon" (Cox, 1994). Kohler had philosophical disagreement with this approach, particularly as it related to reporting structures for the academic programs and in the area of budgeting (Kohler, 1994).

The literature regarding the success or failure of these types of transitions is scant. Rebora and Turri (2010) noted that environmental factors, such as funding and control, have a large impact on universities seeking independence, but they found universities intrinsically reluctant to change: "Behavioral inertia is the tendency to preserve the existing organizational structure, even when it is clearly 
inefficient and unsuited to official goals...it is widespread in all universities in the shape of a 'mix of organizing practices which are historically located and variably resistant and resilient'” (Rebora \& Turri, 2010, p. 285). Further, they found that the same distributed —-they go so far as to call it "fragmented"—nature of universities makes it that much more difficult for cohesive conversations about distribution of resources and to get consensus (Rebora \& Turri, 2010). Their study looked at a university in Italy and found that change was only successful when organizational power is clearly defined and acknowledged. Opportunistic attempts to change processes without formal authority had negative impacts (Rebora \& Turri, 2010). Knott and Payne (2003) found that the relationship between how the university is governed and the quality of its operations remains somewhat of an unknown. There are conflicting data about whether and to what degree the autonomy impacts academic programs - and whether other factors play a role, such as size of endowments, campus size, geographic location, and other factors (Knott \& Payne, 2003). Of relevance to the study of OHSU, Knott and Payne (2003) also noted that medical schools have advantages that other universities do not, in the form of political support, ability to pay higher salaries to faculty, alumni gifts, and federal research grants. Some argue that universities with medical schools also have some disadvantages, including higher costs of providing education due in part to the necessary physical infrastructure, mandated limitations on class sizes, and those higher salaries. Lyall (2011) found that universities have had to respond to their newfound independence with incremental innovations, including creative degree 
solutions (three-year degrees, online learning, etc.), changing the enrollment mix to more non-resident and international students to increase tuition revenue, and increased reliance on adjunct and non-tenured faculty (Lyall, 2011). Some of these changes are controversial and harken back to one of the first topics of discussion: whether a university's services are intended to be a public good. With a focus on faster and arguably lower quality instruction, less in-person learning, and encouragement of higher-tuition-paying students, that debate will likely continue for years to come. As with Kezar (2005), Lyall (2011) also found that making incremental innovations emerges as one of the keys to how to wrestle with the notion of independence.

Lyall (2011) discusses the various quasi-independent structural models that have emerged. For example, the University of Michigan, similar to the University of California at San Francisco, was established in the state constitution as a "charter status" institution, allowing it to have local control over personnel, procurement, tuition, and construction, and the governor of Ohio has proposed that the Ohio University System adopt this model (Lyall, 2011). University of Michigan officials attest that the charter status structure makes them more efficient and adaptable to changing market forces while still remaining true to its mission of serving the public good: “...a public, but independent, entity serving public purposes” (Lyall, 2011, p. 5). Virginia restructured its entire university system in 2005 , creating a threetiered system of autonomy, depending on each institution's ability to effectively manage their own day-to-day operations and their fiscal resources. Virginia system 
officials claim that it is possible to implement a "nuanced flexibility system that enables public institutions with different sizes, revenue sources, and operational capacities all to benefit and operate more effectively to achieve state goals" (Lyall, 2011, p. 6). Lyall also discusses the University of Oregon proposed "publicly endowed" model based on a large bond measure which will earn interest to cover the "endowment" payout, which: "Aims to freeze the state's current annual contribution to the University of Oregon by converting it from an annual appropriation to an endowment" (Lyall, 2011, p. 6). As Lyall describes it, the state's current appropriation would then be used to cover principal and interest payments on an $\$ 800$ million bond. The university would then do a match, with $\$ 800$ million in private gifts—creating the equivalent of $\$ 1.6$ billion, but freeing it from the ups and downs of State budgets and revenues (Lyall, 2011). The University of Oregon argues that this will ensure stability for its educational programs and will not require additional State support in the future (Lyall, 2011).

Each of these models presents advantages and risks for the state systems, for the universities themselves, and for the students and employees of each campus: "Across the country, statewide higher education systems are struggling to find a new mission that adds value, and not just bureaucracy, to the operation of their component universities" (Lyall, 2011, p. 7). While these studies examine the fiscal impacts to the universities and the states in which they exist, and in some cases touch upon the operational effectiveness, few of them explore the direct impacts to 
the employees and processes of the organization. This study of OHSU delves more deeply into some of these impacts of such structural changes.

As with more traditional universities, Academic Health Centers (AHCs) also struggle to find the right model that serve the institutions' best interests, as well as their varied constituents, including faculty, students, and administrators. AHCs also struggle with unique circumstances that include the vagaries of health care reform, competition for patients, the need to train practitioners in a myriad of specialties, competing in the biomedical research realm, and the need to balance an academic environment with a business environment. To that end, AHCs are more apt to look to the tools and techniques utilized in the private sector for transformation strategies (Topping, Hyde, Barker, Woodrell, 1999; Woodard, Fottler, Kilpatrick, 1999). These include external approaches such as strategic partnerships and collaborations, as well as internal approaches that include process improvement, downsizing, expansion of clinical and other revenue generating enterprises, and differentiating or market positioning (Topping, et al., 1999).

In studies by Topping et al. (1999) and Woodard et al. (1999), they discuss lessons learned by AHC institutions that had undergone change-primarily driven by environmental factors such as healthcare reform and competition. The lessons learned included developing thorough plans based on clear vision, engaging employees early, committing time and resources, and communicating actively (Topping et al., 1999; Woodard et al., 1999). Results also showed that even the bestlaid plans resulted in slow transformation and disenfranchised employees: "The 
survey confirmed that the [academic] medical center's employees were not receptive to change and, although they matched well with their jobs, employees felt disenfranchised from the organization" (Woodard et al., 1999). This study of OHSU and its transformation in 1995 speaks to elements of change in universities in general, whether traditional universities or academic health centers. Each of these institutions has the need to understand and embrace the distributed nature of the academic environment in order to successfully achieve transformation.

\section{v. University Employees and Job Satisfaction}

It is important to understand how different types of employees (e.g., faculty, staff, etc.) are part of, and responsive to, governance change in universities. According to the National Center for Education Statistics (NCES), in 2009 there were $3,723,000$ employees in higher education in the U.S., including faculty and staff at public and private universities, and of those, $39 \%$ were faculty, $27 \%$ were administration/management, $26 \%$ were support staff, and the remaining small percentage is made up of graduate assistants (NCES, 2009). Little literature has been found so far that focuses on job satisfaction at universities, and whether there are differing levels of satisfaction among the different groups of employees and in different parts of the university—and whether and how change impacts these groups differently. Most of the literature, as demonstrated in this review, focuses on faculty and administration/management approaches to change and satisfaction. As highlighted by Carpenter (2009), there is a paucity of studies to date that examines 
factors for job satisfaction among many of the positions beyond faculty and leadership at universities.

\section{vi. Faculty Satisfaction and Morale}

Studies of employees in universities have focused primarily on faculty. Johnsrud and Rosser (2002) found that there is no single factor that impacts how satisfied faculty are with their jobs, but instead there are several variables. Work life, which in itself encompasses several factors, plays an important role-particularly the degree of autonomy and intellectual challenge the faculty perceive they have in their work-including the freedom to determine what they teach or study and when they do it (Johnsrud \& Rosser, 2002). The authors also discuss the "legendary" adversarial relationship faculty have with administration. In the context of job satisfaction, that issue is represented by the level of confidence the faculty have in their leadership, and in the autonomy of their own faculty governance structure within the university. According to Johnsrud and Rosser (2002), the majority of faculty view top-level administrators as less than competent-impacting their job satisfaction levels.

Kissler (1997) found that traditionally, the president, vice presidents, deans, and directors comprise the administrative hierarchy in colleges and universities. Parallel structures exist, including faculty senates, student councils, and departmental committees, creating what Kissler terms an organizational dualism (Kissler, 1997). But these parallel structures are usually responsible for academic, or "collegial culture", while the administrative leadership is responsible for 
"managerial culture". Kissler recognizes this dichotomy, and while studies conducted from the 1970s to the 1990s concluded that faculty and others who participate in the "collegial culture" have exercised increasing command and control of academic affairs, these employees have made little advancement in input or control over finances (Kissler, 1997).

Organizationally, this has led to chasms between administrative leadership and faculty that persist today. During periods of difficult financial decision-making, the gap grows wider, with faculty losing confidence in the president as he/she concentrates the decision-making to a more centralized group of administrators (also found in Johnsrud \& Rosser, 2002). However, administrative leadership often finds itself in a bind or "no-win" situation in which faculty back away and let the executives take responsibility for cutting programs during difficult budget situations. Kissler, similar to other studies discussed in this literature review, found that in the 1990s, many university administrative leaders began adopting models that looked more like corporations: restructuring, merging programs, reallocating resources to more productive departments, and looking for new external sources of funding (Kissler, 1997). He also cited a 1993 study (Slaughter, 1993) indicating that when it comes to difficult financial decisions, "although faculty have to be heard, they need not necessarily be heeded" (in Kissler, 1997, p. 430), further indication of the chasm.

Kissler's own study focused on who should be involved in financial decisionmaking in universities (Kissler, 1997). His survey included 225 colleges and universities and contained a complex series of weightings according to the size and 
type of institution and the role(s) of the respondents. He found that the organizational dualism described earlier still exists, and the perception is that presidents seize authority over financial decisions during significant economic downturns (although it is unclear whether the president is seizing authority or merely exercising the authority he/she already has). In reality, the first-hand knowledge the faculty have of the academic programs puts them in a better position than most central administrators to judge the impact of closure or reduction and it would be wise for strong administrative leadership to recognize this and include academicians in the process.

The limiting factor on faculty participation, however, is time. Faculty are commonly criticized for moving slowly—clinging to lengthy processes to determine which programs to cut. Kissler concluded, "If, indeed, there is value to greater faculty participation in times of financial exigency, the challenge will be to devise less time-consuming processes for meaningful faculty participation in budget cut decisions" (Kissler, 1997). All of this jockeying for decision-making authority impacts faculty job satisfaction: "Given the tradition of shared authority and faculty governance, the administration must work with the faculty to initiate changes that affect the academic core of the institution or that affect the reward system for faculty" (Johnsrud \& Rosser, 2002, p. 523). In reality, this likely makes it rare that significant change can be made within universities without involvement of all parties with relevant expertise. 
Other work life factors that Johnsrud and Rosser discuss as impacting faculty satisfaction are salary and benefits, promotion and tenure, and access to support, such as administrative assistants, graduate assistants, and technology resources. They discuss that recent surveys indicate less than half of faculty are satisfied with salary and fringe benefits (Johnsrud \& Rosser, 2002). Putting salary aside, they did find that faculty satisfaction stems from four primary factors: 1) distinctive organizational culture, 2) participatory leadership (greater involvement of faculty in decision-making, which corroborates Kissler's (1997) findings, as well), 3) a sense that the organization has momentum and is moving toward organizational goals and mission, and 4) feeling an identification with the university. These play a role in how faculty feel during difficult financial times-inadequate financial resources seem to have a negative impact on faculty satisfaction and contribute to the feeling that faculty do not have a say in university operations (Johnsrud \& Rosser, 2002).

Further discussion of faculty job satisfaction focuses on morale, and whether morale is an individual or collective factor (or both). Depending on the interpretation of morale, this can be an important concept when discussing campus culture-as morale is often defined as the capacity of people to maintain belief in an institution or its goals. This depends in part on the unit of analysis and whether we are considering the individual, the group, or the institution as a whole. Focusing on faculty satisfaction, the assumption is that morale is a collective concept and that it does have to do with campus cultural and work life. 
Given the consensus among the literature that universities are distributed in nature, it follows that levels of morale will vary among the departments, schools and other units and may not be consistent throughout the entire university. Johnsrud and Rosser (2002) conclude that the quality of the academic enterprise at universities is highly dependent on faculty satisfaction and morale. The challenge is to understand and address the many factors that influence satisfaction-including salary, academic freedom and autonomy, belief in the institution, participation in decision-making, and a sense that the university is working toward its goals. These are varied and complex to address. This study of OHSU explores the faculty's perceptions of their role in OHSU's 1995 transition and how it impacted their levels of job satisfaction.

vii. Staff Satisfaction and Morale

There are few studies that explore employee satisfaction in universities. There are a number of studies in organizational literature that look at this in corporate or government settings, but few focused on higher education. One factor that commonly arises in the organizational literature is that employee satisfaction is frequently tied to employee productivity, and in broader terms, to the vitality and performance of the organization (Volkwein \& Zhou, 2003). Further, Volkwein and Zhou (2003) also assert that this applies to administrative and support staff in the higher education sector as well. However, job satisfaction is more than that and is tied to an array of factors that may relate to the individual, their work group, the 
situational circumstances in which they work, and other factors (Volkwein \& Zhou, 2003).

Administrative and support staff satisfaction falls more clearly into intrinsic and extrinsic categories. Intrinsically, employees look to feelings of accomplishment and feeling valued by the organization, and the ability to take the initiative, feel challenged, and be creative in their work. Extrinsically, employees look to aspects of their jobs such as job security, opportunity for advancement, future income potential, pressure on the job, work hours, and organizational politics (Volkwein \& Zhou, 2003). Volkwein and Zhou also found that there are work-related variables that have a positive influence on employee satisfaction, including: "a supportive organizational culture, teamwork, relationships with colleagues and superiors, worker autonomy, and self-fulfillment" (Volkwein \& Zhou, 2003, p. 151).

Stress was the most common negative indicator to job satisfaction. Administrative staff include leadership and managers, and Volkwein and Zhou (2003) found that the autonomy of the university and how much state control and regulation it was subjected to, in addition to the size and mission of the university and its financial resources, influenced satisfaction for managers and leaders (Volkwein \& Zhou, 2003). They also point out that a common thread in organizational and higher education literature is that those within universities who are engaged in the mission or goals (e.g. teaching or research) have more job satisfaction than those in bureaucratic roles (e.g., finance, personnel, etc.) (Volkwein \& Zhou, 2003). This is not surprising because being closer to the mission likely 
provides more meaning. Nor is it surprising that the authors also discovered that universities are prone to distributed cultures in academic and administrative departments and units where their own subcultures exist and levels of satisfaction vary depending on multiple factors (Johnsrud \& Rosser, 2002; Volkwein \& Zhou, 2003). This dynamic is explored in the study of OHSU.

As noted earlier, intrinsic and extrinsic factors influence job satisfaction-as do interpersonal factors such as co-worker relationships. Job satisfaction related to these intrinsic, extrinsic and interpersonal factors is impacted by large-scale change within the university-and this need not be immediate change; it can be gradual (Volkwein \& Zhou, 2003). We can conclude that all levels of analysis-individual, group, and organizational—should be considered in relation to employee satisfaction in universities. Volkwein and Zhou found that there are very close ties between the organizational environment (whether at the unit level or organizationwide) and administrative job satisfaction (Volkwein \& Zhou, 2003).

When thinking in terms of OHSU's transition to an independent public corporation in 1995 and the impacts to employees, these are important concepts to consider and if Kohler's assertions prior to 1995 to employees and stakeholders hold true, then it is important to consider the work environment as a bellwether of employee satisfaction: “...improvements in the immediate work environment will produce the greatest impact on managerial morale, productivity, and retention" (Volkwein \& Zhou, 2003, p. 167). Conversely, job insecurity was a factor that strongly negatively influenced overall satisfaction. 
Additionally, as noted by Desrochers in discussing the creation of the University of California Merced campus in 2005 (Desrochers, 2011), employees are the key to developing a new operation and: "employees did not always know how to proceed with their jobs, as there was no obvious road map" (Desrochers, 2011, p. 16). UC Merced was built from scratch and decisions involved whether to duplicate services that already existed within the UC system, whether to contract out the work, whether to access resources at other campuses-all similar decisions to those faced by the staff, administration and faculty at OHSU. These factors are relevant to the exploration of the work environment and its relationship to employee satisfaction. viii. Union Populations

A final important aspect of university employee work life is the fact that many universities, OHSU included, have union-represented workforces. In OHSU's case, there are two segments of the workforce represented by bargaining units: administrative and support staff represented by the Association of Federal, State, County, and Municipal Employees (AFSCME) and the nursing population represented by the Oregon Nurses Association (ONA). These segments of the workforce play an important role in OHSU's history and its operations, and how they were impacted by OHSU's transition to an independent public corporation is important to explore. This study looks at the impacts from the perspective of AFSCME-represented employees as one of the key employee groups.

In research done by Vander Putten, Mclendon, and Peterson (1997), they found that an estimated $40 \%$ of clerical and other support staff in public higher 
education institutions are union affiliated. In addition, $25 \%$ of the clerical workforce in private universities are union affiliated. In general studies of organizations and unions, the perceived need for union representation comes from the need to address workplace shortcomings (Vander Putten, McLendon, \& Peterson, 1997). Studies also show that, once an employee joins the union, the perceptions of those shortcomings are exacerbated and can influence the employee's perception of their work and their job satisfaction (Vander Putten, McLendon, \& Peterson, 1997).

Vander Putten, Mclendon, and Peterson (1997) explored the climate in which support staff work within universities and found Schein's definition of organizational culture to hold true in universities: organizational culture includes the basic assumptions and beliefs that are shared by the organization as a whole (Schein, 1985). Further, they found that campus culture is the "organizational glue" that holds the institution together with collective values (Vander Putten, McLendon, \& Peterson, 1997). These definitions are important, the authors say, because an employee's work environment plays such an important role in their job satisfaction. They found that non-faculty employees consider several themes most important: compensation, quality of the work, physical environment, personal experiences on the job, and opportunities for development (Vander Putten, McLendon, \& Peterson, 1997). Effective processes also played an important role-including the structure of their work, the work processes, how processes were communicated, and how leadership supported their work (Vander Putten, McLendon, \& Peterson, 1997). While very little work has been done to study how differently union-represented 
and non-union-represented staff in universities view their work environments, and thus their job satisfaction, Vander Putten, McLendon, and Peterson do suggest that unionized environments are more adversarial and result in increased levels of miscommunications among stakeholders (Vander Putten, McLendon, \& Peterson, 1997). In a study of multiple universities by Baldridge (1978), he asserted that the union environment generated control issues and increased bureaucracy, creating an increasingly restrictive operational environment in universities and leading to less creative thinking on how to make processes more efficient.

Vander Putten, McLendon, and Peterson (1997) discuss briefly the general overview of union vs. non-union environments in business and industry sectors and found mixed results-some studies show that non-union and union employees had few differences about work attitudes, dedication, and values, while other studies found that there are differences in job satisfaction surrounding salary issues. One study of union and nonunion professional librarians found no significant differences in work values (Vander Putten, McLendon, \& Peterson, 1997). Because studies of factors relating to university employee satisfaction are rare, the authors recommend a need for additional research in this area (Vander Putten, McLendon, \& Peterson, 1997).

Their own study endeavored to explore whether and how differently union and nonunion staff (non-faculty) viewed their work environments and job satisfaction: "The quantitative analysis found that union-affiliated staff members perceive their culture, philosophy, climate, and outcomes of their work environment 
more negatively than do nonunion staff" (Vander Putten, McLendon, \& Peterson, 1997, p. 145). Their qualitative analysis confirmed these findings. A key aspect of this study of OHSU explores work environment and satisfaction factors among the AFSCME-represented employees—a population that has not been studied extensively—as well as faculty, allowing a comparison across these two important and diverse populations within OHSU. These factors are relevant to the examination of OHSU and its change in governance structure. How and whether the change in environment impacted represented employees is important to how organizations, and universities in particular, plan for and implement change.

ix. Organizational Theory and Universities

Finally, it is important to explore how organizational theory applies to university frameworks, and also to explore organizational change as a key component of the study of OHSU's transition to an independent public corporation, and how it ties back to employee satisfaction. As Carpenter (2009) illustrates, Mintzberg's (1983) model of professional bureaucracy is consistent with university structure: “Henry Mintzberg's (1983) model of professional bureaucracies illustrates the importance of the faculty, the relationship between faculty and administrators, and potential structural mechanisms for change" (Carpenter, 2009, p. 28). The professional bureaucracy is one of Mintzberg's five dominant structures; which also include the simple structure, the machine bureaucracy, the divisional form, and the adhocracy (Mintzberg, 1983). Mintzberg puts universities in the professional bureaucracy and views the faculty as the dominant "operating core"- 
the group responsible for the output. In Mintzberg's model, the professional bureaucracy has many of the elements that others have described here, such as Baldridge, Tierney, and Biglan: a decentralized model where power is distributed and lies within the professions, or in this case, the faculty (the operating core) (Mintzberg, 1983).

Kissler (1997) discussed this as well, explaining that faculty decidedly want to have control over decision-making processes. As Kissler also demonstrated, there is a duality found in university structure. Faculty control the academic power through faculty senates and other committees, overseeing the curriculum and academic programs, while an administrative hierarchy runs in parallel, overseeing the finance and administration of the university. As Carpenter (2009) explains, Mintzberg's work helps us understand the balance between the organizational leaders and the professional functions. University leaders and faculty are in a continual state of negotiation about the vision and direction of the university. This limits the power of both groups and sets the stage for the unique equilibrium that makes up the university as an organization.

Mintzberg's structural framework does help to understand universities, but as Baldridge (1971), Biglan (1973a \& b) and others make clear, Mintzberg's formal structure does not address the informal structures, groups, and interactions that take place across the institution. Much of the business of universities takes place within distinct units of less formal power structures and it is important to acknowledge these forms of interaction and to embrace them. Engaging these 
informal structures when attempting change within a university as an organization is critical.

Mintzberg also posits that interaction among and between the different groups (e.g., the operating core, the support staff, etc. - and even diverse groups within the operating core) will necessarily be different because each group has a different purpose and are not generally integrated entities: "They are collections of individuals who come together to draw on common resources and support services but otherwise want to be left alone" (Mintzberg, 1983, p. 207). Mintzberg implies that the professionals in an organization (in this case, faculty) are more focused on their profession than they are on the organization as a whole, which is something that Biglan (1973a \& b) also identified as a characteristic of university life, setting the stage for competing groups within the university—competing for resources and their own agendas. The focus on their own professional area rather than on the organization as a whole makes change at the university level problematic (also identified by the University of Minnesota study, Hearn, J.C., Clugston, R.M., \& Heydinger, R.B., 1993), and highlights challenges such as the void in leadership training and experience at the departmental level.

Given that universities demonstrate a long-held and entrenched set of norms, it is important to look at what change in such a complex and distributed organization might look like. Trice and Beyer (1993) assert that changing organizational culture is about planned, all-encompassing and substantial changenot single change events or fractured changes in behaviors. They discuss three 
types of culture change: revolutionary and comprehensive efforts; efforts that change specific subcultures; and efforts that are gradual and incremental, but still result in comprehensive change (Tryce \& Beyer, 1993). Within these types of change, they layer on four dimensions of change: pervasiveness, magnitude, innovativeness, and duration. Similar to Kingdon's Multiple Streams conceptual framework (Kingdon, 2011), Trice and Beyer discuss windows of opportunity, or change circumstances, that make change desirable and they describe stages in which change takes place, including adoption, implementation, and institutionalization (Trice \& Beyer, 1993): “Cultural innovation involves the duality of creation and destruction" (Trice \& Beyer, 1993, p. 390), highlighting the thorny nature of how to go about changing organizational culture.

This, too, is pertinent to the study of OHSU—-the transformation to an independent public corporation and new governance model can be considered the result of leveraging a window of opportunity, followed by the stages of adoption, implementation, and institutionalization, as envisioned by Kohler and his leadership team: "Doing nothing, although immediately the most comfortable option, would have guaranteed that there would be no new ways to address the growing demands of the marketplace and the funding decreases facing medical education" (Alexander, Davis, \& Kohler, 1997, p. 262). Shortly after the separation, Kohler characterized the lessons learned in stages similarly described by Trice and Beyer (1993) as utilizing effective leadership, framing the need for change, communication, planning for implementation, and anticipating that, "[c]hanging the culture of an institution takes 
time, and is different from changing just the structure of an institution" (Alexander, Davis, \& Kohler, 1997, p. 267). Leadership was careful to point out that the change in governance structure that transpired at OHSU did not "just happen" and that restructuring would not miraculously solve all problems.

This study explores the framework of employee (faculty and staff) satisfaction coupled with the intervening variable of change in governance structure and the ensuing impacts. Another important organizational framework explored is the approach used by Beckhard and Harris (1987) expressing the importance of leadership and understanding where the organization is, where it wants to be, and determining how to get there-even if it means wholesale change. The essence of their seemingly simple formula for managing complex change in organizations is exceedingly difficult for organizations to achieve. Their framework taps strong leadership to understand the future state, the present state, and the transition state as the key factors in a roadmap for change. Elements of this framework were present as OHSU's leadership contemplated the roadmap to transition its governance structure and become a more nimble organization.

It is important to briefly explore additional themes pertaining generally to organizational change, include engaging employees in the change process (Ogbanna \& Wilkinson, 2003), the notion of forced change and the likelihood it will backfire (Gotsi, Andriopoulos, \& Wilson, 2008; Kezar, 2002), and adaptability when resetting the organization's mission (Denison \& Mishra, 1995). In the public sector, Ogbanna and Wilkinson (2003) found that mid-level managers and lower level employees can 
be ambivalent about culture change driven by leadership, but that certain factors made employees more favorable to change, particularly open communication, being engaged in the change effort, and having the freedom to implement change as they saw fit. When mid-level managers felt empowered to involve their employees, enthusiasm for the change at both the managerial and lower levels increased. Supporting that study, Gotsi, Andriopoulos, and Wilson (2008) found that forcing a cultural change in an organization can backfire. They wrote that managers and other employees will not align with change, despite elaborate attempts at communicating the purpose, if it is perceived as top-down cultural realignment-instead of a more holistic organization-wide approach (Gotsi, Andriopoulos, \& Wilson, 2008).

Denison and Mishra (1995) identified the linkage between meaning and practice in organizations, and in particular how organizational culture impacts effectiveness. They found that a thorough understanding of culture and mission led employees to be more effective-and that consistent leadership in the areas of mission and culture led employees to be more adaptable and flexible to change. This is consistent with findings discussed earlier regarding studies done in universities, such as Johnsrud and Rosser's (2002) exploration of faculty satisfaction and how it relates to feelings and understanding about the university's goals and whether the university is moving toward those goals. These and other studies are helpful in understanding organizations generally, the role of the different types of employees at all levels within the organization, and how culture and change emerge and evolve. 
Carpenter (2009) also illustrates through examination of studies in higher education done in the 1970s through the 1990s that, "[r]egardless of the conditions under which it happened, faculty support has been identified as instrumental to creating change in higher education" (Carpenter, 2009, p. 17). While Carpenter and others often reiterate that studies of staff (non-faculty) in universities are scarce, it is clear that their roles are critical to the successful and efficient implementation of change in university operations as well. As a result, this study of OHSU takes a closer look at the roles of both faculty and non-faculty populations.

As noted in this literature review, universities are an important part of the fabric of our society and they are challenging to understand organizationally. The distributed and multi-layered nature of universities makes it more challenging to understand their culture and environment. As universities struggle to find the balance needed to be sustainable and accountable-and in an increasing number of cases propose to become independent from their higher education systems-the literature will continue to emerge about how this type of change impacts internal and external stakeholders. This study of OHSU's transition to a public corporation adds to that body of literature. It also adds to the limited literature on employees in universities and what factors drive satisfaction. 


\section{Chapter 3: Research Methods}

\section{A. Introduction}

This is a case study, with the unit of analysis being the employees at the Oregon Health \& Science University (OHSU) in Portland, Oregon. The primary purpose of the research is to explore impacts to two specific employee groups and the work life and culture of OHSU after the university separated from the Oregon State System of Higher Education in 1995 and became an independent public corporation.

\section{B. Questions Addressed}

This study examines two employee groups: OHSU faculty, and staff represented by the American Federation of State, County, and Municipal Employees (AFSCME).

These two groups are important to study for several reasons. First, the governance change impacted faculty tenure and promotion processes, shared governance practices, and faculty pay. How those changes affected faculty job satisfaction and the culture of shared governance is important to understanding universities as organizations in general, and in this case helps illuminate whether and how OHSU's governance change was successful as measured by faculty satisfaction and retention. Second, there is scant study to date of union-represented employees within universities. How the AFSCME-represented staff reacted to the changes at OHSU and how it affected their work life and job satisfaction helps us appreciate this important, yet little understood group. Finally, it is useful to 
compare the reactions of these two divergent groups to this important event in OHSU's history. The questions that are answered by this study:

- How do employees describe the impact of a new business model on their work and productivity levels?

- Did the campus culture and work life of OHSU change from the employee perspective?

- What was the effect on employee satisfaction? During interviews with employees, the questions were broken down further into these areas:

○ Did compensation, benefits, recognition, or promotion practices change? How did these impact job satisfaction, if at all?

- What were these two employee groups' perceptions about job clarity and stability?

○ For faculty, were there perceived changes in tenure opportunities, expectations about faculty productivity, and faculty governance?

- What were the perceptions and impacts on the two employee groups on whether OHSU became more bottom-line and/or customer driven?

The crux of this case study is to examine a dramatic change in the organization's history and how the employees perceived the change. This includes employees' perceptions about the changes to internal processes; to their own job satisfaction based on changes to pay and benefits, recognition, and job clarity; and to their overall satisfaction after OHSU separated from the state. For faculty, this study also looks at faculty perceptions about shared governance, productivity, academic 
freedom, and promotion and tenure practices. Understanding how employees react to these types of significant change in an organization can be important factors in how successful the transformation will be.

\section{Justification for the Case Study Approach}

Based on the review of literature in the preceding chapter, two points have emerged about universities: they have entrenched cultural norms, and change is challenging due to complex nature of these organizations. Universities typically operate in distributed environments and, as a consequence, power and elements of the culture exist less at the central level and more at the unit level-particularly in the case of academic departments where faculty serve as the functional core of the organization. Thus, organization-wide change is difficult to plan for and difficult to implement, and impacts to employees may vary depending on the type of employee and the unit in which they work.

Case study is an effective method when studying a unique situation, such as OHSU's change from being part of a state agency to being an independent public corporation. The case study approach allows the researcher to go deep into the phenomenon. This methodology can extend experience and add strength to what is already known through experience and previous research. Case study allows for a formalized research structure that can still evolve as the research is conducted (Glaser \& Strauss, 1967). It provides an opportunity to ask the questions, illustrate the context, present the issues, and conclude with lessons learned (Creswell, 1998). 
Use of case study allows a thorough examination of OHSU's transition and provides the basis for the application of these research findings to other universities going through governance, cultural, or structural change. Case study allows for "intensive analyses and descriptions of a single unit or system bounded by space and time" (Hancock \& Algozzine, 2006, p. 9). Creswell concurs, asserting that case study is used where there are clear boundaries and when there is opportunity to examine contextual material from multiple sources (Creswell, 1998). In both cases, this is applicable to this dissertation study: there are clear boundaries around the OHSU case, both in terms of a timeframe and as an organizational entity, and material was gathered from multiple sources. Using case study helps gain an indepth understanding of the OHSU case (Hancock \& Algozzine, 2006). Case study methodology, while focused on one case, helps us see that a research strategy integrating different methods produces better results in terms of quality and scope.

\section{i. Case Study in Higher Education}

Case study has strengths and weaknesses, as do all research methodologies. Part of the appeal of case study methodology for this research is its adaptability and applicability to the university setting. As Baldridge (1971) points out in his casestudy research of New York University, it is a way to compile evidence and ideas and get a sense of the dynamics of a situation, while not being bound by one data collection method (Baldridge, 1971). In his research, Baldridge first conducted interviews and then used that data to construct a questionnaire, and finally, did participant observation and document review. He found that the variety of 
techniques he deployed in the field allowed him to gather and assemble a holistic picture of the institution and its dynamics (Baldridge, 1971). This study of OHSU follows a similar path.

Baldridge does identify a limitation of case study research: he points out that the focus on one university limits the generalizability of the study and that great care must be taken to ensure the representativeness of the samples used in the study (Baldridge, 1971). He asserts that this limitation is outweighed by the strengths gained from the depth of a case study: data is collected at the source and there is an irreplaceable usefulness of exploring the processes of an organization (Baldridge, 1971). As discussed in the literature review, Hearn, Clugston, and Heydinger (1993) utilized case study in their five-year analysis of the University of Minnesota and its efforts to do environmental scanning and strategic planning. They found case study methodology allowed them to build systematic understanding of the internal and external factors impacting the university.

Kezar and Eckel (2002) conducted ethnographic and case study research to determine relationships between institutional culture and change, and whether (or to what degree) ignoring culture can thwart change. In addition, Kezar (2005) examined the consequences of radical change in university administration. She used a combination of case study and Grounded Theory (Glaser \& Strauss, 1967) methodologies because of the context-based nature of the case (Kezar, 2005) and to do an in-depth study of the processes at a university and people's reactions to those processes. Finally, Thornton and Jaeger (2007) utilized ethnographically informed 
case study to look at the links between higher education institutions and civic responsibility (Thornton \& Jaeger, 2007). They found strengths in ethnography and case study research, because of the in-person nature of the work, and utilized it in several studies in universities. These situations are analogous to the research in this dissertation and these previous studies demonstrate the strength of this approach for the study of OHSU.

In their discussion of the limitations, Thornton and Jaeger (2007) question whether the case study research in higher education undertaken thus far is generalizable and whether it is possible to extrapolate the knowledge gained about university culture and change to other similar institutions (similar to Baldridge, 1971). When discussing these limitations, they point out that cultural studies of a single institution tend to be specific and are "not generalizable into practical applications for other institutions" (Thornton \& Jaeger, 2007, p. 1001). They do discuss the strengths of case study, specifically the ability to provide a contextual setting for the research and obtain pertinent insights to the organization and the people (Thornton \& Jaeger, 2006).

Case study research is an important methodology in the social sciences, in public administration, and in higher education in particular. In the study of OHSU, as with the other university-focused research discussed here, case study provides the ideal combination of providing value on both an academic and practitioner level (White \& Adams, 1994), because "the laboratories of public administration are the offices of the practitioners" (White \& Adams, 1994, p. 190). These authors go on to 
assert that case study methodology can be as scientifically rigorous as other methods if great care is taken to ensure that data are collected in a uniform manner, that data are analyzed in a manner that can be applied in other situations, and that the findings produced are given uniform conditions and analysis (White \& Adams, 1994). The reliability of the results when data are collected and analyzed consistently indicates that case study produces results generally consistent across universities, despite being based on different institutions and situationsconfirming the validity of this approach.

\section{Utilizing Multiple Sources In Data Collection}

This is a qualitative study, drawing also on quantitative elements. In order to increase the validity and strength of the research, this study collects data from multiple sources (Berg, 2007; Maxwell, 2005; Yin, 1989). This approach reduces the risk of systematic biases and increases the validity of the findings. Broadening the scope of the data collection helps the researcher gain a better understanding of the key issues (Maxwell, 2005). Multiple data sources include document review, interviews, and examination of existing quantitative data from before and after OHSU's separation. Data from these sources provide the best possible outcome: understanding the importance of how universities adopt governance change and how transformation impacts specific employee groups in a variety of departments/locations around the university, their job satisfaction, and the campus culture. This study aids in better understanding of the implications of such a change and how it applies to other universities contemplating or undergoing change. 
Collecting data from multiple sources provides a means of mutual confirmation of the information, and provides a way to augment the validation of findings. Utilizing multiple sources allowed the researcher to test the consistency of findings obtained through different instruments-for example, interviews and data/document review. This increased the opportunity to assess some of the multiple causes influencing the results and was appealing because it clarified results from one method with the use of another method, allowing one method to inform the others. For example, the data collected during the initial document review and foundational leadership interviews informed the quantitative data review done later in the study. Using the data collected in both the interviews and the review of documents helped develop a well-rounded picture of the state of affairs at OHSU during that time period. Finally, multiple sources provided richness and detail to this case study, allowing for exploration of different strengths of each source. Using case-study research employing multiple sources to explore OHSU's governance transition to a public corporation expands the breadth of the study and sheds light on organizational change and transformation in higher education, at academic health centers, and for organizations in general.

\section{E. Data Collection}

\section{i. Overview}

Data collection for this study was conducted in three ways: document review, including review of oral history transcripts; one-on-one interviews; and review of existing quantitative data. Data collection was an ongoing process that continually 
evolved as more data was collected and a story began to emerge. The study began with document review and exploration of the oral histories, followed by conducting one-on-one interviews as detailed below. After going through the process of internal document and oral history review and initial interviews, quantitative data was also examined. The table later in this chapter provides an overview of all of the sources and methods utilized in this study.

\section{ii. Document Review}

Document review began in Spring 2012 and continued throughout the study. Multiple sources for materials were used:

\section{a. OHSU Archives}

OHSU maintains archives dating back to its founding in the late 1800s and the data includes historical documents, institutional reports, newsletters, internal memos and organizational data, as well as extensive media files of stories about OHSU before, during and after the transition in 1995. Internal documents were reviewed for the tone and nature of internal communications and other documents (memos, letters, newsletters, etc.) about the purpose and goals of the public corporation. These documents were utilized to help lay a foundation for the goals of the public corporation so that a comparison between the goals and employee perceptions-and research questions about job satisfaction, changes in pay and benefits, and cultural changes—could be addressed (in chapters four and five). 


\section{b. Oral Histories}

The OHSU archives also include an ongoing oral history project that is included in this study. The oral histories are cross-referenced by key words and this study includes review of oral histories that contain mention of the 1995 separation from OSSHE and the public corporation. The oral histories are an important secondary data set-interviews conducted previously that mention faculty and staff reactions and descriptions of this event at OHSU are important to laying the foundation of the goals for the public corporation and initial employee reactions based on the research questions.

\section{c. General Counsel Files}

Janet Billups was general counsel at OHSU before, during, and after the 1995 separation, and is one of the authors of the legislation executing the separation. Billups generously supplied her entire file for review. The files contain internal memos, news articles, communications between state agencies and OHSU, and communications with the two unions (Oregon Nurses Association and Association of Federal, State, County, and Municipal Employees) throughout the 1990s to the latter part of the 1990s. Her files also contain a review of legislation of similar efforts in other states (her review was done in the early 1990s). These files are a key component of understanding the factors that drove the move to separate. They provide insight into the background of the initiative, the communications to and with employee groups (such as the faculty senate), and leadership's goals for the 
organization and employees. This information is included-along with analysis of documents and oral histories mentioned earlier-in chapter four.

\section{d. Local and Regional News Reports and Articles}

There is a plethora of media information about this topic readily available in OHSU's media archives. These documents were helpful to determine how the media portrayed the perceptions from several points of view, including that of the employees. An external media search and review was also conducted to utilize data and information from around the state and the country pertaining to OHSU and to other universities.

\section{iii. Interviews}

\section{a. Introduction}

This study involved collecting data from human subjects—current and former OHSU employees in two specific employee groups, as well as interviews with former OHSU and AFSCME leadership. Prior to conducting interviews, the research proposal was submitted to the appropriate Institutional Review Board(s) for review and approval. The study is focused on OHSU employees, but is being conducted as part of a doctoral dissertation for the Public Affairs and Policy Program within the Hatfield School of Government at Portland State University (PSU). Thus, the proposal was submitted first to the PSU Human Subjects Research Review Committee (HSRRC) for review and approval, and then to OHSU's review board. The study was approved by PSU's HSRRC on June 28, 2012 for the period of one year (HSRRC \#122204), and renewed by the HSRRC through the continuing review 
process through June 28,2014 . The study was subsequently reviewed and approved via waiver by OHSU on August 29, 2012 (IRB \#8732), and renewed by the IRB through continuing review through July 21, 2014.

\section{b. Study Participants}

Within the limitations of the time available, interviews were conducted with the following samples:

\section{Profile of Study Participants}

The terms "current employee" and "former employee" will be used frequently to describe the overarching population for this study. "Current employees" refers to employees who still work at OHSU, and have worked at OHSU since prior to OHSU's transition to a public corporation. Thus, these employees have been working at OHSU for eighteen or more years. "Former employees" refers to employees who were employed at OHSU during the transition and who left OHSU within ten years of that period. Within these categories, two types of employees were interviewed for this study: employees represented by the American Federation of State, County, and Municipal Employees (AFSCME), as well as faculty. The AFSCME employees will frequently be referred to as "staff".

A stratified purposive (Berg, 2007) manner of selection was used in order to obtain a cross-section of employees from different mission areas and departments at OHSU. After receiving approval from PSU's and OHSU's human subjects committees, the OHSU Human Resources Department provided two lists of current and former employees. 


\begin{tabular}{|c|c|c|c|}
\hline & $\begin{array}{l}\text { AFSCME } \\
\text { Employees } \\
\text { (15 total) }\end{array}$ & $\begin{array}{l}\text { Faculty } \\
\text { (15 total) }\end{array}$ & $\begin{array}{c}\text { Former } \\
\text { Employees } \\
\text { (5 total) }\end{array}$ \\
\hline \multicolumn{4}{|l|}{ Age Group: } \\
\hline Age $40-49$ & 3 & 3 & 0 \\
\hline Age $50-59$ & 6 & 5 & 1 \\
\hline Age 60-69 & 6 & 7 & 0 \\
\hline Age $70+$ & 0 & 0 & 4 \\
\hline \multicolumn{4}{|l|}{ Length @ OHSU: } \\
\hline 17 years & 0 & 0 & 1 \\
\hline $18-25$ years & 10 & 11 & 0 \\
\hline $26-30$ years & 4 & 4 & 0 \\
\hline $30+$ years & 1 & 0 & 4 \\
\hline \multicolumn{4}{|l|}{ Mission area: } \\
\hline Academic & 4 & 11 & 2 \\
\hline Research & 2 & 2 & 1 \\
\hline Healthcare & 1 & 2 & 0 \\
\hline Central Services & 8 & 0 & 2 \\
\hline
\end{tabular}

As Table 1 indicates, fifteen current AFSCME employees and fifteen current faculty employees were interviewed, as well as five former employees. Positions varied widely. A list of AFSCME positions interviewed for this study includes:

$\begin{array}{ll}\text { grants coordinators } & \text { facilities coordinators } \\ \text { analysts/trainers } & \text { administrative assistants } \\ \text { senior financial analysts } & \text { information specialists } \\ \text { human resources specialists } & \text { computer support analysts } \\ \text { shipping coordinators } & \text { business analysts } \\ \text { accounting specialists } & \text { buyers }\end{array}$

The faculty positions of the participants ranged from assistant professor to full professor, from a variety of departments and schools, including research centers, the hospitals and clinics, and the schools of Dentistry, Medicine, and Nursing. When referring to faculty, there is also a distinction of employee type that is cross- 
institutional: whether the faculty member works in the basic sciences or in a more clinical capacity. This distinction is important when studying the themes that emerge in this study relating to faculty perceptions. Faculty who work in the basic sciences are laboratory researchers as well as teaching faculty in departments such as Biochemistry \& Molecular Biology, Cell \& Developmental Biology, etc. This type of faculty is also most common in OHSU's research centers and institutes, such as the Center for Research on Occupational and Environmental Toxicology (CROET), and the Vollum Institute for Advanced Biomedical Research. Clinical faculty work in OHSU's hospitals and clinics with patients. These faculty may also conduct research, potentially both in the basic sciences and in clinical research. The study included clinical, basic science, and library faculty.

Another term frequently used as a description of employee type at OHSU is "mission area". OHSU has three primary mission areas that drive the functions and strategies of the organization. They are: healthcare, education, and research. A fourth mission area is outreach and is a function that crosses all of the other missions. Of OHSU's 14,000 current employees, approximately 6,800 of them work directly in the healthcare mission (e.g., nurses, clinicians, patient care support, etc.) and approximately 5,000 work in education (e.g., Schools of Medicine, Nursing, and Dentistry and other associated education programs). Approximately 1,200 work in the research mission (research faculty and laboratory staff who work in research centers, and support staff); additionally some of the employees who work in education and healthcare also do research and cross over to the research mission as 
well. The remaining employees work in central support functions such as finance, IT, operations, and maintenance (OHSU, 2013a). The term "mission area" to describe an employee type or where an employee works is common at OHSU-it is part of the organizational lexicon, and that is why it appears frequently in this research study.

\section{Sample Size}

Interviews conducted for this study included current and former employees in all of the mission areas. Within those missions, as many employee types were included as possible to get a broad view of the perceived impacts. The ages of those interviewed ranged from 40 to over 70 years old, and the employees had worked for OHSU ranging from eighteen years to over 30 years. There were eleven female staff interviewed, and four male staff; seven female faculty and eight male faculty; and of the five former employees, two were female, three were male. The total gender count was 20 females, 15 males. Again, these ranges served to provide as broad perspectives as possible within the two employee groups that were the focus of this study.

Of the 71 staff invited to be interviewed by e-mail, fifteen agreed to be interviewed, which equates to approximately a $21 \%$ response rate (based on the number invited). Of the 356 current AFSCME employees who have been employed since prior to 1995 on the OHSU Human Resources employee list, fifteen represent approximately $4.2 \%$ of this longtime AFSCME population. The current AFSCMErepresented OHSU population (regardless of length of service) is 5,530.15 interviews represent $0.3 \%$ of the total population. 
Of the 57 faculty contacted, fifteen agreed to be interviewed, which equates to just over a $26 \%$ response rate (based on the number invited). There are 183 faculty on the Human Resources list who have been employed at OHSU since prior to the 1995 transition. Fifteen interviewed represent slightly over 8\% of the faculty population who have been at OHSU since prior to the transition. The current faculty population (regardless of length of service) is 2,510. Fifteen interviews represent $0.6 \%$ of the total population.

Ten former employees were contacted and five interviews were conducted, for a $50 \%$ response rate (based on the number invited). The number of employees who are faculty or staff on the Human Resources list totaled 461 people and five interviews equate to just over $1.0 \%$ of the possible population. Chapter five includes a discussion of the representativeness of these sample sizes.

\section{c. Interview Participant Recruitment}

A Cover/Invitation Letter for the interviews with current and former employees and an Informed Consent form were provided to all study participants (see Appendices E and F). The informational interviews with the OHSU leadership/transition team (president, chief financial officer, provost, general counsel, and director of government affairs) and with AFSCME leadership were conducted as early in the study as possible, beginning immediately following human subjects approval. The goal was to interview three to five leaders, and ultimately five were interviewed-four in-person and one by phone. Initial contact was made by e-mail to explain the study and invite their participation. In all cases, the 
researcher had worked with the OHSU leadership team for varying lengths of timein direct and indirect capacities. Thus, the invitation e-mail required introduction to the nature of the study but was not a "cold call." All of the leadership were generous with their time and their thoughts and sharing information on this topic. Without exception, they demonstrated a clear and passionate recollection of the events during that period of time in OHSU's history and they clearly illustrated their commitment to the success of the endeavor.

AFSCME leadership who worked at the local chapter during the 1995 separation period was contacted through current AFSCME connections. Similar to the OHSU populations, initial contact was via e-mail, introducing the project and inviting participation in an informational interview. The goal was to interview one AFSCME leader and this was achieved.

For the interviews with current and former OHSU employees, it was necessary to cull existing human resources lists before initiating interviews. A preliminary assessment by the OHSU Human Resources Department estimated that there may be approximately $1100-1200$ employees who were employed prior to 1995 who were still employed at OHSU. Once the list of current employees was generated, it contained 850 people in total. Within that list, 356 were AFSCME employees and 183 were faculty. The other employees on the list were unclassified administrative employees and nurses (members of the Oregon Nurses Association, ONA). Since those two employee groups were not part of this study, those names were not included when inviting participants to interviews. Invitation e-mails were 
sent in increments of 50 employees at a time. The goal was to conduct 15 interviews in each employee type, with a caveat of potential reduction, depending on participant availability and as time allowed. Ultimately, 15 interviews in each employee category were achieved. 71 staff and 57 faculty were contacted to achieve the goal of 15 interviews in each category.

Once the control factors based on attributes were applied, remaining participants were selected in a stratified purposive manner (Berg, 2007), in order to obtain a cross-section of employee types from a variety of areas across the university. This type of sampling is used when the researcher has heightened knowledge or expertise about the population or group (e.g., OHSU employee categories) and can select subjects in field investigations in order to ensure that certain types of individuals are included in the study (Berg, 2007). It was anticipated that not all participants in the initial invitations would be able or willing to participate. When potential participants declined or did not respond, additional participants remaining on the lists were chosen in a similarly purposive manner. Prior to interviews, an introductory e-mail was sent to current employees introducing the researcher, explaining the study, and asking for volunteers to participate in a one-hour interview. In the invitation, a window of time was established in which to conduct the interviews and times and dates were proposed and specific dates/times/locations were proposed so that potential participants were able to select the date/time/location that was most convenient for them. 
There were a number of possible locations at OHSU to hold the interviews that provided a private, confidential setting.

With the exception of the OHSU and AFSCME leadership interviews who agreed to be quoted, confidentiality was given the utmost consideration in conducting this research. Current and former employees of OHSU may have had concerns about participating in interviews, and measures were taken to ensure confidentiality throughout the process. Interviews were conducted in neutral and private locations as much as possible, and written assurances of confidentiality were provided to participants. While interviews cannot be completely confidential due to the nature of the method, as many measures as possible were taken to provide a confidential forum for these interactions.

A similar process was used for interviewing former OHSU employees. It was more difficult to reach this population for several reasons, including that some had moved away, it was difficult to find their current contact information, and in some cases they had no interest in participating. The goal was to interview six former employees, three of each employee type. Ultimately five interviews with former employees were achieved.

The human resources director also provided a list of former employees who departed OHSU within ten years after the separation, providing a preliminary estimate of 1300 former employees, 400 of whom might fall into the two employee categories. Former employees were more difficult to reach. The actual list of former employees provided by the OHSU human resources department included 795 
people who had left OHSU within 10 years of the transition, with approximately 461 fitting in to the two employee categories relevant to this study. However, finding their contact information and locating them via Internet search and "cold call" emails and phone calls proved unsuccessful. Thus the Snowball (or Chain) method (Berg, 2007) was utilized to contact former employees. Current employees who had already been interviewed for this project were asked for referrals to employees who left after the transition. This method proved to be more successful and the names of 10 former employees were obtained, five of whom agreed to be interviewed. The five former employees met the same participation criteria for the study as the current employees. Two former faculty and three former staff were interviewed. All of the former employees left OHSU on good terms-due to retirement, new job, or transferring spouse. The former employees left OHSU between 1995 (just after the separation) and 2005; none of the former employees left because OHSU became a public corporation.

In both cases (current and former employees), an incentive was offered for participation-each subject who participated in an interview was entered into a drawing for an iPod Shuffle®. This was not a prohibitively expensive proposition and provided a small incentive for participation, as well as providing an opportunity to thank the participants. After the interviews were completed, all participant names were entered into drawing and a name was randomly drawn. The iPod Shuffle ${ }^{\circledR}$ was awarded to one of the participants. 
Interviews with OHSU and AFSCME leadership were not intended to be confidential. This was acknowledged and agreed upon at the beginning of each leadership interview.

iv. Quantitative Data

Internal and external comparator data was utilized to the extent it was available, to examine OHSU from an internal perspective then and now. Quantitative data reviewed included available salary data, faculty tenure statistics, employee counts, OHSU's funding profile (including research revenues, state funding, debt levels, and tuition rates), as well as patient data (including patient visits and patient satisfaction data). The data provided a quantitative measure of the impacts to employees to compare to employee perceptions.

It was also helpful to compare OHSU prior to 1995 and in current state to other universities and to other Academic Health Centers and other similar institutions. Data from the Association of American Medical Colleges (AAMC), Integrated Postsecondary Education Data System (IPES), Centers for Medicare and Medicaid Services (CMS), Oregon University System (OUS), and Oregon Department of Administrative Services (DAS) were utilized for general comparator data. The data collected from these sources included tuition, salaries, state funding levels, and patient satisfaction levels.

\section{F. Data Analysis and Management}

Collection of documents, oral histories, and quantitative data for review began in Spring 2012. An initial interview was conducted with OHSU's former 
general counsel earlier to lay a foundation and provide some historical context. Informational interviews with the rest of the OHSU leadership team began in Summer 2012, followed by interviews with the two employee groups (faculty and AFSCME-represented staff) and that began with a pilot interview in September 2012 and continued with actual interviews beginning in October 2012. These interviews concluded in January 2013. The analysis of the data from all sources-document review, interviews, and quantitative data-was done concurrently, as time allowed. It was useful to analyze the data as it came in, and in parallel, to aid in identifying patterns.

\section{i. Overview}

Coding and analysis of interviews were done with standard coding software, Atlas.ti, with the assistance and collaboration of a coding assistant. As discussed by White and Adams (1994) earlier, it is critical for the validity and rigor of the study to approach data analysis thoughtfully, with care given to treating the data fairly and evenly, avoiding bias in the results (Hancock \& Algozzine, 2006; White \& Adams, 1994). Yin (1989) recommends adopting a data analysis strategy based on theoretical propositions. This strategy takes the approach that the analysis follows the propositions on which the research questions are based-and allows the researcher to focus on the relevant data and disregard the data that does not fit the proposition (Yin, 1989).

As has been discussed, the distributed nature of universities may mean that faculty and staff perceptions about satisfaction are dependent on the type of 
employee they are and the department or school in which they worked. Using that type of information as input variables, this study helps determine if that plays a role in perceptions about overall satisfaction and also other specific factors, such as shared governance or perceptions about campus culture. To determine this, the leadership interviews were utilized to establish the goals for the institution as it embarked on governance change, and then the current and former employee interviews were utilized to determine perceptions. The internal and external document review and quantitative data provided the opportunity for comparison analysis. Also as discussed by Yin (1989), propositions are posed regarding each research question based on the existing literature.

For example, Baldridge (1971), Biglan (1973a \& b), Tierney (1988; 1998), and Cole (2009) theorize that change within universities does not happen as much at the central level, but instead is fostered within the complex network of diverse singular units. This is aligned with the organizational behavior theories of Mintzberg (1983) and Schein (1993). This study of OHSU used the interviews and other data to illustrate divergent reactions and levels of employee satisfaction within different units and different positions around the university.

Finally, a detailed description of the case emerged through the data collection process, first with emerging themes and issues based on the context (Creswell, 1998). As Yin (1989) advises, it was important to have a strategy in place before beginning the research. While case study research does not come with built-in 
quantitative metrics to analyze, it was possible to begin categorizing the data into themes or patterns that emerged soon after the research began.

\section{ii. Document Review}

Data was collected and cataloged in a uniform manner for consistency and validity. Document review was conducted by topic area, with documents pertaining to internal processes, internal goals, employee groups, management decisions, unions, and other relevant topic areas examined and analyzed first for pertinent information to this study. Secondarily, documents pertaining to legislative issues, external factors, and other groups (non faculty and non AFSCME staff) were examined for relevance to this study of OHSU's internal organizational change.

As the information was collected and categorized, it was possible to identify repetitive themes, patterns and categories in a thematic analysis (Hancock \& Algozzine, 2006) allowing for each new piece of information or document to be reviewed and then categorized based on the areas of interest for this study (e.g., process, culture, job satisfaction, etc.). As Berg (2007) describes, these themes are useful units to count when reviewing documents for a study because: "themes begin to emerge in a variety of places in most written documents..." (Berg, 2007, p. 312). As the research continued with the leadership interviews-followed by the current and former employee interviews and then review of quantitative data-the story of OHSU's transformation from different points of view began to emerge.

To manage the data, after data was collected, it was helpful to create a table of categories and themes and place the information gathered into the applicable 
spot on the matrix (Creswell, 1998). This process was repeated throughout and helped to identify patterns as they emerged (Yin, 1989). Creswell (1998) endorses this approach, asserting that establishing patterns helps spot corresponding information and relationships between categories.

iii. Interviews

Interviews were tracked and coded using one coding structure, for consistency and ease of tracking similar data sets, and were aligned with data relating to the documents reviewed and to the research questions for this study. The interview process was as follows:

- Interviews were digitally recorded and notes were taken simultaneously to increase accuracy;

- Interviews were transcribed shortly after the interviews were conducted;

- Transcripts were de-identified once they were transcribed;

- Transcripts were then coded using pre-determined key words that were used for the interviews (formally) and during the document review (less formally). A coding tree with common terms was developed jointly by the researcher and another student in the PSU College of Urban and Public Affairs ("coding assistant").

This is a qualitative case study, and thus the coding structure was developed primarily to put the data collected into categories to: "facilitate comparison between things in the same categories and [to] aid in the development of theoretical concepts." (Maxwell, 2005, p. 96). The secondary use of coding was to count the 
number of responses to various questions - to coordinate and compare the number of responses to a particular theme that was emerging.

A pilot interview was conducted with a current OHSU employee who has been at OHSU since prior to 1995. The purpose of this pilot interview was to test the interview questions with a subject to determine whether the questions were understandable to the subject, whether the questions guided the subject to useful answers without undue prompting, whether the established time frame for conducting the interview was achievable, and to obtain a data set to analyze prior to conducting the remainder of the interviews. Conducting the pilot interview also provided the opportunity to reframe some of the questions to make them more understandable and to reorder some of the questions to improve the flow of the interview.

Also during data collection a process of "collecting gems" was implemented-pulling de-identified quotes that were particularly meaningful and/or representative of a specific theme emerging from the research. These "gems" are utilized in chapter four for the leadership interviews, and for the current and former employee interviews, and in the discussion in chapter five. To establish and confirm the patterns that emerged, the document review and interview data were compared to the themes that emerged from the interview "gems" to determine if patterns were consistent and to allow discussion if they were not.

With the document review and interviews underway, it was possible to begin a chronology of events, mapping various key events to a timeline. Creating the 
chronology increased the depth of the story that was beginning to emerge (Stake, 1995). Creating this chronological timeline served as a historical classification system (Berg, 2007) allowing the researcher to describe important or interesting past events and developments. Because this study reviewed OHSU over a period of time, it was also useful, after the data collection and coding was complete, to "tabulate the frequency of different events" (Yin, 1989, p. 106), putting those events on that same chronological timeline. Chronologically documenting events leveraged the strengths of the case study methodology and aided in identifying the important and recurring themes as independent and dependent variables (Yin, 1989). This was a process that also helped identify changes in the eyes of the employees that may have been a result of OHSU's change to a public corporation versus changes that may have occurred naturally as the organization evolved, incorporating internal and external factors.

iv. Quantitative Data

This case study is primarily qualitative in nature: interviews with the OHSU and AFSCME leadership teams and with current and former faculty and AFSCMErepresented staff served as the primary data sources. Also primary to this study was the review of OHSU documents for qualitative information in the form of internal memos, newsletters, and communications with and between employee groups. It was also helpful to include relevant pieces of quantitative data that served as baseline, or foundational, information, as well as comparator data. The quantitative data were collected and managed in much the same manner as the data from the 
document review. Data were collected in a uniform manner for consistency and validity. Sorting was by topic area, including salary, tenure and other employee specific data to compare to employees' perceptions about job satisfaction. Other data (research revenue, numbers of employees, debt levels, funding sources, tuition, etc.) were sorted for organizational relevance to this study.

\section{G. Research Methods Summary}

Through all of the data analysis, and independent of the modes utilized, it was important to take care to use replicable logic (Yin, 1989) that makes the data, and thus the outcomes, stronger. Being consistent in how principles were applied to the data laid solid groundwork and foundation for explaining the data and creating a meaningful case study. Creswell (1998) suggests that to achieve this consistency, researchers should do a thorough description—of the case, the story, the context, and the data-and then classify all of the information into categories, themes, and dimensions. This was a useful tool as the research for this study progressed. It was then possible to coalesce it all, as Creswell (1998) recommends, to make sense of it, and develop insights and interpretation to put the case study into perspective within the larger picture.

Understanding organizations and how they pursue, embrace, respond to, and are impacted by change is the first step and can mean the difference between success and failure of an organization (Beckhard \& Harris, 1987; Denison \& Mishra, 1995; Gotsi, Andriopoulos, \& Wilson, 2008; Kezar \& Eckel, 2002; Kezar, 2005). Utilizing case study methodologies to research these questions was the ideal 
method to glean this information. In addition, utilizing multiple sources, pairing

methods like one-on-one interviews with qualitative and quantitative document

review provides the seamless way to validate the data and reduce the chances of

researcher biases (Hancock \& Algozzine, 2006; Maxwell, 2005). Finally, case study

approach was best in delving deeply into the employee perceptions as compared to

the goals of the organization during that seminal period in OHSU's history.

\begin{tabular}{|c|c|c|c|c|c|}
\hline Method & What & Who & Quantity & Purpose & $\begin{array}{l}\text { Analytical } \\
\text { Approach }\end{array}$ \\
\hline $\begin{array}{l}\text { Document } \\
\text { review }\end{array}$ & $\begin{array}{l}\text { OHSU } \\
\text { Archives }\end{array}$ & $n / a$ & $\begin{array}{l}\text { 500 } \\
\text { documents }\end{array}$ & $\begin{array}{l}\text { - Tone and nature of } \\
\text { internal communications } \\
\text { (memos, letters, } \\
\text { newsletters, etc.) } \\
\text { - Learn purpose and goals of } \\
\text { the change and how } \\
\text { employees responded and } \\
\text { reacted. }\end{array}$ & $\begin{array}{l}\text { - Thematic } \\
\text { analysis } \\
\text { - Chronology }\end{array}$ \\
\hline $\begin{array}{l}\text { Document } \\
\text { review }\end{array}$ & $\begin{array}{l}\text { Oral } \\
\text { histories }\end{array}$ & $\begin{array}{l}\text { Current/Former } \\
\text { OHSU } \\
\text { employees }\end{array}$ & $\sim 32$ & $\begin{array}{l}\text { - Utilize secondary data of } \\
\text { faculty and staff reactions } \\
\text { and descriptions. }\end{array}$ & $\begin{array}{l}\text { - Thematic } \\
\text { analysis } \\
\text { - Chronology } \\
\text { - Collecting } \\
\text { gems }\end{array}$ \\
\hline $\begin{array}{l}\text { Document } \\
\text { review }\end{array}$ & $\begin{array}{l}\text { General } \\
\text { counsel } \\
\text { files }\end{array}$ & $\begin{array}{l}\text { Files belonging } \\
\text { to former } \\
\text { general counsel, } \\
\text { Janet Billups }\end{array}$ & $\begin{array}{l}\sim 440 \\
\text { documents }\end{array}$ & $\begin{array}{l}\text { - Internal memos, } \\
\text { communications between } \\
\text { state agencies and OHSU, } \\
\text { communications with the } \\
\text { unions } \\
\text { - Gain understanding of } \\
\text { factors that drove the move } \\
\text { to separate. } \\
\text { - Communications to and } \\
\text { with employee groups (such } \\
\text { as faculty senate) }\end{array}$ & $\begin{array}{l}\text { - Thematic } \\
\text { analysis } \\
\text { - Chronology }\end{array}$ \\
\hline $\begin{array}{l}\text { Document } \\
\text { review }\end{array}$ & $\begin{array}{l}\text { Local/ } \\
\text { regional } \\
\text { media }\end{array}$ & $\begin{array}{l}\text { Newspaper and } \\
\text { journal articles }\end{array}$ & $\sim 100$ & $\begin{array}{l}\text { - Learn how the media } \\
\text { portrayed perceptions of } \\
\text { this event }\end{array}$ & $\begin{array}{l}\text { - Thematic } \\
\text { analysis } \\
\text { - Chronology }\end{array}$ \\
\hline Interview & $\begin{array}{l}\text { OHSU \& } \\
\text { AFSCME } \\
\text { leadership }\end{array}$ & $\begin{array}{l}\text { President, CFO, } \\
\text { provost, gov't } \\
\text { relations, } \\
\text { general counsel, } \\
\text { AFSCME leader }\end{array}$ & 6 & $\begin{array}{l}\text { - Lay a foundation } \\
\text { - Learn leadership's goals } \\
\text { for transition } \\
\text { - AFSCME leadership adds } \\
\text { perspective of goals for } \\
\text { AFSCME membership }\end{array}$ & $\begin{array}{l}\text { - Thematic } \\
\text { analysis } \\
\text { - Chronology } \\
\text { - Collecting } \\
\text { gems }\end{array}$ \\
\hline
\end{tabular}




\begin{tabular}{|c|c|c|c|c|c|}
\hline Method & What & Who & Quantity & Purpose & $\begin{array}{l}\text { Analytical } \\
\text { Approach }\end{array}$ \\
\hline Interview & $\begin{array}{l}\text { Current } \\
\text { employees }\end{array}$ & $\begin{array}{l}\text { Purposive } \\
\text { selection of } \\
\text { faculty \& } \\
\text { AFSCME } \\
\text { represented } \\
\text { staff }\end{array}$ & $\begin{array}{l}15 \text { faculty }+ \\
15 \text { AFSCME } \\
\text { staff } \\
\text { ( } 30 \text { total) }\end{array}$ & $\begin{array}{l}\text { - Focus on employee } \\
\text { perceptions of how the } \\
\text { event changed their work } \\
\text { life, satisfaction, and the } \\
\text { campus culture to answer } \\
\text { primary research questions }\end{array}$ & $\begin{array}{l}\text { - Thematic } \\
\text { analysis } \\
\text { - Chronology } \\
\text { - Collecting } \\
\text { gems }\end{array}$ \\
\hline Interview & $\begin{array}{l}\text { Former } \\
\text { employees }\end{array}$ & $\begin{array}{l}\text { Snowball/ } \\
\text { Chain selection } \\
\text { of faculty \& } \\
\text { AFSCME } \\
\text { represented } \\
\text { staff }\end{array}$ & $\begin{array}{l}3 \text { faculty }+ \\
2 \text { staff } \\
\text { ( } 5 \text { total) }\end{array}$ & $\begin{array}{l}\text { - Similar to "current } \\
\text { employees" } \\
\text { - Determine why they left } \\
\text { OHSU } \\
\text { - Answer primary research } \\
\text { questions }\end{array}$ & $\begin{array}{l}\text { - Thematic } \\
\text { analysis } \\
\text { - Chronology } \\
\text { - Collecting } \\
\text { gems }\end{array}$ \\
\hline $\begin{array}{l}\text { Quantitative } \\
\text { review }\end{array}$ & $\begin{array}{l}\text { Internal } \\
\text { comparator } \\
\text { data }\end{array}$ & $\begin{array}{l}\text { CFS, HR, } \\
\text { archives, } \\
\text { institutional } \\
\text { communications }\end{array}$ & $\begin{array}{l}\sim 50 \\
\text { documents }\end{array}$ & $\begin{array}{l}\text { - Internal comparator data } \\
\text { of OHSU then and now } \\
\text { - Include salary, tenure, } \\
\text { research, employee, student } \\
\text { data } \\
\text { - Provide quantitative } \\
\text { measure of the impacts to } \\
\text { employees to compare to } \\
\text { employee perceptions. }\end{array}$ & $\begin{array}{l}\text { - Replicable } \\
\text { logic } \\
\text { - Thematic } \\
\text { analysis } \\
\text { - Chronology }\end{array}$ \\
\hline $\begin{array}{l}\text { Quantitative } \\
\text { review }\end{array}$ & $\begin{array}{l}\text { External } \\
\text { comparator } \\
\text { data }\end{array}$ & $\begin{array}{l}\text { AAMC, IPEDS, } \\
\text { DAS, CMS }\end{array}$ & $\begin{array}{l}\sim 50 \\
\text { documents }\end{array}$ & $\begin{array}{l}\text { - External data to compare } \\
\text { OHSU to other similar } \\
\text { academic health centers } \\
\text { - Provide baseline } \\
\text { organizational data }\end{array}$ & $\begin{array}{l}\text { - Replicable } \\
\text { logic } \\
\text { - Thematic } \\
\text { analysis } \\
\text { - Chronology }\end{array}$ \\
\hline
\end{tabular}




\section{Chapter 4: Results and Findings}

\section{A. Introduction}

The leadership interviews and review of OHSU's document archive laid a foundation for the study to identify the goals established for the organization as it changed its governance structure to a public corporation. The primary research consisted of interviews with 35 current and former OHSU employees who experienced the governance and structural changes before, during, and after the 1995 transition. This chapter presents the findings from the document review, a discussion of the goals as presented in the foundational interviews with the OHSU and AFSCME leadership, a discussion of the current and former employee interviews, and a discussion of the quantitative data. Exploring the impacts on two specific employee groups regarding the work life and culture of OHSU during an event that took place eighteen years ago presents some challenges. Studying an event that happened in the past required relying on the recollections of a number of people, beginning with interviews with members of the OHSU and AFSCME 1995 leadership teams. Research techniques described in this chapter were employed to help study participants recall the relevant time frame.

\section{B. Research Findings}

\section{i. Document Review and Leadership Interviews}

This section presents the internal aspects of OHSU and the governance change that occurred in 1995. This includes a review of documents from OHSU's archives, including internal memos and newsletters, oral history interview 
transcripts, communications between OHSU and relevant partners, and interviews with the 1995 leadership team and AFSCME leadership. This review of the pertinent documents and initial interviews lays a foundation for the study of OHSU's governance change.

\section{a. Interview Themes}

Many of the OHSU leadership team were accessible and these informational interviews helped lay the foundation as the study progressed. They provided an opportunity for information to emerge that informed how the later interview questions were refined (Glaser \& Strauss, 1967), and were also useful in rounding out and obtaining clarification of the data collected in the document review. As this study focuses on the impacts to employees, the questions in this set of interviews were structured to focus on the leadership goals as they pertained to internal factors (e.g., employees, processes). The questions were, by design, few and relatively open-ended to elicit information and recollection without being leading. See Appendix B for sample interview questions to the OHSU leadership team. OHSU's relationship with AFSCME evolved during this period and the perceptions of the leadership of the local bargaining unit added a perspective and viewpoint that would not otherwise have emerged. The AFSCME labor organization was integrally involved in the separation in 1995 on behalf of their represented employees. 


\section{b. Drivers of Change}

“What made us all very passionate about it was that we didn't think the university would survive if we didn't do this. We literally thought the fate of the university was at stake" (L. Hallick, interview, August 16, 2012) as stated by then Provost, Dr. Lesley Hallick. Dr. Peter Kohler and his leadership team felt very strongly in 1990, when Oregon Ballot Measure 5 limiting property taxes passed, that OHSU was going to eventually have to find another way to govern itself in a world where state funding for higher education was dwindling. The urgency of the need for transformation was exacerbated by changes in the healthcare landscape that required OHSU to be more business and customer driven in order to be competitive in the Portland metropolitan area and in Oregon.

An internal campus newspaper began laying the groundwork to the employees for a proposed change in governance in January 1993, in a Q\&A section with Kohler. In an answer to the question: "Why is OHSU considered a state institution even though most of its funding comes from other sources?" Kohler explained that even though OHSU received only $17 \%$ of its revenue from the state, it was considered to be part of the Oregon State System of Higher Education and that "major new programs or construction must be approved first by the Oregon State Board of Higher Education, the State's Executive Department, and then by the Legislature." (Feeny, 1993a)

Highlighted in a later issue of the Campus Gram in November, 1993: 
"The future of OHSU depends on the work done today. The key is moving beyond the shrinking state funding and enhancing the sources of revenue that now provide the vast majority of OHSU's budget. The transition will be made by continuing to boost the local economy and maintaining excellence in health education, research, and care. It won't be painless...but it will be exciting. To live happily ever after, OHSU must continue to build on the promise that was made when the very first building was built so that a healthy future...is guaranteed for all." (Feeny, 1993b).

As with many organizations embarking on change, internal and external indications began to surface that change was needed. The environment and circumstances began to appear, as described by Barbara Archer in her 2002 study regarding organizational change in public agencies, specifically about OHSU and OSSHE:

"Although there was good faith dealings on both sides, OHSU was not able to achieve the policy and process changes that they believed they needed to be competitive in their business environment. The ultimate control of the overall system resided at the OSSHE level, and OHSU was a relatively minor factor in the overall control of the system. OHSU felt this lack of control hurt their ability to achieve their business and mission goals over time. There was some question about OSSHE's ability to understand OHSU's business needs and why they requested changes and exemptions to policies. The nature of the authority relationship between OHSU and OSSHE did not foster a 
successful collaborative effort, and both sides experienced frustration with the relationship at various points. Overall, OHSU increasingly believed the relationship was suboptimal." (Archer, 2002, p. 158)

Lois Davis, OHSU director of government relations, echoed Kohler's sentiments of the need for the move to a public corporation: "OHSU was not competitive; couldn't compete in healthcare, couldn't compete for employees; couldn't pay employees like we wanted to, or be agile enough to secure financing for buildings because the hoops the state required would take too long." (L. Davis, interview, July 17, 2012). She went on to describe a "macro goal" of the transition in terms of OHSU having the ability to provide better services and to better meet the needs of the employees (L. Davis, interview, July 17, 2012). Davis described some of the goals (L. Davis, interview, July 17, 2012):

- "Move our employees up to market. We were very clear that we could not do that overnight, but we needed the ability to move our salaries to market levels over time."

- "For faculty we needed to be in better position to build the kind of space they needed. We also knew we needed to recruit more researchers and more clinicians, and we needed flexibility to be able to do that."

- "The unions were clear that OHSU had to stay in PERS, and they were comfortable with adding our own retirement plan, as well [which OHSU subsequently called 'UPP']; but clearly we had to be part of PERS. We also agreed that if we were not part of PEBB we had to have a menu of comparable options. 
We had to protect employee benefits." PEBB is Oregon's Public Employees'

Benefit Board, the agency that provides employment benefits to state employees.

The Public Corporation Advisory Committee, a group of local business and community leaders convened at Kohler's request to determine the feasibility of the public corporation model, along with OHSU leadership, explored several options until they settled on the public corporation model to satisfy needs of flexibility and control while still serving the public mission (Alexander, Davis, \& Kohler, 1997; Archer, 2002). As described in the advisory committee's report to the legislature: "The Committee concluded that OHSU's current governance structure would be an insurmountable obstacle to achieving the vision [described by Kohler]. This conclusion was based in part on the following findings: Despite its public mission, OHSU can not separate itself from what is now a rapidly changing, increasingly competitive health care economy; and the dollar amount of state support for OHSU has remained fairly flat since 1985. But state support as a percentage of OHSU's budget has declined dramatically. In 1976 , state support was $42 \%$ of OHSU's total revenue. Today, it is less than 14\%." (Buckman, et al., 1995, p. 4).

The advisory committee report went on to say that OHSU's grants, gifts, and patient revenues were subsidizing the public mission and that the State could not afford to underwrite the costs necessary to sustain the public mission if it failed in the marketplace (Buckman, et al., 1995). Finally, the report concluded that transformation was critical because: 
"OHSU's ability to compete in the marketplace is significantly undermined by its status as a state agency. Unnecessary layers of approval, cumbersome administrative processes and restrictive procurement and personnel requirements slow OHSU down, make it difficult to attract talent, and increase its costs. It cannot respond to new and changing marketplace demands in a timely fashion. It can not hold equity or enter into partnerships that could lead to greater efficiencies and new revenue-raising opportunities." (Buckman, et al., p. 5).

Ultimately the Kohler-formed committee concluded, "that to achieve excellence, OHSU must be free to run its business activities in a more business-like manner. This means being able to seek out opportunities and to act upon them, to move quickly when the marketplace demands it and to enter into partnerships and other arrangements that make good business sense." (Buckman, et al., p. 5).

Archer's study explains that the public corporation model, of all the options, addressed the problems identified by the committee while also addressing the issues that the other models presented-preserving OHSU's mission while providing the necessary organizational flexibility (Archer, 2002). Her report went on to say: "From a policy perspective, this less radical break could probably be better defended in a policy change than could outright privatization. As a result, the public corporation model seemed to be the optimal model based on the initial evaluation of the three models identified as options." (Archer, 2002, p. 124). 
While the road to the public corporation was long and slow, OHSU leadership were meticulous in socializing the idea internally and externally. Kohler said "we did a lot of constituency building. We did a lot of background work to get the process moving. We knew it was going to be hard work and we approached it that way." (Interview, P. Kohler, August 15, 2012). Kohler went on to say that OSSHE eventually also endorsed the effort: "The OSSHE Board came along begrudgingly, but their focus was not on academic health center issues. They were consumed with athletic programs and not hospitals. We needed our own board with a business background." (Interview, P. Kohler, August 15, 2012). In December 1994, Kohler announced to OHSU employees in an internal newsletter that the State Board of Higher Education was on board: "The Oregon State Board of Higher Education on Friday, Dec. 16, unanimously endorsed the proposal to convert OHSU to a public corporation." (Feeny, 1994b, p. 1). He went on to say: "With such agreements and the growing support from a variety of legislators, prospects are very good that we will be successful in achieving the changes in governance we need to survive and thrive in today's highly competitive health care marketplace" (Feeny, 1994b, p. 1).

The Public Corporation Advisory Committee included in their report the benefits of the separation as well as what they viewed as the dire consequences if OHSU were to remain part of the state system (Buckman, et al, 1995). The committee spent four months in 1994 and 1995 doing a thorough review of OHSU's internal and external environment with three questions in mind about the proposal to become an independent public corporation (Buckman, et al, 1995): Would it help 
OHSU better fulfill its statewide public mission, would it make OHSU more competitive, and would it put OHSU at an unnecessary disadvantage to its private sector competitors? The final report contained ten key findings and recommendations, including a goal of becoming a top-ten biomedical institution. The committee expressed a concern that:

"the existing governance structure is not capable of turning that vision into reality. OHSU's future depends on its ability to compete in a rapidly changing, increasingly competitive health care industry. Today, state support makes up less than 14 percent of OHSU's revenue. Yet, as a state agency, it is significantly hampered in its ability to be cost-effective. Unnecessary layers of approval, administrative processes and procurement and personnel requirements slow it down and increase its costs." (Buckman, et al., 1995). The report went on to recommend the public corporation model as the best balance to incorporate the public mission with competitiveness, allowing OHSU to reduce operations costs and react to changes in the marketplace, while still focusing on providing care for Oregonians all around the state. In addition, the report's findings included other recommendations, one that spoke directly to employee satisfaction: "OHSU and its employees are better served under the public corporation proposal. All existing employee rights are retained, and OHSU will have more flexibility to develop competitive employee recruitment packages." (Buckman, et al., 1995). 
SB 2 passed and was signed by Governor Kitzhaber, to be effective July 1, 1995. OHSU's leadership established a transition team to spearhead the many facets of organizational and structural change needed-and there were many factors to consider. OHSU's leadership had been so focused on getting the bill passed that it was now time to refocus the energy to implementation: "[We] had to get a payroll system up within 1 year...[There] was no research accounting system. [We] underestimated what it would take to implement" (L. Hallick, interview, August 16, 2012). Dr. Hallick went on to say: "Initially [we were] so focused on getting it done, that not a lot of thought went into implementation. [So], the first two years, we were running so fast. [We were] learning what freedoms existed and how to manage a new board..." (L. Hallick, interview, August 16, 2012).

Jim Walker, then Chief Financial Officer at OHSU, went on to describe the initial implementation challenges: "I needed to merge the hospital and university data processing-but the cultures were so different! That was a real challenge. We had to combine functions that were duplicated between the hospital and university" (J. Walker, interview, October 13, 2012).

"The first thing we did, we sat down and figured out what needed to be done and when...and we created a timeline" (J. Walker, interview, October 13, 2012). Further, Walker described the atmosphere:

"To be really honest, when we first started, in the first 90 days, I was having a hard time sleeping. Here was this thing that we pushed for two years to getit became a big issue statewide and we pushed for with the governor and the 
State Board of Higher Ed, if we fall flat on our face in payroll, finance, and general ledger, it's going to be really tough. Talk about being on the hot seat-if we couldn't get the infrastructure [in place] it was going to fall apart. If we couldn't get the debt structure to work, we would have to go back to Higher Ed, hat in hand." (J. Walker, interview, October 13, 2012).

"It was very, very stressful, but when it comes to being exciting, it was very exciting" (J. Walker, interview, October 13, 2012). Lois Davis echoed this and mentioned some of the circumstances that made it challenging to move forward: "We underestimated how much work there was to do after the transition to the public corporation. It was a dramatic change and the state agencies were not helpful to us at the time. There was a lot of bitterness that we had said they were inefficient, so there was not a lot of support during the transition period." (Interview, L. Davis, July 17, 2012).

\section{c. Internal Goals for OHSU}

This study looks internally at OHSU and the goals for the organization's internal processes and the impacts to its employees. Leadership was clear that there were specific internal goals for the public corporation. Archer's report stated: "Internal changes and changes in the mindset of OHSU's administration and staff were also required." (Archer, 2002, p. 128). One of the first places to look internally was at process and how to improve efficiencies-a priority for OHSU's leadership. As part of OSSHE, OHSU had been required to utilize the state's systems for purchasing, contracting, and procurement. Early in the first year of transition, OHSU 
administrators did analysis on efficiencies of those processes: "OSSHE's

procurement process as a state agency showed that forty-nine separate steps were required. An OHSU-redesigned procurement flow chart showed the same process could be reduced to fourteen steps if the state procurement process was not used." (Archer, 2002, p. 157). This type of analysis began on other internal systems and OHSU found efficiencies and savings by utilizing other channels, such as healthcare group purchasing arrangements (Archer, 2002). In anticipation of the transition to the public corporation, OHSU's logistics department was already putting the wheels in motion to improve processes post-OSSHE by putting process-driven systems into place that began to increase productivity and lower costs (Feeny, 1994a).

OHSU traditionally had an entrepreneurial spirit. However, the administration of the organization was clearly tied to OSSHE and its bureaucratic processes, so one of the first challenges was to turn away from the entrenched norms of the State system of conducting business. As reported by Archer in one of her interviews: "The single biggest challenge facing the entrepreneur or entrepreneurs was the bureaucratic mindset. 'The main thing...is thinking differently. [We have a] tendency to thinking the State should solve our problems."' (Archer, 2002, p. 165). This manifested itself in a reliance on Corvallis, Oregon where the OSSHE central offices resided and where most of OHSU's financial and administrative processing took place. Phrases that appear frequently in the interviews for this study include: "we had to send everything to Corvallis" or 
"Corvallis was in charge of that and we had to ask their permission to do it differently".

All of the public Oregon universities and colleges functioned this waycollecting data and information and sending it to Corvallis for processing. There was little local information processing or functional control—payroll, budgets, general finances, and human resources all were handled in Corvallis. Jim Walker reflected on that period: "I was worried about the managers and management and to some extent the employees. They had no experience having total responsibility. And we were going through a very stressful time. I had one year to get new systems in place." (Interview, J. Walker, October 12, 2013). Lesley Hallick, who worked closely with Walker on operational issues, reported that the push was on to put new information systems in place: "Jim Walker was struggling with IT issues; should we integrate the systems? [It] took two years but the integrated systems made the new payroll system possible. But we still had to do something for the research community because the first couple of years research got the short shrift." (Interview, L. Hallick, August 16, 2012).

An internal newsletter reported one year after the public corporation that many internal procedures were being rewritten to improve efficiencies. These included implementing a local, automated timekeeping system that alleviated having to send timesheets to Corvallis, converting to an annual budget cycle rather than the two-year State cycle for better and quicker projections and reporting, 
moving to localized risk management, and negotiating contracts directly with vendors (OHSU, 1996).

Another goal for the public corporation was to improve human resources processes and programs for better recruitment, hiring, and retention at OHSU. The leadership had indicated that moving employee pay to market levels and offering alternative benefits options were priorities of the transition to the public corporation. In interviews with the leadership all confirmed that a goal was to get salaries to market levels, while maintaining PERS and other benefits. It was also a goal to provide alternative retirement and health benefit plans. Lois Davis stated what all of the leadership team confirmed: that the goal was to move salaries to market levels—but that it would take time and would not happen overnight (Interview, L. Davis, July 17, 2012). In the internal newsletter one year later, leadership reported that OHSU human resources process improvements were underway, that all HR functions had been consolidated in to one office for more efficiency and better service, and that new job classifications had been created that were more aligned with the private sector (OHSU, 1996). Regarding salaries, the report went on to say that progress was being made to get salaries to market levels, but that "it will take years for the financial benefits of the change in systems to accrue to the public corporation. OHSU must look beyond the next budget cycle to produce long-term strategies to achieve the best outcomes." (OHSU, 1996, p. 13). In the same report, OHSU discussed creation of another pension plan so that employees had a choice between PERS and another plan. 
One of the challenges OHSU faced when it became a public corporation was its relationship with the bargaining units. One of the goals was to maintain strong partnerships with the bargaining units. This study focuses on AFSCME, and shortly after OHSU made the transition away from OSSHE, the AFSCME employees went on a three-day strike. Given that AFSCME membership and leadership had supported the public corporation proposal, this was largely attributed to a breakdown in communications. From the AFSCME perspective, union leaders were looking forward to working directly with OHSU rather than having to work through layers of state bureaucracy to negotiate contracts, and they were looking forward to their members having job security and improved pay and benefits (Interview, D. Lovell, January 30,2013). AFSCME also believed it would be good for OHSU and for the state in general (Archer, 2002). In an interview, an AFSCME member who was active in the union also recalls the misunderstandings that led to the strike:

“...there was the disagreement between the parties in bargaining. And then there's how the union handles its contract ratification. And boy did we-the union-learn. We went on strike based on the way that we do the ratification vote-which is if not very many people vote, you might get a surprising result, but whatever the result is you live with it. We had an obligation to honor the vote."

Jim Walker reflected on the circumstances that led to the AFSCME strike from his perspective: "AFSCME was very supportive of the public corporation. But we were surprised by the amount of money we had to establish [to get the public 
corporation running] and we had no idea how much money was in our 'higher ed account' [the financial accounts at OSSHE] —we just didn't have a good feel." (Interview, J. Walker, October 13, 2012). Walker went on to say that OSSHE did eventually transfer the funds, but it was not the amount he had expected and OHSU had virtually no reserves. "Hence the union wanted to strike because basically they wanted to increase all salaries across the board, we were leaning toward raising some classifications $10 \%-15 \%$, and then others would stay level for the moment. But there were politics involved as well. We couldn't tell Wall Street that we gave everyone $10 \%-15 \%$ increases as soon as we became a public corporation." (Interview, J. Walker, October 13, 2012).

Kohler believed that AFSCME understood the benefits of the public corporation and that it would enable OHSU to survive and carry out its mission. He stated that they also understood that the goal was to get salaries to market levels, eventually. When the strike occurred he was surprised: "Right after the transition the 3-day AFSCME strike happened and it was symbolic on AFSCME's part. We asked why they were doing it—we tried to explain that we didn't have any money, and that was why we were becoming a public corporation." (Interview, P. Kohler, August $15,2012)$.

Faculty satisfaction was a key component of the transition. According to the leadership, it was a priority to also move faculty salaries to national benchmarks and to retain faculty governance, academic freedom, and promotion and tenure 
practices. As Archer (2002) reported, faculty support was critical to the success of the public corporation:

"Academic support for the conversion process was critical to the success of the process. Academics are a major and key component of OHSU's business. Also, achieving faculty support brought along with it the support of the medical groups and the hospital medical staff who all had faculty appointments. Without faculty support, the success of the conversion process could not be guaranteed." (Archer, 2002, p. 170).

Archer went on to describe what Hallick confirmed, that many faculty senate meetings ensued as the leadership continued to socialize the idea of the public corporation (Interview, L. Hallick, August 16, 2012; Archer, 2002). The leadership felt that the faculty understood the critical need to make this move to create a sustainable environment for OHSU in the long term. Archer reported that faculty did express concerns about academic programs, tenure, and having a voice, but that their overarching concern was for OHSU's survival (Archer, 2002).

Factors that influence faculty job satisfaction are difficult to pinpoint (Johnsrud \& Rosser, 2002; Kissler, 1997) and as Biglan (1973a) and Baldridge (1971) discuss, faculty are prone to align within their fields rather than with the broader institution. This was also a topic that appeared in the OHSU oral histories, as in the interview with J. Peter Bentley in 1998:

"For years I saw myself as an entrepreneur, and my research was basically between me, NIH, and my peers throughout the world, not in this institution. 
And I think a lot of people exist that way, too. They may see their own little research group, or wider research group, as their world, and that's a microcosm. If the library works and the lights stay on and the sewage system works, fine, they never come out of their lab. And I think that's the same with many clinical faculty members. It's not myopia, it's just that this is what you're drawn up in. And it's a relatively rare bird who has a wider vision of this place. And probably they'll say, you know, 'That's Peter Kohler's job. Let him get on with it, so long as he doesn't interfere with my research, and let him get on with doing with what he wants to do.' That's a fairly common view of administration." (Interview transcript, J. Peter Bentley, PhD, December 10, 1998).

Understanding that faculty functioned in this manner was a critical component of targeting faculty job satisfaction, particularly during a time of significant change. Bentley went on to describe what others in the oral history archive described, that OHSU grew, became more business-oriented, and a less personal place when it became a public corporation (Interview transcripts: J. Peter Bentley, PhD, December 10, 1998; Reid S. Connell, PhD, July 8, 1999; Joseph Bloom, MD, April 3, 2001; James E. Morgan, April 17, 2001): "Now, the image of the place outside...has grown tremendously, very largely due to the Public Corporation, Peter Kohler's drive to push that through." (Interview transcript, J. Peter Bentley, PhD, December 10,1998). Further: "Central administration—we call them the 'people downstairs' - they tend to use words like 'corporate.' I keep telling them they 
shouldn't do it. But I think the influence of the way the university has been organized since we became a public corporation is along more corporate lines...".

The oral history transcripts also highlighted, however, that faculty and administrators felt that Kohler did the right thing:

“Since we've become a public corporation, we can do things on our own. We've instituted personnel salary policies that can reward activities without a vast salary structure, et cetera; I think we're pretty entrepreneurial there. But I think we were always going in this direction; but we're just a lot freer since '95, since this took place." (Interview transcript, Joseph Bloom, M.D., April 3, 2001).

These perspectives from the oral history archive echo the sentiments in the interviews for this study and present the necessity to achieve a delicate balance between the need for the preservation of the academic life with the need for the institution to survive and thrive, even if it meant significant change and transformation.

In the internal OHSU "Campus Forum" distributed in July 1996, Kohler discussed what had been promised when OHSU became a public corporation and that becoming a public corporation didn't solve all problems:

"In developing the public corporation proposal, we tried to be careful not to over promise. We knew it would be easy for some to view the public corporation as the answer to all our problems. It is not. Becoming a public corporation did not increase the amount of federal research dollars or 
private funds available to us. Neither did it remove our obligations to our patients, our students, the general public or each other. All it did was give us a better chance of succeeding and meeting these obligations by giving us the tools we needed to become more efficient and more competitive." (Kohler, 1996b).

In the same issue of the Campus Forum, Kohler went on to list the items that he had promoted in the proposed new model, which included the need to:

- Continue our mission of education, research, patient care and community service;

- Operate more cost-effectively and in a more efficient manner;

- Improve service to employees through coordination of human resource functions, including personnel recruitment, training, affirmative action and employee benefits;

- Continue our commitment to labor management cooperation programs;

- Conduct a market salary study and within limitations imposed by managing our costs and operating efficiently, begin moving employee total compensation packages to market levels;

- Develop compensation systems that would reward performance and merit;

- Maintain programs that would have been in jeopardy had we remained a state agency and been required to absorb the $\$ 17$ million cut we took last biennium; 
- Continue to explore opportunities for collaborating with other providers where appropriate; and

- Do a better job of communicating with employees and other constituencies. (Kohler, 1996b).

Walker talked of a more professionally run organization as a goal for the transition, and he went on to describe what resulted: "What ended up happening is a lot more professional organization. We were able to bring in more competent people, particularly management. And we were able to pay more-we could recruit people who were top notch-we couldn't do that before. And then the new managers recruited top notch people to report to them." (J. Walker, interview, October 13, 2012). He reiterated that competency levels improved, which improved the organization as a whole: "Employees became upgraded, managers were upgraded. Even though some people left, it ended up that those who remained liked the new environment and everyone became more competent. Plus you were now completely accountable. When you work in your own environment you are completely accountable." (J. Walker, interview, October 13, 2012).

Hallick emphasized other tangible outcomes: "From 1995 on: all construction was on time and on budget...that was the biggest impact-getting construction done on time and within budget. One of the biggest impacts about not paying all the [assessments] to the state." (Interview, L. Hallick, August 16, 2012). She did talk of cultural changes that were subtle, but that were important and may have been missed: "We could have anticipated better how important the cultural difference 
was [when we became a public corporation]." (Interview, L. Hallick, August 16, 2012).

Davis also discussed the outcomes in terms of employees: "The impact on employees: faculty and staff would be in a much worse position, both in terms of stability of employment, and in terms of wages and overall compensation." (Interview, L. Davis, July 17, 2012).

Kohler credits his team for working hard to make a clear case: "It was a collective effort. Really the important thing to remember is that a whole lot of people got behind this and made it work out. I'm sure there were things we wished we had done better, faster, or differently, but certainly we would do it again." (P. Kohler, interview, August 15, 2012). Hallick echoed this sentiment and credited the people of OHSU as the key to making it happen: "We had such good people at OHSU who really cared about the right stuff and doing the right thing. They believed in the institution and the capacity we could achieve as a healthcare provider and as a research institution. We totally believed in the mission and when you believe in it like that, you are passionate about making it happen." (L. Hallick, interview, August $16,2012)$. She went on to discuss the issues that drove the push to separate from the state system and the urgency that was felt: “I don't know if you can forecast those things. The timing has to be right. The external enemies [managed care, measure 5] set up a climate of urgency and helped us to manage internally." (L. Hallick, interview, August 16, 2012). 
The leadership team unanimously talked of the importance of strength in the team, regardless of each individual's different perspective: “We came from very different perspectives, but we were together on the issues and it was a really nice thing-looking back it was very nice." (Interview, J. Walker, October 13, 2012). Hallick reiterated this: "[The] team was a huge key to the implementation and transition. It was a very tight team. A lot of trust—and a lot of fun-[we knew] it was important." (Interview, L. Hallick, August 16, 2012). Davis concurred: "[The leadership team] was a close knit team—everyone knew their job—we gelled as a team, we trusted each other, we backed each other up. Best team I was ever a part of." (Interview, L. Davis, July 17, 2012).

Hallick did point out that it wasn't always perfect, that would have been unrealistic, but that any disagreements were a healthy part of the process: “It wasn't always perfect. There were times when the team was fractured-it wasn't always smooth. But there was still a lot of trust. If I agree with my boss $80 \%$ to $90 \%$ of the time, then I have a good thing. [We were] managing internally and externally the dynamics of change." (Interview, L. Hallick, August 16, 2012). As Archer discusses: "Not only did leadership and management have to implement new processes almost overnight, but they also had to address and respond to the new accountabilities required by the new organizational structure. Most of the leadership group did not have much experience in market-oriented organizations" (Archer, 2002, p. 203). The dynamics of the team were important to the success of the transition. 
The review of internal and external documents and the interviews with OHSU's leadership team have laid a foundation for this study and have identified the goals for OHSU's transition to a public corporation. This study focuses on the impacts to the organization internally, and specifically to two employee groups: faculty and AFSCME-represented staff. The themes of process and efficiencies, culture, and job satisfaction are common throughout this study. In addition, facultyspecific issues such as shared governance, academic freedom, promotion and tenure, and expectations about productivity are also common strands throughout this study. Finally, the circumstances that led to this significant moment in OHSU's history and how leadership anticipated, planned for, and shepherded this transition are common threads that weave throughout the study.

\section{ii. Current and former employee interviews}

The following sections review the questions presented to study participants, how those questions were developed, and findings of the information collected in the interviews. These interviews explored the impacts of the change from the employee perspective. The interview data are organized by the themes guided by the structure of the interview questions. Each theme is presented in segments; for example, first data are presented by and about AFSCME staff, then faculty, then former employees. Within each theme section are sets of summary tables to illustrate the number of participant responses to each question. Graphical representations of participant responses can be found in Appendix G. The themes are process (more or less paperwork, clarity, etc.), culture (did it change, job 
freedom, pressure, customer focus, etc.), and job satisfaction (being valued and recognized, feeling of adding value, expectations about pay and benefits, etc.). This is followed by a section that addresses faculty-specific themes such as shared governance, academic freedom, expectations about productivity, and promotion and tenure. The findings from the last question in the interviews regarding overall impact are then presented. Additional themes that emerged organically through the interview process are identified and woven within these categories as appropriate. The interviews are presented with quotes from participants-sometimes several quotes in succession—along with paraphrased summary comments, initial observations about the responses, followed by a summary from the coded data of the number of interviewee responses per question. As described in chapter three, the coding process in this qualitative study served primarily to help categorize the information into the thematic areas, and secondarily provided a count of the number of responses to each question for illustrative purposes. Substantive further comment about the implications of the data and results of the interviews are presented in chapter five.

\section{a. Interview Themes}

\section{Employees Employed Prior To 1995 and Still Employed At OHSU}

These interviews were fundamental to the study. They were focused on the two employee groups central to this study: faculty and AFSCME-represented staff. The questions focused on employee perceptions of how the event changed their 
work life, satisfaction, and the campus culture. See Appendix C for sample interview questions to OHSU employees.

The interviews were tailored to the type of interviewee based on their employee type, asking questions related to the following topics:

- Demographic information regarding the individual's role at the university and the unit in which the individual worked; longevity, and age group, etc.;

- The changes, if any, to processes;

- Whether systematic practices changed work load and efficiencies of processes;

- Whether and how the culture changed;

- Job satisfaction (including factors such as wages, benefits, recognition/reward, promotion, pressure, perceived job clarity, etc.);

- For faculty: promotion and tenure, academic freedom, and shared governance.

Interviews were conducted as a primary data source, and noting what Maxwell (2005) says: “...the methods you use to collect your data (including interview questions) don't necessarily resemble, or follow by logical deduction from, the research questions; the two are distinct and separate parts of your design" (Maxwell, 2005, p. 91), was helpful when developing interview methodologies and questions that answered the key research questions-either directly or indirectly. Several strategies were used to aid in this process. Maxwell also recommended: "put 
yourself in your interviewee's place and imagine how you would react to these questions and get feedback from others on how they think the questions will work" (Maxwell, 2005, p. 93).

Developing interview questions requires an element of creativity as well. Since the interviews were focused on stakeholders' cognitive, behavioral and emotional thoughts about the culture, structure and effectiveness of OHSU eighteen years ago, it was important to find a balance between the instrumentalist and realist schools of thought (Maxwell, 2005)—on the one hand, asking direct enough questions that did not leave any uncertainty as to the nature of the inquiry, while on the other hand, remaining slightly imprecise with the assumption that the interviewer and interviewees acknowledge and accept certain prior experiences (Maxwell, 2005).

It is important to acknowledge that it was, at times, challenging for interview participants to remember events that took place eighteen years ago. Specialized tools were deployed in an effort to mitigate this issue. The Timeline Follow Back (TLFB) method (Sobell, 2003) was used to encourage participants to focus on the specific period in time. TLFB is primarily used in behavioral studies to determine precise timelines for certain behaviors (e.g., alcoholism, smoking, etc.) (Sobell, 2003) because it is effective in helping interviewees create a timeline for when key events took place: "The TLFB was used to evaluate the representativeness of different time windows for describing annual drinking data" (Vakili, et al, 2008, p. 1123). In this method, researchers ask a series of introductory questions that take 
the participant back in time to help orient them to the time period of interest in the study. "The TLFB method asks respondents to provide retrospective estimates of their [behavior] over a specified time period...Several memory aids including a calendar are used to enhance recall” (Sobell, et al, 1996, p. 49). The questions that were asked using this method were general and innocuous in nature and are not part of the final analysis; they are simply used as a tool to help participants hone in on a specific period of time and specific events during that time. A graphical timeline of important events in OHSU's history was also used to help participants place the events chronologically and to help jog their memories (this timeline is included with the sample interview in the appendices).

\section{Former Employees Employed Prior To 1995 Who Left The University Within Ten} Years After The Transition

Questions to this population were structured similarly to those of the current employees, with additional questions about why they left OHSU. See Appendix D for sample interview questions for former OHSU employees.

\section{b. Findings}

From the broader research questions discussed in chapter three, seven specific questions emerged:

- How do employees describe the impact of a new business model on their work and productivity levels?

- What were these two employee groups' perceptions about job clarity? 
- Did the campus culture and work life of OHSU change from the employee perspective?

- What was the effect on employee satisfaction?

- Did employees' perceptions of compensation, benefits, or promotion practices change? How did these impact job satisfaction, if at all?

- For faculty, were there perceived changes in tenure opportunities, expectations about faculty productivity, and faculty governance?

- What were the perceptions and impacts on the two employee groups on whether OHSU became more bottom-line and/or customer driven?

These questions helped determine how employees felt about the day-to-day processes of their jobs, their perceptions about whether the public corporation caused a culture change, their feelings about job satisfaction, and the impacts overall. In addition to the themes that were driven directly by the questions asked in the interviews, other important themes emerged organically during the interviews. These will be described within the other categories, as appropriate, and then discussed more fully in chapter five.

The findings are described below.

\section{Process}

\section{a. Staff, Faculty, Former Employees: Day-to-Day Process}

While there was some uncertainty among AFSCME-represented staff about the future and the impacts to employees' jobs, the general consensus was that dayto-day work processes improved and became more efficient following the transition. 
An administrative employee in the School of Dentistry reported that before the change to the public corporation: "Everything was state-related and [there was] a lot of pencil pushing back then." She went on to say that "everything definitely [became] streamlined and more efficient." Several other employees confirmed this sentiment: an employee in IT said, "I would certainly say that the change made us more efficient." Another classified employee said: "We could have our own systems. I know we could not have done that as part of the state. Flexibility to find our own system was an issue. We became very efficient." Another employee stated: "Systems all got a lot better and processes all got a lot better." One employee did express that processes did not improve significantly overall: "It seems that the red tape is about the same length as it always was. That part of the state connection hasn't changed; unfortunately...there are a lot of people and a lot of steps. And that's when I want to ask 'Are you sure we're not [still] a state institution?'”

The data from the interviews confirms that most staff felt that there was less "paperwork" but they were mixed about more efficient process (across missions and positions, age groups, and length of time at OHSU). 14 responses (of 16 expressed opinions; or $n=16$ ) in all groups ${ }^{1}$ agreed that there was less paperwork; however, 5 out of 6 respondents who expressed an opinion about improved process believed that more process emerged as OHSU grew.

\footnotetext{
${ }^{1}$ Unless otherwise noted, all responses are reported across all of the employee categories (mission area, age group, and length of time at OHSU) because in most cases the responses were comparatively consistent across these segments of the employee population. In cases where there was divergence in a category, it will be noted.
} 
Despite the feeling of more process, one employee summed up what several expressed: "Everyone in the union was hoping it would flatten out and become more efficient. Taking the long view-a lot of that has come true. From the business end I don't know, but from the working end, the bureaucracy became more efficient-if you can say those two words in the same sentence."

Faculty have more mixed feelings than the staff do about the impacts of OHSU's new governance structure-a pattern that emerged throughout this study. While the faculty were farther removed from the administrative and operational processes than staff, they did have reactions to changes in process and efficiencies after OHSU became a public corporation. A clinical/research faculty member stated: "There were some changes in centralization of work...and we found that to not be efficient. Our cohesion was broken up. And most importantly, that interrupted and interfered with better communication." In contrast, a basic science faculty member stated: "When they decided to get serious about research funding they decided to pursue a more professional operation." He went on to say that this did lead to efficiencies. Further, another basic scientist said: "Initially, yes, there were some old dusty processes that were eliminated. And people really thought about what they were doing." There was a sense among the faculty that this was an opportunity to find efficiencies, as one faculty member put it: "at the outset there seemed to be a feeling of empowerment-everybody go find ways to be more efficient and think of better ways to do things." 
Another theme that emerges here and continues throughout the other categories of the study is that some faculty felt there were, to some extent, lost opportunities, as one faculty member stated: "It's not as though [inefficiency] wasn't a problem at the state. But I think it was that 'here was an opportunity of changing' and we haven't done a very good job." Some even felt that a new bureaucracy emerged when OHSU became a public corporation, and that it has grown bigger than the original, as one faculty put it: “...re-creating a new bureaucracy: it has become as big as what we walked away from at the state, and then some."

The data from the faculty interviews underscores these mixed reactions: the faculty are split on whether paperwork improved, with 4 faculty believing there was more paperwork, 3 believing there was less, and 7 indicating they saw no change ( $\mathrm{n}=14$ responses). There was a fairly uniform belief across all faculty types that there was more process involved as OHSU grew, with 4 out of 5 faculty believing there was more process involved in day-to-day operations.

Responses from former employees were consistent with those of current staff and faculty. In terms of whether there was more or less paperwork, they reported that it felt tumultuous at first and then it improved, as explained by this former employee who worked in Human Resources:

"In the beginning it was more chaotic, everybody was so used to [sending things to Corvallis], so everybody knew what to do before-you've got to get this form down to Corvallis, or to the Chancellor. So it was nerve-wracking in the beginning. As time progressed, it did become easier. You could go directly 
to our HR people, instead of having to go through all the hoops and barriers that were in the way."

Another former employee, an administrator, confirmed that sentiment and identified that it took a while for staff to achieve clarity in their roles: "So many people at OHSU had worked there all of their working lives. They were under that state system for so long and it took a lot of people a long time to figure out what to do and who to contact with questions."

While it appeared from the responses from former employees that there was some confusion when OHSU became a public corporation, the perception was that processes did improve, as one former employee who worked in clinical research reported: "There was a substantial [improvement] in how the human subjects committee was managed." This former employee went on to report that the focus on doing business more professionally made their jobs better. However, one employee noted an agreement to Kohler's sentiment reported earlier: "Everyone would agree with the Kohler comment about how we got lean for a while and then grew our own bureaucracy." Former employees were mixed with 1 believing there was more paperwork, 1 believing less, and 2 no change $(n=4)$.

b. Staff, Faculty, Former Employees: Job Clarity

There was mixed sentiment about the pros and cons of the new structure. Some felt it allowed for more control while others indicated uncertainty or lack of clarity about their roles. Some expressed anxiety: "Everyone was in that "hold your 
breath' mode and thinking: 'what's this going to be like?'” In some areas, employees reported:

"[In my unit] from day to day we were unsure of what was expected of us. Systems and responsibilities grew at a very rapid rate and because of that we were often uncertain about what a procedure might be. We were unsure what to do, and it may have been difficult for even our management to keep up, and for our department. There was confusion because of that." Conversely, some reported an increased feeling of control over their own jobs. An employee in the finance office recounted: "In all we got more control over how and what we wanted done. It was rough, we made mistakes in the beginning that Corvallis could have handled without even blinking, but we didn't know...we had bumps, but not insurmountable bumps."

Further, an IT employee stated: “Once it was clear that our job was to create a new payroll system, [it became] relatively straightforward, although it was a huge undertaking." One other employee, an accounting staff member who works in a research support role, said: "It was really nice because we had more control over our work. We didn't have to call Corvallis and say, 'how do we do this?' and then wait for them to respond. I felt like having more control was very nice. And yes, quicker." She went on to say: "It was one of those things where it's challenging when you are going through it, but what a great experience." Faculty did not express significant feelings one way or the other about clarity, since their roles and job functions did not change. 
The interview data also reflect this mixed reaction about clarity and control.

This was generally consistent when analyzed across mission areas, age groups, and length of time at OHSU, with some variations: 6 of the staff across mission areas felt that there was more clarity and control over their own work, while 4 felt there was less clarity, and 4 felt there was no change $(n=14){ }^{2}$ Former employees were evenly split about the perceptions of the level of clarity in their roles, with an $n=2,1$ who responded that there was more clarity, and 1 feeling there was less clarity.

\begin{tabular}{|c|c|c|c|}
\hline & Staff & Faculty & $\begin{array}{r}\text { Former } \\
\text { Employees }\end{array}$ \\
\hline \multicolumn{4}{|l|}{ Paperwork } \\
\hline More & 1 & 4 & 1 \\
\hline Less & 14 & 3 & 1 \\
\hline No Change & 1 & 7 & 2 \\
\hline \multicolumn{4}{|l|}{ Clarity } \\
\hline More & 6 & $*$ & 1 \\
\hline Less & 4 & $*$ & 1 \\
\hline No Change & 4 & $*$ & 0 \\
\hline \multicolumn{4}{|l|}{ Process-Overall } \\
\hline More & 5 & 5 & 0 \\
\hline Less & 1 & 0 & 2 \\
\hline No Change & 0 & 0 & 0 \\
\hline
\end{tabular}

\footnotetext{
${ }^{2}$ A slight variation appeared when examined across age groups. Instead of the split described above, the older age groups indicated there was less clarity ( 6 in the 60+ age group), and 6 in lower age groups felt there was more clarity. This is slight variation from the other groups (mission, length of time at OHSU, etc.).

${ }^{3}$ Note in all data reported, some totals $=>15$ responses (or $>5$ for former employees). This is due to the topic being reported more than once by a single respondent. Also, in some cases the total $=<15$ responses (or $<5$ for former employees). This is due to participants not responding to the question or having no opinion or recollection about the topic in question.
} 


\section{Culture}

a. Staff, Faculty, Former Employees: Culture Change

Several themes emerged about the effects on OHSU's culture. The interview data reveal that the responses were consistent across all categories of staff: 11 felt the culture did change, while 4 of the participants did not notice a culture change. One of the respondents expressed a wish that the culture had changed.

How did the culture change? One staffer summed it up: "Culture is spread out more. We grew and it wasn't as much of a little family anymore. It's gone from smallfeel campus to conglomerate. It was a matter of time." And for those who did not notice a culture change, one employee represented it this way: "Policies, people, departments changed. But overall I think our culture hasn't changed." How the culture change manifested itself is less clear cut than the fact that employees felt it did change. When asked about whether there was more freedom to do their work, staff reaction was mixed:

"There was a lot of hope generated out of the transition that we could join the modern world, and have world class kind of people come work here, and world class research, because we were finally going to be able to compete. I remember people being hopeful. To be considered something other than a state university."

Another employee stated: “I think OHSU's values had to change-we were on our own. They had to be thinking about and planning for the future and they were 
doing that. Systems all got a lot better and processes all got a lot better. People all got a lot stronger."

Similar to staff, the faculty felt that the culture at OHSU changed when the organization transitioned to a public corporation. 12 of the faculty felt the culture changed, while 5 did not notice a change in culture. One of the respondents expressed that they wished it had changed $(n=18)$.

Former employees reported that the culture at OHSU did change when it became a public corporation-and that change was already in the air leading up to the transition, as described by an administrator: "The culture on the campus was beginning to change already. We were getting so big. And in the early days it was like a little community. Practically everybody knew everybody." She followed that sentiment with this statement: "I think that once we became a public corporation it felt like it was a lot bigger, it wasn't such a close knit, family type place." A former employee who worked in a research center described the change in culture as exciting: “The campus began to grow in a way that it hadn't in the past. I hadn't really thought about that. The last couple of years that I was there it was exciting from that standpoint." A former clinical faculty member described peoples' fears of loss of academic culture: "I think there was some concern among some it would lead to a loss of culture, or a diminishment." Former employee respondents were unanimous that the culture did change $(n=5)$.

A theme that appeared in the context of OHSU's culture is silos. Whether or not the fact that silos exist as a result of OHSU becoming a public corporation, it did 
appear in the interviews conducted for this study. One staff member in a department in the School of Medicine described it this way: "There are still silos, but more mission-based. It's not just [department] vs. [department], it's silos of healthcare mission vs. research mission." A clinical faculty member in the School of Nursing expressed it this way: "There are silos. That's a culture at OHSU that has been here a really long, long time. When I started here there were silos, and that culture is still there. There are pros and cons to that, it's just the way it is."

A faculty member in a research center described his feelings about the silo'ed nature of OHSU in terms of a single-minded focus on the fiscal aspects of the organization that causes a loss of sight of the bigger picture:

"I still feel positively about the organization and the individuals in the organization, but when you get a group of people where they are so driven by the financial aspects of the organization, they lose to some degree their mission-directedness and their heart."

Another clinical faculty member in the School of Medicine simply said: "Fiefdoms and departments prevail." Still another faculty member in a research center reflected on a missed opportunity to better integrate OHSU's silos: "Integrating the campus more closely-that was a missed opportunity because we were undergoing this organizational change and in some respects it would have been the perfect time to say 'we're going to do some [integration].' At least looking at the campus, we could have [used the opportunity] to integrate better." 
This sense of silos and lack of integration of the missions was also expressed when interviewees were asked about job satisfaction and employee recognition. As indicated when discussing employee satisfaction later, some of the study participants indicated that their job satisfaction and feeling of value and recognition were rooted in the department or unit in which they worked, rather than at the organizational or institutional level. The issue of silos appeared directly in over $14 \%$ of the interviews ( $n=5)$, and was indirectly referred to in answers to other questions. b. Staff, Former Employees: Freedom

Staff presented mixed perceptions about the freedom to do their jobs. One employee felt that the public corporation led to more freedom to do the job:

"There was more of an emphasis on 'now we need to focus on making sure we get our work done efficiently,' but at the same time, at least in my area, we found ourselves being more self-directed, we weren't so cookiecutter...instead it became more of 'here's what you need to do, here's what you're skilled in doing, please go do it. And you guys can figure out the best way to do it."'

The interview data show that the staff members' feelings were mixed about whether there was more freedom to do their work after OHSU became a public corporation: 4 felt more freedom, 3 felt there was less, and 7 believed there was no change $(n=14)$. Faculty address this question later in relation to academic freedom, and thus are not presented here. 
Only one former employee expressed an opinion that there was more freedom to get their work done as described here: "I felt I had more autonomybecause I didn't have to jump through so many hoops to get things done."

c. Staff, Faculty, Former Employees: Pressure

Pressure to perform the work did increase, according to most of the staff interviewed: "Definitely felt pressure. We wanted to be autonomous from Corvallis, but also accountable." Another employee expressed it this way: "I think the growth was the pressure. For a while staffing did not keep up with growth, and so there was a lot of [pressure]." Another point of view from a staffer in the School of Dentistry talked of how the expectations changed: "There was a culture before [the public corporation] that you didn't have to deliver very much work. Some kept that culture. Then, it was suddenly about work." One employee had a similar explanation for why he thought the pressure increased:

"As the institution realized we needed to step up and compete, I think to a degree, we lagged behind. A lot of employees got on board with that as well. There was a culture change from the quintessential state employee of just coming in, eat my breakfast, take a coffee break, do a little work between 1 and $2 \mathrm{pm}$...there was definitely a change from that."

Some staff did not feel there was more pressure: “The pressure didn't change, the way we approached our work was a little bit different even at the beginning, and then it just kept evolving. We definitely became more self-directed." Another staffer, in the School of Medicine expressed it this way: "I don't see it as pressure in the 
slightest. There was a culture change in attitude. You hear all the time about state workers and the state worker mentality. And it's NOT that anymore, it's people for the most part are perhaps more professional and they just developed an attitude of control over their jobs...and...their destiny."

While most did think there was more pressure, it wasn't necessarily viewed as a stress factor or a negative: "There was more pressure: performance, customer service, savings, all of those pressures became more of a factor. And that's a good thing. It's good for the institution." The interview data show that 8 of the staff felt there was more pressure, one person felt there was less, and 6 believed there was no change in the pressure level $(n=15)$.

When it comes to whether there was an increased sense of pressure after OHSU became a public corporation, the faculty overwhelmingly agreed that the pressure did increase. One basic science faculty member expressed: "Yes-more pressure in basic science departments: you lost your grant, you lost your salary. Period." Another faculty member said this: "I think that was the real change, it became more a sort of a bottom line kind of pressure." The sense among the basic science faculty was that the pressure stemmed from an increased focus on financial aspects of the organization, and less about the scholarly and academic pursuits: "It was what I would consider a gradual erosion of traditional academic support; to a more corporate model." This sense that pressure increased was also felt by clinical faculty who felt the need to generate more revenue through clinical activity: "there was disillusionment in MDs and clinical [faculty] because of pressure to generate 
funds." A faculty member in the School of Dentistry said this: "The pressure was definitely cranked up on the sources and flow of dollars into the school." The interview data also reflect this sense of increased pressure, with 10 of the faculty indicating that there was increased pressure, and just one indicating no change. None of the faculty indicated less pressure $(n=11)$.

Some former employees felt there was confusion, but not necessarily added pressure: “A lot of people I dealt with every day were just frustrated, they didn't understand what was going on, and wondered why did things have to change." A former clinical faculty member in the School of Medicine defined the additional pressure in terms of the financial pressures, as some current employees did:

“OHSU had a 'happy place' reputation and had a reputation as an enjoyable place to work. OHSU was known for good people. It got worse, but it had more to do with the system of financing clinical departments, which shifted quickly to almost $100 \%$ clinical earnings, than leaving the state. The amount of time that a faculty member has to teach and let alone do research, it just wasn't there."

Former employees were split down the middle about their perceptions of whether there was more pressure, with one respondent believing there was more pressure when OHSU became a public corporation, and one feeling there was no change. None indicated that there was less pressure $(n=2)$. 


\section{d. Staff, Faculty, Former Employees: Customer Focus}

Another area of the culture that changed according to the perceptions of faculty and staff, and one that was a priority for the OHSU leadership at the time of the transition was the customer focus. The staff were consistent in that they felt the culture shifted to being more customer-oriented almost immediately. One employee expressed it this way: “...there was pressure to pay attention to who the customer was and to be as customer friendly to them as we could be within the parameters of our job." Another staff member said: "The focus on customers after we left the state was pretty immediate. The focus on research, patient-care, ER, became more state of the art. And that started pretty quickly, I thought." A staff member in logistics said: "[I saw] my department become more customer oriented rather than rule oriented. And to me that's a big difference and [I saw] that throughout the organization."

The converse side of this customer focus was that some staff felt the organization lost the academic feel: "That point in time-before a change to a public corporation - there was much more a feeling of academia. More of a collegial feel. That changed to bottom-line driven. It was the loss of collegiality." The data from responses to the interviews with staff reflect that 9 of staff believed the customer focus increased, with one each of the remaining respondents believing it decreased or there was no change $(\mathrm{n}=11)$.

While slightly more mixed than the staff reaction, faculty felt the culture changed to more customer-focused when OHSU became an independent public corporation. One faculty member in the School of Dentistry summed it up this way: 
"Absolutely. I think [the separation] was really the beginning. OHSU began to market itself to Oregon, and especially the metropolitan area, that we are here and that we are the only academic health environment in the state, and that we're premier [for patients]. The whole concept of being in competition with other health systems and hospitals emerged. I don't think that prior to that we did much of that at all. It was much like we were the citadel on the hill, put on our cap and gown and be academic, rather than be competitive." In contrast, some faculty felt that the culture did not wholly embrace a focus on the customer, as expressed by a faculty member in the School of Nursing: "I don't know if the culture has embraced the customer service environment that was envisioned." The faculty views on the notion of increased customer focus were mixed. The interview data indicate that 9 believed there was an increased customer focus, while 5 believed there was a decrease in this area, and 3 believed there was no change $(\mathrm{n}=17)$.

The former employees reported that OHSU became more customer focused after the transition to the public corporation, as described by this former clinical faculty member:

"One clear benefit of the shift, was that the institution was able to develop facilities that enabled us to provide the clinical care that we wanted to provide in a much more suitable environment. We wouldn't have been able to do that without the shift to public corporation." 
Similar to current employees, 4 of the respondents felt that OHSU was more customer-focused, and one felt there was no change $(n=5)$.

\begin{tabular}{|c|c|c|c|}
\hline & Staff & Faculty & $\begin{array}{r}\text { Former } \\
\text { Employees }\end{array}$ \\
\hline \multicolumn{4}{|l|}{ Culture Change } \\
\hline Yes & 11 & 12 & 5 \\
\hline No & 4 & 5 & 0 \\
\hline Wish & 1 & 1 & 0 \\
\hline \multicolumn{4}{|l|}{ Job Freedom } \\
\hline More & 4 & $*$ & 1 \\
\hline Less & 3 & $*$ & 0 \\
\hline No Change & 7 & $*$ & 0 \\
\hline \multicolumn{4}{|l|}{ Pressure } \\
\hline More & 8 & 10 & 1 \\
\hline Less & 1 & 0 & 0 \\
\hline No Change & 6 & 1 & 1 \\
\hline \multicolumn{4}{|l|}{ Customer Focus } \\
\hline Increased & 9 & 9 & 4 \\
\hline Decreased & 1 & 5 & 0 \\
\hline No Change & 1 & 3 & 1 \\
\hline
\end{tabular}

A theme that emerged during the interviews that relates to the changes in OHSU's culture and customer focus is the impact that OHSU's transition to a public corporation had on its ability to expand and grow-in terms of people and also in terms of buildings and physical presence. A staff member in public safety put it this way:

"In the next five years [after the public corporation], there was quite a lot of hiring in [my unit]. Within 5 years we added quite a lot of people. With the new buildings, the campus got bigger. We needed more people. And new equipment. And that was to keep up with the rate of growth on the campus." 
A staff member in logistics who was active in AFSCME put it this way:

"In general YES, it was the right thing to do. Many of us felt that at the time we were at a dead end. Obviously [it resulted in] the physical growth and the growth in expertise. The growth in renown and recognition across the country and around the world has grown. Our bargaining unit has grownwe have more AFSCME-represented employees—and they have been able to rise up economically along with OHSU. It seems trite, but it has been a winwin."

A staff member in the School of Dentistry expressed it this way: "People didn't have a good impression of OHSU [before 1995]; our buildings were run down. Because OHSU has been able to grow now, and to separate from the state- there is more pride as a public organization."

Still another member of the staff, this person in human resources:

"It was a good idea, because so much building has happened. We now have the Primate Center [Oregon National Primate Research Center] and OGI [former Oregon Graduate Institute], and South Waterfront. We're all over the place. We're not just locked to this hill. I don't think this would have happened as readily if we hadn't been a public corporation."

Many of the faculty interviewed also raised the topic of improved facilities as a result of the public corporation, as described by this clinical faculty member in the School of Medicine: 
"It enhanced [the culture] from the standpoint of having greater institutional prestige. The greater emphasis of being able to build labs and the facilities that attract researchers began to increase the academic prestige of the institution. And that ramps things up a lot."

This same faculty member went on to say: "As a young clinician...seeing the newer facilities that came with the independence-and having facilities that we could be proud of-it was very important."

A contrasting point of view came from another clinical faculty member: “...the investment in buildings [was] much greater than the investment in staff to occupy them-that has gotten no better and is still the same. It seemed to me that they invested a lot in buildings and not so much on operations."

A former faculty member recalled the physical growth that resulted from the public corporation as a benefit for the institution: "One clear benefit of the shift was that the institution was able to develop facilities that enabled us to provide the clinical care that we wanted to provide in a much more suitable environment."

The interview data indicate that the topic of improved facilities as a result of the public corporation came up across all employee types and groups (faculty and staff) and appeared in $40 \%$ of the interviews (mentioned in 14 interviews). Facilities and the physical growth of the university was not a direct question, but did emerge as a factor in OHSU's changing culture and employee perceptions about the more customer-focused and business-driven model. 


\section{Job Satisfaction}

Within the domain of job satisfaction there are several sub-categories. The participants were asked questions relating to whether they felt more or less valued after OHSU became a public corporation; whether they felt they were adding more or less value as employee-contributors; whether they had the expectation that their pay would change when OHSU became independent (and whether they perceived that their pay did change); whether they noticed a change (increase or decrease) in the amount of recognition employees received for the work they did; and their overall job satisfaction after OHSU separated from the state system.

\section{a. Staff, Faculty, Former Employees: Value}

The AFSCME staff consistently agreed both that they were valued as employees by the institution and that they were adding value as contributors to OHSU's missions. There were some comments that much of being valued depended on the department in which you worked, as one employee from the IT department stated: "I really did [feel valued] and a big part of that is who you worked for and your department." This sentiment was repeated frequently and from several different areas of the university. An accountant in a research center said: "I felt like I was valued by the people I worked with in my immediate department." Similarly, a buyer stated: "Certainly on the individual level. I certainly felt that my work was valued and appreciated." An administrator in the School of Medicine expressed it this way: "It's hard to separate out working for OHSU and working in my department. I can only speak from my own personal experience; I felt very valued." 
Also from a staffer in the School of Medicine: "I always felt appreciated by my department and I never looked beyond that." An employee in the facilities department who was active with the union stated that he believed that showing that the organization valued employees was a joint effort and responsibility between AFSCME and OHSU:

"In terms of how they valued the employees, I personally feel that that was one of the major roles of the union, to make sure OHSU had to consider the impact on the employees and how you valued them-you have to pay attention to the employees."

The general consensus was that feeling valued depended on the department in which you worked and the people for and with whom you worked: "I've always felt like I've been appreciated. And it's gotten better-it always gets better and better. Of course, it helps that I have always worked for the same people. We're family." Conversely, some felt a lack of appreciation for their work-again, based on department or unit: “There was a 'use them and lose them' attitude...that people were expendable. An attitude that you could use them up. But that was more departmentally based. [It was] a departmental culture thing. There were some places that were great, some that weren't."

Some staff expressed their perceptions about adding value in terms of how their supervisors and managers treated them: "I've always been very fortunate, because I've had managers that gave me the resources that I need but also the ability to do my job. I was never micro managed. These were the goals that they set 
in front of me and I was very much able to work inside those." Another employee, in the School of Dentistry stated: "Culturally, the university made time to show that they value our time here." This was a common theme, as expressed by an employee in accounting:

"It was an interesting time for me because working in the payroll office and being a part of the team that was creating the new payroll system-I was in several meetings with Jim Walker [CFO at the time], and I was just a lowly, fairly new AFSCME employee, but I appreciated having my opinion heard and being brought to those meetings [to contribute to creating the new system]." Another employee, this one in IT, expressed a similar sentiment: “Being brought into some of those meetings with Lesley Hallick [Provost at the time] and Jim Walker was good. A person at that level that asks, and is actually interested in, your opinion is good and actually brings people on board to wanting to make it a success." An employee in research administration discussed how they were able to add more value because of the investment OHSU made in them: "I did like the fact that people gave me tasks and projects because they felt like I could do them. I got the training that I needed to do them. And it increased my value as an employee and it increased my self-esteem. It was a nice thing."

One employee did express frustration and not feeling as though they were adding value:

"[I had] finally made accountant. And then [a decision was made] that everybody that didn't have a four-year degree in accounting could not be an 
accountant. So I was made an accounting specialist, even though I'd been an accountant for numerous years and had more experience hands on with the system that we used than the kids they were hiring out of Portland State.

That hurt. That is still a very sore, sore point. That hurt."

Despite that sentiment, most AFSCME staff believed both that they were valued and that they were adding value. The interview data confirm this: 13 of the staff believed they were more valued after OHSU became a public corporation, while only 2 believed there was no change, with none of the respondents expressing that they were less valued $(\mathrm{n}=15)$. Similarly, 14 of the staff believed they were adding value to OHSU's missions, while only one person felt that they were not adding value after OHSU became independent $(n=15)$. It may be that employees would have believed they were adding value whether OHSU became a public corporation or not, but these data are worth reporting to factor in to employee satisfaction in general after the transition to the public corporation.

Faculty were asked about job satisfaction in the same manner as staff, and then they were asked specific questions that relate to faculty work-life. This section will first describe the general job satisfaction results. As with the process and culture-oriented topics, faculty were mixed in their perceptions and feelings about job satisfaction. When asked about feeling valued and feeling as though they were adding value to the organization, the faculty were split. Among those who did not feel valued, one basic science faculty member expressed it this way: "It seemed like this is an area where there was change. It seemed like the faculty wasn't really 
viewed as anything special. Just viewed as a bunch of employees that could be replaced. I thought that that was a change." Another faculty member, this one in the School of Dentistry stated:

"The culture here has always been of fear. [You were] always afraid you're going to get axed. [There was] always the fear of losing, not gaining things. And I don't think that was just the dental school, I got the same impression elsewhere, such as the basic sciences [in the School of Medicine]."

Still another faculty perspective of not feeling valued was expressed this way: "I have always been one to look at peoples' actions, not what they say. There was just a big divorce between what was said and I don't think that there was much appreciation for the talented people that were around."

Those faculty who did feel job satisfaction expressed it in terms of being able to fund their research and to teach, as this basic science faculty member said: “I'm a happy camper, I'm funded, I teach...". Another faculty member expressed being conflicted because there were pros and cons to the change in the organization: "The thing about working at OHSU that's always been great is that there are just really great people around. I've never picked up the phone to call someone and asked for help and have them not help. People always help. And that's the plus side. On the negative side, it's never felt like we were as good as the sum of the parts should be. Never quite been able to understand why. And that's frustrating. I think sometimes just feeling like you're not able to change the things that need to be changed doesn't feel very good." 
Still another faculty member described it this way: "It was more the pride in the organization that changed-in a positive way. I was really impressed with Kohler and how people felt about him. I felt pride about that." A clinician also expressed his job satisfaction and the value he provided in terms of pride in the institution: "I felt greater pride as a physician when OHSU changed because I could take greater pride in the facilities. I felt that my patients were being better taken care of. That increased job satisfaction in that way." Finally, one faculty member put it this way: “I don't really hear from upper levels, but I have very appreciative immediate supervisors." This aligns with the feeling staff had that the perception of being valued originated and/or lived within the individual units or departments rather than at a university-wide level.

The data indicate that four of the faculty interviewed felt more valued by the institution, 3 felt less valued, and 3 felt there was no change in how much they were valued before the institution became a public corporation versus after $(n=10)$. Additionally, 9 faculty respondents felt they were adding value to OHSU's missions after it became independent, while 4 believed they were not adding value $(n=13)$.

Former employees mirrored some of the trends of the current staff and faculty in the areas covered in the job satisfaction category. One administrator indicated that she felt valued and that she was adding value, and that she could tell who felt that way and who didn't:

"It was, again, departmental-you can tell the employees in those departments that do a good job-people really do like their jobs. While in 
others they go to work every day because they have to. In an organization that big that's bound to happen."

The interview data regarding job satisfaction after OHSU became a public corporation as described by former employees is as follows: 3 of the participants felt more valued, while 2 felt less valued $(n=5)$. However, the one former employee who expressed an opinion, felt they were adding value to OHSU (n=1). b. Staff, Faculty, Former Employees: Expectations about Pay \& Actual Pay

The next areas regarding job satisfaction pertain to expectations about pay and benefits and further, whether pay and benefits actually improved after OHSU became a public corporation. There was some anxiety among employees immediately after the separation from the state that benefits would be maintained: "When the change came about, I wanted to make sure my benefits were safe and wanted to be in PERS [Public Employees Retirement System]; once I knew that was safe, I was fine." In general, staff felt that being part of the state was limiting how much pay could increase and that separating allowed for more flexibility (or at least stability) in that area, as expressed by an employee in a research institute: "It seemed to me like we were always restricted in pay by the State Board of Higher Education and Salem and the fluctuations of state funding. That part of it did seem to stabilize. It did change after becoming a public corporation." Rather than having an expectation of increased pay, staff were concerned with maintaining what they had before: “The focus was on what's going to happen to 'me' and my benefits and my security?" 
Some hoped for better pay with growth: "With the growth of the university the hope was to look forward to being able to pay employees better." And still others believed that while pay may not have improved dramatically, that benefits did: "There was a big improvement there, on the benefits side, not necessarily the pay side." Other employees, such as this one in logistics believed pay did improve: "In the long run, yes, we did see marked improvement in wages." The interview data bear out that employees did not have the expectation that pay and benefits would improve, with 11 expecting no change in pay and benefits, and 4 expecting increases $(n=15)$. Yet when asked about what actually happened after the university became a public corporation, 8 said their pay did increase noticeably and 4 indicated there was no change $(\mathrm{n}=12)$.

This contrasts with what resulted in the September 1995 AFSCME 3-day strike, with salaries as the primary driver. As was discussed earlier, and as Lesley Hallick explained: "We discussed getting salaries to market repeatedly. There was a misunderstanding about expectations about salaries-and [getting salaries to market levels] in one fell swoop was just not possible" (Interview, L. Hallick, August 16, 2012). But for the union staff, it was an important point: "A lot of it comes down to pay. The stronger the union member, the more likely they were to be unhappy." And another employee said: "We wanted more than they were willing to give." But some did not recall that a change in pay was a promise of the public corporation: "I don't think AFSCME ever led the membership to believe that the public corporation had anything to do with more money." Still another employee felt that some benefits 
were taken away: “For me it wasn't the pay: it was the taking away [when we left the state] of some of the other items we had: we lost two days of vacation, and a floating Governor's Day and then we had the Veteran's Holiday. We had those taken away."

While the interview data indicate that the faculty did not have expectations that pay would improve, the perception about whether pay did go up is mixed. The faculty's expectations about whether becoming a public corporation would improve pay and benefits were based around communications from leadership, as described earlier, and as mentioned by this basic science faculty member: "I remember Dr. Kohler, what he really wanted to do was to have more flexibility for salaries. But the salaries didn't go up—so I'm not sure whether he was sincere on that because the salaries didn't go up. Benefits went down." Their perceptions about what happened to pay and benefits after OHSU separated from the state were mostly negative: "Salaries went down and the flexibility led to a decrease in benefits." Another faculty member in a research center concurred: "My salary is very low for a full professor."

The data indicated that 3 of the faculty expected their pay to increase, while 13 expected no change $(n=16)$ - confirming that the faculty generally did not expect pay to change. However, the results of the interview data are more mixed regarding whether pay and benefits did actually increase, with 4 of the faculty interviewed indicating that pay did increase, while 5 indicated that it stayed relatively flat-did not change $(n=9)$. 
While the former employee group did not elaborate about their expectations that pay and benefits would increase as a result of OHSU becoming an independent public corporation, one former employee who worked in a research center expressed her retrospective thoughts this way:

"When I moved [to another employer] it was a little bit of shock because the salaries are tremendously lower [where I moved to]. We were well paid in retrospect. And I always felt well-paid there. But I appreciated it even more when I moved. Particularly from the standpoint of benefits."

Again, the majority of five former employees expected no pay change when OHSU became a public corporation, and 3 did expect pay to increase $(n=8$ opinions expressed). When asked if they perceived their pay to change, 2 former employees said their pay did not change, and one felt it did $(n=3)$.

\section{c. Staff, Faculty, Former Employees: Recognition}

Another area discussed with employees was whether they felt employee recognition increased after OHSU became a public corporation. While some of the sentiments shared were mixed, overall, staff felt that recognition improved. One employee in the School of Medicine stated it this way: "I think they did a good job. How much can you do with 14,000 employees? That's part of the problem. I think that they try is huge. I think that they have the yearly employee recognition is good. They try." However, another School of Medicine staffer was less enthusiastic when describing the recognition pins given to employees at their 10-, 15-, 20-year, etc. milestones: "The employee recognition, such as the fancy lunches they used to 
have, it seemed kind of silly to us. And the pins are just unbelievably silly, with their tiny speck of color. They didn't get it right and still haven't gotten it right." Still another point of view from an employee in the finance office: "I don't remember there being any kind of [employee appreciation] program under the staterecognition started after we left the state and became semi-private. I think Jim Walker did a good job of trying to make employees feel appreciated." The interview data indicate that 12 of the staff believed that employee recognition increased after OHSU became independent, while 4 felt it did not change $(n=16)$.

Faculty were also mixed about recognition and how it related to job satisfaction:

"They were handing out crumbs to the faculty. This is the view of the faculty, they were crumbs to faculty, that rather than improve the real conditions, and support for what they were here for, it was much less costly to have a whole bunch of certificates printed and have a luncheon."

Similarly, a faculty member in the School of Dentistry succinctly stated: "Not really much recognition in the SOD either, but I don't come here for the recognition." Faculty perceptions about recognition were primarily tied to their productivity, which will be discussed in the next section within the discussion of faculty-specific topics. The interview data are mixed with regards to faculty perceptions about recognition: 6 opinions were expressed that recognition did increase after OHSU became a public corporation, 7 felt that recognition decreased, and 4 believed there was no change $(n=17)$. 
The former employee group did recall a lack of employee recognition as OHSU became a public corporation. One former employee in Human Resources put it this way:

“[Employee recognition] efforts were pretty feeble. We had a time-in-service recognition program [rewarding people for longevity], that was institutionwide, not really well attended, but those who did favor it were die-hard fans. But other than that, the ceremonies and awards were pretty much within segments of the institution."

Another former employee concurred with that sentiment: "There were a lot of employees down in the trenches who never really did get the recognition they deserved. As far as the university as a whole, I always thought they could recognize more employees in a little better way." Former employees were split about recognition: 2 felt that recognition decreased, one felt it increased and 3 indicated that it did not change at all $(n=6)$.

\section{d. Staff, Faculty, Former Employees: Overall Satisfaction}

Finally, employees were asked about whether their overall job satisfaction increased, decreased, or did not change at all. Some felt some uncertainty about what it meant: "I remember it being the big hot topic of conversation among employees for several months before and after. It took us all a while to figure out who we were and whether it affected our jobs or not." While others were happier, as expressed by one employee in the Finance Department who was very satisfied, personally and with leadership: "I was still happy as a little clam in my area. It was 
nice having a president that stuck all the way through it. Dr. Kohler got us through all the tough times." Many expressed that they had a very personal and local reaction: "It definitely impacted $m e$. [It was] very difficult to understand. It was a part of our identity and it was difficult to explain. All I cared about was that nothing was going to change for me personally." The data describe that 11 of the staff interviewed felt that their overall job satisfaction increased, while one felt it decreased, and one felt there was no change $(n=13)$.

In general, the faculty responses were still more mixed than those of the staff. One basic science faculty member summed it up this way:

"I loved it up to '95, the faculty were smiling, they were interacting with each other. There was growth, the future looked rosy here. We wanted to be as good as UCSF, we could do it, people wanted to be in Portland and be here. When they came here they could be successful. But any of the basic science faculty that you talk to will not consider this a fun place to be [now]. They are here and they will try to make the best of it."

Similar sentiments emerged from other faculty, this one in a research center, also a basic scientist:

“1985-1995 we went from a sleepy backwoods teaching college to a robust, nationally renowned, comprehensive university. Everyone wanted to come here. It was really exciting. Then, our national reputation just slipped way down. Because the faculty are demoralized [by the corporate nature of the place]. They talk. Lots and lots of top faculty have left." 
A more middle of the road response did emerge from some faculty, such as this response from a faculty member in the OHSU library: "I feel like us becoming a public corporation-for whatever things I've experienced positively or negatively for our organizational culture-I don't feel like it had a huge negative impact on me or my job satisfaction." The positive responses have more to do with how the change to the organization impacted the opportunities that became available and the improved stature of the organization, or to the camaraderie that faculty felt for each other, as expressed by this clinical faculty member in the School of Medicine: "I really do believe that many opportunities became available because of the improved status of OHSU." The same faculty member expressed their satisfaction in terms of camaraderie: "I think initially it had really big benefits. You know, this idea that we were all in it together-a camaraderie. And I think people did put their shoulders to the wheel and there was some benefit to that."

This is one of the few categories in which faculty responses varied based on the different types of employee (e.g., mission area, age, length of time at OHSU). A table with the faculty breakdown illustrating the slight variations among the different employee categories is directly below the job satisfaction table. Note that no respondents said that their overall satisfaction was unchanged.

The responses from former employees were mixed, and this continued when discussing overall job satisfaction, with some feeling positive, others frustrated. A former employee who worked in a research center expressed their positive recollection this way: "From the job satisfaction standpoint-we were going to grow, 
we were going to get a new facility. And we were planning all of that and it was tremendously exciting from that standpoint. Job satisfaction in that regard certainly was high." Former employees felt that overall satisfaction did increase, with 4 indicating that it did, and one indicating that there was no change in their overall satisfaction $(n=5)$.

\begin{tabular}{|c|c|c|c|}
\hline & Staff & Faculty & $\begin{array}{l}\text { Former } \\
\text { Employees }\end{array}$ \\
\hline \multicolumn{4}{|l|}{ Valued } \\
\hline More & 13 & 4 & 3 \\
\hline Less & 0 & 3 & 2 \\
\hline No Change & 2 & 3 & 0 \\
\hline \multicolumn{4}{|l|}{ Adding Value } \\
\hline Adding & 14 & 9 & 1 \\
\hline Not Adding & 1 & 4 & 0 \\
\hline \multicolumn{4}{|l|}{ Pay-Expectations } \\
\hline Expected increase & 4 & 3 & 3 \\
\hline Expected no increase & 11 & 13 & 5 \\
\hline \multicolumn{4}{|l|}{ Pay-Actual } \\
\hline Increased & 8 & 4 & 1 \\
\hline No Change & 4 & 5 & 2 \\
\hline \multicolumn{4}{|l|}{ Recognition } \\
\hline Increased & 12 & 6 & 1 \\
\hline Decreased & 0 & 7 & 2 \\
\hline No Change & 4 & 4 & 3 \\
\hline \multicolumn{4}{|l|}{ Overall Satisfaction } \\
\hline Increased & 11 & $*$ & 4 \\
\hline Decreased & 1 & $*$ & 0 \\
\hline No Change & 1 & $*$ & 1 \\
\hline $\begin{array}{l}\text { * Faculty responses to over } \\
\text { group (mission, age, length } \\
\text { breakdown. }\end{array}$ & $\begin{array}{l}\text { atisfact } \\
\text { ime at }\end{array}$ & $\begin{array}{l}\text { laried dep } \\
\text { J). See tab }\end{array}$ & $\begin{array}{l}\text { nding on } \\
\text { e } 6 \text { for }\end{array}$ \\
\hline
\end{tabular}




\begin{tabular}{|c|c|c|}
\hline & Increase & Decrease \\
\hline \multicolumn{3}{|l|}{ Faculty (Mission) } \\
\hline Education & 6 & 6 \\
\hline Research & 2 & 1 \\
\hline Hospital & 2 & 1 \\
\hline Central Services & 0 & 0 \\
\hline \multicolumn{3}{|l|}{ Faculty (Age) } \\
\hline $40-49$ & 3 & 0 \\
\hline $50-59$ & 3 & 3 \\
\hline $60-69$ & 5 & 4 \\
\hline $70+$ & 0 & 0 \\
\hline \multicolumn{3}{|l|}{ Faculty (length) } \\
\hline 17 years & 0 & 0 \\
\hline 18-25 years & 7 & 5 \\
\hline $26-30$ years & 2 & 3 \\
\hline $30+$ years & 0 & 0 \\
\hline
\end{tabular}

One other aspect of employees' perceptions of overall satisfaction merits discussion: the AFSCME 3-day strike in 1995. During the review of OHSU's archival documents and report of the leadership interviews, the AFSCME 3-day strike was discussed. The employees represented by the AFSCME bargaining unit at OHSU went on a 3-day strike shortly after OHSU became a public corporation. While the strike was not a direct question asked in the interviews with participants, the topic arose frequently in discussions with current and former employees. One of the staff active in the union noted that "interest-based bargaining" had begun in 1993 and he recalled: "Once we became a public corporation, [AFSCME] could bargain directly with OHSU—it was a big plus and a big change." However, he went on to say: "There were disagreements, and we wanted them to get resolved. A threat of a strike was always there to help argue your point. And it got to the point 
where we had to vote on the contract, and it got rejected and we were obligated to take that next step which was to hold the strike. Even if we hadn't had a strike, there was bad feeling that was going to have to be worked out."

Another staff member reported that she did participate in the strike, but she did not recall that it was related to OHSU becoming a public corporation: "I participated in the strike. I didn't connect that with the change at all. Bargaining is always bargaining. It never occurred to me that it was related to the public corporation." Another employee in the finance department reported that they supported the strike: "[They] wanted to take away a percentage of what we got in the PERS. That was my reason for voting for the strike. During those 3 days I was out [for personal reasons]. But I wouldn't have crossed the picket line. Not for anything."

The coded data of the interviews show that the strike was mentioned as a topic in approximately $45 \%$ of the interviews conducted $(n=16)$. None of the faculty interviewed mentioned the strike. The strike was a result of a breakdown in communications and misunderstanding of the interests of the two parties. Employee perceptions of what led to the strike and how it was resolved did leave a lasting impression as it was mentioned frequently, but did not seem to impact overall job satisfaction in the long-term. 


\section{Faculty Matters}

Faculty-specific questions focused on perceptions of the impacts to shared governance, academic freedom, expectations of faculty productivity, and promotion and tenure.

\section{a. Current, Former Faculty: Shared Governance}

Faculty generally felt that shared governance did not improve after OHSU became a public corporation in 1995-rather that it either did not change at all or decreased somewhat. A faculty member in basic science expressed a perception that others also in basic sciences shared: "It felt like faculty governance just stopped [after 1995]. There was an abrupt loss of [faculty] governance at that point." One basic science faculty member also stated: "The public corporation—the administration—judges my success and the success of any faculty member, in dollars. That is not an academic model. An academic model would be the best researchers, teachers, etc." Several mentioned that Lesley Hallick, then provost, did focus on faculty: "[Lesley Hallick] took faculty senate very seriously." But the overarching themes that emerged when interviewing faculty were that faculty senate became a more advisory body than a governing body after OHSU became a public corporation: "Being a public corporation lessened the faculty senate's say into the operation of the university."

A faculty member in the School of Dentistry put it this way:

"Honestly I don't think it had any real power [after 1995]. But I'm not sure that its role was to have power. I think its role was to monitor, advise, and 
make recommendations. But maybe at other universities the faculty senate has power."

Still another, similar point of view from a faculty member in the School of Nursing: “Governance has been less shared [since 1995], but we're getting better, but there's still a lot of decisions that happen without faculty input that impact faculty." The interview data bear out what faculty shared: 15 of the faculty felt that shared governance at OHSU decreased or did not improve after it became a public corporation, and one felt it increased $(n=16)$.

Former faculty shared the mixed feelings that the current faculty discussed. In terms of shared governance, one former clinical faculty member, who had also become a department chair by the time OHSU transitioned to the public corporation described his thoughts on shared governance this way:

"It was a sort of gentle evolution and it depends where you were in the system. In the 70s I was relatively junior faculty, but at the time of the transition I was a chair and I was meeting regularly with the dean and Dr. Kohler. Perhaps chairs are not the people to ask about this. I certainly didn't feel disenfranchised. If I needed to present a point of view on behalf of the departmental faculty or later the medical group, I was able to-there was always a way to present that view. You didn't always get what you asked for. But I didn't feel out of the loop." 


\section{b. Current, Former Faculty: Academic Freedom}

When it comes to academic freedom, the distinct majority of faculty respondents felt that academic freedom was not impacted when OHSU became a public corporation—faculty felt that they were still able to pursue their own academic agenda. The only concerns expressed about influences on academic freedom came in terms of the pressure to pursue research areas that would assist in the financial aspects of the university, as expressed by a faculty member in the School of Dentistry: "In terms of academic freedom it was more restricted—but primarily due to financial exigencies we had at the time." The interview data confirm that faculty overall felt that academic freedom was not significantly impacted when OHSU became a public corporation: 10 of the respondents believed there was no change to academic freedom, 3 felt it decreased, and 2 felt that it increased $(n=15)$.

The former faculty interviewed felt that academic freedom either improved with one faculty expressing that academic freedom increased and 2 expressing that there was no change to academic freedom when OHSU became independent. None of the respondents indicated that it decreased $(n=3)$.

\section{c. Current, Former Faculty: Expectations About Productivity}

Faculty did express the perception that there was a clear expectation that faculty should increase productivity, as described by a faculty member in a research center: "I think that was the real change, it became more a sort of a bottom line kind of pressure." Faculty linked this pressure to how they were valued, as described by 
faculty in the School of Dentistry: “I didn't feel valued as a researcher, in part because I wasn't bringing in enough money." Still another expression of this came from a faculty member in the basic sciences: "And then it became a corporation, and it started...to only be interested in revenues and expenditures and the academic missions are expenditures." Further, another basic science faculty stated it this way: "There was a change in the sense that they were pushing us to get more grants."

The interview data confirm this perception of an expectation of increased productivity: 12 opinions were voiced that there was an expectation that faculty productivity should increase, 4 felt there was no change in this expectation, and one felt that the expectation decreased $(n=17)$.

There was a recollection among former faculty that expectations about productivity did increase, but that it was not solely due to OHSU becoming a public corporation:

“I don't think it was ever explicitly an instruction that came from the president's office. Departments are relatively autonomous. And you run your own affairs. It was clear to me and to us in the department, we knew what we had to do...It was clear that if we were going to grow and evolve and develop the subspecialty areas that we wanted to develop, the only way we were going to do that was on the backs of the clinical faculty and their productivity. That probably happened to every medical school in the country, so I don't think it was a direct consequence of the public corporation, it was part of the evolution of medical education." 
Three of the former faculty indicated that expectations about faculty productivity did increase; none indicated that it decreased or did not change $(n=3)$.

\section{d. Current, Former Faculty: Promotion and Tenure}

Finally, faculty were asked about promotion and tenure practices after OHSU became a public corporation. Again, faculty were mixed in their responses as to whether these practices were impacted with the 1995 change in governance. While most described that promotion practices continued as they had before the separation and were departmentally specific and driven, the perceptions about tenure were different. A clinical faculty member in the School of Medicine indicated that an expectation of tenure was an artifact of a bygone era: "My view was that tenure was a vestigial of the old days when there was money for people [to have] employment for life." In contrast, a basic science faculty member expressed a different point of view about tenure:

"There was for many years, an attempt to do away with it in the basic sciences, it was fought tooth and nail. And the administration was barked down. Because it would be very hard to recruit at least good basic scientists without tenure. So the tenure amount was fixed. The administration was satisfied because over the years it would diminish. And over the years it has."

A faculty member in the School of Nursing expressed frustration that OHSU administration began issuing annual appointments to faculty, even if they were tenured: "Annual contracts for tenured faculty? That was meant to serve OHSU as a business...It's to serve the public corporation rather than the academy." The 
interview data were divided about the perceived impacts to promotion and tenure practices. Three felt that promotion and tenure practices got better in terms of benefiting faculty, 6 felt there were no changes, and 7 believed they got worse $(n=16)$. In a summary of concerns regarding the public corporation concept, the faculty senate also identified tenure as one of 26 issues or concerns as OHSU contemplated the public corporation model (Faculty Senate Summary of Concerns, Undated).

One former faculty member mentioned that promotion practices did not appear to change when OHSU became a public corporation, but he did state that at that time tenure became meaningless:

"Tenure also became an issue-because it disappeared. In the old days, when you were here 8 or 10 years, you got to take a sabbatical. [Then it gradually evolved to] 'you can take a sabbatical...IF you can pay for it.' Today you can be a tenured professor, but unless you are bringing in the money to cover your salary, you're a tenured professor without salary. Tenure became a meaningless term."

Former faculty were split evenly about shared governance - that it either increased or there was no change $(n=2)$. Two former faculty felt that there was no change to academic freedom, and one felt that it actually increased (n=3). All 3 of the former faculty responses to this question held the perception that the expectation of productivity increased $(n=3)$. Finally, former faculty felt that promotion and tenure practices either did not change, or got worse, evenly split $\mathrm{N}=2$ ). 


\begin{tabular}{|c|c|c|}
\hline & Faculty & $\begin{array}{l}\text { Former } \\
\text { Faculty }\end{array}$ \\
\hline \multicolumn{3}{|l|}{ Shared Governance } \\
\hline Increased & 1 & 1 \\
\hline $\begin{array}{r}\text { Decreased or did not } \\
\text { improve }\end{array}$ & 15 & 1 \\
\hline \multicolumn{3}{|l|}{ Academic Freedom } \\
\hline Increased & 2 & 1 \\
\hline Decreased & 3 & 0 \\
\hline No Change & 10 & 2 \\
\hline \multicolumn{3}{|l|}{ Productivity-Expectations } \\
\hline Increased & 12 & 3 \\
\hline Decreased & 1 & 0 \\
\hline No Change & 4 & 0 \\
\hline \multicolumn{3}{|l|}{ Promotion \& Tenure } \\
\hline Better & 3 & 0 \\
\hline Worse & 7 & 1 \\
\hline No Change & 6 & 1 \\
\hline
\end{tabular}

\section{Overall Impact: Staff, Faculty, Former Employees}

In the end, the staff interviewed felt overwhelmingly positive about OHSU's transition to a public corporation model overall. One employee in the School of Medicine summed it up this way:

"[It was a] brilliant idea. We wouldn't have CHH [Center for Health and Healing] or the Knight Cancer Institute or any of that. Being our own university has allowed us to develop our own identity. And has allowed us to morph, just like I have been able to morph. The university as a whole, as a private entity, has been allowed to morph into what was needed, as opposed to being constricted by what the state needed. We were not confined. Instead 
of having to just think outside the box, we get to live outside the box. And become what we want."

This sentiment was echoed across functions and units. An employee in public safety concurred:

“[Becoming a public corporation] was VERY good idea. Almost brilliant. It was a very good idea. Probably made, in a sense, the difference between life and death for the institution in a lot of ways. I know particularly on the research side and the ability to be a world-class research institution. Might never have happened if we had stayed within the state system. Because we would have been limited..."

Another employee, this one in the IT department: "It was a positive change for OHSU and it put OHSU in a position to make more of a positive change for other people." The only somewhat negative sentiments were related to the uncertainty of what would happen to individuals' positions: "I was never worried about OHSU becoming a different place to work. I was worried about what is our role going to be. I understood why we didn't fit into the OSSHE umbrella...we could be so much more than we could under that umbrella."

The interview data for staff were unanimous: All 15 of the staff in all employee categories and across all missions felt that OHSU's becoming a public corporation was a good thing and that it created a generally better place to work $(n=15)$. 
Faculty were generally positive when discussing the overall impacts of OHSU's transition, but again, there were some mixed feelings. Some described it in terms of the external impacts of being tied to the state, as did this faculty member in the School of Dentistry:

"It's better off that we're not as tied to the state and its current situation and their budget troubles. Looking back, if we were still dependent on the state for funding we'd be in a more dire situation because the state is having trouble getting their act together."

Others described it as a welcome change due to increased investments in faculty and infrastructure, such as this clinical faculty member in the School of Medicine: "It was a welcome change to have the investment in our clinical and research enterprise. That brought people and it brought opportunities with it." Still another faculty member had unquestionably positive thoughts on the overall impacts:

"It was a great idea. And it was in fact probably brilliant and the best thing that happened since they laid the first brick up here. In fact, I think it was transformational for the institution and I doubt we would be in the position we are today without that step."

On the negative end of the spectrum, some faculty had negative feelings about the separation, such as this comment from a clinical faculty member in School of Medicine: 
"On the negative side, as a faculty member and as an Oregonian, I look and see that we've had this dramatic increase in medical school tuition and dramatic decrease in the number of Oregonians that are populating our medical school. It's great that we attract high quality students from around the country - but it saddens me that we are not meeting our mission of being Oregon's medical school in that way."

Still other faculty, primarily in the basic science realm, had more negative feelings about the overall impacts of OHSU's independence: "It has been terrible experience for faculty, students, and staff. And a lot of people have left. Nobody on the faculty supported the public corporation model." This faculty member went on to explain: “It hasn't made things better. Certainly not for the faculty and students. Huge bureaucratic expansion has benefited the administration. But I don't think the faculty, students staff have." A faculty senate subcommittee tasked with examining the pros and cons of the public corporation concept expressed concerns for students as well: "if higher tuition results from reduced state support, the caliber of students may be affected. Academically gifted, but poorer students may not be able to attend" (Fiscal Advisory Committee report to Faculty Senate, March 30, 1993).

Others had a reflective view that it had benefits, but that there were missed opportunities, as described by this faculty member in a research center: "It was the best of two 'not perfect' options." He went on to explain:

"It was the right thing to do. What didn't happen at any level was a careful thinking through of what it was going to mean-for some of the non-business 
side of things. The academics and research: how were we going to pay for academics? And what did that mean? And what does this mean for faculty? It would have been a great time to talk about faculty governance. And it would have-if at any time you were going to bring in consultants—-that would have been a time to bring them in and say ' $\mathrm{OK}$, we have this opportunity how could we reorganize?' We just missed that opportunity."

A faculty member in the School of Nursing believed it was the right thing to do for OHSU's hospitals, but not for academics: "It was good for the health systemthey should have done it all along. I absolutely agreed with that. They should not have dragged academic programs along with them." While a faculty member in the School of Dentistry expressed it this way: "It allowed the institution to progress and to do more and be more independent in how we use the money. [I] see us as being a more modern institution than we were when we were part of the state system."

These mixed reactions are reflected in the interview data: 8 of the faculty interviewed felt that OHSU was generally better overall after the separation, while 7 felt it was generally worse, and one felt there was no change $(n=16)$.

Former employees were in somewhat more agreement-landing somewhere between the staff enthusiasm and the faculty ambivalence. One former clinical faculty member put it this way: "It was a very positive move. Peter Kohler's leadership — he should feel very proud of that, it's not an easy job being a president of a university like that, and he should be proud." Another former faculty member who was a clinical department chair explained that each employee viewed it from a 
personal perspective: "Almost everyone on the faculty was looking at it from their own point of view. We were looking at it from our own salary point of view and how much support and help the hospital was giving. It was a little more personal point of view, but the same story." Still another former faculty member viewed it positively that OHSU was able to extract itself from the state system, thus alleviating the worries of supporting the rest of the universities in the system: "We've created our own bureaucracy, but it's still better to take care of your own than to worry about a professor of classical languages."

One employee who worked in a research center who left OHSU because her husband was transferred explained:

“I would have never left if my husband hadn't been transferred. I have really fond memories of working there. The staff [where I am now] — we always talk about where the best places to work are and I always fondly remember OHSU as one of the best places to work—before and after the change." The interview data regarding former employees' perceptions of the overall impact of OHSU's change to a public corporation reflect these generally positive feelings: 3 of the former employees interviewed felt that the overall impact of OHSU's separation was generally positive, while one felt there was no change, and none felt that the overall impact was worse after OHSU became independent $(n=4)$. Another aspect of employees' perceptions of the overall impact of OHSU's transition to the public corporation was the comportment of the leadership. OHSU's leadership were mentioned throughout the interviews. Staff and faculty mentioned 
Hallick and Walker as inclusive leaders who gathered input from staff on process issues and kept staff informed of what was going on; for example:

“[My manager] kept us totally apprised of what was going on and how it would affect us. It would always depend on how much information she got from her manager, and how much he got from Jim [Walker]. Jim was always really good about letting us know what was going on. In fact in most situations he would pull us in and even the lowest people, even the student workers, and tell us what was going on. Really good open door communication."

One AFSCME staff in logistics mentioned Kohler's vision: “We understood the business benefits that Dr. Kohler felt, but we also could see that we could cut some of the shackles that were preventing some of our members from moving up economically." A staff member in one of the research centers remembers Dr. Kohler's "selling" of the public corporation idea:

"My recollection is that Dr. Kohler had to sell this to the union in order for it to happen. One of the ways he did that was to say that we were going to be separated from the state bureaucracy. And he specifically mentioned things that I had to do, such as purchasing. Those processes were ridiculously long and complicated processes before. He used that as a selling point, that we're going to be doing away with all this at OHSU. So it was great! There was a lot of enthusiasm for it." 
Faculty had more mixed reflections about leadership, particularly as it related to OHSU's transition to a public corporation. One faculty member in a research center reflected: "These were sincere people [Lesley Hallick and Peter Kohler]. Their heart came across. Because of the nature of both of them-both good people." A clinical faculty member recalled that Kohler's push to separate from the state improved OHSU's financial position: "All of that was very meaningful in terms of the investments that were able to occur under Dr. Kohler's leadership. We were under a disadvantage before." Another clinical faculty member stated: "Kohler...it was a great idea, and he was forward thinking and I thought this was all positive when he did it." In contrast, a basic science faculty member reported that he was not in favor of the public corporation and felt that it was a "...fabulous experience for the executive leadership team," but that few others benefited. A colleague in another basic science department reported that he did not feel the faculty were consulted about the transition: "Leadership did not talk with the basic science faculty or with the chairs [about making this change]."

A former employee who was an administrator reflected on Kohler's leadership style and that it was a factor in improved job satisfaction:

"Dr. Kohler had this thing about him that he seemed to be able to instill in people, that this is a caring institution, and the thing that we're here for is to educate students and take care of patients. He was really good at communicating that to the employees. Especially once we became a public corporation. For some reason, people just seemed to turn to him." 
A former clinical faculty member and chair agreed with Kohler's approach: “Kohler's point of view: I agree with that $100 \%$. He was looking at the big pictureand as a chair I had to too." Leadership in general were mentioned in over $62 \%$ of the interviews conducted ( $n=22)$, and Kohler specifically was mentioned in approximately $51 \%$ of the interviews $(\mathrm{n}=18)$. This study does not address whether the leadership did a "good" or "bad" job before, during, and after the transition, but rather this study focuses on the impacts to staff and faculty when OHSU transitioned to become a public corporation. How leadership shepherded that transition had impacts on the culture of the institution, employee job satisfaction, and the overall impacts that will be explored in chapter five.

\begin{tabular}{|c|c|c|c|}
\hline & Staff & Faculty & $\begin{array}{r}\text { Former } \\
\text { Employees }\end{array}$ \\
\hline Generally Better & 15 & 8 & 3 \\
\hline Generally Worse & 0 & 7 & 0 \\
\hline No Change & 0 & 1 & 1 \\
\hline
\end{tabular}

\section{iii. Findings From Quantitative Analysis}

In addition to the interviews conducted in 2012 and 2013, the research for this project included review of OHSU archival documents and oral histories pertaining to the transition to the public corporation. This research also included collection of data from external sources as it applied to points of interest that 
emerged during this project. The quantitative data acquired is detailed below, in some of the same categories explored throughout this dissertation.

\section{a. About OHSU}

As a public corporation, OHSU does receive some state funds specifically for education programs. However, this amount has dwindled over the years, due in part to less state support for higher education. Figures 1 and 2 highlight OHSU's operating budget growth as well as the diminishing state appropriations from 1985 to 2010:

Figure 1: Operating Budget

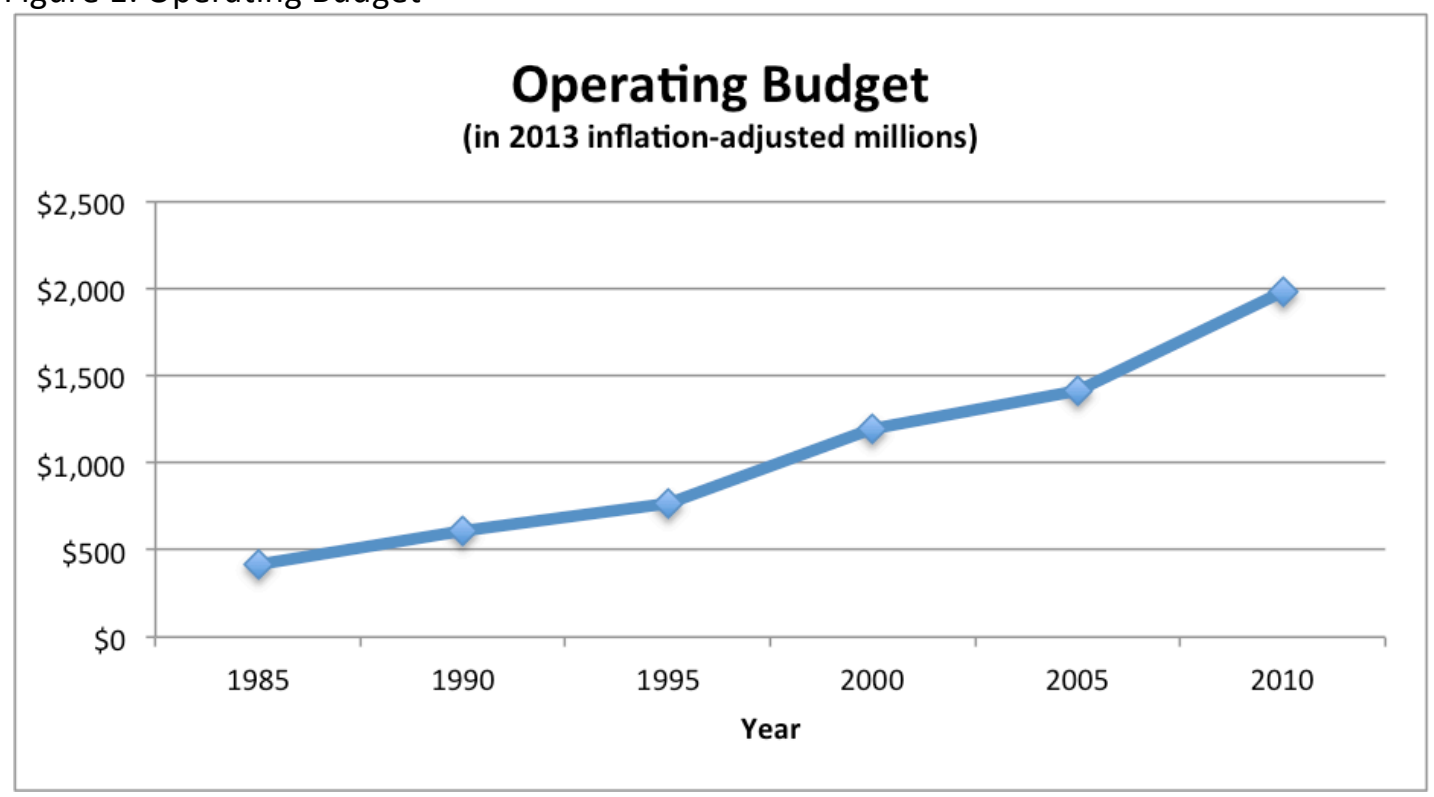

Source: OHSU, 2011 
Figure 2: State Appropriations

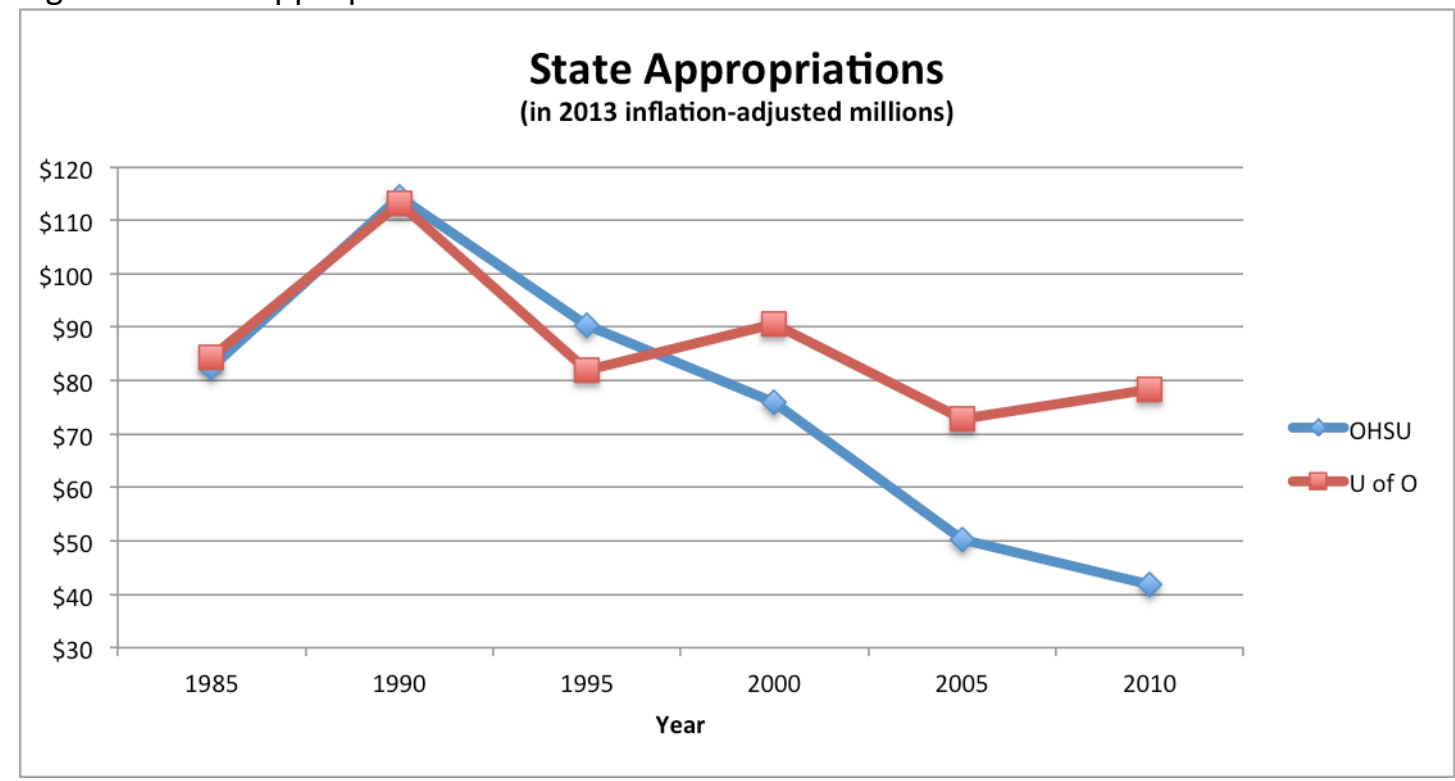

Sources: OHSU, 2011; OUS, 2013

The graph of OHSU's operating budget (Figure 1) highlights the organization's significant growth since 1985, and particularly beginning in 1995, the year of the public corporation, when it grew 159\% from 1995 to 2010. In contrast, the state appropriations graph (Figure 2) highlights the peak of appropriations in 1990, and then continuously dropping appropriations through 2010, a drop of 54\% from 1995 to 2010. The University of Oregon state appropriations have also dropped during the same time period, but not as significantly as OHSU's. During the period 1995 to 2000 University of Oregon's appropriations increased somewhat and have remained relatively consistent through 2010. From their peak in 1990 to 2010, U of O's appropriations dropped by 31\%, however, since 1995 it has changed by only $4 \%$. 
OHSU's numbers of employees and students jumped during this period, as illustrated in Figure 3:

Figure 3: OHSU Employees \& Students

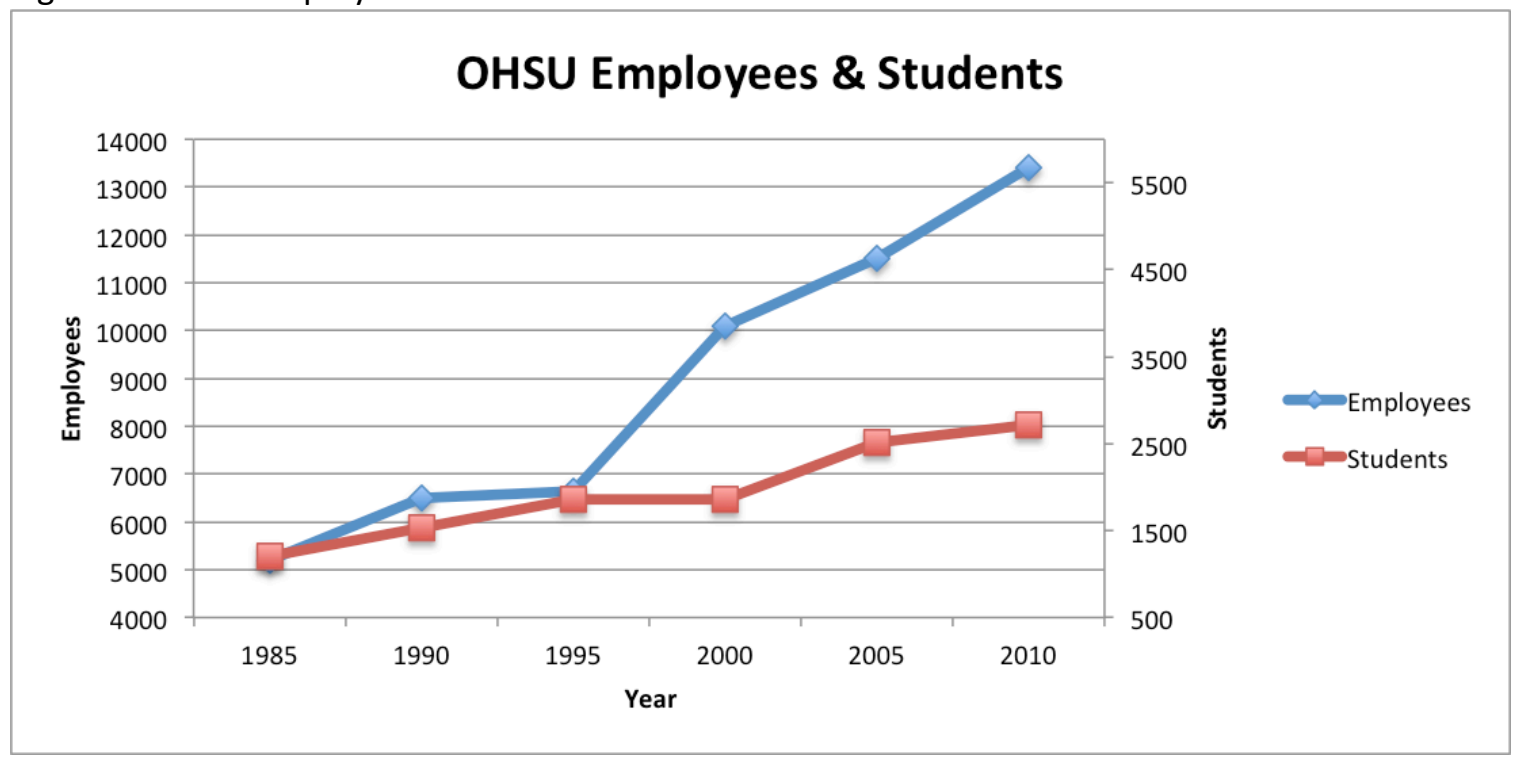

Source: OHSU, 2011

The number of employees at OHSU jumped from 6,651 in 1995 to 13,400 in 2010. Prior to 1995 the number of employees had grown very little, in the decade between 1985 and 1995 it went from 5,200 to 6,651, a growth of 28\%, while from 1995 to 2010 the growth was over $100 \%$. The student population also went up during this period, from 1,855 in 1995 to 2,721 in 2010, representing a growth in students of $47 \%$. Of note here is that while the levels of employees to students was relatively correlated until 1995, after that the growth of employees was greater than the growth of the number of students.

Some of the challenges OHSU has faced since it became a public corporation may be attributed to the growth in debt due to long-term loans. According to OHSU's 
annual financial statements, loans and long-term debt increased from 1995 to 2009 by $373 \%$ (Figure 4). Some debt existed prior to OHSU becoming a public corporation. Debt recorded in 1995 was due to bonds issued by OSSHE, primarily related to the OHSU hospital, which had to be repaid. This rapid growth in debt presented challenges for OHSU, limiting the flexibility that it sought by becoming a public corporation. "Institutions should be concerned with their ability to be flexible and adapt quickly to new situations and operating environments. Financial flexibility varies inversely with the degree to which institutions are constrained" (Kenton, 2002, p. 17). The rapid debt increase after OHSU became a public corporation presented constraints by draining cash reserves and jeopardizing its credit rating (Redding, 2009).

Figure 4: OHSU Loans/Long-Term Debt

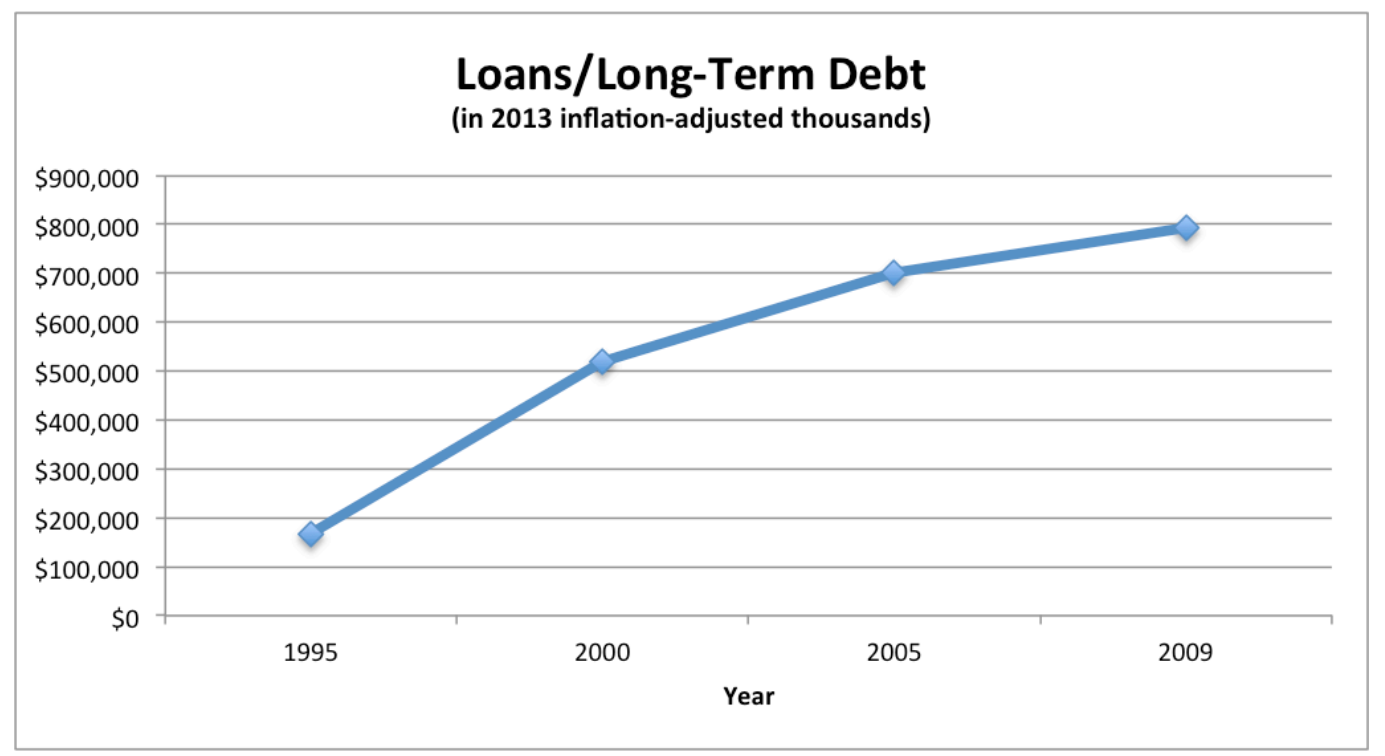

Sources: OHSU 1995e, 2000, 2005a, 2009 


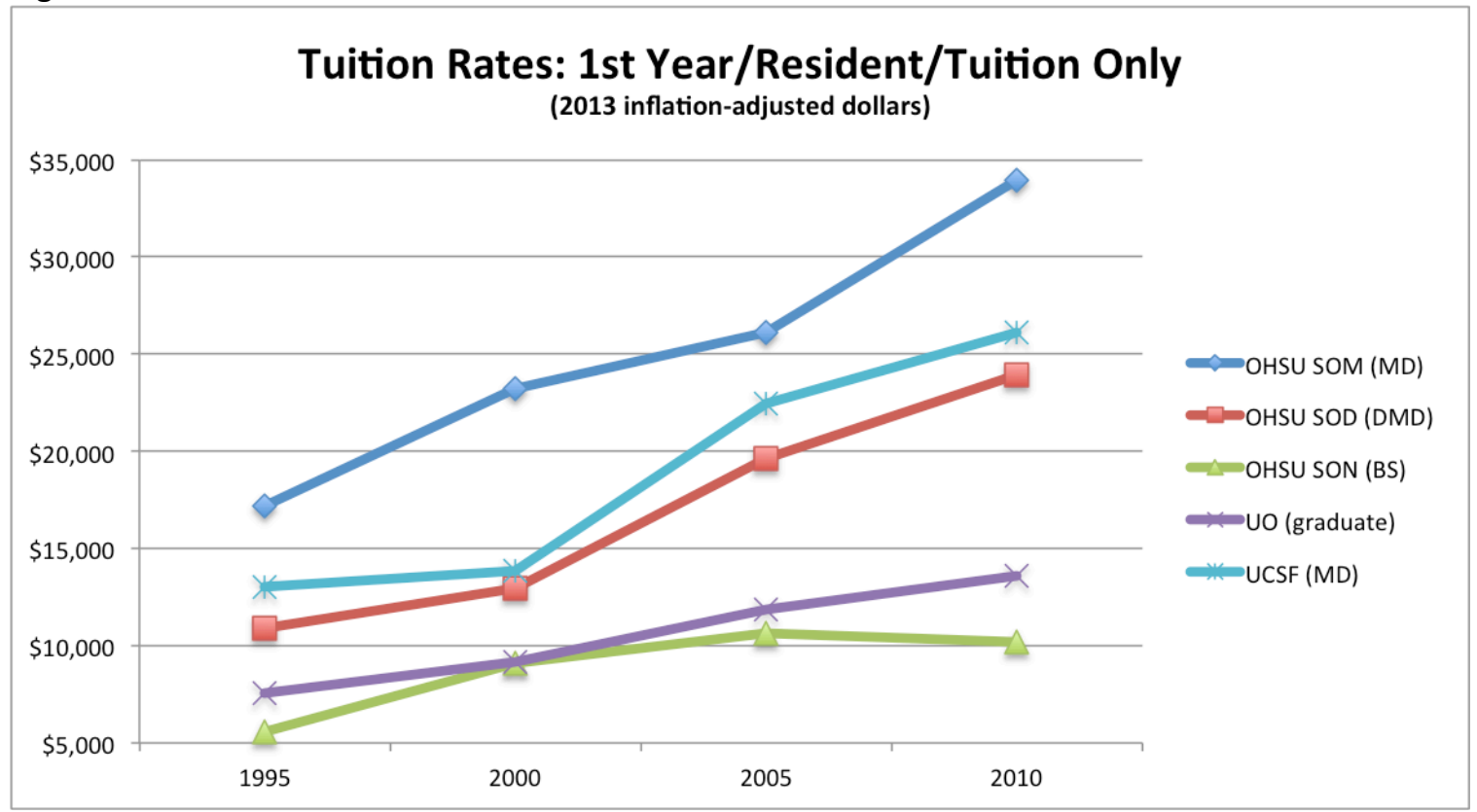

Sources: OHSU 2010a; OHSU 2001 \& 2005b; AAMC

Figure 5 illustrates OHSU's professional schools' tuition rates 1995 through 2010 as compared to graduate tuition rates at University of Oregon (UO) and Medical School tuition at the University of California-San Francisco (UCSF) during the same period. OHSU's School of Medicine tuition increased by $98 \%$ during that period, the School of Dentistry by $120 \%$. The School of Nursing had the least increases and has remained relatively flat the past few years, with an overall increase from 1995 to 2010 of $84 \%$. In comparison, University of Oregon graduate program tuition increased $80 \%$ during the period 1995 to 2010 . UCSF first year medical tuition increased at roughly the same rate as OHSU's, with some fluctuations. UCSF's tuition has remained roughly 25\% lower than OHSU's during that period. 


\section{b. Increased Productivity}

The interviews with staff and faculty revealed that as OHSU became a public corporation it shifted its focus to a more business driven, customer-focused model. Faculty felt that there was pressure to be more productive, and both staff and faculty felt there was a move to be more competitive in the Portland metropolitan area healthcare marketplace.

Figure 6: Research Grants

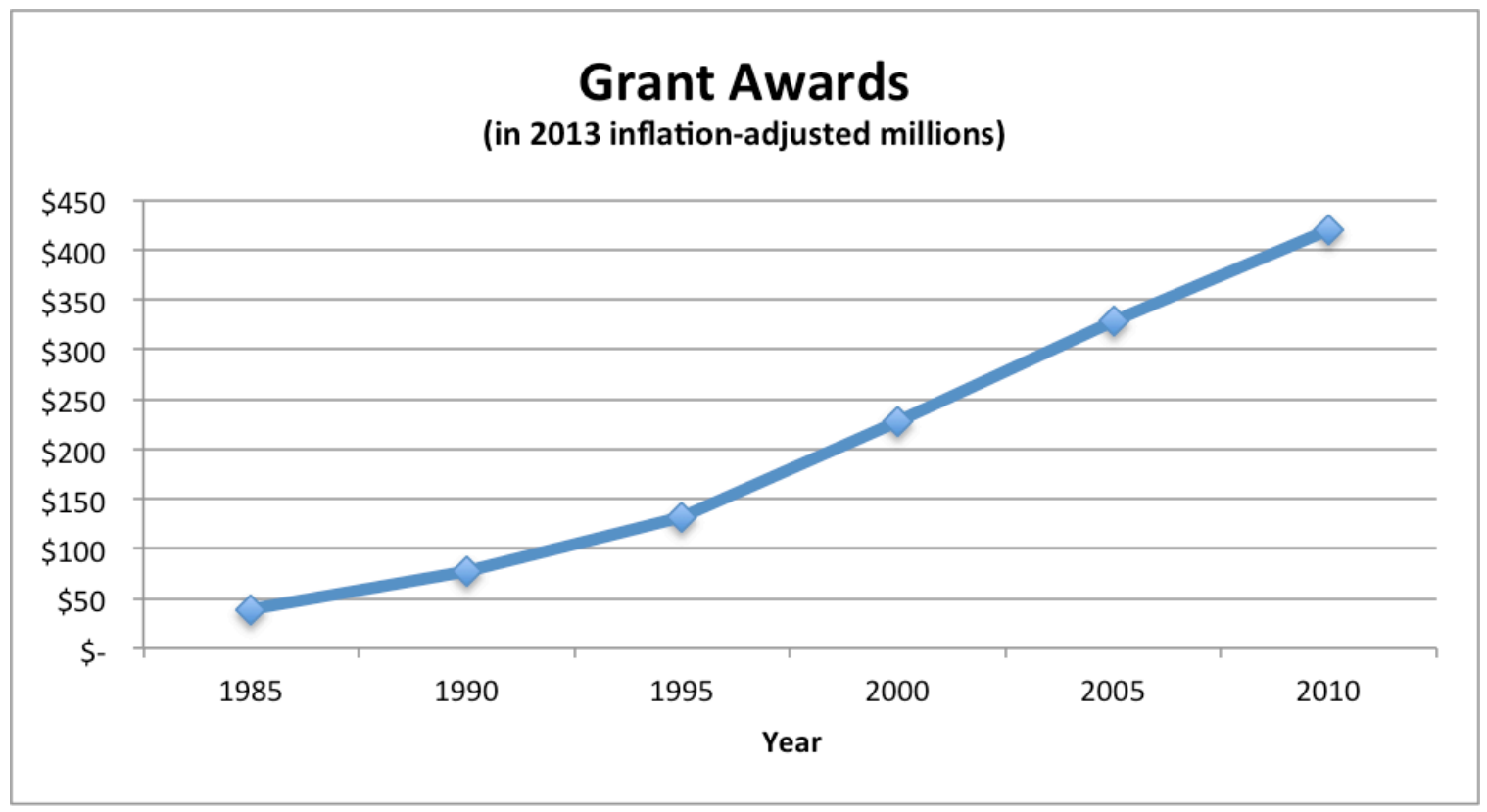

Source: OHSU, 2011

Figure 6 provides a snapshot of the increases in OHSU's research portfolio from 1985 to 2010. Again, growth of the research enterprise began to significantly increase in 1995, when grant awards were $\$ 86$ million to 2010 when grant awards were $\$ 392$ million, an inflation-adjusted increase of $219 \%$. 
During the period 1995 to 2010 OHSU increased hospital beds from 354 to 534 and total ambulatory visits from 286,982 to 686,871 . Figure 7 below illustrates the growth in hospital patients, representing a growth of $94 \%$ :

Figure 7: Number of Hospital Patients 1995-2010

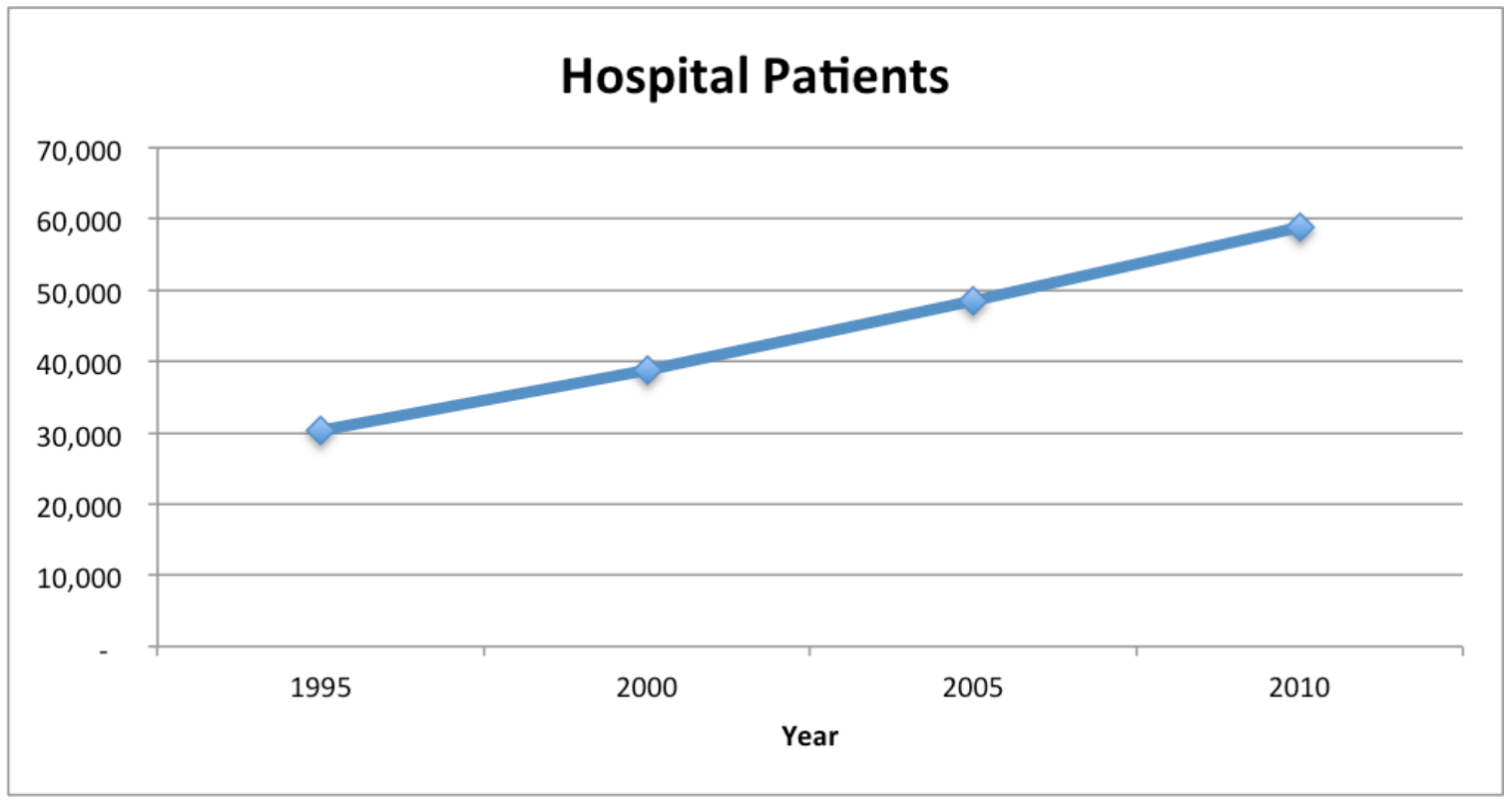

Source: OHSU, 2010a

It has been reported that OHSU's patient satisfaction levels have fluctuated (Lund-Muzikant, 2009; Rojas-Burke, 2012), with earlier reports indicating that OHSU's patient satisfaction levels were low or mid-level (Lund-Muzikant, 2009). As reported by The Oregonian (Rojas-Burke, 2012), patient tracking data can be confusing and sometimes misleading because of the multiple ratings services and surveys that exist, as well as the numerous types of rankings (overall ratings, questions relating to staff, nurses, doctors, facilities, response times, cleanliness, pain control, and more). The most trusted data is tracked by the Centers for 
Medicare and Medicaid Services (CMS) via the Hospital Consumer Assessment of Healthcare Providers and Systems (HCAHPS). OHSU's own tracking of the HCAHPS data since 2008 indicates that OHSU has seen improvement from a 63.7 overall "rate the hospital" score in fiscal year 2009 to a 73.1 score in fiscal year 2013 (OHSU, 2013b). For comparison, available HCAHPS data in the category of "how do patients rate the hospital overall" for 2011 indicate that OHSU patients rated it a 9 or 10 (highest 10) 73\% of the time, while two other Portland, Oregon providers, Providence and Legacy, were both at 74\%. OHSU ranked slightly lower, but the Oregon and National averages were both 70\% (CMS, 2013; HCAHPS, 2013).

c. Staff Satisfaction Factors: Staff Salary Data

Classified staff indicated in the interviews that generally they did not expect to get salary increases as a result of OHSU becoming a public corporation. Of the 15 responses, only four expected increases. However, after OHSU became a public corporation, eight out of 12 responded that they did feel they received notable salary increases. 
Figure 8: Classified Salary Comparison

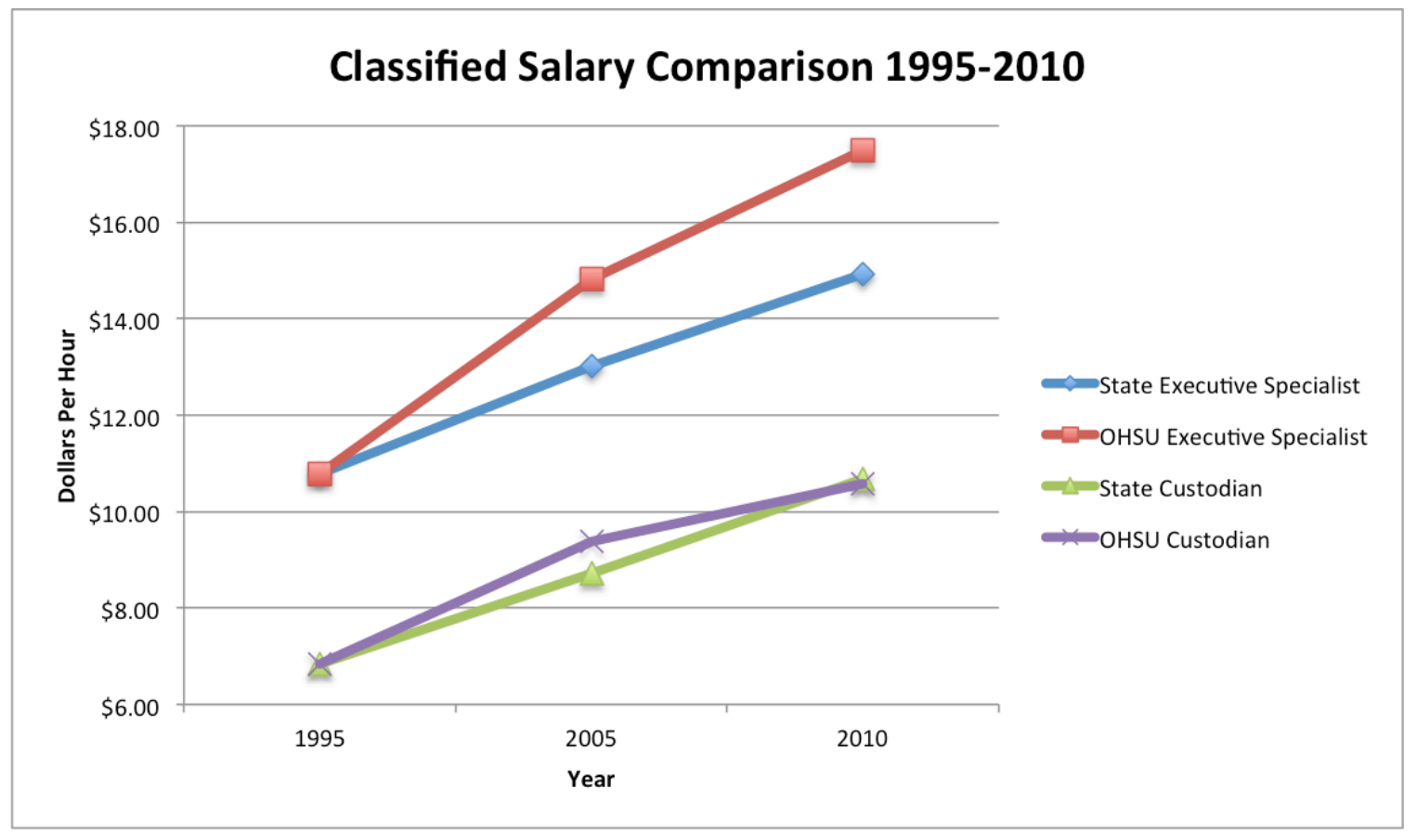

Source: OHSU, 2005c, 2010b; DAS, 1995, 2005, 2010

Staff salary data is illustrated in Figure 8. When comparing similar job classifications, for some, such as custodian, it appears that OHSU's hourly rates increased more rapidly from 1995 to 2005, but that the salaries for that position type evened out by 2010. In contrast, the OHSU executive specialist position continually increased at a larger rate than the state equivalent position, and by 2010 the difference between the two is significant, with the OHSU classification earning $\$ 2.50$ more per hour than the state executive specialist. There are many factors that influence salary data. In this particular instance the study looks only at classified, union-represented positions (not unclassified administrative or executive level positions). Also, looking at the salary data does not account for reclassifications or 
step-increases that may have occurred. The data represented here reflect two positions (custodian and executive specialist), both at step one of their classes.

\section{d. Faculty Satisfaction Factors: Faculty Tenure \& Salary}

A key element in faculty responses in the interviews, particularly for basic science faculty, was that the academic culture at OHSU was lost when the institution became a public corporation in 1995. One of the factors of the academic culture they felt was diminished was faculty tenure. According to data from the OHSU School of Medicine Dean's Office, in 1994, there were a total of 2,827 faculty in the School including visiting and volunteer faculty. Counting only those who were tenureeligible, there were approximately 682 with primary paid appointments. Of those $682,15.59 \%$ were tenure-track or tenured faculty in 1994 . Looking at the same data for 2013, there are 5,080 faculty, including those who are not eligible for tenure. Of those who are eligible, approximately 2,258 primary, paid faculty, $7.88 \%$ are tenuretrack or tenured faculty in 2013. The percentage of tenure-track and tenured faculty dropped significantly during this period.

Faculty salaries were a factor for both OHSU faculty and leadership. One of leadership's goals for the public corporation was to have more flexibility to pay salaries more aligned with an urban academic health center. Being part of OSSHE limited that flexibility. Figures 9 through 12 below illustrate the percentage of increases for the ranks of professor, associate professor, assistant professor and instructor at OHSU, Portland State University, University of Oregon, and University of Washington from 1995 to 2010. 
Figure 9: Professor Salaries

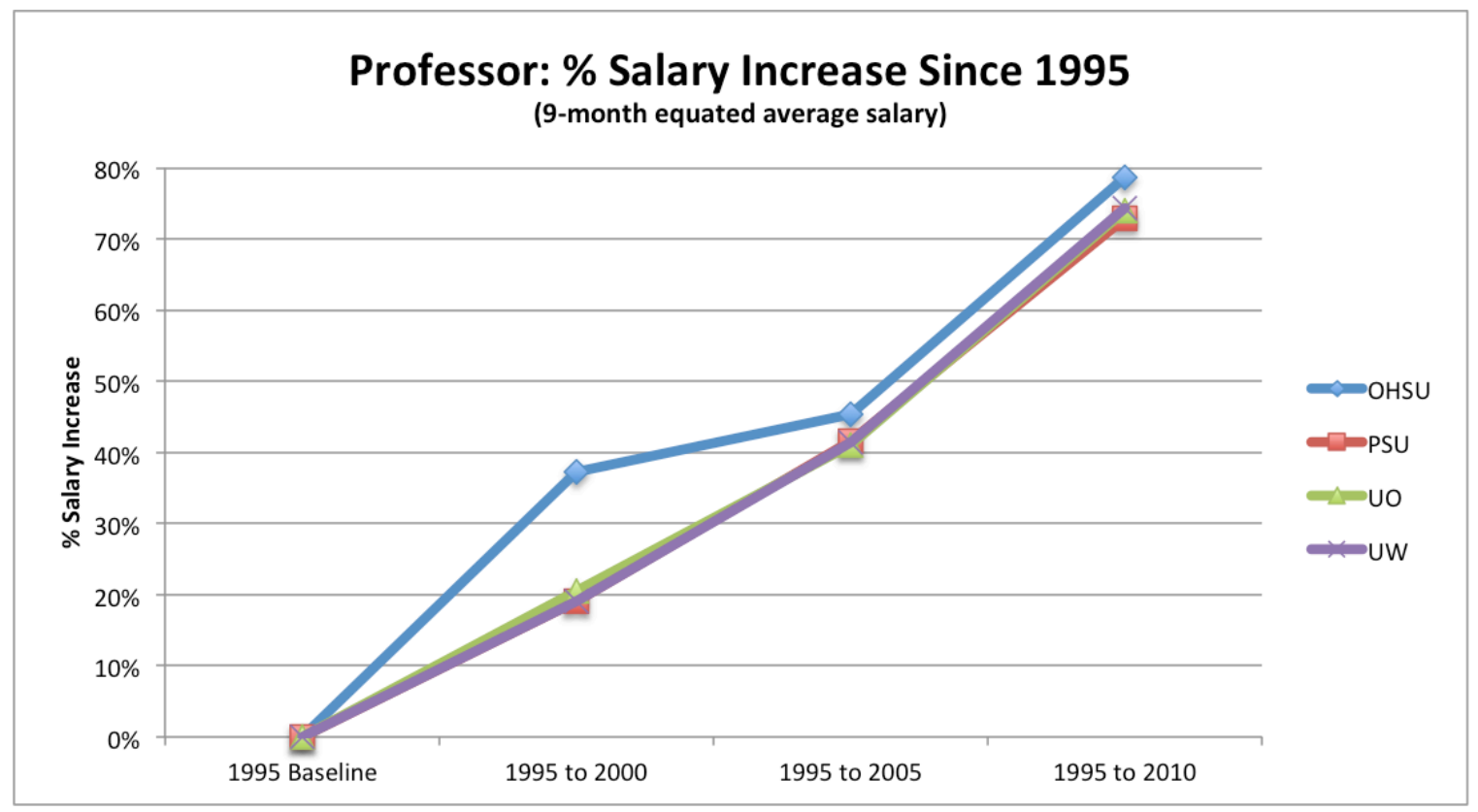

Source: IPEDS

Figure 10: Associate Professor Salaries

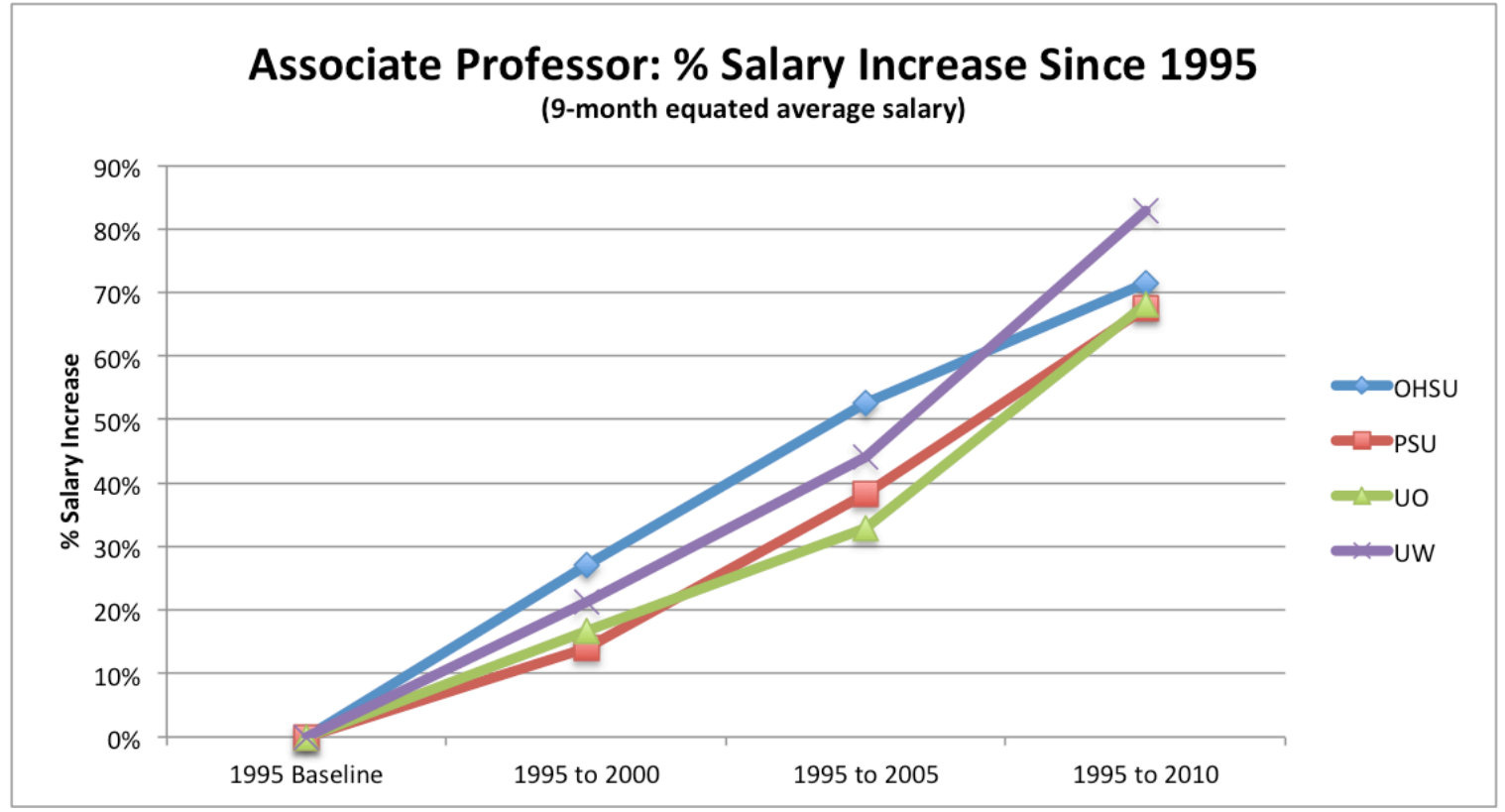

Source: IPEDS 
Figure 11: Assistant Professor Salaries

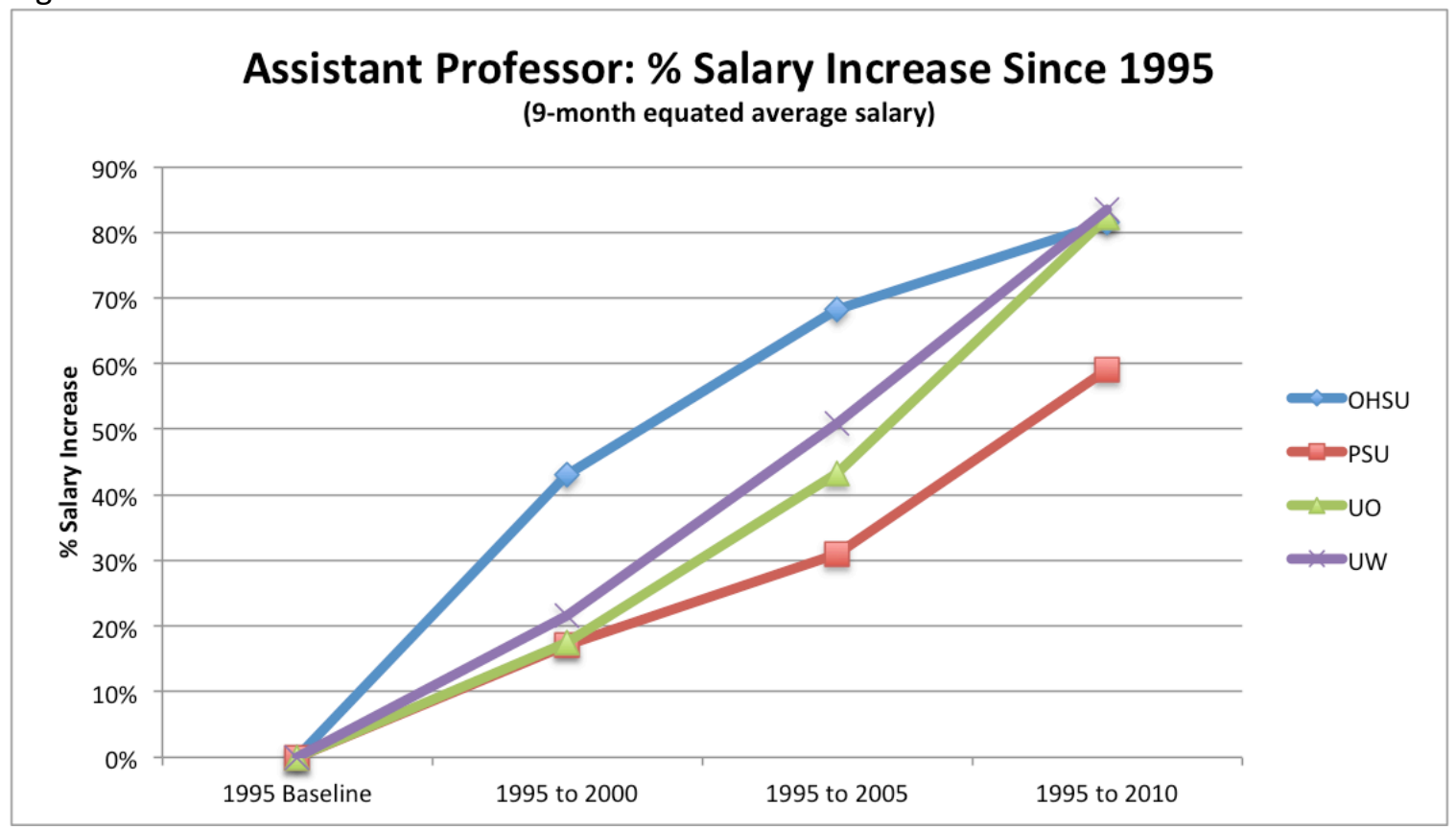

Source: IPEDS

Figure 12: Instructor Salaries

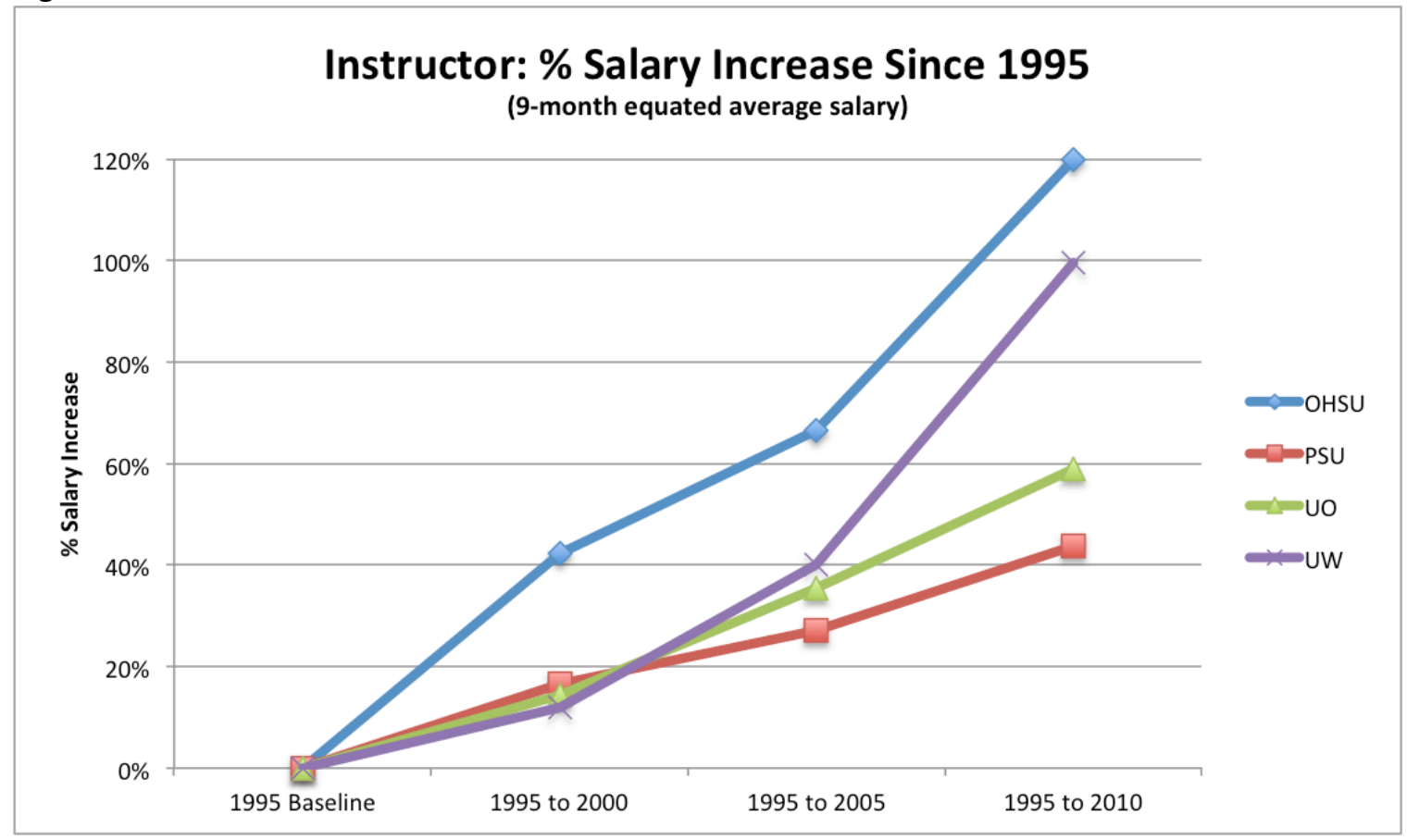

Source: IPEDS 
In almost every faculty category the data show that the percentage of initial increases at OHSU were dramatic, particularly 1995 to 2000, shortly after OHSU became a public corporation. For example, Professor ranked salaries (Figure 9) jumped by $37 \%$ in that period, while the other university salaries increased only 19\%-20\%. Similarly, the OHSU assistant professor rank saw an increase of 43\% between 1995 and 2000, while the other universities increased between $17 \%$ and $22 \%$. By this measure, OHSU's leadership were able to initially achieve the goal of increasing faculty salaries in the five years following the public corporation. However, since then, the other universities have increased salaries a comparable amount, obviating the initial OHSU advantage.

\section{Conclusion}

As universities around the country grapple with issues that force them to contemplate structural change, it is important to recognize that the staff and faculty of an institution play an important role in the success of a major organizational change such as OHSU underwent in 1995. The findings and results reported here describe the impacts that occurred as perceived by the faculty and the AFSCME staff—-two employee groups at $\mathrm{OHSU}$-in areas such as process, culture, job satisfaction, and overall impacts, as well as to faculty specifically in the areas of shared governance, academic freedom, faculty productivity, and promotion and tenure. 
The interviews were structured with questions grouped in categories according to the theme of how OHSU's transition impacted staff and faculty from their own perspectives. In order to provide a comprehensive view of the information gleaned in the interviews, the findings were reported in those same categories, by staff, faculty, and then former employees. Following the preestablished categories, additional data were presented on themes that emerged during the interview process, including OHSU's growth in physical facilities and how that made employees feel; silos at OHSU and whether and how those impact employees and the culture; the AFSCME strike that occurred shortly after OHSU became a public corporation and how that affected the employees; and how the leadership and the two employee groups interacted during that period. In order to provide a visual and descriptive account of the interviews, the data were presented qualitatively with direct quotes and paraphrasing from interview participants, followed by tables that illustrated the frequency of occurrences when coding the data with coding software.

In chapter five, these data will be further explored comparing information from OHSU's archival documents and the reported goals of the 1995 OHSU leadership and what they intended to achieve when they sought to separate OHSU from OSSHE. Chapter five will also discuss the implications of this kind of change on the organization's employees; and will tie the outcomes learned here to the literature available about these types of groups at universities and to applicable organizational frameworks; will explore the overarching themes that emerged 
during this study that can be useful to other universities contemplating this type of change; and will identify areas for further study. 


\section{Chapter 5: Discussion}

\section{A. Introduction}

This chapter explores the findings of this case study research and compares the goals of OHSU's transition to a public corporation with the perceptions of select employee groups in the context of the research questions. Also in this chapter, the relevant organizational theories are revisited with discussion of the implications of this case study in relation to those theories. With the theoretical models in mind, a proposed framework is discussed that melds elements of those existing theories as well as elements gleaned from this research into a context for effective governance change in universities. This will be followed by a discussion of the implications of this research. Finally, this chapter will close with a discussion of some of the limitations of this study and possible areas for future research.

\section{B. Comparison of Goals to Perceptions}

The leadership of OHSU articulated a number of internal and external goals when it transitioned to a public corporation; this study focuses on the internal goals that impacted the organization and its employees.

\section{i. Goals and Perceptions About Efficiency and Process}

a. Goals: Efficiency and Process

One of the primary internal goals as expressed by leadership was to improve operating efficiency. In a 1996 internal newsletter president Kohler reiterated that two of his goals were to operate more cost-effectively and in a more efficient manner and to do a better job of communicating with employees and other 
constituencies (Kohler, 1996b). Jim Walker, then CFO, in addition to increasing efficiencies, was looking to create a more professional operation where people were accountable and also innovative-with the goal that this would lead to greater efficiency. He had concerns about lack of accountability prior to the transition: "The atmosphere of the folks who worked in accounting and budgets had a culture of not having to be highly accountable because they were simply doing transactionsbecause all of the transactions were sent off to Corvallis for processing." (Interview, J. Walker, October 13, 2012). He went on to say that he quickly had to make some changes: "Within 6 months I had to let some people go. And then I had to recruit new people. That was tough on people." (Interview, J. Walker, October 13, 2012). He made these changes because he needed innovation: "You want to be creative and innovative-when we were part of [OSSHE], you had to call the Higher Ed office to ask if you can do something, they said 'no, absolutely not, this isn't done at any other institution,' and we'd say 'but we're a health sciences university, we have unique needs' - and they still said no. It was frustrating." (Interview, J. Walker, October 13, 2012). Lesley Hallick, then provost, reiterated these sentiments, adding that there were needs for new systems, including payroll and research accounting systems that would make operations more efficient (Interview, L. Hallick, August 16, 2012).

\section{b. Perceptions: Efficiency and Process}

When asking the research questions, "how do employees describe the impact of a new business model on their work and productivity levels?" and "what were perceptions about job clarity?", the theme that emerged from the research is that 
while the transition to becoming an independent public corporation caused uncertainty and perhaps pushed employees (particularly staff) out of their comfort zones, that work life and process efficiencies did improve. As described by one employee in the finance department: "We got more control over how and what we wanted done. It was rough and we made mistakes in the beginning that Corvallis could have handled without even blinking, but what we didn't know, we figured out over time." Still another employee had a similar view: "I was never worried about what changes were in store. There were many things I don't think we would have gotten to as quickly or gotten as well balanced had we stayed within the state system. So change was good." Others reported that they were "working without a roadmap" and that change was slow, but noticeable. Finally, one employee in IT put it this way when it came to changing employee attitudes: "One of the big things [before the transition] was that there was a lot of dead wood-employees with no motivation, there wasn't a big impetus to improve, or to look at duplicate processes or ask if there was a better way to get things done." He went on to say that with the transition, those attitudes began to change.

The interview data regarding employee perceptions about more or less paperwork and clarity and control over their work life mirrors the theme that staff generally felt uncertain about what the transition to a public corporation meant to them and their jobs and work-life, but that there was more efficiency gained with the separation from the state. Faculty felt less uncertainty about process, but felt that there were missed opportunities: “It's not as though it wasn't a problem at the 
state. But I think it was that 'Here was an opportunity of changing' and we haven't done a very good job." Others echoed this concern, that there was a sense of missed opportunity to really make it a more professional and efficient operation while undergoing the organizational change. While staff and faculty differed in their reflections of this, in general both groups felt there were more efficiencies, despite feeling as though there was uncertainty. This general sense that things got better was only overshadowed by the sense that there were missed opportunities to truly orchestrate organizational change at all levels.

\section{c. Summary: Efficiency and Process}

According to leadership, the goals were to find efficiencies and run OHSU more professionally - to find the administrative flexibility to make OHSU a more lean and productive-and ultimately more sustainable-institution. When comparing this goal to employee perceptions, it is clear that employees did feel that OHSU became more efficient and did improve processes. What also became clear was that the new environment allowed employees to feel empowered on an individual and department level to look for better ways to do things: "After the transition we started to get different managers and we were encouraged to make improvements. They were encouraging employees to take initiative, instead of management just being the source of control." It also provided the setting in which those who were more comfortable with a more business-oriented model could succeed, while also identifying those who were less comfortable in this new environment. This created a situation where some leaders had to make difficult 
decisions in order to run the new, more efficient workplace. Jim Walker recalls how he worried that OHSU was drawing attention to OSSHE's inefficiencies: "basically we were saying that the systems and people were inefficient and that was an insult to those who worked in OSSHE and at the state. No matter how you couch it, we were saying they were inefficient." (J. Walker, interview, October 13, 2012). Archer reiterates this in her study of OHSU: "The bottom line was that the organization 'needed to create the infrastructure for a complex, $\$ 600$ million organization from scratch ... in a year's time.' This was complicated by some lack of support from the organizations whose systems OHSU was transitioning." (Archer, 2002, p. 205).

ii. Goals and Perceptions About Employee Satisfaction and the Relationship With AFSCME

a. Goals: Employee Satisfaction and AFSCME

In terms of employee satisfaction, Kohler articulated the goals of the transition to be:

- Improved services to employees through combined and coordinated human resources, recruiting, training, affirmative action, and payroll functions;

- Continued commitment to labor-management cooperation;

- Moving total compensation packages to market levels and reward performance and merit rather than just seniority; and

- Providing more flexibility in employee health and retirement benefits.

The relationship between OHSU and AFSCME was decent prior to the transition. Interest-based bargaining had begun several years before and all parties 
agreed it was a step in the right direction. However, both AFSCME and OHSU leadership felt that having the added layer of the state involved made the relationship more challenging and both felt that the separation and removal of the state as an intermediary would improve the relationship. The goals of OHSU leadership involved maintaining a strong relationship with AFSCME before, during, and after the transition to a public corporation. Lois Davis, then director of government relations, said: "The public corporation set up a situation for a very strong relationship with AFSCME." (Interview, L. Davis, July 17, 2012). The AFSCME leadership also felt that there would be benefits of dealing directly with OHSU, rather than having to negotiate with the state. Diane Lovell of AFSCME recalled:

"From the union's perspective it was an absolute nightmare to negotiate with both OHSU and the state. The state did not care about the hospital being successful. It was a huge impediment. There was a lot of dissatisfaction. People felt that there were a lot of cultural issues. One of the reasons [AFSCME] supported the public corporation idea is that OHSU could not make business decisions. Everything had to be run by the state, everything was controlled by the state. We just knew that was an impediment to our growth and survival." (Interview, D. Lovell, January 30, 2013).

Lovell went on to articulate that the motivating factors for supporting the public corporation were tied to salaries and benefits for AFSCME members: "Very specifically the goal was to improve the salaries. From my perspective that was really where the state held us back." (Interview, D. Lovell, January 30, 2013). 
OHSU leadership began publishing an internal newsletter called "Transition News" to address specific questions about the transition to the new public corporation. Summarizing the goals for the public corporation, in the first issue (published just after Oregon's governor signed the bill to make OHSU a public corporation) Kohler stated: “This new streamlined governance structure will help OHSU carry out its missions more efficiently and effectively and respond better to the demands of a changing marketplace." (OHSU, 1995a).

In the same introductory newsletter, the leadership answered questions from employees in a Q\&A section about benefits and compensation, tenure for faculty, questions about human resources process, and more. The answers provided were consistent with what had been discussed throughout the process: that benefits would be maintained and that other retirement options in addition to PERS would be offered; that union contracts would be maintained and that the goal was to strengthen the relationship between OHSU and AFSCME; that faculty tenure would be maintained, and that the president would continue to have the power to grant tenure; and that there would be more flexibility in administrative processes, particularly human resources (recruiting, merit increases, promotions, terminations, etc.). One of the important final points stated in that initial "Transition News" highlighted that the changes would take time, particularly the human resources policies:

"Yes, the new Human Resources Department will develop guidelines that will allow for more flexibility within appropriate levels of compensation based on 
the market, the uniqueness of OHSU, negotiated union and employee groups and the laws that regulate all public employers. However, it will take time to change existing policies and procedures. Until then, OHSU will continue to follow existing state and higher education administrative rules and guidelines. We hope to create our own policies within 12 to 18 months." (OHSU, 1995a).

\section{b. Perceptions: Employee Satisfaction and AFSCME}

When asking the research question, "what was the effect on employee satisfaction when OHSU became a public corporation?", there are again a few themes that emerged during the research. Staff overwhelmingly agreed that their overall job satisfaction improved when OHSU became a public corporation-with $85 \%$ of those interviewed ( $n=11$ of 13$)$ in agreement. Faculty, again, were more mixed about their overall job satisfaction—but the slight majority in all faculty categories (mission, age group, and length of time at OHSU) felt their overall job satisfaction improved. When exploring the reasons employees felt improved satisfaction, a common and important theme emerged: job satisfaction levels were closely tied to the department or unit in which they worked. This was evident across several different topics in this study, including whether the employee felt valued, felt they were adding value, felt recognized for their work, and their perceptions about pay increases.

This variation illustrates divergent reactions and levels of employee satisfaction within different units and different positions around the university, and 
will be discussed in relation to organizational theories of Biglan (1973a \& b) and others later in this chapter. One AFSCME employee from the research mission said it this way: "Honestly feeling appreciated for what I did depended on the people I worked for and I worked for good people." And a faculty member expressed it in terms of identifying with their specialty rather than identifying with the institution: “I just don't identify myself as part of the public corporation, I identify myself, first off, as a clinician, if someone asks me what I do, I say I'm a clinician in [my department]. I don't say I work at OHSU."

As with the perceived changes to the institutional culture, these levels of job satisfaction may have fluctuated whether OHSU made this organizational change or not. This may simply be an organizational reality that existed before OHSU changed and would have continued whether or not OHSU made the transition to a public corporation. Whether job satisfaction levels were closely tied to the unit or department is still an important factor in this study and will play a role in a proposed framework for implementing effective governance change in universities, and thus it is worth including here as one of the conclusions of the research.

Compensation and benefits were a central motivating factor to OHSU becoming a separate public corporation. When asking the research questions, "did compensation, benefits, or promotion practices change? How did these impact job satisfaction, if at all?" It is clear that this topic was key to the leadership who orchestrated the change and to the staff and faculty. Kohler and Hallick established goals to increase faculty and staff pay to be at par with market standards, and to be 
more aligned with what was appropriate for an urban academic health center. This meant transitioning away from the state pay grade structure, which paid the same amount to an employee in Portland as it did to the same type of employee in rural Eastern Oregon, where the cost of living might be significantly different.

The staff and faculty did not generally have an expectation that pay would increase significantly after OHSU became a public corporation, with $73 \%$ of staff $(n=11$ of 15$)$ and over $81 \%(n=13$ of 16$)$ of faculty stating that they did not expect their pay to increase. Both groups did express consistent concern that retirement and health benefits remain in place or improve, per the discussions with the OHSU leadership prior to the transition. However, after OHSU separated in July 1995, the issue of pay did become more important, particularly to the AFSCME employee population.

This aspect of OHSU's separation was integral to the relationship with AFSCME, and through a breakdown in communications between OHSU leadership and AFSCME, this issue led to the AFSCME strike that occurred in 1995 after OHSU became a public corporation. As Diane Lovell of AFSCME described it: "The transition to the public corporation was the largest contributor to the strike, but not solely because of people's expectations." (Interview, D. Lovell, January 30, 2013). She went on to say that it was a combination of factors: previous negotiations with the state; the fact that Hallick and Walker (who were well respected and considered to be the points of contact for much of the transition) were so consumed by making the public corporation a reality that they did not have enough bandwidth to pay 
attention to the ongoing AFSCME negotiations; and a new lead OHSU representative who, in Lovell's opinion, was not suited to the negotiations. (Interview, D. Lovell, January 30, 2013).

After the implementation of the public corporation, OHSU leadership expressed frustration that AFSCME representatives expected pay adjustments so quickly, particularly when one of the arguments presented when advocating for the public corporation was that OHSU had no money independent of the state, and that it would take time to build up reserves. (Interview, P. Kohler, August 15, 2012). As described by Lois Davis, at one point right before the strike she was confronted by AFSCME representatives who said she had promised that salaries would be at market, and "We were firm that indeed that was the goal. But we never said it would happen on day one. There were some people who, in their heads, thought they would see benefits on day one." (Interview, L. Davis, July 17, 2012). Hallick confirmed that sentiment: "It was clear that AFSCME had unrealistic expectations. The strike was purely about expectations management." (Interview, L. Hallick, August 16, 2012). Before the strike, Kohler stated:

"We intend to be fair to everyone, and it is our expectation that all OHSU employees, including faculty, management and classified, be financially rewarded for their continued and valued contributions. We will continue to work toward bringing all employees' salaries in line with the marketplace, but we will have to be cautious if we want to avoid eliminating programs or causing long-term damage to the institution as a whole." (OHSU, 1995b). 
After the strike, Kohler wrote: "Although it was painful for the entire campus community, the recent AFSCME strike did provide some valuable insights that hopefully will help us all avoid a similar situation in the future." (Transition News, October 6, 1995). He went on to answer questions about the confusion that existed around timelines for getting salaries to market. The newsletter reiterated that the intent was to get salaries to market levels (by doing salary surveys and other research) but that this goal could not be achieved in a single step, that it needed to be done in stages over time. To be successful, sustainable, and ultimately profitable enough to afford salary adjustments to market levels, OHSU first had to become competitive, something the leadership contended that it could not have done as a state agency (OHSU, 1995c).

While the strike was a pivotal moment in OHSU's history, those who were involved at the time recall that it eventually strengthened the relationship between the two entities: "The relationship with AFSCME really improved from that point from what it had been historically. It became much more collaborative; a closer working relationship." (Interview, L. Davis, July 17, 2012). Hallick also confirmed that it became stronger, but that it took three years to build back after the strike (Interview, L. Hallick, August 16, 2012).

\section{c. Summary: Employee Satisfaction and AFSCME}

The goals for employee job satisfaction were directly related to pay, benefits, and a strengthened relationship with AFSCME. It is difficult for leadership to simply improve job satisfaction because there are many intrinsic and extrinsic factors that 
impact employee job satisfaction - there are rarely blanket solutions. Employee satisfaction at OHSU frequently depended on the department or field in which the employee worked and, to some extent, the type of recognition they received from their superiors and colleagues-a feeling of being valued, of adding value to the organization, and the recognition they received for their work. Pay and benefits were also important considerations, particularly since a goal of the public corporation was to move salaries-for staff and faculty-to market rates. According to the data presented in Figure 8 in chapter 4, over the period 1995 to 2010 indicate that staff salaries have increased, but that some classifications have risen at the same pace as state salaries for the same classifications. There are a number of factors that influence salary data for classified positions (the type of position, bargaining unit negotiations, market factors for each position, etc.). It is possible to extrapolate that some OHSU classifications (such as executive specialist) have risen to at or above market levels achieving the goals set forth when becoming a public corporation, while others (e.g., custodian) have risen at the same pace as state classified positions.

However, the road to get staff salaries up was not smooth. The most significant example of that was the AFSCME strike. The strike was counter to one of leadership's goals, which was to maintain and strengthen the relationship with AFSCME. The communications breakdown and lack of expectations management led to the strike, which made the road to strengthening that relationship-and AFSCME employee satisfaction in general-a slower and harder road than it could have been. 
This plays a role in the proposed framework for effective organizational change that will be discussed later in this chapter.

For faculty, job satisfaction is linked integrally to the discipline in which they work, their affiliation with the department or unit, and the perceptions of academic culture, including shared governance, tenure, and productivity. The data indicate that faculty do feel the public corporation was a success, but by only a slight margin. While they generally feel there has been more opportunity and that the public corporation did lead to improved research programs and clinical care, they also felt the loss of academic culture was significant. This was particularly true for basic science faculty through perceived diminished faculty governance and tenure practices and a new focus on the bottom line. This was identified as a concern by the faculty senate prior to the public corporation. A faculty senate subcommittee reviewed the issues related to the concept of a public corporation and identified strengths, weaknesses, opportunities, and threats. In their final report they noted the potential for finances to drive decisions: "financially productive activities might take priority over the less reimbursed activities." (Fiscal Advisory Committee Report to Faculty Senate, March 30,1993). A similar report from the Faculty Welfare Committee recommended an:

"Explicit commitment by faculty and administration to secure the primacy of the academic missions of teaching and research. There is a danger that a move to a public corporation model will diminish support for academic activities by an increased focus on the fiscal bottom line, represented by care 
delivery and its accompanying revenue generating capability." (Faculty Welfare Committee Report to Faculty Senate, April 23, 1993).

The report went on to say that the public corporation may have a tendency to view teaching and research as secondary activities, when they believed that those activities are the central identity of the university, and that students would suffer due to inevitable higher tuition (Faculty Welfare Committee Report to Faculty Senate, April 23, 1993).

Faculty salaries were also a consideration of overall satisfaction. While the interviews revealed that faculty did not have the expectation that salaries would increase, it was a goal of leadership to provide salaries more reflective of an urban academic health center, both to improve compensation for faculty already at OHSU and to be able to recruit world-class faculty. The data indicate that OHSU did achieve overall increases for faculty, particularly during the period immediately following the separation from the state, increasing professor salaries 37\% in that period. While the faculty had very little expectation of increases-19\% of those interviewed expected increases-after the separation $44 \%$ of those interviewed indicated that salaries did increase.

iii. Goals and Perceptions About OHSU's Culture

\section{a. Goals: Culture}

While the OHSU leadership did not explicitly express a desire to change the culture of OHSU, they did express goals of being more customer-focused, more competitive, and more professional in operations. Leadership acknowledged that 
these types of changes would alter OHSU's culture, but that culture change takes time: "The rapid change of administrative systems was difficult for all, and the culture shift on campus has taken a while to take root. Fifteen years in, the culture shift is in many ways still ongoing" (Kringen, 2011; Robertson, 2011). These are important factors to the culture of an organization and they had a big impact on OHSU, particularly from the employee perspective.

\section{b. Perceptions: Culture}

When asking the question, "did the campus culture and work life of OHSU change from the employee perspective?" clear themes emerged. The data showed that $69 \%$ of staff ( $n=11$ of 16$), 67 \%$ of faculty ( $n=12$ of 18 ), and $100 \%$ of former employees ( $n=5$ of 5$)$ felt that the culture at OHSU changed in some way. Staff did express repeatedly the sense that OHSU lost its "sense of family" and that there were growing pains. Some expressed this in a positive way, that it brought along with it modernization and professionalism. One person expressed it this way: "There was kind of a light that started to dawn on campus of 'let's try and change how we relate to people."”

Still others felt a loss of collegiality. This was particularly true with faculty. One faculty member in the basic sciences said: "[The transition to a public corporation] has driven us away from academics and toward big business." One faculty member who served on the faculty senate before and during the transition said that the leadership made a very convincing case about how the public corporation model would be good for the hospital and that it made good business 
sense. But he recalls not knowing what questions to ask about the potential impacts to the academic segments of the institution, and that not asking those questions ahead of time was a mistake: "In retrospect, it was like we only thought about half of the issues... But there was no real thinking through what it meant to the academic mission." A faculty member in the School of Nursing put it this way: "We lost the academic culture, principles, philosophies...that we had as a benefit of being part of the [state system]." Still other faculty, also who served on faculty senate, went on to describe it this way: "There was a notion on the faculty senate that OHSU was referred to as 'OHS-Inc'." While some faculty did see the upside of making OHSU sustainable through a more business-focused model, the overarching sentiment was that it was an academic institution and that a business model doesn't necessarily serve academics well. As stated by a faculty member in the library:

"It became all about the bottom line. It became less about how we are helping create the physicians and nurses for the state, although that was also one of the lines that was used, and it was all about how... if your program is not making money then why are we continuing to support it. And I think that piece of the culture has grown and continued to this day."

Faculty also tied this loss of academic culture to the increased pressure to be more productive, whether it was in terms of increasing the number of externally sponsored grants or in terms of increasing the clinical output by seeing more patients. 


\section{c. Summary: Culture}

It is important to note that the culture of an organization reflects the values and norms of that organization and the culture does evolve naturally over time. The cultural changes that employees at OHSU noted in the interviews may very well have occurred regardless of the transition to the public corporation. As a counterpoint, the cultural changes that employees, and particularly faculty, perceived were in some cases directly related to the change to a more businesscentered model. In other words, the changes that some staff and faculty noted that related to the growth and a less close-knit feel may have occurred naturally, as they might have done in any organization that is growing. However, the changes related to OHSU feeling less like an academic institution and more like a business may be directly correlated to the change in governance in 1995.

The issue at hand is not whether OHSU's culture did change, because most agree that, to some degree, it did change. In addition, the issue is not whether the culture would have changed with or without OHSU becoming a public corporation. OHSU's culture would likely have changed regardless, due to changing internal and external factors and the environment in general-the factors that make all institutional cultures change and evolve. The question at hand in this study is what the separation's impacts to the cultural changes were on specific employee groups. In this area, the outcomes differ depending on the type of employee you were and the area of the university in which you worked. This is directly tied to the research 
findings regarding employee identification more with their individual groups than with the larger organization.

AFSCME staff reported that they felt somewhat unsettled about working without a roadmap, but many reported that they felt empowered by the challenges of finding new and more efficient ways to do their work with fewer perceived barriers. In general, while some felt a loss of a smaller, more close-knit family operation, many reported experiencing the feeling of a new era dawning that allowed for freedom to do their job and flexibility to find solutions with less bureaucratic oversight. In contrast, the faculty had less reaction to the freedom to improve processes and more reaction to the sense of loss of the academic culture of the university. Again, this was not a universal perception, as a number of faculty felt that the cultural shift brought world-class researchers and clinicians to OHSU which lifted the institution up significantly. One faculty member recalled feeling a sense of pride at OHSU's investment in infrastructure that enticed physicians and researchers to come from around the world.

Were the goals for the public corporation achieved with regards to OHSU's cultural presence? Since this was not a specifically stated goal, the answer is less obvious. After OHSU became a public corporation, the internal culture did change and did aid in achieving the goals that the leadership envisioned: an administrative workforce more focused on professionalism, accountability and efficiency, and a business-oriented institution more focused on scientific and patient-care excellence. Faculty, however, were mixed about the emerging cultural changes, some believing 
the changes would make OHSU a better place, particularly for clinical excellence, while others were concerned it meant the loss of academic culture in the traditional university sense.

iv. Goals and Perceptions About OHSU's Faculty

\section{a. Goals: Faculty}

Lesley Hallick articulated the goals for the faculty, which included analysis of faculty salaries: "[For the] faculty at OHSU, we started pegging salaries to national data so we could figure out where people should be." (Interview, L. Hallick, August 16, 2012). Hallick, Kohler, and Walker all reported that they spent a good deal of time working with faculty to ensure they understood the reasons for the public corporation. Hallick stated that there were many internal discussions because some thought the academic mission was threatened by the notion of the public corporation: "[There were] countless progressions, with stalls in between; we talked internally a lot...we built the case with the unions, the faculty senate-some thought it would destroy the educational mission." (Interview, L. Hallick, August 16, 2012). Walker concurred and said that he and Hallick attended many faculty senate meetings together with a consistent message: "Lesley Hallick and I had to walk into a lot of meetings together-locked arm in arm to present a unified approach of the information we had to present." (Interview, J. Walker, October 13, 2012). Kohler felt that it was critical to have faculty support and that it was a "crisis situation" based on the passage of a state tax-limit initiative, the competitive healthcare marketplace, and the inflexibility of the state system: 
"This was one of those situations where crisis action needed to be takenand we were able to present it that way. We had a faculty retreat and Lesley Hallick ran that. The faculty had to understand that this was something that was going to be good for them. We kept talking to them." (Interview, P. Kohler, August 15, 2012).

In terms of shared governance, Hallick, who worked most closely with the faculty, did not feel faculty life was going to change significantly after the transition to a public corporation and that faculty would have the same role in the public corporation as they did before. She reflected back: "I don't actually think the public corporation changed the faculty governance model very much, if at all. It was and remains advisory." (Interview, L. Hallick, August 16, 2012). She went on to explain that the structure was different at OHSU because of the nature of the academic health center: "[Historically] it was a weak shared governance model at OHSU, which was different than most [traditional] universities." (Interview, L. Hallick, August 16, 2012). As a key component of faculty satisfaction, leadership also indicated that tenure practices would not be disturbed - that all tenure rights would be maintained and continue to be managed by the president's office (Archer, 2002; OHSU, 1994b).

\section{b. Perceptions: Faculty}

When asking the research question, "for faculty, were there perceived changes in promotion and tenure practices, expectations about faculty productivity, and shared governance?", the faculty have strong reactions and reflections which 
play an important role in the overall impacts of the transition to a public corporation from the employee perspective. In most other categories, faculty perceptions were mixed, with no overwhelming majority one way or the other. It is a different story when faculty reflect on the core issues that relate to the academy: shared governance, faculty productivity expectations, and promotion and tenure practices. In these areas there is much more consensus among the faculty interviewed that the 1995 transition to a public corporation was a seminal point that changed OHSU from academy to corporation.

This was particularly true when faculty interviewed reflected upon shared governance practices and expectations about faculty productivity. Over $93 \%$ of the faculty ( $n=15$ of 16$)$ felt that shared governance decreased, or did not improve, after OHSU became a public corporation. As one faculty put it: "Becoming a public corporation did not help faculty." Still another faculty member, who served on the faculty senate, recalled that the faculty senate used to ask the administration for approval to meet with the board of directors, but that opportunity never happened, making the faculty feel that it was not a priority. One basic science faculty member went on to declare that the faculty had no choice in the matter: "I know that faculty senate approved it, but I also know from people who were at that faculty senate meeting that they basically were browbeaten into submission."

Another area where faculty felt that academic life changed was in expectations about productivity - in terms of research, teaching and healthcare delivery. $70 \%$ of the faculty ( $\mathrm{n}=12$ of 17 ) felt that expectations of productivity 
increased after OHSU became a public corporation. This was followed by comments that OHSU became more bottom-line driven. One faculty member felt that the message from administration after the public corporation was: "You are on your own, don't expect help." The notion of having to support yourself was reflected in several interviews-for researchers, if you lost your grant funding, you also lost your salary. For clinicians there was increased pressure to see more patients. Finally, the evolution of tenure practices at OHSU also registered with faculty, the largest portion of those interviewed ( $\mathrm{n}=7$ of 16$)-44 \%$-believing that tenure declined when OHSU became a public corporation.

\section{c. Summary: Faculty}

The disconnect between faculty perceptions versus leadership's recollections of an approach that engaged faculty in shared governance and other faculty-specific matters is one of the significant divergence of perceptions revealed in this study. The faculty interviewed believed their role in guiding OHSU was diminished during and after OHSU became a public corporation, while the leadership felt that faculty life in terms of shared governance did not change significantly and that faculty were consulted as much as they had been in the past. This will be discussed further in the proposed framework for implementing change, in terms of a potential missed opportunity that might have made the transition smoother for faculty.

For the leadership, a goal was to be able to have more flexibility to recruit the strongest faculty to build bigger and better programs: "[the separation] worked well. You can see the result: OHSU is one of the strongest academic health centers in the 
country. We've been able to expand the campus and build up our research program." (Interview, P. Kohler, August 15, 2012). In general, the expectation of increased productivity was not articulated by the leadership prior to the public corporationthe economic factors were tied to the new business-oriented nature of the institution.

The goals discussed by OHSU leadership indicated that they believed the faculty played an important role and stated that they made it a priority to include the faculty in the public corporation discussions and decisions. Kohler made a point of working with all of the stakeholders: "[I was] worried about changes and how people would view it...so I spent a lot of time working with the various constituencies." (Interview, P. Kohler, August 15, 2012). He also felt that the faculty were included at the Board of Directors level: "The faculty got to see the board in action and I think they felt it was going to be all right." (Interview, P. Kohler, August $15,2012)$.

Lois Davis concurred that the faculty had ample opportunities to provide feedback during the lengthy discussion period and that there was not a lot of pushback or protest. (Interview, L. Davis, July 17, 2012). Lesley Hallick attended many faculty meetings and led many faculty discussions during the planning and preparation time and felt that faculty input was as important as ever. (Interview, L. Hallick, August 16, 2012). In an internal memo to faculty senate, the leadership wrote: "OHSU would retain its character as a public university; however, the 
structure of a public corporation would create opportunities for efficiencies that OHSU does not currently have." (OHSU, 1994b).

Faculty tenure has evolved since OHSU became a public corporation, and new approaches to faculty appointments have emerged, such as annual fixed-term and rolling appointments, that have resulted in fewer faculty attaining tenure-track and tenured positions at OHSU. Tenure in the School of Medicine dropped by half from 1994 to 2013, potentially a function of OHSU's more business-driven model, and a concern of the faculty (particularly the basic science faculty) that was identified prior to the public corporation was realized.

\section{v. Goals and Perceptions About OHSU As a Customer-Focused Business}

\section{a. Goals: Customer-Focused Business}

Kohler emphasized that he envisioned a new competitive spirit for the public corporation:

"The creation of a public corporation for OHSU gives us the tools we need to compete in demanding, dynamic markets. Our demonstrated commitment to excellence helped convince key constituents that we could handle the transition and manage our own future. Superior customer service, to our patients and to one another, will be our hallmark as we move forward. Our commitment to quality education, cutting edge biomedical research, the highest standard of patient care as well as a productive work environment will guide the transition priorities." (OHSU, 1995a). 
He said a number of times that he didn't want to change OHSU's missions, but that he wanted to change how OHSU did business (OHSU, 1995a; Oregonian, 1994). Driven by state tax limitations, healthcare reform, and a new competitive external environment, one of his goals was to have a customer-focus and a business-driven model.

\section{b. Perceptions: Customer-Focused Business}

When asking the research question, "did OHSU become more bottom-line and/or customer driven and, if so, how did that impact these employee groups?", it is clear from respondents that OHSU did become more bottom-line driven and business oriented. It was one of the established motivating factors of OHSU's separation - to become more responsive to customers, competitive, and efficient and nimble in operations. There are an array of reactions to this transitionpositive and negative. A clinical faculty member who felt the loss of academia put it this way: "Focus quickly became percentage of healthcare market in Portland. Not on an academic health center." In contrast, another faculty member put it this way: "As a faculty person I viewed it very positively. Again, it's hard to know what would have been possible or could have been possible without [becoming a public corporation], but I feel that our position, and my professional position, was enhanced by the flexibility that institutionally occurred, because it created infrastructure and allowed for everything that occurs in research services to progress and moved our institution forward." 
$81 \%$ of staff ( $n=9$ of 11$), 53 \%$ of the faculty ( $n=8$ of 15$)$, and $80 \%$ of the former employees ( $n=4$ of 5 ) interviewed felt that OHSU became more customerfocused and shifted toward a competitive business model rather than a traditional university model when OHSU became a public corporation. A staff member put it this way: "I don't think we would have been able to grow the way we have if we hadn't [become a public corporation]. And really, even though we are public or quasi-public, we are competing with private entities. My perception is that we are competing quite a lot. We are competing in supply chain, finances, staffing. All these things fit together to form a competitive organization."

Still, some faculty tied the pressure to increase productivity with the shift to a more competitive business model. One faculty member said: “...the justification that we must grow and compete has become an end in itself."

\section{c. Summary: Customer-Focused Business}

The data indicate that the number of patients OHSU served began to increase significantly after 1995 (see Figure 7 in chapter 4). While the growth may indicate that OHSU did shift to a more customer-focused model, the patient satisfaction data is mixed as to whether that effort was completely successful. Staff and faculty did feel that the shift to customer-focus was noticeable and comments from interview participants indicate that it changed, in some ways, the way they did their jobs.

The leadership felt that a business-oriented model was key, but that not everyone understood that or was comfortable in that reality: "We had to deal with issues around getting people to think of OHSU as a business-raising tuition was 
part of that. People had trouble dealing with that." (Interview, L. Hallick, August 16, 2012). Hallick went on to say that the leadership "began to change the culture to make economic models and be more business-oriented. And we promulgated the notion that if you bring in money; you get to spend more money." (Interview, L. Hallick, August 16, 2012). Further, she believed that the cultural changes at OHSU were driven primarily by the new fiscal policies rather than the notion of being a public corporation. There was a belief that the change to a public corporation led to big improvements for OHSU:

"The big cultural differences: we could DO things. [We could] execute contracts, partnerships, etc. in reasonable timeframes. The business community wanted to start doing business with OHSU. [We still had] public disclosure-it was part of SB 2. But we could move in a reasonable timeframe." (Interview, L. Hallick, August 16, 2012).

vi. Goals and Perceptions About OHSU's Leadership

\section{a. Goals: Leadership}

OHSU leadership had a clearly defined vision of where they wanted to take the university. While it may not have been clear how to get there, they felt they were doing the right thing. Kohler described how the team functioned: "Lesley always said that I never told her exactly what to do, but I always told her to do the right thing.” (Interview, P. Kohler, August 15, 2012). As Hallick explained: “We just kept adapting." (Interview, L. Hallick, August 16, 2012). 
The leadership team felt a sense of urgency about the public corporation, primarily due to the situational external factors bearing down on the institution. Kohler felt strongly that having a cohesive leadership team was key to the success of the endeavor (Interview, P. Kohler, August 15, 2012). He did agree, however, that it was inevitable that OHSU's administration would eventually grow: "In the early days [after the public corporation], we had a very small executive team. As time went on, it got bigger and bigger, and it got a little unwieldy. I was always looking for ways to get back to a smaller working group, which gets harder and harder to do because you've created a bigger bureaucracy." (Interview, P. Kohler, August 15, 2012). He learned that success hinged on having the right people at the table: "One thing that I have learned is to have good people around you." (Interview, P. Kohler, August 15, 2012). Hallick concurred, reiterating that everyone involved firmly believed the survival of the institution was at stake and that convincing all of the stakeholders was directly tied to that. She also felt that faculty were included in important decisions and that they had worked through the angst: "There was never a huge rally and cry that our problems afterward were the fault of the public corporation...it was always clear that the programs were better off." (Interview, L. Hallick, August 16, 2012).

\section{b. Perceptions: Leadership}

One of the themes that emerged from the research with staff and faculty, but was not explicitly asked during interviews, was the theme of leadership's role as OHSU withdrew from the state system and became a public corporation. In general, 
the faculty indicated that their perception was that at first the bureaucracy shrank and processes became more efficient, but then that OHSU "grew it's own bureaucracy" that became as big, if not bigger, than before. Some of this they attributed to decisions made at the leadership level. Faculty did feel that the separation from the state was successful overall, as stated by this faculty member: “...after the change in status it became apparent that there was a reach to reduce barriers to reach higher. Separating out from under [the state] was wonderful because we were not subject to the same restraints as public schools or colleges."

However, there were concerns about administration after OHSU became a public corporation - that there was a move away from the academic mission and that the new board of directors did not understand the academic institution. One faculty put it this way: "The salaries and the administration expanded a lot. And that made me distrust the process." Still another faculty member recalled this: "Along with the public corporation came a really large university administration. We went from way too skimpy to having a huge administration." Along with these concerns were faculty perceptions that the board of directors was only interested in the bottom line, particularly with limited or no representation by academics on the board: "It is unusual for a board of a large university to not have academic credentials on it. At traditional universities, the board's heart is in academics, and the ancillary aspects...are and should be secondary." A faculty senate report prior to the public corporation identified this as a concern: "An institution run by business 
people instead of academics may have philosophical differences" (Faculty Senate Summary of Concerns, Undated).

There were concerns expressed that the administration was growing larger than the education mission and that faculty and graduate student support dropped in order to support the increased administration. This led some to mistrust of leadership, who some felt had sold [the faculty] on the idea that the public corporation would become a lean, efficient organization, only to eventually become another bureaucracy.

Still, many faculty expressed faith in the 1995 leadership team—that they did include the faculty in the process, that they communicated what it meant to the organization and the vision, and that it meant survival for OHSU: "We knew that was happening. We had the opportunity to provide input if we wanted to. They were good at selling it. We bought it." There were many who felt that it was not just a good sales job, but that the leadership expressed their vision and executed it as best they could. Still others expressed appreciation for the leadership foresight in getting OHSU out of the state system and for bringing the opportunities that freedom presented. Trust and respect for the leadership was also high among staff who described the leadership as sincere, passionate, and "good people".

\section{c. Summary: Leadership}

While successful leadership is not a specifically-stated goal to be achieved by becoming a public corporation, it emerged as a significant theme and should be discussed as a conclusion. It also plays a role in the proposed framework for 
effective governance change. OHSU had charismatic leadership and that was an integral factor in how employees perceived and reacted to the transition to the public corporation. Kohler, in particular, clearly expressed his vision for where he wanted OHSU to be and how he believed it could and should get there in a model similar to that described by Beckhard \& Harris (1987). He assembled a strong leadership team who banded together to achieve this vision. Hallick recalls: "We had to be our own support group-there was a lot to get done and not a lot of time to do an inventory of our accomplishments." (Interview, L. Hallick, August 16, 2012). Further, Kohler recalled: "I knew the endpoint, but relied heavily on an excellent group of people to do what was necessary along the way to get it done." (Interview, P. Kohler, August 15, 2012). The pressure of the transition “...taxed the leadership skills of the administrative team and line managers. There were different and, in some ways, more demanding accountabilities placed on the organization's leadership and management groups" (Archer, 2002, p. 202). The leadership team clearly had established a great deal of trust-amongst themselves, throughout the organization, and externally. While trust is not the only element to effective leadership, it is vital to achieve key goals: "trust is lubrication." (Bennis \& Nanus, 1985, p. 43).

A lot of the success of the public corporation depended on Kohler and his leadership team. A measure of success includes OHSU's ability to expand its physical presence with additional research and clinical buildings and to do so in timeframes that allowed it to be efficient and competitive. As Hallick described it, from 1995 on 
OHSU was able to run construction projects on time and on budget and she considered that a significant impact of the public corporation (Interview, L. Hallick, August 16, 2012). Another measure of success includes OHSU's research growth since 1995, and its ability to attract the world's leading researchers and to become a top biomedical research institution in the eyes of the National Institutes of Health, as highlighted in the research growth (Figure 6). In addition to other data, Figure 6 identifies OHSU's research growth trajectory from 1995 to 2010. The data illustrate the realization of Kohler's vision that if OHSU became a public corporation he would be able to recruit the top researchers and build research buildings in order to grow the research mission.

However, other measures indicate the public corporation was not completely successful, including the rapid expansion leading to increased debt and a decreased credit rating. It also led to increased tuition rates in OHSU's professional schools and programs, to the point of being at the high end of the tuition spectrum nationally, as described in Figure 5 in chapter 4. Figure 5 highlights OHSU's tuition rates 1995 to 2010. The tuition increases equate to an overall increase of $98 \%$ in the School of Medicine through 2010, resulting in the third highest tuition rate for a public medical school in the nation (Oregonian, 2013). The data confirms one of the concerns identified by the faculty senate and others prior to the public corporation.

Archer's report discussed the increased need for capital for physical expansion: “Large building projects were underway and others were needed and anticipated. This created the need for access to large amounts of capital. Capital 
needs were far beyond the amount available through state resources." (Archer, 2002, p. 119). The role the leadership team played in how OHSU conducted its affairs to become a public corporation and then to manage as one is integral to how OHSU has shaped itself in the last 20 years. And the perceptions of the employees about that leadership are important to how universities go about implementing large-scale change. By most accounts, the leadership team were well- respected and trusted by staff and faculty. As staff and faculty have articulated throughout this study, they relied on information from the leadership team to understand and to ultimately buy-in to the proposed change. The staff and faculty also felt that it was a time of opportunity—and that some opportunities were seized, while others were missed.

The role of institutional leadership in the successful transition to a new governance model is a key component of organizational change generally, and was specifically critical at OHSU. This is a factor that will be discussed in relation to the organizational theories later in this chapter, as well as in the proposed framework for successfully implementing change in universities.

\section{Discussion of Framework for Effective Governance Change In Universities}

Looking back at the purpose of this study, it was to determine the impacts to specific employee groups when universities undergo significant organizational change. Specifically, this case study of OHSU and its transition to a public corporation in 1995 looks at how the change impacted faculty, and also unionrepresented staff, from their own perspective. Based on the research conducted for 
this study, combined with relevant organizational theories, it is possible now to meld elements of the existing theoretical models with the new knowledge obtained from this research project. This allows for discussion of a framework that incorporates lessons learned and illustrates effective tactics for implementing governance change in universities.

This framework has two key components-an understanding of the organizational structure and how to leverage that understanding to effectively implement change; and effective leadership across the structure, demonstrating an understanding of what needs to happen and leveraging the clout leadership possesses to make it happen. This framework discussion consists of three primary components that incorporate theory and capitalize on tactical opportunities, actions, and outcomes. Layered over these opportunities, actions, and outcomes are two considerations that require a situational assessment in any attempt to make change in an organization: first of the environment, and the second, of the timing.

\section{i. Opportunity, Action, Outcome 1: Acknowledge and Embrace What Exists Now} (Culture, Structures, State)

As identified by Kezar (Kezar \& Eckel, 2002a), Tierney (1988), Biglan (1973a \& b), Baldridge (1971 \& 1978), and Beckhard \& Harris (1987 \& 1997), in order to realize change you must recognize, understand, embrace, and engage the multiple cultures and structures that exist within the organization. These can be formal or informal groups or structures, recognized or unrecognized social groups, or groups who possess authority in a formal or less formal manner. Whatever the group and 
whomever is part of it (faculty, staff, students), it is important to acknowledge the existence and understand how they can play a role in facilitating change for the organization.

Biglan studied universities from the perspective of how and with whom people within the university identify and feel allegiance or loyalty. His research showed that employees, particularly those in the sciences, felt allegiance and ties to their scientific and academic foci, rather than to the organization as a whole (Biglan, 1973a \& b). This distributed approach of employees being more aligned with their departments or units is borne out in other literature (Baldridge, 1971; Cole, 2009) and in the research with OHSU's employees-who felt job satisfaction, recognition, and value based on identification with their individual departments. This may have been the case if OHSU had become a public corporation or not, but it is a factor to consider when implementing organizational change in universities. This knowledge can be applied to how universities best plan for and adapt to strategic change in the institution and the importance of taking the distributed and informal structures of the university into account.

In addition, Adrianna Kezar studied change at universities theorizing that in order for universities to embrace change there has to be a recognition of the existing culture (Kezar \& Eckel, 2002a \& b; Kezar, 2005; Kezar, 2006). She found that broad organizational strategies were just that: too broad and lacking in nuance of understanding what the university really was (Kezar \& Eckel, 2002a). However, she also found that getting too entrenched at the micro-level of the university was also 
inadequate. It was helpful in understanding the diverse issues of the university, but got too specific to be helpful even to other departments within the same university (Kezar \& Eckel, 2002a). Ultimately, Kezar found that a middle-ground can be found by recognizing the culture(s) that exist within a university and approaching the proposed change by recognizing and embracing those cultures: "The distinct nature of the campus cultures cannot be overlooked in trying to understand how change processes unfold and which strategies institutional leaders should emphasize." (Kezar \& Eckel, 2002a, p. 456).

As OHSU prepared for the governance change in 1995, the approach to planning and implementation proceeded at the institutional level. As has been identified in this study, by faculty in particular, and also AFSCME, this approach led to the belief that there were missed opportunities to look at the organization from the perspective of the various existing formal and informal structures. The conclusions of this study reinforce the significance of decentralized authority in such sweeping change. Thus, the opportunity here is to understand that there are distributed pockets of influence and power throughout the organization and to recognize these formal and informal structures, cultures, and groups. A key example of this at OHSU is the distinction between basic science and clinical faculty. While the needs of some (clinical faculty) were met or exceeded, the needs of others (basic science faculty) were not fully addressed and questions remained about the wisdom of the public corporation. The opportunity was to recognize the distinction at OHSU that there were subgroups of influence within the faculty. 
As Kezar (Kezar \& Eckel, 2002a) recommends, it is important to step outside the organization ("get on the balcony") and look inside to fully identify the key stakeholders. The action here is to engage these groups in productive manner. Similar to interest-based bargaining between management and unions, this is an interest-based process. Interest-based bargaining is based on a mutual understanding between the negotiating parties. The concept behind it is that if each party understands the issues that are important to the other party-particularly issues that are a high priority and those that give cause for concern-then the negotiation will be based on mutual understanding and a process of searching for solutions to common goals, rather than adversarial as negotiations of this nature have been in the past.

This engagement can be a useful tool. Leadership, who is most often the initiator of organizational change, would be well-served to lay out the high priority items and those that cause concern so that key internal stakeholders (all of these formal and informal groups) can participate in the process. Discussing the issue with each others' interests in mind puts each party in the other's shoes-empathy and identification can be powerful tools.

Two other theories come together to help us better understand structures of universities and aid in the discussion of the case study of OHSU, that of Mintzberg (1983) and Baldridge (1971 \& 1978). As we have determined OHSU, like other universities, is a complex and distributed organization. Mintzberg's research asserts that the more complex an organization, the more distributed and decentralized it is 
likely to be (Mintzberg, 1983). His model for the university is the professional bureaucracy, with the faculty (or the technical experts) as a operational core of the organization-the group that is responsible for the output (Mintzberg, 1983).

Mintzberg's theory is aligned with what we have already determined to be the case: the university is a distributed and decentralized institution where the power can lie in several places, and for Mintzberg lies primarily with the professional/operational cores. This is consistent with the theories of Baldridge (1971 \& 1978), Biglan (1973a \& b), and Tierney (1988 \& 1998). It is also aligned with what we have learned about OHSU through this research project. OHSU's complexity lends itself to what Mintzberg describes as complex and decentralized. In the interviews with current and former staff and faculty, it became apparent that alignment and loyalty within OHSU frequently happens at the department or unit level rather than at the centralized level. This pairs with Biglan's (1973b) belief that faculty in specific disciplines, particularly the "hard sciences"—-such as the basic sciences at OHSU—see the world differently depending on their discipline, and affiliate with each other (sometimes exhibiting the same traits), marshalling resources and alliances together (Biglan, 1973b).

Baldridge takes these ideas further-helping to define the informal structures, interactions between groups, and pockets of influence that exist in universities. As described in chapter two, Baldridge identifies the collegial, political, and bureaucratic aspects of universities. He also describes academic units as loosely connected confederations with varying agendas and loyalties (Baldridge, 1971). As 
Baldridge began to delve into universities more deeply through case study, he determined that due to the complexity and distributed nature of universities, change is rarely adapted by all parts of the university at the same time (Baldridge, $1971 \& 1978)$.

Bringing all the theories discussed here full circle, Baldridge bridges the idea that Kezar (Kezar \& Eckel, 2002a) identifies, that it is critical to understand these divergent cultures within the overarching organization in order be able to implement change (Baldridge, $1971 \& 1978$ ). He asserts that universities have formal structures that everyone recognizes (e.g., departments, schools, AFSCME, faculty senate, etc.), but just as importantly, they have informal and social structures that wield a lot of influence and power (e.g., basic science faculty, etc.). These are the places that Baldridge feels leadership should turn to when addressing culture change within the organization, and he found it to be a delicate balance between recognized authority structures and informal structures. In Baldridge's study of colleges and universities he found that "social influence" (Baldridge, 1971, p. 137) is critical and shines a light on the complex relationship between authorities and partisan groups (Baldridge, 1971).

Understanding the nuanced and multiple structures that exist within OHSU, whether formal or informal, is important when discussing how to implement change effectively. This is the action element that is key to the change framework. It is not only important to identify the existence of these structures, but to begin to understand them and how they are operationalized, and to engage them so that they 
can be facilitators of change, rather passive or resistant. In interviews with OHSU current and former employees, it became apparent that multiple structures existnot just mission specific, but within missions-that are sometimes overlooked when it comes time to plan for or implement future change. The nuance discussed earlier of the OHSU basic science faculty and clinical faculty highlight that these informal structures have divergent interests and agendas. Within the context of OHSU's transition to the public corporation, each also carries significant importance in the new model. Faculty in each area felt differently about how the change was conceived and executed, and how it impacted them and their work life. As the interviews with leadership and then with current and former staff and faculty at OHSU revealed, there may have been a disconnect between what leadership was communicating and what some staff, faculty, and AFSCME were hearing. Early, clear, and frequent communication in all directions is a key component of the action.

The outcome is that engaging key internal stakeholders will form a partnership rather than an "us vs. them" standard that is difficult to recover from, regardless of how well intended the proposed change is. The interviews with OHSU faculty indicated that some subsets of faculty felt that opportunities were missed and that their concerns were not addressed, leading to a less than optimal outcome. ii. Opportunity, Action, Outcome 2: Leadership-Understanding and Utilizing the Power To Change

Leadership's role in effective change at universities can not be underestimated. Leadership is generally responsible for institutional change-in 
addition to having the vision to identify the drivers of change in the first place. Beckhard and Harris's (1987) theory expresses the critical need to understand where the organization is, where it wants to be, and determining how to get thereincluding the need for wholesale change. Managing complex change in organizations is exceedingly difficult, as their framework posits, because leaders have to recognize and fully understand the future state, the present state, and the transition state as the key factors in a roadmap for change (Beckhard \& Harris, 1987). Determining the pressure points that are driving change and identifying where the organization need to be are two first important steps, before even looking at the present state of the institution. Not surprisingly, the transition state, according to Beckhard and Harris's theory, is the most difficult: "being forced to let go temporarily of the present and [take on] the responsibility for figuring out how to achieve the ambiguous and threatening goal, and shifting attention to the future and the encouraging task of defining what should be achieved" (Beckhard \& Harris, 1987, p. 51).

In Beckhard and Harris's model, leadership is the key component. Leaders have to be able to communicate clearly and possess the clout to mobilize groups of people and resources. They must have effective interpersonal skills and the respect of those they are leading (Beckhard \& Harris, 1987): “Managing complexity involves a strong ability to deal with ambiguity, a talent for managing conflicts, a deep concern for people and their potential, the ability to maintain balance between reliance on systematic planning skills and gut feeling, and-most importanthaving a sense of vision" (Beckhard \& Harris, 1987, p. 116). In essence, leadership is 
asking the organization to form a whole new culture (Beckhard, 1997, p. 76). Trust also plays a crucial role, as discussed by Bennis and Nanus (1985). As they describe it, trust at the leadership level is about accountability, reliability, and predictability (Bennis \& Nanus, 1985). In addition, they discuss how strong leaders develop trust by picking a direction and sticking with it, building integrity along the way. Further they illustrate trust by referring to it as the glue that binds the leader and the follower (Bennis \& Nanus, 1985). This was clearly true in the case of OHSU's 1995 leadership team who, during the leadership interviews, expressed a great deal of trust for each other. The faculty and staff expressed pronounced trust in that leadership team during their interviews as well.

These concepts connect with the other organizational theories discussed in this chapter and are key to OHSU's transition, relative to understanding the cultures and structures that exist within the university and engaging those groups in the change process: asking who are the individuals to engage, what groups do we need commitment from, who will be willing to persevere. The role that Kohler and his leadership team played in OHSU's transition to the public corporation was integral to its success. Charismatic, passionate, and trusted leadership that could clearly describe where the "future state" was and then engage key stakeholders to participate in the transition state-letting go of what was comfortable-was critical.

Leadership's opportunity within this framework is to have foresight and vision-foresight to recognize and understand the multiple cultures and structures that exist within the organization, and vision to understand the drivers of change, 
being aware of the internal and external environmental factors that create the need for the organization to evolve. As Beckhard and Harris point out, this power to see where the organization needs to be is unique to charismatic leaders (Beckhard \& Harris, 1987). Having built up trust through consistent behavior and accountability (Bennis \& Nanus, 1985), OHSU's leadership were able to seize the opportunity to take OHSU to the next stage.

When engaging stakeholders in change, Kezar points out that terms such as "collaborative process" can be much more effective if they are used in the context of the university's specific culture (Kezar \& Eckel, 2002a). This can help leaders who are interested in implementing change focus their efforts where it will have the most impact. One of Kezar's strategies for helping leaders understand the culture within their organization is to become an outsider, as described earlier: "they need to be able to 'get on the balcony' [as described by Heifetz, 1994] to see the patterns on the dance floor below. Reading institutional culture in order to develop and match the strategies for change are fundamental to an effective change process." (Kezar \& Eckel, 2002a, p. 457).

This study of OHSU is a good example of the need to recognize the "patterns on the dance floor" in order to implement change-something Kohler and the leadership team recognized but may not have fully leveraged in OHSU's move to become an independent public corporation. As has been identified by faculty at OHSU, for those who felt the separation was positive or negative, there were missed opportunities that may have made the change more successful. From the 
administrative perspective, Jim Walker, CFO, recognized that there would be significant cultural differences going forward in departments such as finance and IT. He needed a more professional and innovative organization and that meant that some employees would need to go and new employees recruited (Interview, J. Walker, October 13, 2012). He described the period after the public corporation was formed as challenging, difficult, and stressful because of the urgent need to change, implement new, more efficient processes, and get new systems up and running quickly. Had the leadership team considered Kezar's approach as the planning developed for the public corporation, this may have been a smoother transition. Tierney (1988) corroborates Kezar's approach by asserting that understanding organizational culture aids leadership in spotting and resolving conflicts prior to them becoming a problem that detracts from operations.

The action here for dynamic leadership is to utilize and leverage the information at hand to steer the organization to the future state. While this sounds simple, it is exceedingly difficult to achieve, for a myriad of reasons, not the least of which is the existence of multiple stakeholders. The outcome is that effective leaders who successfully leverage their gut instincts and established trust, with their knowledge of systems thinking and planning, and who recognize the power of the people who work within the organization, will be able to effectively influence one of the largest stakeholder groups: employees. Through acknowledgement of the partnership to be forged with stakeholders, these leaders will be in a better position to convince employees to step outside their comfort zones to embark on a journey of 
change, potentially filled with ambiguity. In essence, they are asking employees to work without a roadmap, as described by one of the OHSU staff interviewed.

\section{iii. Timing and Environment-Considerations For The Change Framework}

There are two components that overlay the framework that ask the organization and its leadership to assess the situation driving change: the broader environment and timing.

First, the environment: While this study focused on the internal impacts of governance change on OHSU employees, it is important to understand the internal and external environments. The term "environmental scan" is used frequently when discussing strategic planning and change within organizations. In this instance, that refers to understanding the political, technological, and economic factors that may impact the organization. For example, it is important to ask: what are the political ramifications of this governance change? Will there be an economic impact to the organization; the state; the students, faculty, and staff (existing and incoming)? Is there an impact to the public good that our university provides? And if so, what? Further, doing an environmental scan should include an exploration and examination of other business models that exist or that have been attempted. What are other universities doing and how has that worked? What situation led the universities' drive for change? What makes one model successful and another fail? These environmental questions should be applied throughout the discussion of this framework. 
Second, timing is an essential overlay. Questions should be asked about the timing of the proposed change. Leaders must be keenly aware of the drivers of change and why they have appeared at a particular point in time. It may be that new legislation will impact the organization, or perhaps technology is a driver. In this case study of OHSU, the two overlay components came together to present the opportunity for change. The timing and environmental factors included the recent passage of a tax-limiting ballot measure, healthcare reform requiring OHSU to be more competitive, a need for more flexibility both in terms of practices and in terms of expansion, and the political climate-including an incoming governor (who signed the legislation) who was an OHSU alumnae. Understanding and leveraging these factors can be critical when orchestrating significant change.

\section{Broader Implications of This Research}

This proposed framework of effective governance change in universities is based on the knowledge gained through study of relevant organizational models and from lessons learned through the case study of OHSU and its governance change when it transitioned from being part of the Oregon State System of Higher Education to a public corporation.

Looking at the first "Opportunity/Action/Outcome," recognizing and engaging the multiple formal and informal structures that existed within the organization is critical. The OHSU leadership worked to engage the unions and the faculty as formal groups, but there is little evidence that the less formal structures and cultures within the university were engaged. For example, one conclusion of 
this study finds that employees who worked in the healthcare mission (clinical faculty, staff in the hospitals and clinics) were unfazed by the notion of the public corporation, but that subgroups of faculty and staff within the academic and research missions (e.g., basic science faculty, library) were skeptical going into the transition and unconvinced of the success of the outcomes. This is evidence of the importance for other universities contemplating this change to recognize and embrace informal groups and subgroups and to leverage those relationships. This is illustrated in the first component of the proposed framework, illustrated in Figure 13:

Figure 13: Framework for effective governance change in universities: understanding the structures in an organization

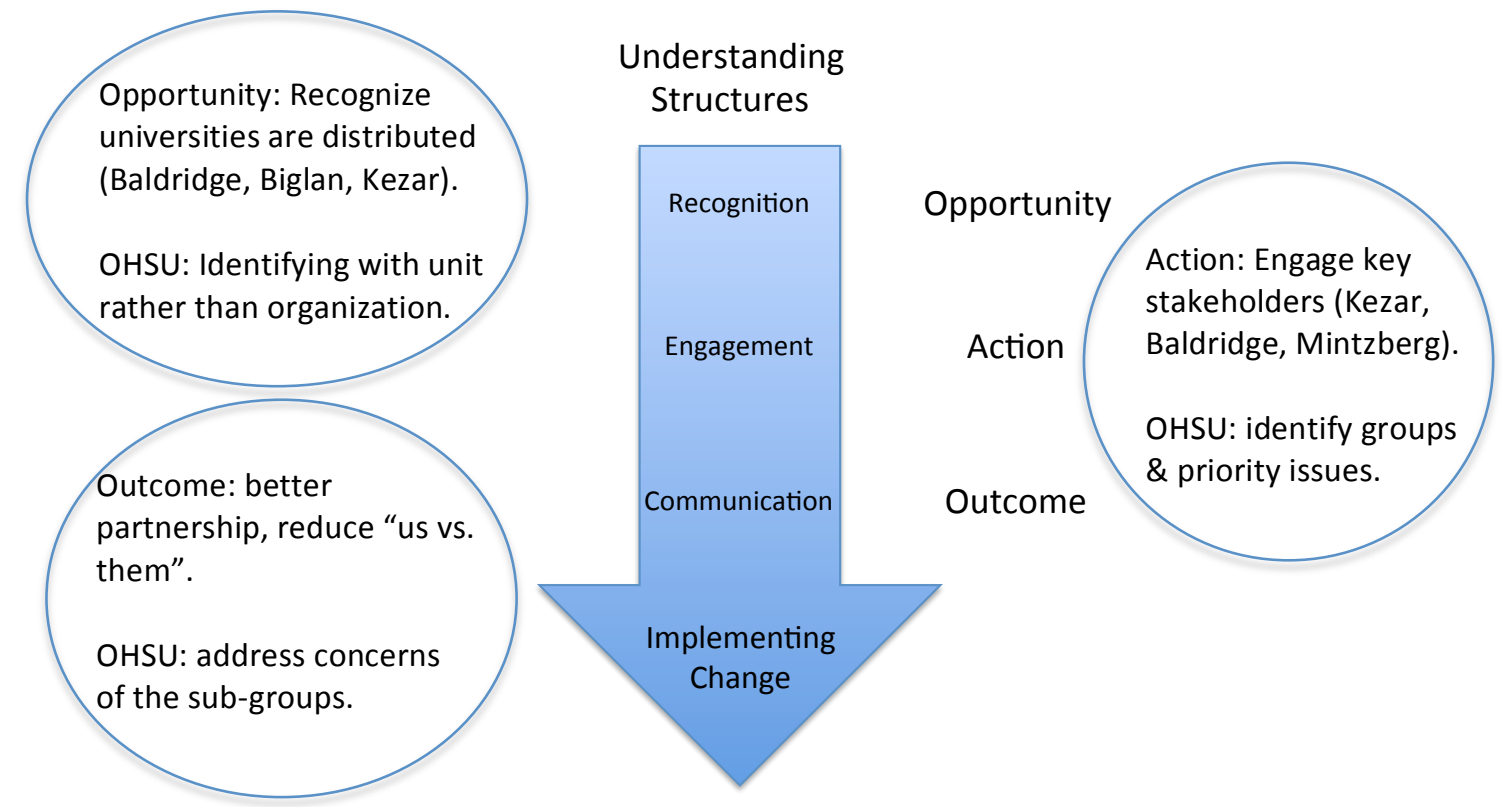

Applying the proposed model to other universities, we first examine "Opportunity/Action/Outcome" \#1: acknowledge and embrace what exists now (culture, structures, state). Stepping outside the university ("getting on the balcony") to assess what currently exists is a critical first step. This is meant in 
terms of what exists in formal and informal cultures, structures, and groups. This will allow universities to engage stakeholders who exist within the distributed pockets of influence and power early in the process, such as pockets of employee groups—faculty and staff-that are less defined within the organization.

This engagement will help form partnerships with mutual interests (similar to interest-based bargaining) rather than an antagonistic approach that will lead to many iterations of having to "convince" constituents to "get on board" or "buy in". One outcome will be the ability to do more implementation planning, training, and preparation of employees for the new model, allowing for possibly less turnover, or at least more constructive and proactive turnover rather than reactive.

When looking at OHSU's transition through the lens of "Opportunity/ Action/Outcome \#2," it is evident that the leadership, and particularly Kohler, demonstrated some of the unique qualities necessary to achieve a change of this magnitude. First and foremost, Kohler recognized the drivers of change-the decrease in state funding for higher education due to changes in tax law, the shifts in healthcare that led to OHSU's need to be more competitive, the need for flexibility to build and invest, and the vision to see that OHSU needed a stronger research program and more modern buildings in order to recruit world-class faculty and physicians. He and his leadership team also possessed the necessary clout to engage the formal constituencies (faculty, staff, unions) and to convince them to make the journey. This is illustrated in the second component of the proposed framework, 
illustrated in Figure 14 below, showing the importance of leadership understanding the needs of organization to change:

Figure 14: Framework for effective governance change in universities: Leadership understanding the needs in an organization

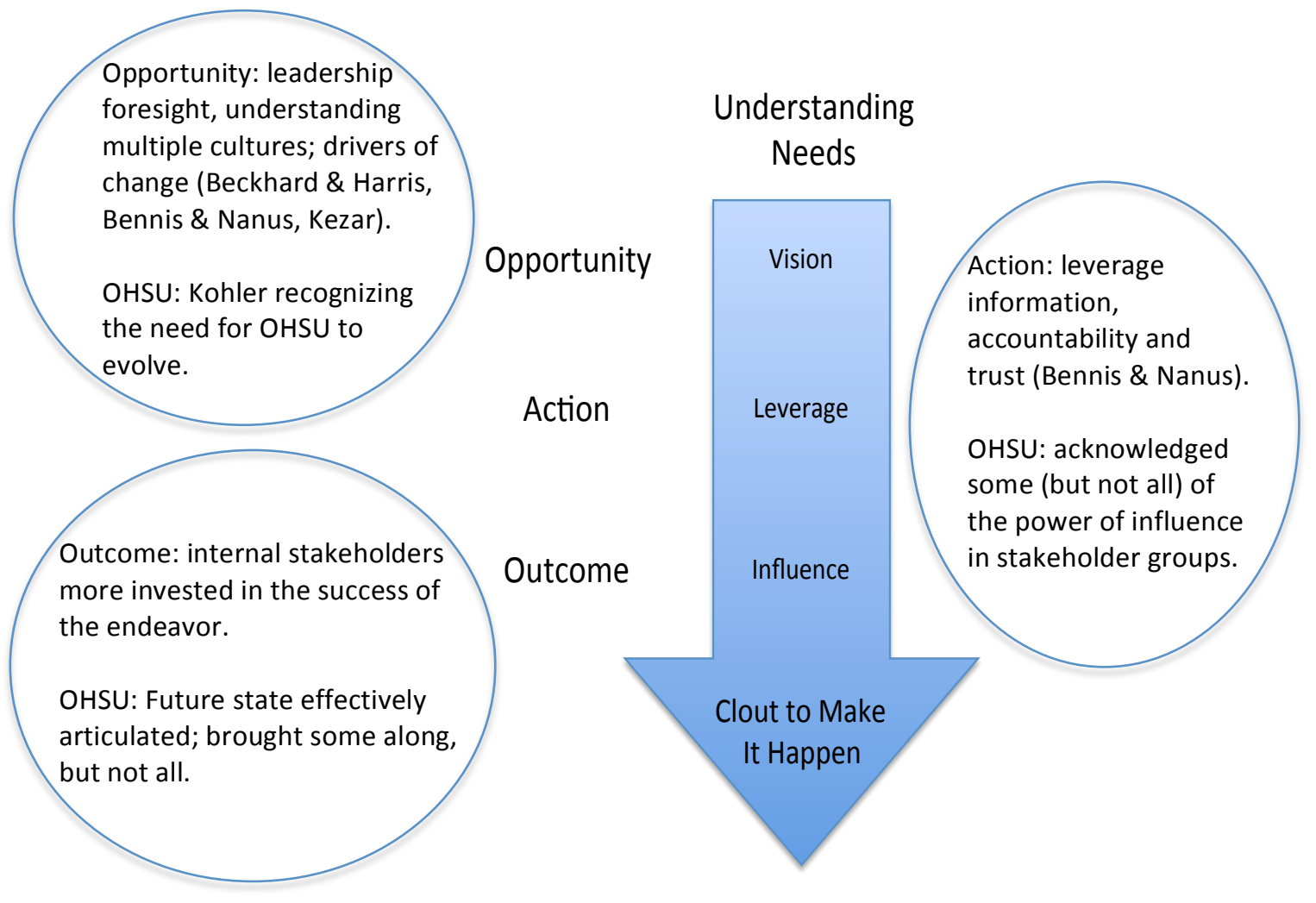

Looking at "Opportunity/Action/Outcome" \#2 in a broader context, there needs to be an assessment of the leadership-do they have the unique capabilities to understand and utilize their power to change the university? Do they understand the future state, the current state, and how to convince stakeholders to embark on the transition state? Do they have the respect and trust of the employees and other stakeholders? In OHSU's case, the leadership had vision, respect, and trust-a powerful combination. Do they have the capability of recognizing that the opportunity to make change is linked to all of these factors? This ability is 
situational, and an effective leader knows how to develop a strategy that leverages the situation. Finally, do they know their own limitations? If successful, the outcome will be internal stakeholders who are more invested in the success of the change because their leader has effectively communicated the future state.

The overlay of timing and environment were also well managed in OHSU's transition to the public corporation. The environmental scan involved the aspects discussed above and the timing was an important consideration for Kohler-he began exploring models before tax changes had even been approved by voters. 
Figure 15: One Framework for Effective Governance Change in Universities (Overlays of environment and timing applied to the change framework)

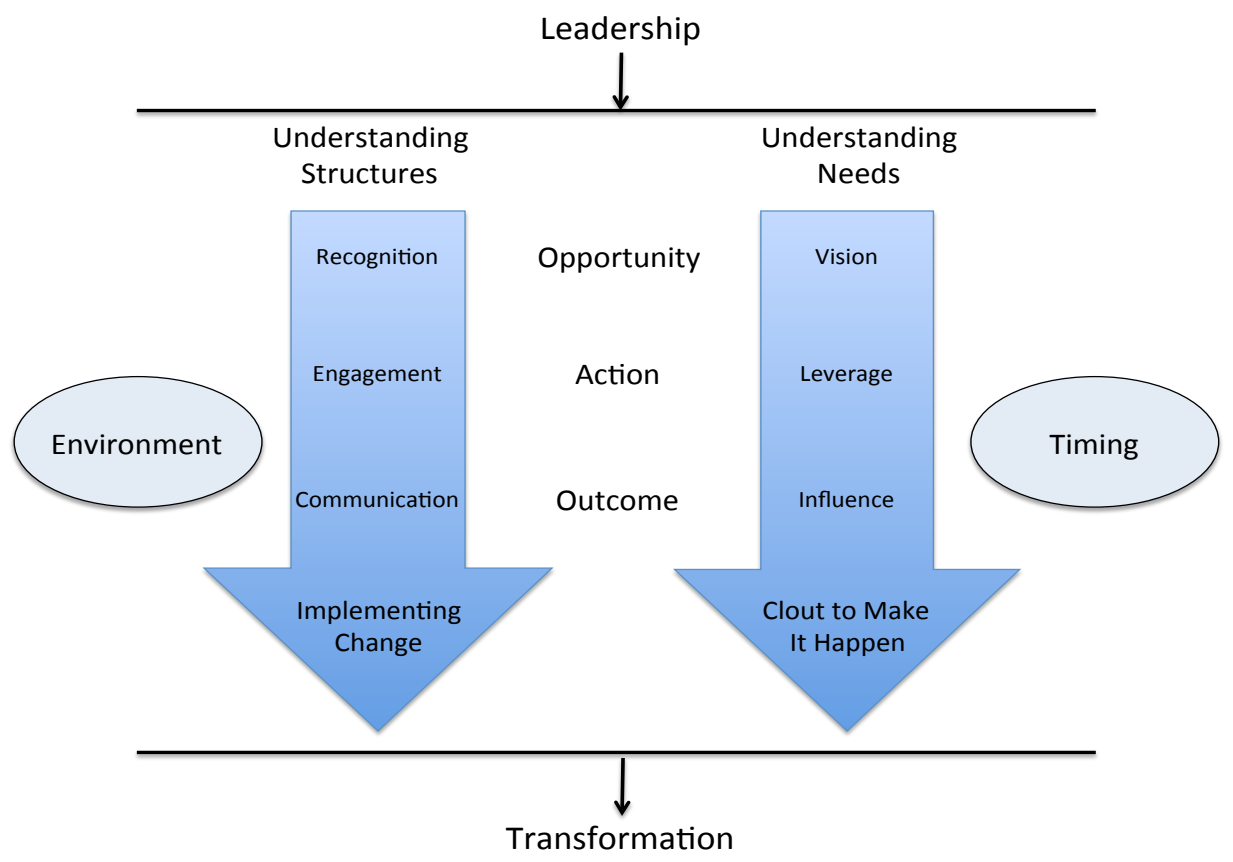

Finally, the overlays need to be applied to determine the readiness for effective change, as illustrated in Figure 15. In the current higher education environment, it is now common for universities to seek alternatives to the current models because funding is declining and traditional university structures are changing-student demographics, research portfolios, and for academic health centers, the healthcare environment is changing rapidly. Doing an environmental scan and looking at the timing may not seem necessary given that everyone assumes change must happen. But it is actually more important than ever to determine what the political, economic, technological, and timing ramifications will be. 
Understanding the impacts to the state and the public good, and whether there will be financial impacts to students, employees, patients, etc. will help determine the future state. OHSU's leadership and the Public Corporation Advisory Committee envisioned OHSU becoming a leading biomedical research university that would spur Oregon's biotechnology industry (Buckman, et al., 1995), but OHSU could only achieve that if they acted quickly due to the rapidly-changing external environment (Buckman, et al., 1995). It is also particularly important to examine what other universities have attempted-in the current climate there are now other models to examine (including OHSU). Doing the environmental and timing analysis will result in an outcome of better preparation for the institutional change-for leadership, staff, faculty, students, and patients.

Considering the long-term health of the university, the data collected from this study and from most informal and formal accounts of the situation indicate that the university was well-served by OHSU's separation. In Kohler's opinion, the university would have been severely weakened if the leadership had not done something (Interview, P. Kohler, August 15, 2012). There are still questions that can be asked: was the option to form a public corporation (including the hospitals) the right option? In 1999, the Medical College of Georgia transitioned its healthcare enterprise (hospitals and clinics) to a private, non-profit corporation, while splitting off the university (Rausch, 2007), as was proposed by Joseph Cox, then Chancellor of OSSHE (Cox, 1994). Georgia's transition happened after OHSU's, but could this have been a model that would have worked for OHSU? While Kohler, Davis, and Billups 
explored other conceivable models around the country, there were few to examine prior to 1995 and none had done exactly what OHSU was proposing to do. It was difficult, then, to apply experiences of what others had done to determine why they succeeded or why they failed.

OHSU has encountered challenges since becoming a public corporation. As illustrated throughout this study, there have been tests as to whether becoming a public corporation was the best route for OHSU to take. Access to the bond markets did allow OHSU to improve its physical infrastructure with upgraded equipment and facilities, as illustrated in Archer's study: “...[0]ne of OHSU's first acts as a public corporation was to acquire capital in the bond market. To let bonds for facilities' improvements and new construction...' (Archer, 2002, p. 202). However, this led to debt and credit difficulties that resulted in lower credit ratings and higher interest rates (Redding, 2009; Sickenger, 2009). Less state support for OHSU's education programs led OHSU to increase tuition rates. This is not an uncommon response and states across the country have seen this as a result of dwindling state support to higher education (Lyall, 2011; Redding, 2009). The pursuit of the public corporation model was, in the eyes of OHSU leadership and ultimately the legislature, the route to take to allow OHSU to compete in a competitive healthcare marketplace by becoming more business-focused, while still staying true to its public mission to serve Oregonians.

The leadership believes, despite the challenges of increased debt levels, lower credit rating, and higher tuition, that the university is still in a stronger 
position than it would have been had it done nothing in 1995 . This is attributed to growth in physical presence, increased hospital revenues and research grants, mergers with ONPRC and OGI, and other factors (Robertson, 2011).

Looking at broader application of this research, the caveat discussed in chapter three still applies: this is a case study of OHSU and of a particular point in time when OHSU transitioned to a public corporation. With case study research, it is sometimes difficult to generalize the impacts to other universities. Having said that, there are aspects of the framework, developed during this case study research, that can be expanded to be useful to other universities contemplating this type of change.

It is also important to acknowledge two other points: this case study and the proposed framework for effective change in universities are not meant to apply criticism for how OHSU planned for and implemented the governance change, quite the contrary. OHSU's change to the public corporation is widely thought to have been a success. Since we are addressing change in universities and how to effectively plan for and implement change, it is also important to point out that processes can always be improved. An important way to do that is to capitalize on lessons learned from what others have attempted in the past, whether they were successes or failures, or somewhere in between.

\section{E. Limitations of This Study}

The limitations of this study vary from personal to technical. First, on a personal level it was crucial for me to recognize my current role at OHSU and in the community and how these inherent biases may impact my observations (Hancock \& 
Algozzine, 2006). While conducting interviews, an important factor was my position as a vice president at OHSU. My position played a role, whether consciously or subconsciously, in how some participants viewed me and responded to the questions asked. This was taken into consideration when analyzing the data to avoid bias. In some cases the participants may have been reluctant to speak freely about their thoughts about the organization; while others may have felt exploited and could have potential hostility (unlikely, but possible), while still others may have been over-eager to respond positively. In reality, it appeared that my position was rarely a factor and was mentioned just three times in over 40 interviews conducted. Interviewees may also have been aware that the 1995 leadership team and others at OHSU may read this study and altered their answers to avoid offending anyone. The same applies to the interviewer, who knows the leadership team professionally. This topic was not mentioned or discussed by the interviewees and, while it is difficult to determine if this was a factor, it is possibly a minor element.

Interpretation of the participant responses may also be colored by the factors above and potential lack of understanding of the respondent's position within the organization. A fellow student who is unaffiliated with the study or with OHSU conducted the majority of the coding to ensure objectivity of interpretation of the data.

Second, it was difficult to contact former employees to invite their participation in the study. The list of former employees provided by OHSU's Human Resources Department did not include current contact information and it was 
difficult to obtain that information via Internet and other means. This required a reevaluation of the method and a change to the Snowball (or Chain) method (Berg, 2007) in order to find potential participants via word of mouth. This resulted in one fewer interview, and meant that it was more difficult to get a cross section of employees from different parts of the university and with diverse perspectives on the public corporation. It was also not possible by this method to find employees who left because of the transition to the public corporation.

Third, time was a factor. The study proposed to conduct interviews and document review and then to analyze the data collected. Time and resources had to be carefully assessed and managed to ensure the study stayed on track and was not prolonged-causing unanticipated expense and delay. To that end, colleagues and fellow students at PSU agreed to assist with data coding and initial analysis, as well as to audit outcomes for trustworthiness.

Fourth, there are limitations of case study methodology. As outlined earlier, case study methodology is viewed as less generalizable from institution to institution. As this study aims to explore the impacts to employees at a university, the outcomes will be helpful to other similar universities and organizations, even if they are not precisely alike. This concern is mitigated through rigorous data collection processes, including collection of several types of data and asking colleagues not directly involved with the study to aid in coding, analysis, and review of outcomes. Case study methodology did allow for an in depth examination of OHSU 
from the internal perspective, provided depth and richness not found in other methods.

It is also important to note the impact of internal and external factors on the university since 1995, as well as process changes and improvements due to technological advancements. Internally, these include funding challenges leading to decisions to raise tuition and/or cut programs and the above-mentioned technological advances. Externally, these include market factors that impact academic health centers, state funding cuts to OHSU, federal funding changes since 1995, impacts of health care reform, and perceptions within the community about the quality of healthcare services. One clear example of this is the technological evolution since OHSU became a public corporation. As was noted in the leadership interviews, Jim Walker, CFO, was responsible for merging old systems and implementing new data systems for finances, research administration, student administration, etc. While he was able to be more nimble and move to implement these systems quicker than he may have been able to as part of OSSHE, these changes would have occurred eventually, as they did at the other Oregon universities. These are all factors that may have had an impact on employees and their perceptions, their work life and the efficiencies that resulted, the campus culture, and their job satisfaction and are acknowledged, identified, and illustrated to the extent possible in the conclusions. To aid in teasing apart environmental factors from actual events related to the public corporation that impacted the participants' work life, an additional question was asked at the end of the interviews. 
Each participant was asked about any other events or activities going on during that time period that had nothing to do with OHSU's transition to a public corporation. As with the questions at the beginning of the interview that aided in setting the timeframe, this question is not part of the formal data analysis, but helped in determining important issues, events, or activities that may have had an impact on the participant during that transition time period.

As an additional measure of rigor to mitigate some of the limitations of the study, it served the project well to develop a plan to audit for trustworthiness. Again, this was done with the assistance of another doctoral student who is not involved with the study. The collaborator examined samples of the data and traced them back to the source. Once they reviewed the data trail they determine if they would have come to the same conclusions. This objective sample audit increased the validity of the study.

Another limitation of this study is the representativeness of the sample size. The study included interviews with most of the OHSU 1995 leadership team and a full review of hundreds of archived documents and data as well as an external media review. This is a fairly comprehensive representation. However, due to the limits of time and resources, the interviews with current and former faculty and AFSCME staff were limited to 15 current faculty, 15 current AFSCME staff, and 5 former employees. While every effort was made to interview a broad representation of faculty and staff from all of the schools, research centers, central departments, and hospital, and to include a representative variety of ages, gender, and length of time 
at OHSU, it is impossible to determine if the opinions of the faculty and staff interviewed are representative of the greater population. As stated earlier, however, utilizing case study methodology did allow for an in-depth analysis of OHSU during the period of this transition, providing a full and rich picture telling the story that emerged from all of the data sources employed for this research.

\section{F. Future Research}

This report would be incomplete without a brief discussion of future research paths for studying effective governance change in universities. While this study of the perceptions of OHSU's faculty and AFSCME staff and the impacts of a significant organizational change has provided new and valuable insight into how universities and their employees prepare for and react to change, additional research could be done on the perceptions of employee groups compared to additional quantitative data, and whether or how that impacted the implementation of the governance change. For example, a comparison of salary increase perceptions to the rate of increases based on inflation adjustments and other "hard" factors may be illustrative. While most participants interviewed for this study reported that salaries did increase and eventually did achieve the goal of urban-based market rates as expressed by OHSU leadership, it is still difficult to tell if salaries increased at a pace different than they would have otherwise. A study of unclassified administrative and top administrator/executive level salaries is also warranted. This topic did arise in interviews as an issue that hindered OHSU's abilities to 
support programs and may have contributed to tuition increases and other challenges.

In addition, a comparative analysis would be very helpful, particularly to other universities now contemplating this type of change. Now that there are more models to examine, including Georgia Tech, OHSU, and others, it would be useful to have a comparative analysis with measures including internal and external data. Expansion of this study of faculty and AFSCME staff would be helpful in that comparative analysis - to include other types of staff (e.g., unclassified administrative, leadership) and students. One other metric that could be included specifically for academic health centers is that of the patient population. Satisfaction levels, perceptions about costs and services offered, and relative value could be examined as one of the measures of success for a university that has gone through significant governance change, such as OHSU. Patient data is regularly collected by hospitals and clinics and satisfaction surveys are regularly conducted, so this data may be readily available to be included in a study. Another path for research, and one that would be helpful to universities contemplating this type of transformation is to explore the state of OHSU's financial position now compared to the Public Corporation Advisory Committee's assessment in 1995 (Buckman, et al., 1995).

Finally, a study of the external impacts is warranted. That work would be significant to a number of internal and external stakeholders, and was not undertaken in this study due to time and resource constraints. Understanding the implications to the external community-in OHSU's case, the City of Portland, the 
State of Oregon, the business community, potential students and patients, and the impact on the region in general-remains of great interest.

\section{G. Conclusion}

The idea for this study began to formulate in 2010 when the University of Oregon proposed to separate from the Oregon University System (the current iteration of the Oregon State System of Higher Education). At that time, many in the legislature and around Oregon looked to OHSU and pondered the successes and challenges that OHSU encountered when it became a public corporation. Since University of Oregon and OHSU are quite different in their mission and structure (i.e., University of Oregon is a large, traditional university with thousands of undergraduate and graduate students while OHSU is smaller, has only graduate students in biomedical sciences, and has two hospitals and many clinics), many believed one could not make comparisons about the successes and challenges that OHSU experienced versus what University of Oregon might encounter should they be successful in their bid for independence.

However, the notion of exploring the impacts to internal stakeholders presented itself, and research began on whether other universities had undertaken such a change and whether there had been any study of the internal impacts to those organizations and their employees. Review of the literature revealed that other universities had undergone similar restructuring, frequently for similar reasons-such as declines in state funding, new competition for changing student demographic, increased costs. However, the literature focused primarily on the 
political and economic implications of these changes, not on the organizational impacts. Universities are the cornerstones of development and prosperity in our society - training future leaders and generating partnerships and economic and intellectual development that are critical to a state's growth and sustainability. Because employees who work in universities make up a very important component of how universities operate and whether change is successful, this study was launched to examine the impacts of large-scale governance change on specific employee groups within OHSU. By studying OHSU's move from the state's umbrella system and examining the organizational and cultural changes OHSU has undergone, it is possible to learn how this type of governance change impacts this key stakeholder group. In doing this research, it was possible to explore, from the employee perspective, the changes to OHSU's operational processes, to its campus culture, and to its organizational structure. While there are limitations to the findings of this study, I am hopeful it has added valuable insight into the important role of employees in universities, particularly when undergoing significant change. 


\section{REFERENCES}

Association of American Medical Colleges (2013). Tuition and student fee reports. Data retrieved from: https://services.aamc.org/tsfreports/index.cfm.

Alexander, B., Davis, L., \& Kohler, P.O. (1997). Changing structure to improve function: one academic health center's experience. Academic Medicine, 72(4), 259-268.

Asimov, N. (2012). UCSF seeks to ease ties with UC. San Francisco Chronicle 01.20, 17:17.

Archer, B.L. (2002). Transformations in public organizations. (Doctoral dissertation). University of Southern California, Los Angeles, CA.

Baldridge, J.V. (1971). Power and Conflict in the University. Stanford University Press.

Baldridge, J.V. (1978). Policy Making and Effective Leadership. Jossey-Bass Press.

Beckhard, R. (1997). Towards a culturally sensitive approach to organization structuring. In Agent of Change, 76. Jossey Bass, San Francisco, CA.

Beckhard, R., \& Harris, R.T. (1987). Organizational Transitions: Managing Complex Change. Reading, MA: Addison Wesley Publishing Company.

Bennis, W., \& Nanus, B. (1985). Leaders: The Strategies for Taking Charge. New York, NY: Harper \& Row.

Berg, B.L. (2007). Qualitative Research Methods for the Social Sciences (6 ${ }^{\text {th }}$ Ed.). Boston, MA: Pearson Education, Inc.

Biglan, A. (1973a). The characteristics of subject matter in different academic areas. Journal of Applied Psychology, 57(3), 195-203.

Biglan, A. (1973b). The relationship between subject matter characteristics and the structure and output of university departments. Journal of Applied Psychology, 57(3), 204-213.

Bolden, R., Petrov, G., \& Gosling, J. (2008). Tensions in higher education leadership: towards a multi-level model of leadership practice. Higher Education Quarterly, 62(4), 358-376.

Buckman, F., Gilbaugh, J., Gray, J., Goldschmidt, N., Meyer, J., Stewart, L.L., Thorne, M., \& Whiteley, B. (1995). Oregon Health Sciences University: Public Corporation Advisory Committee Final Report, January 20, 1995. 
Carpenter, R.L. (2009). The institutionalization of diversity and gender equity norms and values in higher education settings. (Doctoral dissertation). Portland State University, Portland, OR.

Centers for Medicare and Medicaid Services (CMS). (2013). Updated 04.09.2013; retrieved from http://www.healthgrades.com/hospital-directory/oregon-orportland/ohsu-hospital-hgstb339e6a6380009.

Checkoway, B., (2001). Renewing the civic mission of the American research university. The Journal of Higher Education, 72(2), 125-147.

Cole, J.R. (2009). The Great American University. New York, NY: Public Affairs Press.

Cox, J. (1994). Board meeting comments: "The Higher Education Efficiency Act and OHSU," November 18, 1994.

Clark, B. R., (1972). The organizational saga in higher education. Administrative Science Quarterly, 17(2), 178-184.

Creswell, J.W. (1998). Qualitative inquiry and research design: choosing among five traditions. Thousand Oaks: Sage Publications.

DeMillo, R.A. (2011). Abelard to Apple. Cambridge, MA: MIT Press.

Department of Administrative Services (1995). PPDB rate table system, current compensation plan, 7/17/95. Salem, OR.

Department of Administrative Services (2005). Class search query. Salem, OR.

Department of Administrative Services (2010). Class search query. Salem, OR.

Denison, D.R., \& Mishra, A.K. (1995). Toward a theory of organizational culture and effectiveness, Organizational Science, 6(2), 204-223.

Desrochers, L.A. (2011). The birth of a research university: UC Merced, no small miracle. Research \& Occasional Paper Series, University of California, Berkeley, CSHE.14.11.

Edwards, Bates, Beyer, Devlin, Kruse, Barnhart, Beyer, Harker, Holvey, Hoyle, and Nathanson (2011). Establishes University of Oregon as independent public university, governed by University of Oregon Board of Directors, SB 559 (76th Oregon Legislative Assembly). 
Faculty Senate Fiscal Advisory Committee (1993). Report to faculty senate executive committee from OHSU faculty senate fiscal advisory committee: "Potential creation of public corporation to replace OHSU legal structure," March 30, 1993.

Faculty Senate Faculty Welfare Committee (1993). Report to the OHSU faculty senate executive committee from the faculty welfare committee: "Potential creation of a public corporation to replace the OHSU legal structure," April 23, 1993.

Faculty Senate. Summary of concerns from senators re: public corporation (undated).

Feeny, P. (Ed.) (1993a). OHSU Campus Gram, January 18, 1993, 32(29).

Feeny, P. (Ed.) (1993b). OHSU Campus Gram, November 22, 1993, 33(11).

Feeny, P. (Ed.) (1994a). OHSU Campus Gram, November 21, 1994, 34(11).

Feeny, P. (Ed.) (1994b). OHSU Campus Gram Special Edition, December 20, 1994.

Glaser, B., \& Strauss, A. (1967). The discovery of grounded theory. Chicago, IL: Aldine.

Gotsi, M., Andriopoulos, C., \& Wilson, A. (2008). Corporate re-branding: is cultural alignment the weakest link? Management Decision, 46(1), 46-57.

Hacker, A., \& Dreifus, C. (2010). Higher Education? How Colleges Are Wasting Our Money and Failing Our Kids-And What We Can Do About It. New York, NY: Henry Holt and Company, LLC/Times Books.

Hancock, D.R., \& Algozzine, B. (2006). Doing Case Study Research. New York, NY: Teachers College Press.

Hearn, J.C., Clugston, R.M., \& Heydinger, R.B. (1993). Five years of strategic environmental assessment efforts at a research university: a case study of an organizational innovation. Innovative Higher Education, 18(1), 7-36.

Heifetz, R. (1994). Leadership without easy answers. Boston, MA: Harvard University Press.

Hospital Consumer Assessment of Healthcare Providers and Systems (HCAHPS) (2013). Hospital care quality information from the consumer perspective. Retrieved from: http://www.hcahpsonline.org/home.aspx. 
Hossler, D. (1997). State funding for higher education: the Sisyphean task. Journal of Higher Education 68, 160.

Hovey, H.A. (1999). State spending for higher education in the next decade: the battle to sustain current support. National Center for Public Policy and Higher Education.

Integrated Postsecondary Education Data System (2013). National Center for Education Statistics. Data retrieved from: http://nces.ed.gov/ipeds/.

Johnsrud, L.K., \& Rosser, V.J. (2002). Faculty members' morale and their intention to leave: a multilevel explanation. The Journal of Higher Education, 73(4), 518542.

Jones, D. (2003). Policy alert: state shortfalls projected the decade. National Center for Public Policy and Higher Education.

Kamenetz, A. (2010). DIY U: Edupunks, Edupreneurs, and the Coming Transformation of Higher Education. White River Junction, VT: Chelsea Green Publishing.

Kenton, J. (2000). An analysis of the anticipated effect of budgetary reform at Portland State University (Doctoral dissertation). Portland State University, Portland, OR.

Kenton, J. (2002). Presentation and Analysis of Financial Management Information. Washington, DC: National Association of College and University Business Officers.

Kezar, A., \& Eckel P.D. (2002). The effect of institutional culture on change strategies in higher education: universal principles or culturally responsive concepts? The Journal of Higher Education, 73(4), 435-460.

Kezar, A.J. (2005). Consequences of radical change in governance: a grounded theory approach. The Journal of Higher Education, 76(6), 634-668.

Kezar, A.J. (2006). Rethinking public higher education governing boards performance: results of a national study of governing boards in the United States. The Journal of Higher Education, 77(6), 968-1008.

Kingdon, J.W. (2011). Agendas, Alternatives and Public Policies (updated 2nd ed.). Boston, MA: Longman Publishing.

Kissler, G. R. (1997). Who decides which budgets to cut? The Journal of Higher Education 68(4), 427-459. 
Knott, J.H., \& Payne, A.A. (2003). The impact of state governance on management and performance of public organizations: a study of higher education institutions. Institute of Government and Public Affairs, University of Illinois.

Kohler, P.O. (1994). Letter to Joseph Cox, Ph.D., Chancellor. November 15, 1994.

Kohler, P.O. (1995). A message from president Kohler. Transition News, 1(3), 1-2.

Kohler, P.O. (1996a). The first year. OHSU Public Corporation News: A report to employees on the public corporation, August 1996.

Kohler, P.O. (1996b). A message from the president. OHSU Campus Forum, July 15, 1996.

Krause, E.A. (1996). Death of the guilds: professions, states, and the advance of capitalism, 1930 to present. New Haven, CT: Yale University Press.

Kringen, T. (2011). OHSU as a public corporation: Launching a period of growth and programmatic excellence. White paper: April 11, 2011.

Leuty, R. (2012a). UCSF plan to separate from UC system is a start, not the end. San Francisco Business Times, Jan. 20, 2012. Retrieved from http://www.bizjournals.com/sanfrancisco/blog/2012/01/ucsf-universityofcalifornia.html.

Leuty, R. (2012b). Desmond-Hellmann: UCSF wants new structure. San Francisco Business Times, Jan. 20, 2012. Retrieved from http://www.bizjournals.com/ sanfrancisco/blog/2012/01/susan-desmond-hellmannucsf-uc.html.

Lewin, T. (2011). Public universities seek more autonomy as financing from states shrinks. New York Times, March 2, 2011.

Lund-Muzikant, D. (2009). Oregon hospitals rated by Consumer Reports but patients give hospitals very low scores on medication and discharge planning. The Lund Report; August, 12, 2009.

Lyall, K. (2011). Seeking sustainable public universities: The legacy of the great recession. Research \& Occasional Paper Series, University of California, Berkeley. Retrieved from http://escholarship.org/uc/item/2pm97582.

Maxwell, J.A. (2005). Qualitative Research Design: an interactive approach. Thousand Oaks, CA: Sage Publications. 
Mintzberg, H. (1983). Structures in fives: designing effective organizations. Englewood Cliffs, NJ: Prentice Hall.

National Center for Education Statistics (2009). Digest of Education Statistics [Data set]. Retrieved from http://nces.ed.gov/programs/ digest/2010menu_tables.asp.

Ogbonna, E., \& Wilkinson, B. (2003). The false promise of organizational culture change: a case study of middle managers in grocery retailing, Journal of Management Studies, 40, 1151-1178.

The Oregonian (1994). Maternity wing's gestation a case in bureaucratic point. The Oregonian.

The Oregonian (2013). On higher ed, an incomplete (editorial Saturday, July 2013, B6).

OHSU (1994a). Oregon Health Sciences University Briefly. OHSU internal memo.

OHSU (1994b). A Case for restructuring: memo to faculty senate March 10, 1994. OHSU internal memo.

OHSU (1994c). OHSU Factsheet 1994.

OHSU (1995a). OHSU Transition News, May 30, 1995, 1(1).

OHSU (1995b). OHSU Transition News, August 25, 1995, 1(5).

OHSU (1995c). OHSU Transition News, October 6, 1995, 1(6).

OHSU (1995d). From state agency to public corporation, August 28, 1995.

OHSU (1995e). Oregon Health Sciences University financial statements as of June 30, 1995 together with auditors' report. Portland, OR.

OHSU (1996). OHSU's public corporation: the first year. OHSU Views, Fall/Winter 1996/1997.

OHSU (2000). Oregon Health Sciences University combined financial statements as of June 30, 2000 and 1999 together with auditors' report. Portland, OR.

OHSU (2001). A report to the 2001 Oregon legislative assembly. Portland, OR. 
OHSU (2004). OHSU School of Medicine History: Reflections of Yesterday, 2004: 0404 (5).

OHSU (2005a). Oregon Health \& Science University financial statements June 30, 2005 and 2004 (with independent auditors' report thereon). Portland, OR.

OHSU (2005b). A report to the 2005 Oregon legislative assembly (OHSU in Oregon: improving health, advancing knowledge and growing the economy). Portland, OR.

OHSU (2005c). OHSU Compensation Plan for AFSCME, ONA, Unclassified Administrative, Faculty Rank and Academic Research Rank. July 1, 2005. Portland, OR.

OHSU (2007). Vision 2020: Strategic Plan 2007-2011. Retrieved from: http://www.ohsu.edu/xd/about/facts/history.cfm.

OHSU (2009). Oregon Health \& Science University financial statements June 30, 2009 and 2008 (with independent auditors' report thereon). Portland, OR.

OHSU (2010a). Oregon Health \& Science University 2010 fact book. Portland, OR: Goldschmidt, N., \& Bushek, R.

OHSU (2010b). OHSU pay ranges - compensation plan July 1, 2010. Portland, OR.

OHSU (2013a). OHSU headcount report, February, 2013.

OHSU (2013b). OHSU HCAHPS trending FY 09 - YTD FY 14., Updated August, 2013.

Oregon University System (2013). OUS State Appropriations Data. Corvallis, OR: Kenton, J.

Portland State University. (November 2009). Restructuring PSU's Relationship with the State: The Case for Change. Portland, Oregon.

Rausch, T. (2007). The fixer. Augusta Chronicle 12.24.07. http://chronicle.augusta.com/news/business/your-business/2007-1224/fixer.

Rebora, G., \& Turri, M. (2010). Change management in universities: more a question of balance than a pathway. Tertiary Education and Management, 16(4), 285302. 
Redding, M.W. (2009). Autonomy policy in U.S. public higher education: a comparative study of Oregon and Virginia. (Doctoral dissertation). University of Pennsylvania: Philadelphia, PA.

Ritter, I. (1996). Loosening the ties that bind: OHSU's progress toward a "quasiprivatization" is yielding new opportunities but causing some growing pains. The Scribe, February 2, 1996.

Roberts, B. (1994). Message from the governor.

Robertson, J. (2011). OHSU as a public corporation: launching a period of growth and excellence.

Rojas-Burke, J. (2012). Portland's best and worst hospitals, according to patients. The Oregonian, April 3, 2012. Retrieved from: http://www.oregonlive.com/health/index.ssf/2012/04/portland_metro_are a_hospital_r.html.

Rubenstein, S. (1995). Cutting loose: Oregon's medical school may break from state system of higher education. The Oregonian, January 1995.

Salins, P.D. (2011). Should university flagships go it alone? Minding the Campus: Reforming our Universities. Retrieved from http://www.mindingthecampus. com/originals/2011/04/ should_university_flagships_go.html.

Schein, E.H. (1993). Defining organizational culture. In Shafritz, J.M., Ott, J.S., \& Jang, Y.S. (Eds.), Classics of Organization Theory (6th ed.) 360-367. Boston, MA: Wadsworth

Sickenger, T. (2009). OHSU works to preserve quality amid deep cost cuts. The Oregonian, July 18, 2009. Retrieved from: http://www.oregonlive.com/business/index.ssf/2009/07/ohsu_works_to_p reserve_quality.html.

Slaughter, S. (1993). Retrenchment in the 1980s: The politics of prestige and gender. Journal of Higher Education, 64(3), 250-282.

Sobell, L.C. (2003). Alcohol Timeline Followback (TLFB). Assessing Alcohol Problems: A Guide for Clinicians and Researchers, NIH Guide, 301-305.

Sobell, L.C., Brown, J., Leo, G.I., \& Sobell, M.B. (1996). The reliability of the Alcohol Timeline Followback when administered by telephone and by computer. Drug and Alcohol Dependence 42(1996), 49-54. 
Stake, R.E. (1995). The Art of Case Study Research. Thousand Oaks, CA: Sage Publications, Inc.

Thornton, C. H., \& Jaeger, A. J. (2006). The role of culture in institutional and individual approaches to civic responsibility at research universities. Journal of College Student Development, 47(1), 52-68.

Thornton, C. H., \& Jaeger, A. J. (2007). A new context for understanding civic responsibility: relating culture to action at a research university. Research in Higher Education, 48(8), 993-1020.

Tierney, W.G. (1988). Organizational culture in higher education: defining the essentials. The Journal of Higher Education, 59(1), 2-21.

Tierney, W.G. (1998). The Responsive University. Baltimore, MD: Johns Hopkins University Press.

Timms, Adams, Bradbury, Bunn, Derfler, Hannon, Johnson, Kennemer, Lim, Miller, Smith, Stull, Walden (Senators); Baum, Brian, Clarno, Jones, Josi, Montgomery, Norris, Oakley, Roberts, Schoon, Sowa, Wells (Representatives) (1995). Establishes Oregon Health Sciences University as public corporation, SB 2 (68th Oregon Legislative Assembly).

Topping, S., Hyde, J., Barker, J., Woodrell, F.D. (1999). Academic health centers in turbulent times: strategies for survival. Health Care Management Review, 24(2), 7-18.

Trice, H.M., \& Beyer, J.M. (1993). Changing organizational culture. In Shafritz, J.M., Ott, J.S., \& Jang, Y.S. (Eds.), Classics of Organization Theory (6th ed.) 383-392. Boston, MA: Wadsworth.

U.S. News (2013). U.S. News Best Hospitals 2013-14. Retrieved from: http://health.usnews.com/best-hospitals/rankings.

Vakili, S., Sobell, L.C., Sobell, M.B., Simco, E.R., \& Agrawal, S. (2008). Using the Timeline Followback to determine time windows representative of annual alcohol consumption with problem drinkers. Addictive Behaviors, 33(2008), 1123-1130.

Vander Putten, J., McLendon, M.K., Peterson, M.W., (1997). Comparing union and nonunion staff perceptions of the higher education work environment. Research in Higher Education, 38(1), 131-149. 
Volkwein, J.F., \& Zhou, Y. (2003). Testing a model of administrative job satisfaction. Research in Higher Education, 44(2), 149-171.

Weber, M. (1922). Bureaucracy. In Shafritz, J.M., Ott, J.S., \& Jang, Y.S. (Eds.), Classics of Organization Theory ( $6^{\text {th }}$ ed.) 73-78. Boston, MA: Wadsworth.

Woodard, B., Fottler, M.D., Kilpatrick, A.O. (1999). Transformation of an academic medical center: lessons learned from restructuring and downsizing. Health Care Management Review, 24(1), 81-94.

White, J.D. \& Adams, G.B. (1994). Research in public administration: reflections on theory and practice. Thousand Oaks: Sage Publications.

Yin, R.K. (1989). Case study research: design and methods. Newbury Park: Sage Publications. 
APPENDIX A

OSSHE Proposed Governance Structure

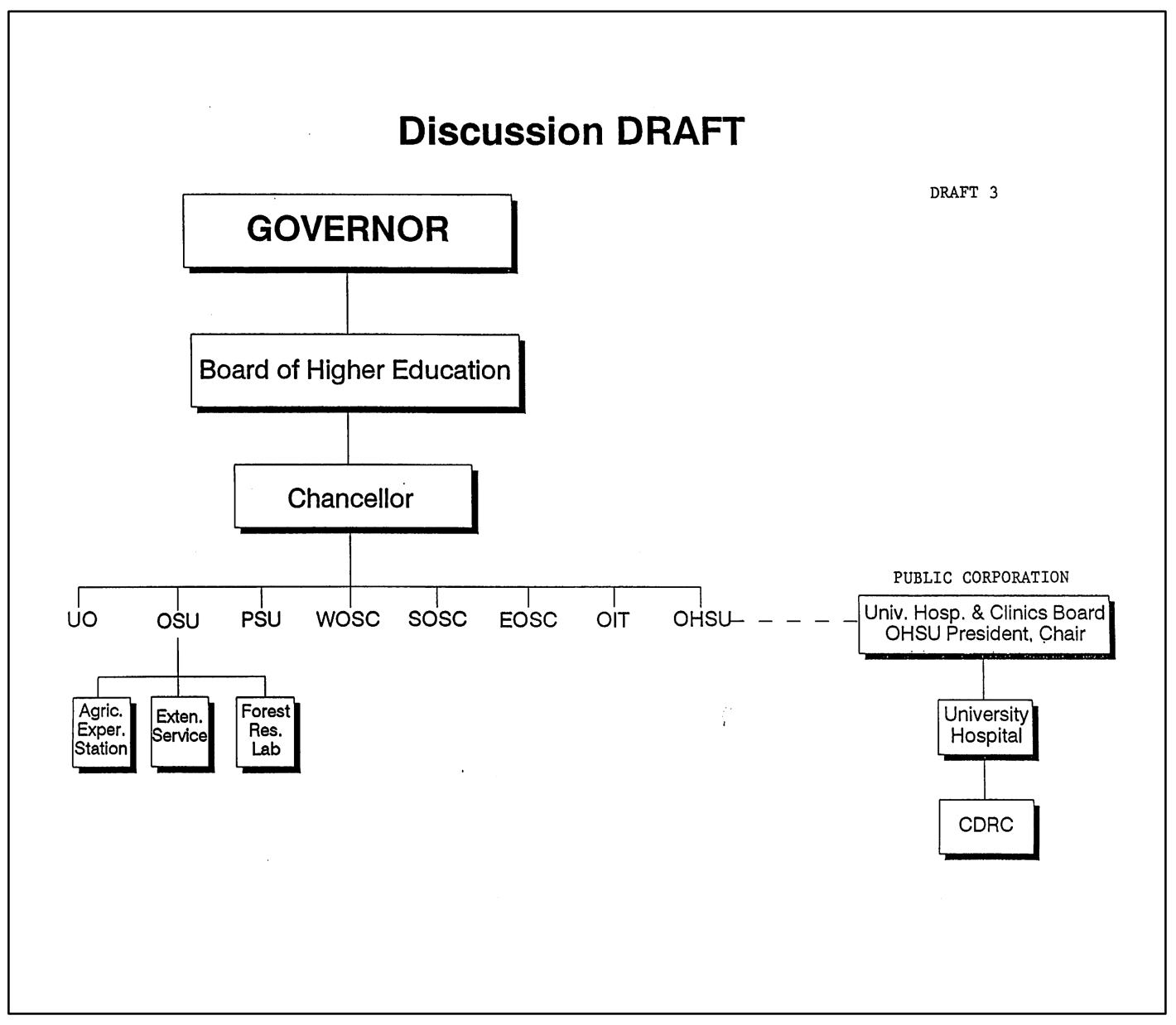

Page 252 
APPENDIX B

\section{OHSU 1995 Leadership Team Interview Guide 1:1 Interview}

Introduction:

Thank you for making the time to talk with me. This interview should take about an hour. The study I am conducting is for my Ph.D. dissertation aimed at discovering how OHSU's transition to a public corporation in July 1995 impacted employees, particularly to how the changes in the organization impacted work life, campus culture, and how employees felt about their jobs and OHSU. In this study I am specifically focusing on two employee groups: tenured faculty and AFSCME employees.

I am interested in your observations and candid insight about how the transition unfolded.

This study has been reviewed and approved by the PSU Human Subjects in Research Review Committee (\#122204) and the OHSU Institutional Review Board (\#8732). I will be recording the interview so that I can transcribe the answers, the tape recording will not be shared with anyone, it will specifically be used for my transcription purposes. Since you were one of five key leaders integrally involved in OHSU's 1995 transition to a public corporation, with your permission, you may be identified in the dissertation/report. I have the standard "informed consent" form for your review and signature.

Interviewee Name \& Date:

1. Please describe your role at the time of OHSU's separation in 1995 and also the goal for the separation as you recall?

$\begin{array}{ll}\circ & \text { President } \\ \circ & \text { CFO } \\ \circ & \text { Provost } \\ \circ & \text { Legal Counsel } \\ \circ & \text { Director of Government Relations } \\ \circ & \text { AFSCME leadership (former) } \\ \circ & \text { Other, please specify: }\end{array}$

(e.g. some of the goals for the transition included increased efficiencies and being more patient-focused, and that work life at OHSU would be better, job satisfaction would increase, and that compensation and benefits would be more competitive and better suited to an urban academic health center.) 
2. What were your concerns about becoming an independent public corporation?

3. Did you have goals specifically for internal components or constituencies (about the separation)? What were they?

4. What were the challenges from internal constituencies (for example, employee groups like the faculty or union-represented folks)?

5. Please describe how you feel it worked (becoming a public corporation).

a. What was positive and what were the challenges? Were there twists and turns?

b. What was it like right after the transition?

6. In retrospect, what do you think of the separation now? Would you describe it as successful or not?

a. What criteria are you applying when you assess the success of the separation?

7. Any other thoughts you would like to add? 


\author{
APPENDIX C \\ Interview Guide (for OHSU current employees) \\ 1:1 Interview
}

Introduction:

Thank you for making the time to talk with me. This interview should take about one hour. The study we are conducting is for my Ph.D. dissertation aimed at discovering how OHSU's transition to a public corporation in July 1995 impacted employees, particularly to how the changes in the organization impacted work life, campus culture, and how you felt about your job and OHSU.

In the early 1990s Dr. Peter Kohler, then president of OHSU, led the initiative that became Oregon Senate Bill 2 to make OHSU a public corporation outside of the Oregon State System of Higher Education (the precursor to what is now the Oregon University System).

The OHSU Leadership/Transition Team assured employees that, in addition to increased efficiencies and being more patient-focused, work life at OHSU would be better, job satisfaction would increase, and that compensation and benefits would be more competitive and better suited to an urban academic health center.

Today I am going to ask you a series of questions about the period of OHSU's transition, around 1995, and what you recall as some of the changes within the organization and how you felt about them. This is to help me better understand the impacts of OHSU making a big change like that. There are a number of universities around the country (and in Oregon!) considering making a similar change. I am hopeful my study will help inform those decisions by providing insight into how the structural change impacts employees, processes, and campus culture.

Your responses will be kept confidential. This study has been reviewed and approved by the PSU Human Subjects in Research Review Committee and by the OHSU Institutional Review Board. I will be digitally recording the interview so that I can transcribe the answers, the recording will not be shared with anyone and neither will the notes. I have the research study informed consent form for you to review/sign, and I have a copy for you to keep. 
First, please tell me a little bit about yourself and your position at OHSU at the time of the transition:

1. What is your age group?

Less than $30 \quad 30-39$

older

40-49 50-59 $\quad 60-69 \quad 70$ or

2. How long have you worked at OHSU?

○ 17 years

○ $18-25$ years

- 25-30 years

- More than 30 years

3. What was your position at the time of OHSU's separation from the State in 1995?

- Classified Support Staff (AFSCME-represented)

- What type of position did you have? What sort of work did you do?

- Faculty/Physician/Resident

- If faculty/physician, what was your rank?

4. What is your position now?

5. What mission or area were you affiliated with at that time?

○ Hospital

- Academic unit (for example, School of Medicine, School of Nursing, etc.)

- Research Institute or Center (for example, Vollum Institute, CROET, etc.)

- Central Services Unit (for example, Facilities, Parking \& Transportation, ITG, etc.)

Other, please specify: 
First, let me go over a brief timeline with you that may help jog your memory about milestone events in OHSU's recent history:

\begin{tabular}{|c|c|c|c|c|c|c|c|c|}
\hline$\underset{⿱}{\stackrel{+}{\sigma}}$ & $\begin{array}{l}\overrightarrow{-} \\
\stackrel{-}{\sigma}\end{array}$ & $\begin{array}{l}\text { مे } \\
\text { ने } \\
\infty \\
\text { ने } \\
\stackrel{-}{-}\end{array}$ & 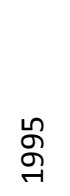 & $\begin{array}{l}\infty \\
\stackrel{\infty}{-}\end{array}$ & ర్రి & 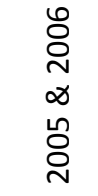 & $\stackrel{\infty}{\stackrel{\infty}{0}}$ & $\underset{\sim}{\vec{D}}$ \\
\hline 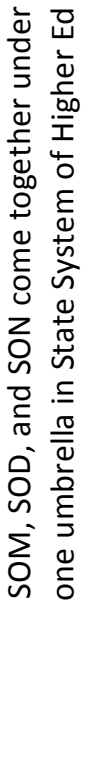 & 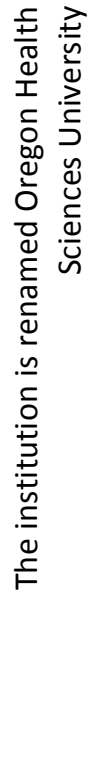 & 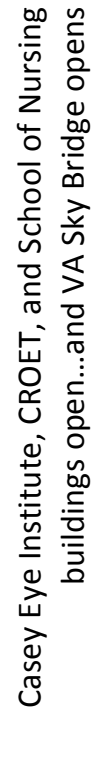 & 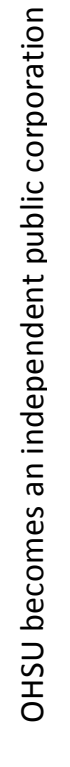 & 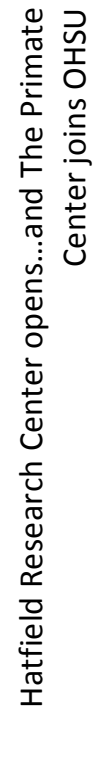 & 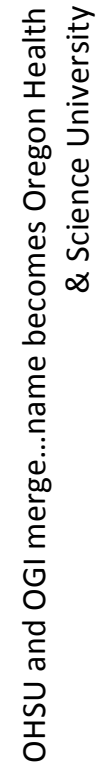 & 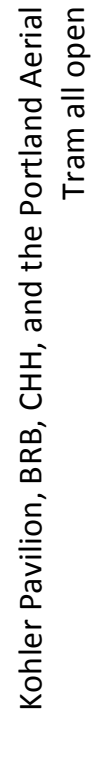 & 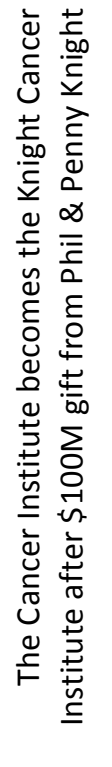 & 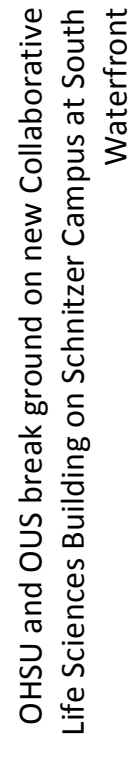 \\
\hline
\end{tabular}


Now, I'd like you to think about OHSU in the early 1990s before it became an independent public corporation in 1995, and then think about OHSU several years later, to 1997-era. Between these times, how, if at all, did the following areas change, in your experience? The following questions are about your personal experiences at OHSU at the time.

\section{Process}

(Efficiency of how the work got done can be defined several ways depending on where you worked at OHSU at the time.)

6. Was there more or less "paperwork" and/or steps to take to get your work done? Did you notice a change in the amount of time it took to complete your work? If so, how?

7. Did you know what you were expected to do day-to-day? Were you clear about your role? Tell me about that.

8. Of the things we just talked about (more or less paperwork, knowing what was expected of you, amount of time to get your work done) ... which of those do you feel had the most impact or was the most important to you at the time?

\section{Campus Culture and Work Life}

(Organizational culture is often described as the collective behavior of people that are part of the organization.)

9. Did the campus culture change? If so, how? For example, did it feel like the values of the organization changed? The norms, symbols, beliefs? How?

10. How did you feel about the freedom to do your job? Did it change at all? If so, how? (did you feel as though you had more or less autonomy? If so, how?)

11. What about the pressure to perform your job? Did that change-increase or decrease? How so? 
12. Did you feel that OHSU's focus on "customers" (patients and students) changed? For example, what do you think about this statement: "patients and students were the driving force at OHSU"?

13. Of the things we just talked about (campus culture change, freedom to do your job, pressure to do your job, customer focus) ... which of those do you feel had the most impact or was the most important to you at the time?

\section{Job Satisfaction}

(Think back to how you felt about working at OHSU when it became an independent public corporation in 1995 and how satisfied you felt about pay, benefits, etc. based on the assurance of a more competitive and appealing work environment.)

14. Did you feel valued by OHSU after the change? Were you appreciated? Tell me more about that.

15. Did you feel like you were adding value? Like you were making a difference? Tell me more about that.

16. What was your expectation about pay and benefits before and after the transition? How did you develop those expectations?

17. Did you notice a change in your pay-did your wages/compensation/benefits change when OHSU became independent? If so, how? Do you recall when?

18. How did you feel about employee recognition and incentives after OHSU became a public corporation?

19. Of the things we just talked about (feeling valued, feeling like you were adding value, your pay, your benefits, or employee recognition) ... which of those do you feel had the most impact or was the most important to you at the time? 
20. Did your overall satisfaction about working at OHSU change? If so, how?

\section{I have a few questions that are just for faculty}

(If you were a faculty member during the transition...)

21. Did the shared governance model change after OHSU became independent? For example, did the relationship between faculty senate and administration change? If so, how?

22. How did you feel about the level of academic freedom? If it changed after the transition, how so?

23. Did you notice any changes in the expectations of how productive faculty should be? What were the new expectations?

24. How about promotion and tenure-did those practices change? If so, how? How did you feel about that?

25. Of the things we just talked about (shared governance, academic freedom, faculty productivity, promotion and tenure) ... which of those do you feel had the most impact or was the most important to you at the time?

\section{I have two final questions for you (these questions are for all participants):}

26. How do you feel in general about the separation? Are things better or worse now? In what ways?

27. What is the one biggest thing that happened at OHSU that you remember from around the time when OHSU became an independent public corporation in 1995? 


\section{APPENDIX D}

Interview Guide (for OHSU former employees)

1:1 Interview

Introduction:

Thank you for making the time to talk with me. This interview should take about one hour. The study we are conducting is for my Ph.D. dissertation aimed at discovering how OHSU's transition to a public corporation in July 1995 impacted employees, particularly to how the changes in the organization impacted work life, campus culture, and how you felt about your job and OHSU.

In the early 1990s Dr. Peter Kohler, then president of OHSU, led the initiative that became Oregon Senate Bill 2 to make OHSU a public corporation outside of the Oregon State System of Higher Education (the precursor to what is now the Oregon University System).

The OHSU Leadership/Transition Team assured employees that, in addition to increased efficiencies and being more patient-focused, work life at OHSU would be better, job satisfaction would increase, and that compensation and benefits would be more competitive and better suited to an urban academic health center.

Your responses will be kept confidential. This study has been reviewed and approved by the (PSU/OHSU) Institutional Review Board [once approved, will provide IRB\#]. I will be digitally recording the interview so that I can transcribe the answers, the recording will not be shared with anyone and neither will the notes.

Today I am going to ask you a series of questions about the period of OHSU's transition, around 1995, and what you recall as some of the changes within the organization and how you felt about them. This is to help me better understand the impacts of OHSU making a big change like that. 
First, please tell me a little bit about yourself and your position at OHSU at the time of the transition:

1. What is your age group?

Less than $30 \quad 30-39$

older

40-49 $\quad 50-59-69 \quad 70$ or

2. How long have you worked at OHSU?

17 years

18-25 years

25-30 years

More than 30 years

3. What was your position at the time of OHSU's separation from the State in 1995 ?

Classified Support Staff (AFSCME-represented)

What type of position did you have? What sort of work did you do?

Faculty/Physician/Resident

If faculty/physician, what was your rank?

4. When did you leave OHSU?

5. What mission or area were you affiliated with at that time?

Hospital

Academic unit (for example, School of Medicine, School of Nursing, etc.)

Research Institute or Center (for example, Vollum Institute, CROET, etc.)

Central Services Unit (for example, Facilities, Parking \& Transportation, ITG, etc.)

Other, please specify: 
Now, think about OHSU in the early 1990s before it became an independent public corporation in 1995, and then think about OHSU several years later, to 1997-era. Between these times, how, if at all did the following areas change, in your experience? The following questions are about your personal experiences at OHSU at the time.

\section{Process}

(Efficiency of how the work got done can be defined several ways depending on where you worked at OHSU at the time.)

6. Was there more or less "paperwork" and/or steps to take to get your work done? Did you notice a change in the amount of time it took to complete your work? If so, how?

7. Did you know what you were expected to do day-to-day? Were you clear about your role? Tell me about that.

8. Of the things we just talked about (more or less paperwork, knowing what was expected of you, amount of time to get your work done) ... which of those do you feel had the most impact or was the most important to you at the time?

\section{Campus Culture and Work Life}

(Organizational culture is often described as the collective behavior of people that are part of the organization.)

9. Did the campus culture change? If so, how? For example, did it feel like the values of the organization changed? The norms, symbols, beliefs? How?

10. How did you feel about the freedom to do your job? Did it change at all? If so, how? (did you feel as though you had more or less autonomy? If so, how?)

11. What about the pressure to perform your job? Did that change-increase or decrease? How so? 
12. Did you feel that OHSU's focus on "customers" (patients and students) change? For example, what do you think about this statement: "patients and students were the driving force at OHSU"?

13. Of the things we just talked about (campus culture change, freedom to do your job, pressure to do your job, customer focus) ... which of those do you feel had the most impact or was the most important to you at the time?

\section{Job Satisfaction}

(Think back to how you felt about working at OHSU when it became an independent public corporation in 1995 and how satisfied you felt about pay, benefits, etc. based on the assurance of a more competitive and appealing work environment.)

14. Did you feel valued by OHSU after the change? Were you appreciated? Tell me more about that.

15. Did you feel like you were adding value? Like you were making a difference? Tell me more about that.

16. What was your expectation about pay and benefits before and after the transition? How did you develop those expectations?

17. How about your pay-did your wages/compensation/benefits change when OHSU became independent? If so, how?

18. How did you feel about employee recognition and incentives after OHSU became a public corporation?

19. Of the things we just talked about (feeling valued, feeling like you were adding value, your pay, your benefits, or employee recognition) ... which of those do you feel had the most impact or was the most important to you at the time?

20. Did your overall satisfaction about working at OHSU change? If so, how? 
I have a few questions that are just for faculty

(If you were a faculty member during the transition...)

21. Did the shared governance model change after OHSU became independent? For example, did the relationship between faculty senate and administration change? If so, how?

22. How did you feel about the level of academic freedom? If it changed after the transition, how so?

23. Did you notice any changes in the expectations of how productive faculty should be? What were the new expectations?

24. How about promotion and tenure-did those practices change? If so, how? How did you feel about that?

25. Of the things we just talked about (shared governance, academic freedom, faculty productivity, promotion and tenure) ... which of those do you feel had the most impact or was the most important to you at the time?

I have four final questions for you (these questions are for all participants):

26. Why did you leave OHSU? For example, did you get a different job? Retire? Other?

27. Did OHSU's transition to a public corporation have any bearing on your decision to leave OHSU? If so, in what way? 
28. How do you feel in general about the separation? Are things better or worse now? In what way?

29. What is the one biggest thing that happened at OHSU that you remember from around the time when OHSU became an independent public corporation in 1995? 


\title{
APPENDIX E
}

\author{
Invitation To Participate In Study
}

September 9, 2012

Dear

My name is Dana Director, and I am a doctoral student at Portland State University, as well as an employee at OHSU. I am beginning a study of OHSU and its separation from the Oregon State System of Higher Education (OSSHE) in 1995. The purpose of the study is to explore the impacts to the organization and its employees when it became an independent public corporation. I would like to invite you to participate.

You are being asked to take part because you were an employee at OHSU prior to and during the 1995 period when OHSU made the transition to a public corporation. As part of the study I am interested in your opinions and attitudes about how the changes in the organization impacted work life, campus culture, and how you felt about your job and OHSU. I hope that the information I collect will help us to better understand organizational change in universities, as well as the question of the benefits, challenges, and potential outcomes for other universities contemplating this type of change. If you decide to take part, you will be asked to participate in an interview, which involves answering questions about your feelings about your work life at OHSU during that period. It should take approximately one hour to complete.

As a result of this study, it is possible that we will discuss aspects of your job and/or your work at OHSU that were challenging, or it is possible that colleagues' names or specific situations will be discussed as part of an answer to a question. My primary goal is to ensure the confidentiality of the information you share during the interview. It is important to note, though, that it is possible that your identity could be inadvertently detectable from the nature of the information you share during the interview. Your answers will be transcribed for analysis, but in keeping with my goal of confidentiality, your name will not be associated with your comments. Any information that is obtained in connection with this study and that can be linked to you or identify you will be kept confidential.

You may not receive any direct benefit from taking part in this study, but the study may help to increase knowledge that may help others in the future. As a participant in this study, you will be eligible to be included in a drawing for an Apple iPod Shuffle. This is offered partially as incentive to increase the number of participants, but also as a way to say thank you to interviewees. 
Participation is entirely voluntary. Your decision to participate or not will not affect your relationship with me or with OHSU in any way. If you decide to take part in the study, you may choose to withdraw at any time without penalty. Please keep a copy of this letter for your records. If you agree to take part, please respond to this e-mail. I will then send you possible dates, times, and locations for the interview. You can choose the place and time that works the best for you. When we meet I will ask you to sign an Informed Consent form stating that you are volunteering to participate in this study.

If you have questions or concerns about your participation in this study, contact me at director@pdx.edu or 503.547.7835. If you have concerns about your rights as a research subject, please contact Research and Strategic Partnerships, Market Center Building 6th floor, Portland State University, 503.725.4288.

Sincerely,

Dana Director

Ph.D. Student

Portland State University

and employee at Oregon Health \& Science University 


\title{
APPENDIX F
}

\author{
Informed Consent
}

Study Title: Studying the Impacts of Change in Governance on Faculty and Staff at Higher Education Institutions: A Case Study of OHSU

Researcher: Dana Director, doctoral student, Public Affairs \& Policy Program, Division of Public Administration, Hatfield School of Government

Date: August 16, 2012

\section{PSU Human Subjects in Research Review Committee \#: 122204 OHSU Institutional Review Board \#: 8732}

You are invited to participate in a research study conducted by Dana Director, a doctoral student in the Public Affairs and Policy Program at Portland State University, Hatfield School of Government. This study is being conducted as partial fulfillment of the requirements for a doctoral degree, under the supervision of Dr. Jay Kenton and Dr. Lindsay Desrochers. This research is a case study of the Oregon Health \& Science University (OHSU) and its separation from the Oregon State System of Higher Education (OSSHE) in 1995. The purpose of the study is to explore the impacts to the organization and its employees when it became an independent public corporation. You were selected as a possible participant in this study because you were an employee at OHSU during the period of interest for this project.

If you decide to be a part of this study, you will be asked to participate in a one-hour interview at a mutually agreed-upon location at a pre-arranged date and time. The purpose of the interview is to ask you a series of questions about OHSU's transition to a public corporation in July 1995 and how it impacted you, particularly about how the changes in the organization impacted work life, campus culture, and how you felt about your job and OHSU. The interview will be audio recorded for purposes of transcription.

While participating in this study, it is possible that we will discuss aspects of your job and/or your work at OHSU that were challenging, or it is possible that colleagues' names or specific situations will be discussed as part of an answer to a question. The primary goal is to ensure the confidentiality of the information you share during this interview. However, it is important to note that it is possible that your identity could be inadvertently detectable from the nature of your answers to the interview questions. Your answers will be transcribed for analysis, but in keeping with the goal of confidentiality, your name will not be associated with your comments. Any information that is obtained in connection with this study and that can be linked to you or identify 
you will be kept confidential. This information will be kept confidential by de-identifying the interviews once they are completed and coding the data separately from the identifying information. If you are concerned about being identified, it may be possible for you to review relevant portions of the final dissertation/report.

You may not receive any direct benefit from taking part in this study, but the study may help to increase knowledge which may help others in the future. As a participant in this study, you will be eligible to be included in a drawing for an Apple iPod Shuffle. This is offered partially as incentive to increase the number of participants, but also as a way to say thank you to interviewees.

Your participation is voluntary. You do not have to take part in this study, and it will not affect your position or status at OHSU. You may also withdraw from this study at any time.

If you have questions or concerns about your participation in this study, contact Dana Director at director@pdx.edu or 503.547.7835. If you have concerns about your rights as a research subject, please contact Research and Strategic Partnerships, Market Center Building 6th floor, Portland State University, 503.725.4288.

Your signature indicates that you have read and understand the above information and agree to take part in this study. The researcher should provide you with a copy of this form for your own records.

Signature

Date

Print name 


\section{APPENDIX G}

\section{Graphical Representations of Participant Responses}

\section{Process Graphs}

Staff: More or Less Paperwork

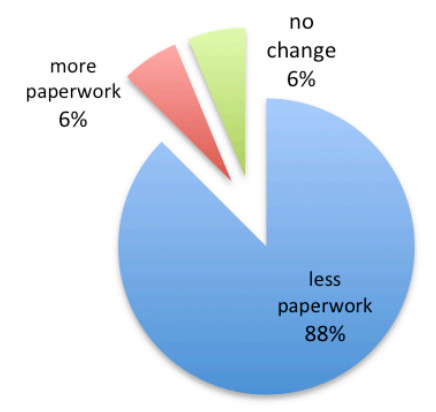

Faculty: More or Less Paperwork

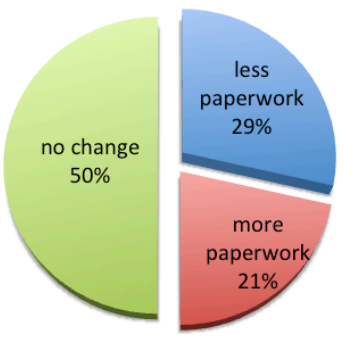

Former Employees: More or Less Paperwork

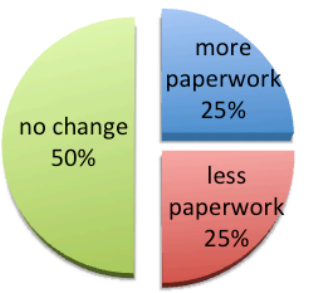

Staff: More or Less Process Process-less

$17 \%$

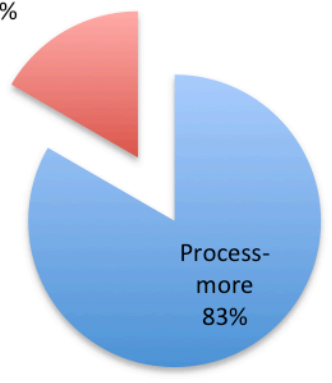

Faculty: More or Less Process

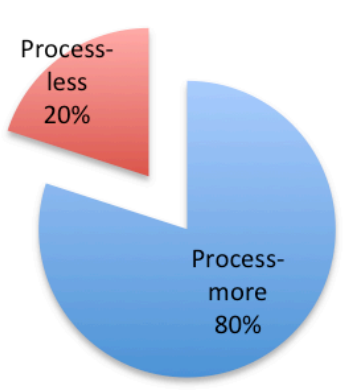

Former Employees: More or Less Process

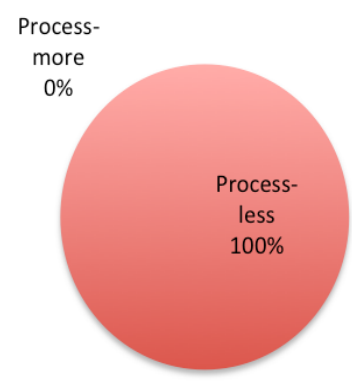

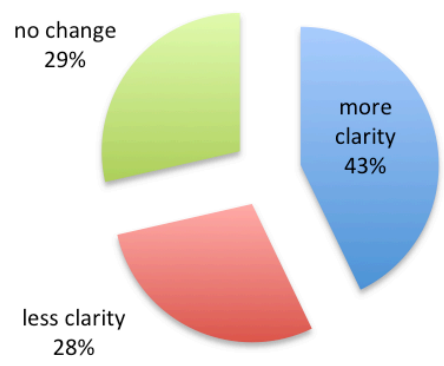

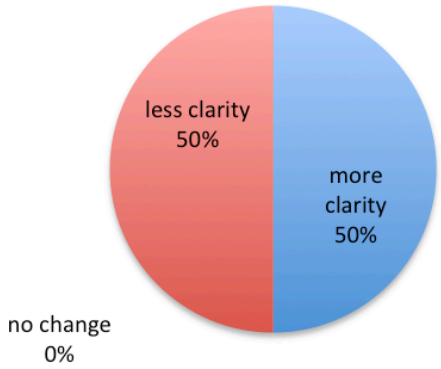

Page 271 


\section{Culture Graphs}

Staff: Culture Change

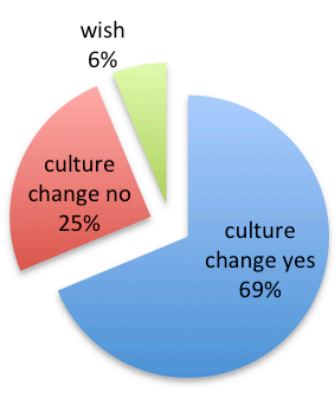

Faculty: Culture Change

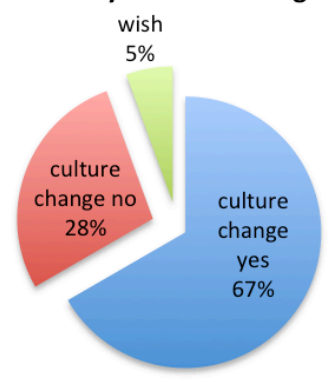

Former Employees: Culture Change

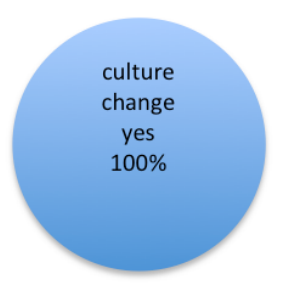

Staff: More or Less Job Freedom

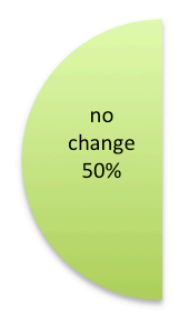

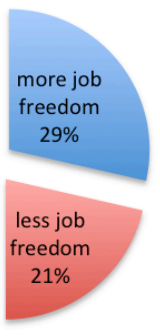

Staff: More or Less Job Pressure

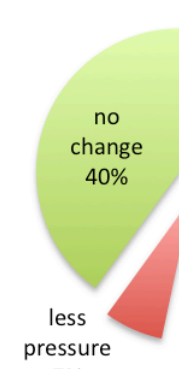

$7 \%$

\section{Faculty: More or Less Pressure}

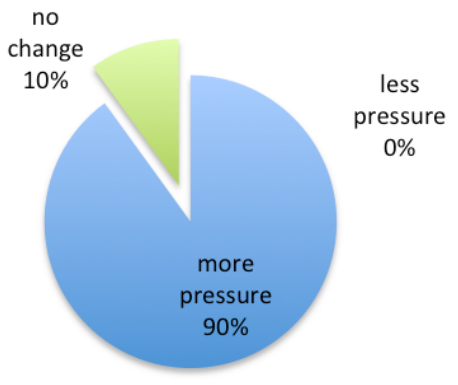

Former Employees: More or Less Job Freedom

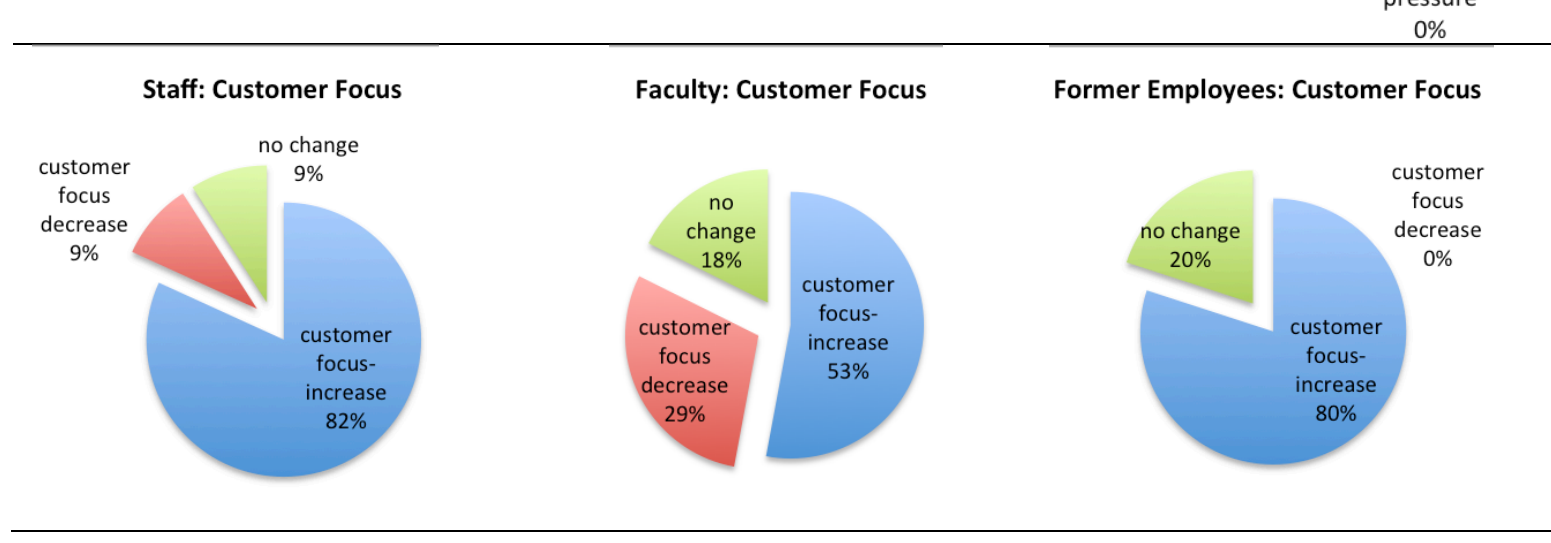

Page 272 


\section{Employee Satisfaction Graphs}

Staff: More or Less Valued

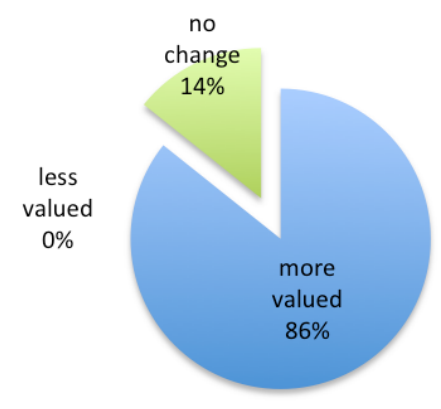

Faculty: More or Less Valued

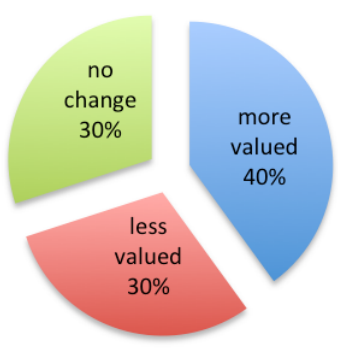

Former Employees: More or Less

Valued

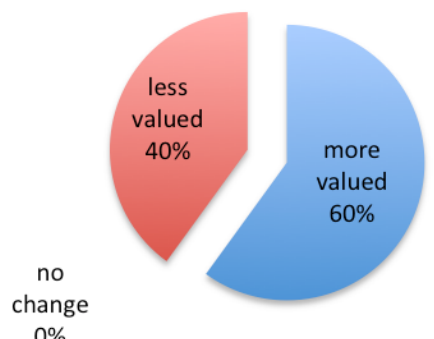

$0 \%$

\begin{tabular}{cccc}
\hline Staff: Adding Value & Faculty: Adding Value & $\begin{array}{c}\text { Former Employees: Adding } \\
\text { Value }\end{array}$ \\
not \\
adding \\
value \\
$7 \%$
\end{tabular}

Page 273 


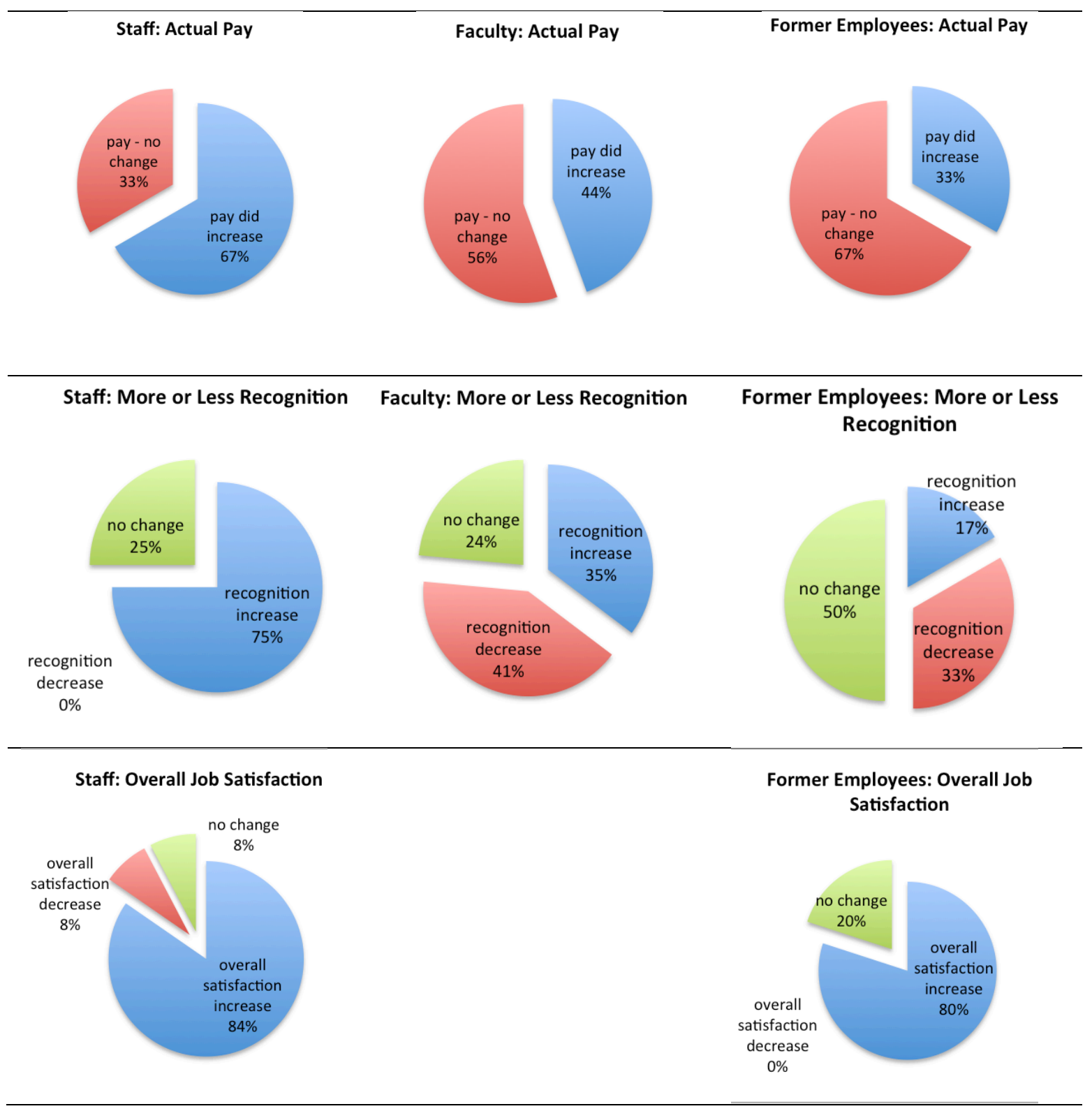

Page 274 
Faculty Graphs

Faculty: Shared Governance

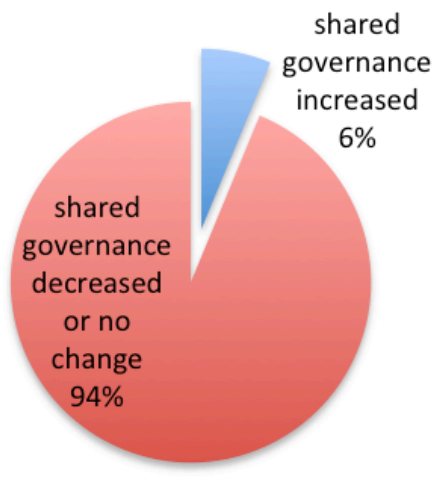

Faculty: Academic Freedom

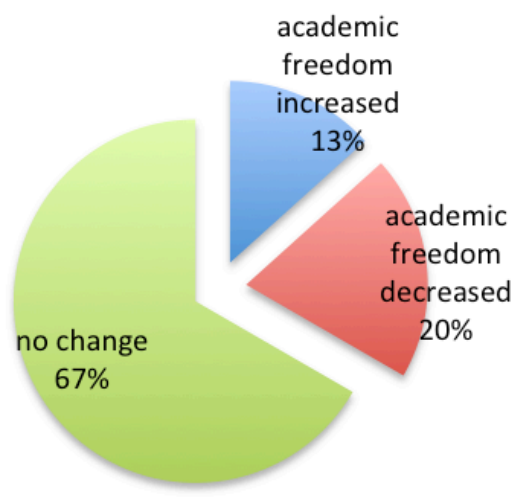

Faculty: Productivity Expectations

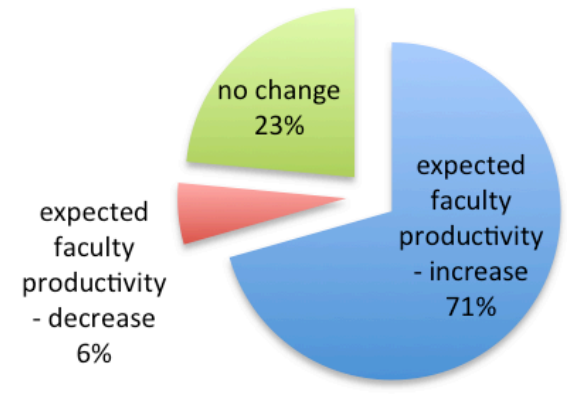

\section{Former Faculty: Shared Governance}

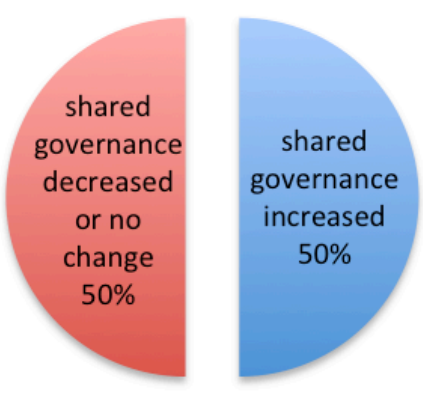

Former Faculty: Academic Freedom

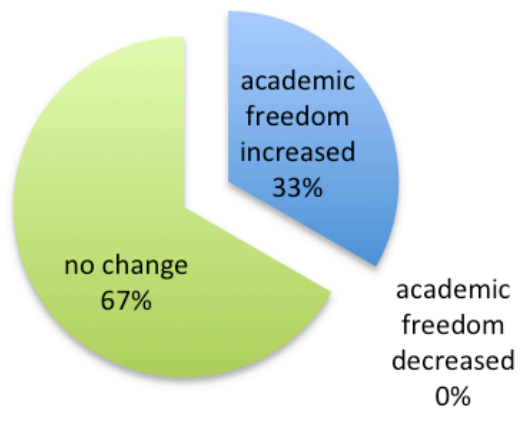

Former Faculty: Productivity Expectations

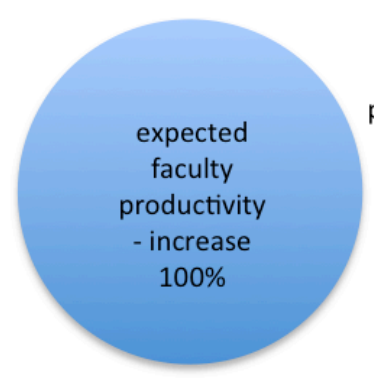

expected

faculty productivity - decrease $0 \%$ no change $0 \%$ 


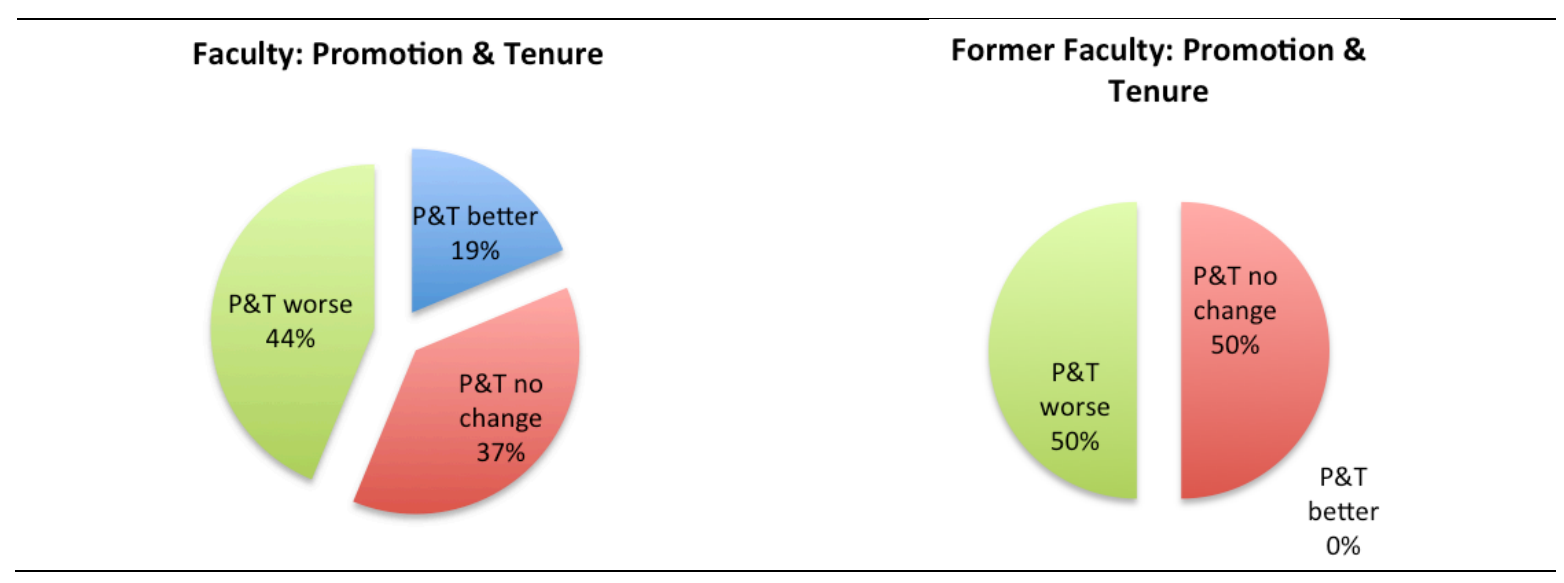

Overall Impact Graphs

Staff: Overall Impacts

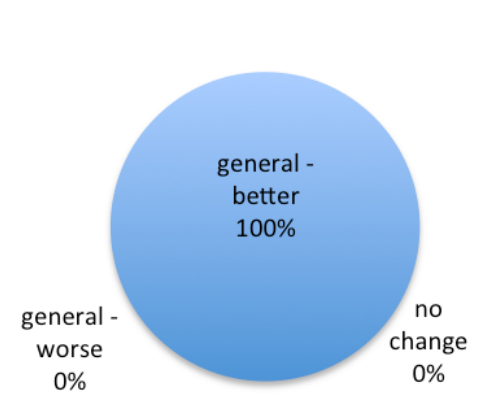

Faculty: Overall Impacts

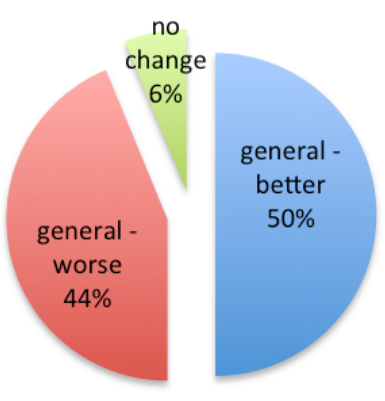

Former Employees: Overall Impacts

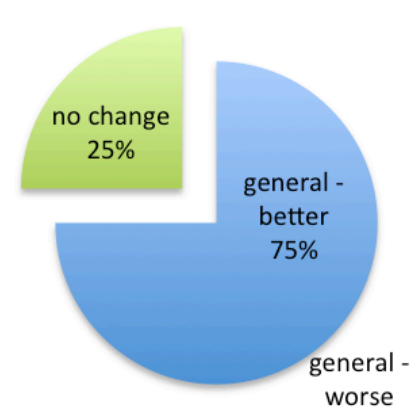

$0 \%$ 